\author{
Universidade de São Paulo \\ Escola de Engenharia de São Carlos \\ Departamento de Engenharia Mecânica \\ FERNANDO ANTÔNIO PASCOAL JÚNIOR
}

\title{
ANÁLISE MICROESTRUTURAL, TENACIDADE À FRATURA E VIDA EM FADIGA DAS LIGAS AA7050-T7451 E AA2050-T84 (Al-Li)
}

\author{
São Carlos - SP \\ 2014
}




\section{FERNANDO ANTONIO PASCOAL JÚNIOR}

\section{ANÁLISE MICROESTRUTURAL, TENACIDADE À \\ FRATURA E VIDA EM FADIGA DAS LIGAS AA7050-T7451 E \\ AA2050-T84 (Al-Li)}

Tese apresentada à Escola de Engenharia de São Carlos, da Universidade de São Paulo, como parte dos requisitos para a obtenção do título de Doutor em Ciências.

Área de Concentração: Materiais

Orientador: Prof. Tit. Waldek Wladimir Bose Filho

São Carlos

2015 
AUTORIZO A REPRODUÇÃO TOTAL OU PARCIAL DESTE TRABALHO, POR QUALQUER MEIO CONVENCIONAL OU ELETRÔNICO, PARA FINS DE ESTUDO E PESQUISA, DESDE QUE CITADA A FONTE.

Pascoal Júnior, Fernando Antonio

ANALISE MICROESTRUTURAL, TENACIDADE À FRATURA E VIDA EM FADIGA DAS LIGAS AA7050-T7451 E AA2050-T84 (Al-Li) / Fernando Antonio Pascoal Júnior; orientador Waldek Wladimir Bose Filho. Såo Carlos, 2014.

Tese (Doutorado) - Programa de Pós-Graduaçăo em Engenharia Mecânica e Area de Concentraçăo em Materiais -- Escola de Engenharia de Săo Carlos da Universidade de Săo Paulo, 2014.

1. Taxa de propagaçăo de trinca. 2. Tenacidade à fratura. 3. temperatura criogênica. I. Título. 
FOLHA DE JULGAMENTO

Candidato: Engenheiro FERNANDO ANTONIO PASCOAL JÚNIOR.

Título da tese: "Análise microestrutural, tenacidade à fratura e vida em fadiga das AA7050-T7451 e AA2050-T84 (AI-Li)".

Data da defesa: 23/02/2015

Comissão Julgadora:

Prof. Titular Waldek Wladimir Bose Filho (Orientador)

(Escola de Engenharia de São Carlos/EESC)

Prof. Dr. Conrado Ramos Moreira Afonso

(Universidade Federal de São Carlos/UFSCar)

Prof. Dr. Ruís Camargo Tokimatsu

(Universidade Estadual Paulista "Júlio de Mesquita Fiho"/UNESC "\#ndro solteira)

Dra. Giorgia Taiacol Aleixo

(EMBRAER)

Prof. Dr. Mauricio Angeloni

(Faculdade de Tecnologia de Sertãozinho/FATEC)
Resultado:

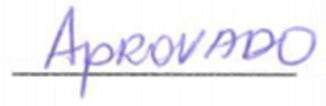

Amovang

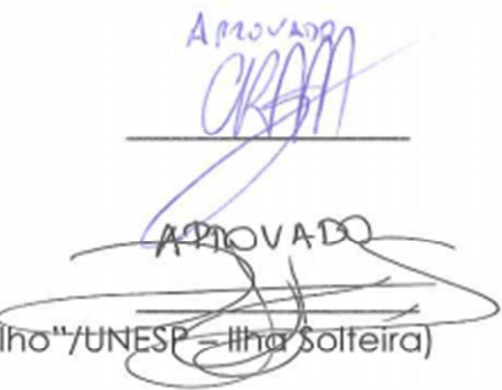

Aprovado

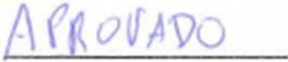

Coordenador do Programa de Pós-Graduação em Engenheira Mecânica: Prof. Associado Marcelo Areias Trindade

Presidente da Comissão de Pós-Graduação: Prof. Associado Paulo César Lima Segantine 
Dedico este trabalho a Deus; aos meus pais, Fernando e Lifonsina; a minha querida mulher Antonieta; aos meus tios Pereira e Maria; e ao meu irmão Vinícius. 


\section{AGRADECIMENTOS}

A minha cunhada Rigléia, pelos empréstimos dos livros técnicos.

Ao Senhor Adão, da Gráfica, pelo apoio na encadernação.

A Ana Paula e a lara, do Departamento de Engenharia Mecânica, pela ajuda na entrega da tese.

Ao Prof. Dr. Waldek Wladimir Bose Filho, pela orientação e confiança depositada.

A Dra. Giorgia Aleixo, pela disponibilidade em ajudar.

Aos meus amigos Aline, Luis Bonazzi, Leonelli, Filippe, Douglas, Carla, João, pela disponibilidade em ajudar nos acompanhamentos dos ensaios.

Aos meus colegas de empresa Vicente, Rodrigo e Lúcio, pela colaboração.

Ao Prof. Dr. Spinelli (In memoriam), pelos esclarecimentos e explicações sobre esta tese, na qual ele tanto acreditou.

À Embraer, pela colaboração e material fornecido. 


\section{RESUMO}

PASCOAL JUNIOR, F.A. Análise microestrutural, tenacidade à fratura e vida em fadiga das ligas AA7050-T7451 e AA2050-T84 (Al-Li) 2014. XXf. Tese (Doutorado) - Escola de Engenharia de São Carlos, Universidade de São Paulo, 2014.

No presente trabalho foi realizado um estudo comparativo entre as ligas AA7050T7451 e AA2050-T84, bem como entre as direções L-T e T-L para analisar o comportamento das ligas, quando submetidos à temperatura ambiente e criogênica. Para realizar a análise comparativa entre as ligas e entre as direções, foram utilizados corpos de prova tipo $\mathrm{C}(\mathrm{T})$ (Compacto Tension), pré-trincados em fadiga. A análise comportamental das ligas foram avaliadas através dos ensaios de tenacidade à fratura, $K_{I C}$, Curva $K_{R}$ fadiga, $d a / d N$. A microestrutura foi caracterizada através da microscopia ótica, microscopia eletrônica de varredura e microscopia eletrônica de transmissão. Foi observado que na direção L-T há uma maior resistência à propagação da trinca em relação à direção $T-L$, no que diz respeito à Curva $K_{R}$, tanto para temperatura ambiente quanto para temperatura criogênica. Quando comparou-se as duas ligas na direção L-T em temperatura ambiente, ambas apresentaram um fator de intensidade de tensão similar. Os resultados dos ensaios de fadiga mostraram que a direção T-L é mais sensível à razão de carga. Analisando os resultados entre as direções L-T e T-L, observou-se que as duas ligas apresentaram comportamento anisotrópico.

Palavras chave: Ligas de Al; Ligas de Al-Li; Taxa de propagação da trinca, tenacidade à fratura 
ABSTRACT

\section{PASCOAL JUNIOR, F.A. Microstructural analysis, fracture toughness and fatigue life of AA7050-T7451 and AA2050-T84 (Al-Li)} alloys XXf. Thesis (Ph.D.) - School of Engineering of São Carlos, University of São Paulo, in 2014.

A comparative study was made of the AA7050-T7451 and AA2050-T84 alloys and of the L-T and T-L directions to analyze the behavior of the alloys when subjected to room and cryogenic temperatures. The comparative analyses of the alloys and directions were performed using fatigue-precracked compact tension (CT) test specimens. The behavior of the alloys was analyzed based on fracture toughness, $K_{I C}, K_{R}$ curve, fatigue, and $d a / d N$ tests. Their microstructure was characterized by optical microscopy, scanning electron microscopy and transmission electron microscopy. The $K_{R}$ curve indicated that resistance to crack propagation was higher in the L-T direction than in the T-L direction at both room and cryogenic temperatures. In a comparison of the two alloys in the L-T direction at room temperature, they were found to present a similar stress intensity factor. The results of the fatigue tests demonstrated that the $\mathrm{T}-\mathrm{L}$ direction is more sensitive to the load ratio. An analysis of the results in the L-T and T-L directions indicated that the two alloys exhibited anisotropic behavior.

Keywords: Al-Li alloys, crack propagation rate, fracture toughness, low temperatur 


\section{LISTAS DE FIGURAS}

FIGURA 1: ESQUEMA MOSTRANDO AS POSSÍVEIS FASES PRESENTES NA LIGA AL-LI AA8090

(PRASAD ET AL 2003). 37

Figura 2: PRECIPITADOS NO CONTORNO DE GRÃO E ZONA LIVRE DE PRECIPITADOS

(PASANG, 2012). 39

FIGURA 3. BALANÇO DE ENERGIA DE GRIFFITH (ANDERSON, 2005) 41

FigurA 4. MOdELO DE GRIFFITH (ANDERSON, 2005) 43

FIGURA 5. MODOS DE ABERTURA DA TRINCA (ANDERSON, 2005) 46

Figura 6. TENSÕES EM TORNO DA TRINCA (ANDERSON, 2005). 48

FigurA 7. TENSÕES NORMAIS AO PLANO DE TRINCA (ANDERSON, 2005). 49

FIGURA 8. TENACIDADE À FRATURA, VALOR CRÍTICO (GODEFROID, 1995) 50

FIGURA 9. EFEITO DA ESPESSURA DOS CORPOS DE PROVA NA MORFOLOGIA DA FRATURA PARA MATERIAIS QUE EXIBEM CRESCIMENTO DE TRINCA DÚCTIL. A) FRATURA POR CISALHAMENTO; B) FRATURA PLANA E POR CISALHAMENTO; C) FRATURA PREDOMINANTE PLANA COM UMA PEQUENA PORÇÃO CISALHANTE. 52

FIGURA 10. CRESCIMENTO RÁPIDO DA TRINCA NO CENTRO DO CORPO DE PROVA, DEVIDO À ALTA TRIAXILIDADE DAS TENSÕES E O CRESCIMENTO LENTO DA TRINCA DEVIDO À BAIXA TRIAXILIDADE (ANDERSON, 2005). 52

Figura 11. FormaÇÃo dAS ARESTAS DE CISALHAMENTO E TUNELAMENTO DA TRINCA (ANDERSON, 2005). 53

FIGURA 12: REPRESENTAÇÃO ESQUEMÁTICA DA CURVA $K_{R}$ E CURVAS DAS TENSÕES APLICADAS PARA PREDIZER A INSTABILIDADE DA TRINCA (ANDERSON, 2005). 54

FIGURA 13. DESLOCAMENTO CONTROLAdO (ANDERSON, 2005). 55

FIGURA 14: COMPORTAMENTO FRÁGIL DO MATERIAL (ANDERSON, 2005). 56

FIGURA 15. FORMAÇÃO DAS BANDAS DE DESLIZAMENTO PELA SOLICITAÇÃO CÍCLICA E SEU ASPECTO. EstáGIOS de PROPAGaÇão de UMA tRINCA de fadiga. (LeE, Y.-L, et AL, 2005). 58

FIGURA 16. ESTRIAS (SCHIJVE, 2003). 58

FIGURA 17. MECANISMO DE PROPAGAÇÃO DE TRINCA POR FADIGA, PROCESSO REPETITIVO DE ARREDONDAMENTO PLÁSTICO E AFILAMENTO DA EXTREMIDADE DA TRINCA; (CALLISTER JUNIOR, 2002) 59

Figura 18. FalHa CATASTRÓfica (SCHIJVE, 2003). 60 
FIGURA 19. TAXA DE CRESCIMENTO DA TRINCA DA/DN PLOTADO EM FUNÇÃO DO FATOR DE INTENSIDADE DE TENSÃO $\Delta K$ (ANDERSON, 2005). 63

FIgURA 20. GRÁFICO EVIDENCIANDO O EFEITO dA RAZÃO DE TENSÕES NA TAXA DE PROPAGAÇÃO DA TRINCA (DOWLING, 2007).

FIGURA 21.CORRELAÇÃO ENTRE AS COMBINAÇÕES DE DADOS DE $\triangle K$ E R UTILIZANDO A EQUAÇÃO DE FORMAN.

FIGURA 22. CORRELAÇÃO ENTRE AS COMBINAÇÕES DE DADOS DE $\triangle K$ E R UTILIZANDO A EQUAÇÃo de PEARSON (PEARSON, 1972). 67

FIgURA 23. FLUXOGRAMA DETALHANDO SEQUÊNCIA DOS ENSAIOS REALIZADOS. 68

FIGURA 24. DESENHO ESQUEMÁTICO MOSTRANDO AS DIREÇÕES OBSERVADAS 71

FIGURA 25 - PREPARAÇÃO DA LÂMINAS CORTE E LIXAMENTO. 73

FIgURA 26. ESTAMPAGEM E POLIMENTO.

Figura 27. CALOTA ESFÉRICA.

FIGURA 28 - ETAPA FINAL DA LÂMINA, ATRAVÉS DO POLIMENTO IÔNICO. 74

FIGURA 29. GEOMETRIA E DIMENSÕES DOS CORPOS DE PROVA OBTIDOS PARA AS LIGAS DE AA2050-T84 E AA7050-T7451 PARA OS ENSAIOS A -54C. DIMENSÕES EM MM. 74 FiguRA 30. GEOMETRIA E DIMENSÕES dOS CORPOS DE PROVA OBTIDOS PARA AS LIGAS DE AA2050-T84 E AA7050-T7451 PARA OS ENSAIOS EM TEMPERATURA AMBIENTE. DIMENSÕES EM MM.

75

Figura 31. DESENHO dO CORPO DE PROVA C(T) TIRADO DO CENTRO DA PLACA COM ESPESSURA DE 25MM. DIMENSÕES EM MM.

FIGURA 32. ESQUEMA MOSTRANDO A CONFIGURAÇÃO DA RETIRADA DOS CORPOS DE PROVA, TIPO C(T) (ASTM E399-12).

FIGURA 33. CORPO DE PROVA ACOPLADO NA MÁQUINA DURANTE ENSAIO DE TENACIDADE À FRATURA.

FIGURA 34. CORPO DE PROVA MONTADO PARA ENSAIO EM BAIXA TEMPERATURA $\left(T=-54^{\circ} \mathrm{C}\right)$

Figura 35. DESENHO dO CORPO DE PROVA C(T) PARA DETERMINAÇÃo DA CURVA KR. DIMENSÕES EM MM.

FiguRA 36. ESQUEMA DA GEOMETRIA E DIMENSÕES, REALIZADO EM CAD, DOS CORPOS DE PROVA DO TIPO C(T). DIMENSÕES EM MM.

FIGURA 37. MICROGRAFIA ÓTICA MOSTRANDO A MICROESTRUTURA DA LIGA AA7050-T7451 
FIGURA 38. MICROGRAFIA DOS GRÃOS E DOS PRECIPITADOS NA DIREÇÃO LONGITUDINAL DA LIGA AA7050-T7451

FIGURA 39. ANÁLISE POR ESPECTROSCOPIA DE RAIO-X POR DISPERSÃO DE ENERGIA EM PRECIPITADOS INCOERENTES DA LIGA AA7050-T7451

FIGURA 40.( A) MICROGRAFIA DE MICROSCOPIA ELETRÔNICA DE TRANSMISSÃO POR VARREDURA (METV) MOSTRANDO, EM SINAL DE CAMPO CLARO, PRECIPITADOS FINOS DENTRO DOS GRÃOS, E PRECIPITADOS GROSSOS NOS CONTORNOS DE GRÃOS, E OS RESPECTIVOS MAPEAMENTOS ELEMENTARES DE RAIOS-X ATRAVÉS DE EDX: (B) ZR, (C) $\mathrm{AL},(\mathrm{D}) \mathrm{MG},(\mathrm{C}) \mathrm{CU},(\mathrm{D}) \mathrm{ZN}$.

FIgURA 41. ANÁLISE DE ESPECTROSCOPIA DE RAIO-X POR DISPERSÃO DE ENERGIA (EDX) DO PRECIPITADO NO CONTORNO DE GRÃO.

Figura 42. MiCROGRAFIA DE MET (MICROSCOPIA ELETRÔNICA DE TRANSMISSÃO) (A) IMAGEM DE CAMPO CLARO (CC) MOSTRANDO PRECIPITADOS NANOMÉRICOS E (B) DIFRAÇÃO DE ELÉTRONS DE ÁREA SELECIONADA (DEAS) NA ORIENTAÇÃO [011] E (C) DEAS EM EIXO DE ZONA QUALQUER, MOSTRANDO SPOTS DA MATRIZ DE AL E DOS PRECIPITADOS.

FIgURA 43. MICROGRAFIAS DE HRTEM (MICROSCOPIA ELETRÔNICA DE TRANSMISSÃO DE ALTA RESOlUÇÃO) (A) E (B), MOSTRANDO, NA ESCALA ATÔMICA, PRECIPITADOS NANOMÉTRICOS NO INTERIOR DO GRÃO (INTRAGRANULARES) E RESPECTIVOS SPOTS NA TRANSFORMADA DE FOURIER (TF) NO CANTO SUPERIOR DIREITO DE CADA IMAGEM. 94

FIGURA 44. MICROGRAFIA ÓTICA MOSTRANDO A MICROESTRUTURA DA LIGA AA2050-T7451

FIGURA 45. MICROGRAFIA DOS GRÃOS E DOS PRECIPITADOS NA DIREÇÃO LONGITUDINAL DA LIGA AA2050-T84 96

FIgURA 46. ANÁLISE POR ESPECTROSCOPIA DE RAIO-X POR DISPERSÃO DE ENERGIA EM PRECIPITADOS INCOERENTES DA LIGA AA7050-T7451 98

Figura 47. MICROGRAFIA DE MET (MICROSCOPIA ELETRÔNICA DE TRANSMISSÃO) (A) EM CAMPO CLARO (CC) E (B) ANÁLISE DE EDX GERAL, MOSTRANDO ELEMENTOS MAJORITÁRIOS QUE COMPÕEM A LIGA METÁLICA DE AL AA2050-T84 (EXCETO O LI QUE NÃO PODE SER DETECTADO). 100

FIGURA 48. MICROGRAFIA DE MET (MICROSCOPIA ELETRÔNICA DE TRANSMISSÃO) (A) EM CAMPO CLARO (BF) E RESPECTIVA (B) ANÁLISE DE EDX DA REGIÃO CIRCULAR DO PRECIPITADO COM FORMATO RETANGULAR. PADRÕES DE DIFRAÇÃO DE ELÉTRONS DE 
ÁREA SELECIONADA (DEAS) NO EIXO DE ZONA (C) DA MATRIZ [AL-FCC] E (D) $\left[\begin{array}{ll}1 & 0\end{array}\right]_{\text {AL-FCC }}$ MOSTRANDO SPOTS DA FASE INTERMETÁLICA S'.

FiguRA 49. MiCROGRAFIA DE METS (A) EM SINAL DE CAMPO ESCURO (DF - “DARK FIELD”) E (B) EM SINAL DE CAMPO CLARO (BF — "BRIGHT FIELD”), MOSTRANDO REGIÃO LIVRE DE PRECIPITADOS (PFZ) NO CONTORNO DE GRÃO E PRECIPITADOS INTRAGRANULARES NA ESCALA NANOMÉTRICA.

104

FIGURA 50. MICROGRAFIA DE (A) METV (MICROSCOPIA ELETRÔNICA DE TRANSMISSÃO POR VARREDURA) EM SINAL DE CAMPO CLARO (BF - "BRIGHT FIELD”) E RESPECTIVOS MAPEAMENTOS ELEMENTARES DE RAIOS-X ATRAVÉS DE EDS: (B) Al, (C) MN, (D) Mg, (C) CU, (D) ZN, MOSTRANDO A COMPOSIÇÃO DE PRECIPITADOS NOS CONTORNOS DE GRÃO (MAIORES) E NO INTERIOR DO GRÃO (MENORES) NA ESCALA NANOMÉTRICA. 105

FIGURA 51. CURVA $K_{R}$ VERSUS $\triangle A$ DA LIGA AA7050-T7451 NAS DIREÇÕES L-T E T-L. 114 FIGURA 52. CURVA KR VERSUS $\triangle A$ DA LIGA AA2050-T84 NAS DIREÇÕES L-T E T-L. 116 FIGURA 53. CURVA $K_{R}$ VERSUS $\triangle A$ DAS LIGAS AA2050-T84 E AA7050T7451 NA DIREÇÃO L-T 117

FIgURA 54. CURVA R COMPARATIVA ENTRE AS LIGAS AA2050T84 E AA7050-T7451 NA DIREÇÃO T-L.

FIGURA 55. ENSAIO DE PROPAGAÇÃO COM R0,1 E R0,5 NA DIREÇÃO L-T PARA AS LIGAS AA7050-T7451 NA TEMPERATURA AMBIENTE, USANDO-SE O MODELO DE PARIS. 119 FIGURA 56. ENSAIO DE PROPAGAÇÃO COM R0,1 E RO,5 NA DIREÇÃO T-L PARA AS LIGAS AA7050-T7451 NA TEMPERATURA AMBIENTE, USANDO-SE MODELO DE PARIS. 120 FIGURA 57. ENSAIO DE PROPAGAÇÃO COM R0,1 E R0,5 NA DIREÇÃO L-T PARA AS LIGAS AA7050-T7451 EM TEMPERATURA CRIOGÊNICA, USANDO-SE MODELO DE PARIS. 121 FIGURA 58. ENSAIO DE PROPAGAÇÃO COM R0,1 E RO,5 NA DIREÇÃO T-L PARA AS LIGAS AA7050-T7451 EM TEMPERATURA CRIOGÊNICA, USANDO-SE MODELO DE PARIS. 121 FIGURA 59. EFEITO DA TEMPERATURA NA RESISTÊNCIA A PROPAGAÇÃO DA TRINCA DA LIGA AA7050-T7451, USANDO-SE MODELO DE PARIS COM R0,1.

Figura 60. EFEITO dA RAZÃO DE CARGA NA TAXA DE PROPAGAÇÃO DA TRINCA DA LIGA AA2050-T84, NA DIREÇÃO L-T, NA TEMPERATURA AMBIENTE, USANDO-SE MODELO DE PARIS.

FIGURA 61. EFEITO DA RAZÃO DE CARGA NA TAXA DE PROPAGAÇÃO DA TRINCA DA LIGA AA2050-T84, NA DIREÇÃO T-L, NA TEMPERATURA AMBIENTE, USANDO-SE MODELO DE PARIS. 
FigurA 62. EFEITO dA RAZÃO dE CARGA NA TAXA DE PROPAGAÇÃO DA TRINCA DA LIGA AA2050-T84, NA DIREÇÃO L-T, NA TEMPERATURA CRIOGÊNICA, USANDO-SE MODELO DE PARIS.

FigurA 63. EFEITO dA RAZÃO DE CARGA NA TAXA DE PROPAGAÇÃO DA TRINCA DA LIGA AA2050-T84, NA DIREÇÃO T-L, NA TEMPERATURA CRIOGÊNICA, USANDO-SE MODELO DE PARIS.

FIGURA 64. EFEITO DA TEMPERATURA NA RESISTÊNCIA À PROPAGAÇÃO DA TRINCA DA LIGA AA2050-T84, USANDO-SE O MODELO DE PARIS COM R0,1.

FIgURA 65. COMPARAÇÃO ENTRE AS LIGAS AA7050-T7451 E AA2050-T84, USANDO-SE O MODELO DE PARIS, EM TEMPERATURA AMBIENTE, COM R0,1.

FIgURA 66. COMPARAÇÃO ENTRE AS LIGAS AA7050-T7451 E AA2050-T84, USANDO-SE O MODELO DE PARIS, EM TEMPERATURA CRIOGÊNICA, COM R0,5.

FIGURA 67. ENSAIO DE PROPAGAÇÃO COM R0,1 E R0,5, NA DIREÇÃO L-T, EM TEMPERATURA AMBIENTE, PARA A LIGA AA7050T7451, UtILIZANDO-SE MODELO DE PEARSON. 133

FIGURA 68. ENSAIO DE PROPAGAÇÃO COM R0,1 E R0,5, NA DIREÇÃO T-L, EM TEMPERATURA AMBIENTE, PARA A LIGA AA7050T7451, UTILIZANDO-SE O MODELO DE PEARSON. 134 FiguRA 69. ENSAIO dE PROPAGAÇÃO COM R0,1 E R0,5, NA DIREÇÃO L-T, EM TEMPERATURA CRIOGÊNICA, PARA A LIGA AA7050T7451, UTILIZANDO-SE MODELO DE PEARSON. 134 FiguRA 70. ENSAIO DE PROPAGAÇÃO COM R0,1 E R0,5, A DIREÇÃO T-L, EM TEMPERATURA CRIOGÊNICA, PARA A LIGA AA7050T7451, UTILIZANDO-SE MODELO DE PEARSON. 135 FIGURA 71. ENSAIO DE PROPAGAÇÃO COM R0,1 E R0,5, NA DIREÇÃO L-T, EM TEMPERATURA AMBIENTE, PARA A LIGA AA2050T7451, UTILIZANDO-SE MÉTODO DE PEARSON. 138 FIGURA 72. ENSAIO DE PROPAGAÇÃO COM R0,1 E R0,5, NA DIREÇÃO T-L, EM TEMPERATURA AMBIENTE, PARA A LIGA AA2050T7451, UtILIZANDO-SE MÉTOdO DE PEARSON. 139 FIGURA 73. ENSAIO DE PROPAGAÇÃO COM R0,1 E R0,5, NA DIREÇÃO L-T, EM TEMPERATURA CRIOGÊNICA, PARA A LIGA AA2050T7451, UTILIZANDO-SE MÉTODO DE PEARSON. 139

FIGURA 74. ENSAIO DE PROPAGAÇÃO COM R0,1 E R0,5, NA DIREÇÃO T-L, EM TEMPERATURA CRIOGÊNICA, PARA A LIGA AA2050T7451, UTILIZANDO-SE MÉTODO DE PEARSON. 140 FIGURA 75. ENSAIO DE THRESHOLD COMPARATIVO ENTRE R0,1 E R0,5, NA DIREÇÃO L-T, EM TEMPERATURA AMBIENTE, PARA A LIGA AA7050T7451.

FIgURA 76. ENSAIO DE THRESHOLD COMPARATIVO ENTRE R0,1 E R0,5, NA DIREÇÃO T-L, EM TEMPERATURA AMBIENTE, PARA A LIGA AA7050T7451.

FIGURA 77. ENSAIO DE THRESHOLD COMPARATIVO ENTRE R0,1 E R0,5, NA DIREÇÃO T-L, EM TEMPERATURA AMBIENTE, PARA A LIGA AA2050T84. 
7FIGURA 78. ENSAIO DE THRESHOLD COMPARATIVO ENTRE AS LIGAS AA7050-T7451 E AA2050-T84, NA DIREÇÃO T-L, COM R0,1, EM TEMPERATURA AMBIENTE. 145

FIGURA 79. ENSAIO DE THRESHOLD COMPARATIVO ENTRE AS LIGAS AA7050-T7451 E AA2050-T84, NA DIREÇÃO T-L, COM R0,5, EM TEMPERATURA AMBIENTE. 146

FIGURA 80. GRÁFICO MOSTRANDO O EFEITO DO AMBIENTE EM UMA CURVA DA/DN VERSUS $\triangle$ K (PLASCIK ET AL, 1993). 147

FIGURA 81. TAXA DE CRESCIMENTO DA TRINCA POR FADIGA INTRÍNSECO DA LIGA AL-LI-CUMG, NO VÁCUO (SLAVIK ET AL, 1993). 148 


\section{LISTAS DE TABELAS}

TABELA 1: DESIGNAÇÕES NUMÉRICAS PARA IDENTIFICAÇÃO DAS LIGAS DE ALUMÍNIO. 28

TABELA 2: COMPOSIÇÃO QUÍMICA DA LIGA AA7050 T(ALCOA). 33

TABELA 3: PROPRIEDADES MECÂNICAS dA LIGA AA7050-T7451 (AlCOA). 33

TABELA 4: COMPOSIÇÃO DA LIGA AA2050 T84 (ALCOA) 35

TABela 5: Propriedades MeCÂNICAS das ligas AA2050 T84, AA2024 T351, AA7050 T7451(ALCOA). 36

TABELA 6. COMPOSIÇÃO QUÍMICA DAS LIGAS DE ALUMÍNIO (\%PESO) 69

TABELA 7. COMPOSIÇÃO QUÍMICA DO REAGENTE DE KELLER 71

TABela 8. PARÂMETROS UtILIZADOS PARA EXECUÇÃo dE PRÉ-TRINCA NOS CORPOS DE PROVA DO ENSAIO DE TENACIDADE À FRATURA DA LIGA AA7050-T7451 78

TABELA 9. TAXAS DE CARREgamento PARA CADA CORPO DE PROVA EXTRAídO NAS DIREÇÕES L-T E T-L UTILIZADOS NOS ENSAIOS DE TENACIDADE $\left(K_{I C}\right)$ EM TEMPERATURA AMBIENTE DA LIGA AA7050-T7451 80

TABela 10. TAXAS de CARREgamento para CADA CORPO DE PROVA EXTRAído NAS DIREÇÕES L-T E T-L UTILIZADOS NOS ENSAIOS DE TENACIDADE $\left(K_{\text {IC }}\right)$ EM TEMPERATURA CRIOGÊNICA DA LIGA AA7050-T7451 80

TABela 11. MATRIZ DE ENSAIO DE FADIGA PARA a LIGA AA7050-T7451 83

TABela 12. Resultados dos ensaios de tRAÇÃo dA liga AA7050-T7451 EM TEMPERATURA AMBIENTE ( $\left.23^{\circ} \mathrm{C}\right)$.

Tabela 13. Resultados dos ensaios de tRaçÃo da liga AA7050-T7451 em TEMPERATURA CRIOGÊNICA $\left(-54^{\circ} \mathrm{C}\right)$.

Tabela 14. Resultados dos ensaios de traçÃo da liga AA2050-T84 EM TEMPERATURA AMBIENTE $\left(23^{\circ} \mathrm{C}\right) . \quad 109$

Tabela 15. Resultados dos ensalos de tração da liga AA2050-T84 em TEMPERATURA CRIOGÊNICA $\left(-54^{\circ} \mathrm{C}\right)$.

Tabela 16. Resultados dos Ensaios de Tenacidade À fRatura em temperatura AMBIENTE $\left(23^{\circ} \mathrm{C}\right)$ ENTRE AS LIGAS AA7050-T7451 X AA2050-T84 111

TABela 17. Resultados dos Ensaios de Tenacidade À fRATURA EM TEMPERATURA CRIOGÊNICA $\quad\left(-54^{\circ} \mathrm{C}\right)$ ENTRE AS LIGAS AA7050-T7451 E AA2050-T84 113

TABELA 18. RESUMO DOS RESULTADOS OBTIDOS DOS ENSAIOS DE PROPAGAÇÃO DE TRINCA POR FADIGA EM TEMPERATURAS AMBIENTE E CRIOGÊNICA PARA A LIGA AL-CU AA 7050T7451 E PARA $R=0,1$. 
TABELA 19. RESUMO DOS RESULTADOS OBTIDOS DOS ENSAIOS DE PROPAGAÇÃO DE TRINCA POR FADIGA EM TEMPERATURAS AMBIENTE E CRIOGÊNICA PARA A LIGA AL-CU AA 7050T7451 E PARA $R=0,5$.

123

TABELA 20. RESUMO DOS RESULTADOS OBTIDOS DOS ENSAIOS DE PROPAGAÇÃO DE TRINCA POR FADIGA, EM TEMPERATURAS AMBIENTE E CRIOGÊNICA, PARA A LIGA AL-LI AA 2050T84 E PARA $R=0,1$.

TABELA 21. RESUMO DOS RESULTADOS OBTIDOS DOS ENSAIOS DE PROPAGAÇÃO DE TRINCA POR FADIGA EM TEMPERATURA AMBIENTE E CRIOGÊNICA PARA A LIGA AL-LI AA 2050T84 E PARA $R=0,5$.

130

TABELA 22. RESUMO DOS RESULTADOS OBTIDOS DOS ENSAIOS DE PROPAGAÇÃO DE TRINCA POR FADIGA, EM TEMPERATURAS AMBIENTE E CRIOGÊNICA, PARA A LIGA AL-Cu AA 7050-T7451 E PARA R $=0,1$.

136

TABELA 23. RESUMO DOS RESULTADOS OBTIDOS DOS ENSAIOS DE PROPAGAÇÃO DE TRINCA POR FADIGA, EM TEMPERATURAS AMBIENTE E CRIOGÊNICA, PARA A LIGA AL-LI AA 7050T7451 E PARA $R=0,5$.

TABELA 24, RESUMO DOS RESULTADOS OBTIDOS DOS ENSAIOS DE PROPAGAÇÃO DE TRINCA POR FADIGA, EM TEMPERATURAS AMBIENTE E CRIOGÊNICA, PARA A LIGA AL-LI AA 2050T84 E PARA $R=0,1$.

TABELA 25. RESUMO dOS RESULTADOS OBTIDOS DOS ENSAIOS DE PROPAGAÇÃO DE TRINCA POR FADIGA, EM AR E EM CRIOGENIA, PARA A LIGA AL-LI AA 2050-T84 E PARA R = 0,5. 


\section{LISTAS DE ABREVIATURAS E SIGLAS}

$a$ : Comprimento da trinca

$a_{\mathrm{c}}$ : Comprimento da trinca crítico

$a_{\text {eff: }}$ Comprimento efetivo da trinca.

B: Espessura do corpo de prova

C: Constante de Paris

$\mathrm{C}_{2}$ : Constante de Pearson

D: Diâmetro da impressão visto lateralmente;

D: Diâmetro da impressão da vista superior.

$d a / d N$ : Taxa de popagação de trinca por fadiga (função do número de ciclos)

$E$ : Módulo de Elasticidade

$f$ : Fator de forma ou fator geométrico

$f_{i j}$ : Função adimensional

G: Taxa de liberação de energia

$G_{c}:$ Taxa de liberação de energia crítica

$K$ : Fator de intensidade de tensão

$K_{\text {eff: }}:$ Fator de intensidade de tensão com o tamanho de trinca

$K_{I}$ : Fator de intensidade de tensão crítico no estado plano de tensão $a_{\text {eff }}$

$K_{I C}$ : Fator de intensidade de tensão crítico no modo I de fratura no estado plano de tensão

$K_{\max }$ : Fator de intensidade de tensão máximo

$K_{\min }:$ Fator de intensidade de tensão mínimo

$K_{Q}$ : Fator de intensidade de tensão provisório.

$K_{R}$ : Fator de intensidade de tensão relativo à curva $K_{R}$ 
m: Expoente de Paris

$m_{2}$ : Expoente de Pearson

P: Carga

$P_{\max }$ : Carga máxima

$P_{\min }$ : Carga mínima

$P_{m}:$ Carga média

$P_{a}$ : Carga alternada

$R$ : Razão de carga

$r$ : Distância polar da trinca ao ponto onde se deseja calcular as tensões $\sigma_{x} \sigma_{y}$ e $\sigma_{z}$

$r_{p}$ : Zona plástica de Irwin

$r_{y}$ : Zona plástica Irwin corrigida

$U_{e}$ : Energia elástica de uma placa não trincada.

$U_{s}$ : Energia elástica da superfície devido a trinca

$U_{t}$ : Energia total de uma placa trincada

V, $\vee 0 \vee$ e $V_{0}$ : potenciais de saída medidos na posição $\vee y$.

W: Largura do corpo de prova

$\mathrm{w}_{\mathrm{f}}$ : Energia de fratura

$\beta$ : Correção da zona plástica de Irwin

$\Delta a$ : Variação do comprimento da trinca

$\Delta \mathrm{K}$ : Variação do fator intensidade de tensão

$\varepsilon_{t}$ : Alongamento total

v: Coeficiente de Poison

$\sigma:$ Tensão nominal

$\sigma_{c}:$ Tensão Coesiva 
$\sigma_{0,2}$ : Limite de escoamento a $0,2 \%$

$\sigma_{i j}:$ Tensor de tensão

$\sigma_{r}:$ Limite de resistência

$\sigma_{x}$ : Tensão na direção $\mathrm{x}$

$\sigma_{y}:$ Tensão na direção y

$\rho$ : Zona plástica de Dugdale

$\gamma_{p}:$ Energia superficial plástica

$\gamma_{e}$ : Energia superficial elástica

$\gamma_{s}:$ Energia superficial

$\tau_{x y}, \tau_{x z}, \tau_{y z}:$ Tensões de cisalhamento

$\theta$ : Ângulo que o raio polar faz com o plano da trinca.

$\lambda$ : Comprimento de onda. 


\section{LISTAS DE ABREVIATURAS E SIGLAS}

ABNT - Associação Brasileira de Normas Técnicas

ASTM - American Society for Testing and Materials

CFC - estrutura cúbica de face centrada

CMOD - crack opening displacement

CST - corrosão sob tensão

$C(T)$ - compact tension specimen

CC - campo claro (BF - Bright field).

CE - campo escuro (DF - Dark Field)

CDP: Corpo de prova

DIN: Instituto Alemão para Normatização

EDX - Energia dispersiva de raio $\mathrm{X}$

EMBRAER - Empresa Brasileira de Aeronáutica S/A

MEV - Microscópio eletrônico de varredura

MET - Microscópio eletrônico de transmissão

MFLE - mecânica da fratura linear elástica

MFEP - mecânica da fratura elasto-plástica

TA - Temperatura ambiente

TC - Temperatura criogênica

ZGP - Zona de Guiner-Prest 


\section{SUMÁRIO}

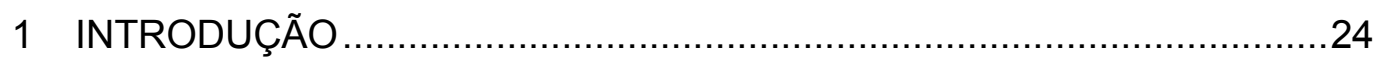

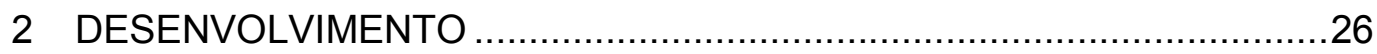

2.1 Características do alumínio e suas ligas .......................................26

2.1.1 Ligas conformadas ou trabalhadas ......................................27

2.1.2 Nomenclatura e simbologia dos tratamentos térmicos das ligas de alumínio 28

2.1.3 Ligas de Al da série 7XXX.....................................................

2.1.3.1 Ligas de alumínio - zinco - magnésio ..................................31

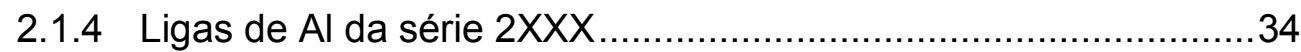

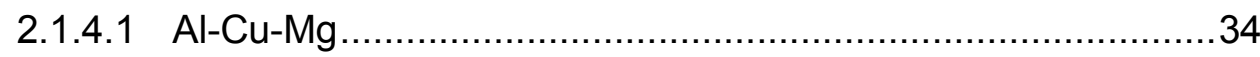

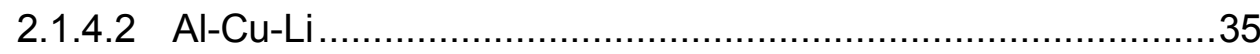

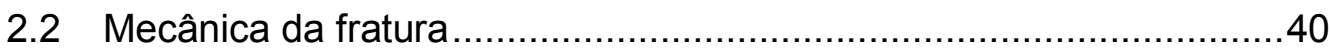

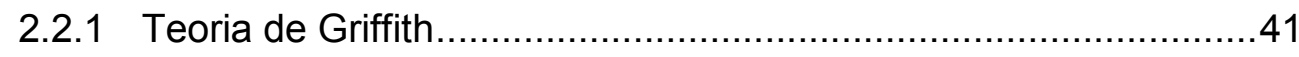

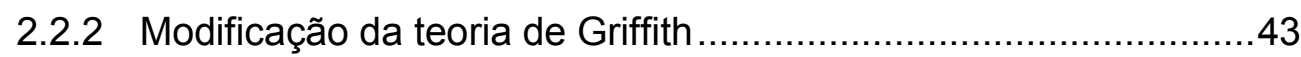

2.2.3 Mecânica da fratura elástica linear ...........................................45

2.2.3.1 Modos de abertura da ponta da trinca .................................46

2.2.3.2 Fator de intensidade de tensão ......................................... 47

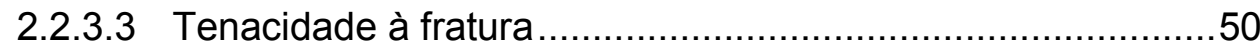

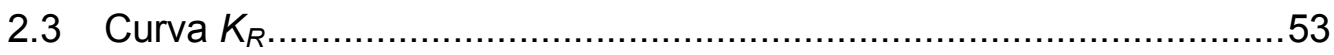

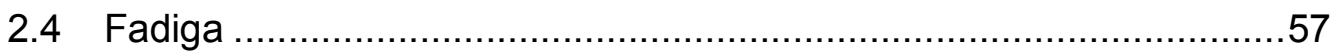

2.4.1 Nucleação e Propagação .........................................................57 
2.4.2 Propagação por trinca de fadiga baseada na mecânica da fratura elástica linear

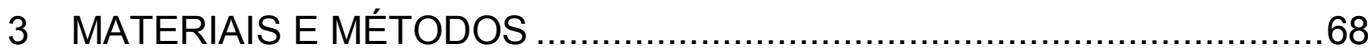

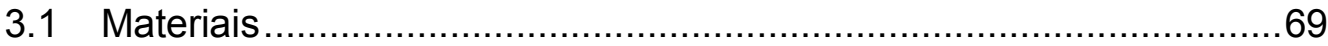

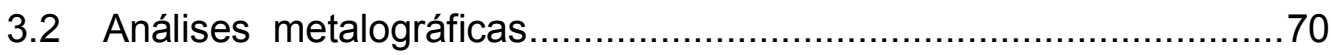

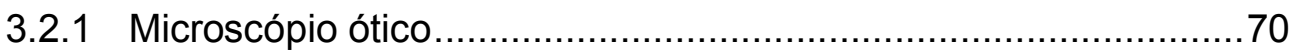

3.2.2 Microscópio eletrônico de varredura (MEV) …...........................72

3.2.3 Microscópio eletrônico de transmissão (MET) ............................72

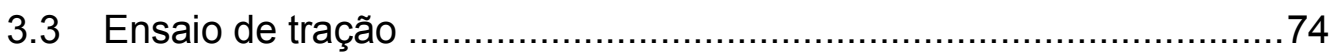

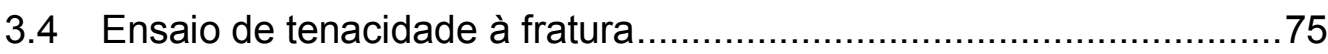

3.4.1 Ensaios de tenacidade à fratura na temperatura ambiente ..........80

3.4.2 Ensaios de tenacidade à fratura na temperatura criogênica .........80

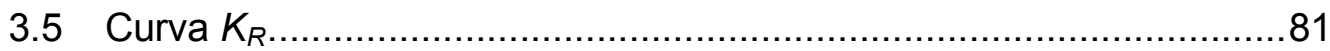

3.6 Propagação de trinca por fadiga em temperatura ambiente e $\begin{array}{ll}\text { criogênica } & 82\end{array}$

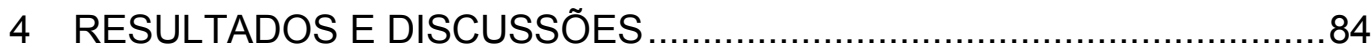

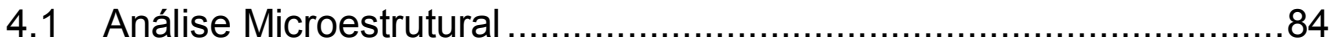

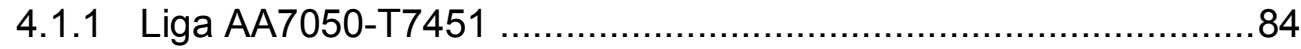

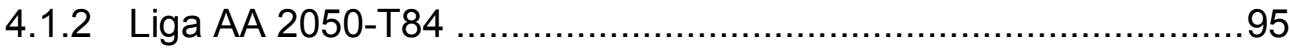

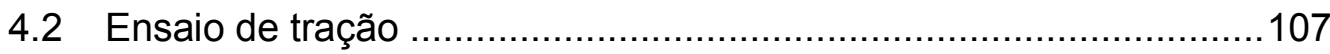

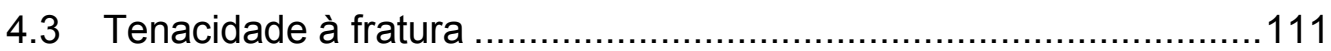

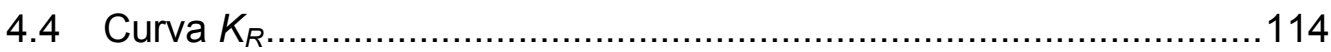


4.5 Ensaio de Fadiga ..................................................................... 119

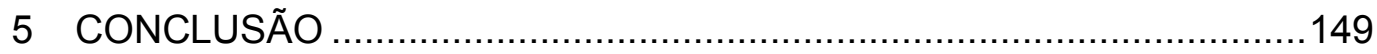

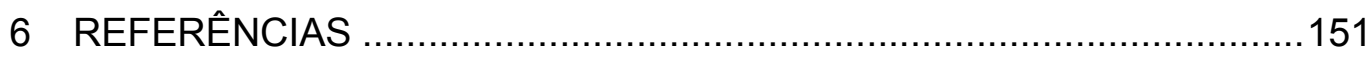




\section{INTRODUÇÃO}

O alumínio tem sido o material primário na escolha para componentes estruturais aeronáuticos desde 1930. Embora os compósitos estejam sendo usados com mais frequência em aviões militares de alta performance e em alguns aviões comerciais modernos, as ligas de alumínio sempre foram consideradas materiais aeronáuticos por excelência. Sua baixa massa específica, aliada às boas propriedades mecânicas, conferem a estes materiais uma elevada resistência mecânica específica, pela relação entre a tensão desenvolvida e a massa específica do material, particularmente quando ligado a outros elementos (Carmargo 2007; Starke, Staley, 1996).

Com a exigência das indústrias aeronáuticas pela diminuição dos custos com combustíveis, o que requer a diminuição do peso do avião, uma nova geração de ligas alumínio foi desenvolvida. Essas novas ligas são baseadas no sistema Al-Li, que possuem densidades relativamente pequenas (entre aproximadamente 2,5 e $2,6 \mathrm{~g} / \mathrm{cm}^{3}$ ), módulos específicos elevados (razão módulo de elasticidade - gravidade específica) e excelentes propriedades de fadiga e tenacidade a baixas temperaturas.

Essa tese se justifica porque propiciará elevar o conhecimento sobre o comportamento da tenacidade à fratura e fadiga, das ligas Al-Li, submetidas a ambientes de temperatura ambiente e criogênica. Assim, no futuro, os aviões com as ligas tradicionais poderão ser substituídos por aqueles com ligas de maior desempenho, aumentando a sua eficiência.

Neste trabalho será estudado o efeito da temperatura na tenacidade à fratura das novas ligas de $\mathrm{Al}-\mathrm{Li}$, bem como a influência da mesma no limite de resistência à fadiga, determinando os micromecanismos de fratura e comparando os resultados com os obtidos para as ligas convencionais, atualmente em uso na indústria 
aeronáutica. Para tanto, serão determinados o fator de intensidade de tensão, $\mathrm{K}_{I c}$, taxa de propagação de trinca, da/dt $x K$ com razões de cargas variando entre $0,1 \mathrm{e}$ 0,5 , na temperatura ambiente e criogênica $\left(-54^{\circ} \mathrm{C}\right)$, e curva de resistência (Curva $\mathrm{K}_{\mathrm{R}}$ ). As superfícies fraturadas serão analisadas usando microscópio ótico, microscópio eletrônico de varredura e microscópio eletrônico de transmissão. 


\section{DESENVOLVIMENTO}

\subsection{Características do alumínio e suas ligas}

O alumínio e suas ligas são caracterizados por uma densidade relativamente baixa $\left(2,7 \mathrm{~g} / \mathrm{cm}^{3}\right.$, em comparação com uma densidade de $7,9 \mathrm{~g} / \mathrm{cm}^{3}$ para o aço), condutividade elétrica e térmica elevadas, e uma resistência à corrosão em alguns ambientes comuns, incluindo a atmosfera ambiente. Muitas dessas ligas são conformadas com facilidade em virtude das suas elevadas ductilidades, o que resta evidente através das finas folhas de papel alumínio nas quais o material relativamente puro pode ser laminado.

Uma vez que o alumínio possui uma estrutura cristalina CFC, a sua ductilidade é mantida até mesmo em temperaturas reduzidas. A principal limitação do alumínio está na sua baixa temperatura de fusão $\left[660^{\circ} \mathrm{C}\left(1220^{\circ} \mathrm{F}\right)\right]$, o que restringe a temperatura máxima em que o alumínio pode ser utilizado.

A resistência mecânica do alumínio pode ser aumentada através de deformação plástica a frio e mediante a formação de ligas. Entretanto, ambos os processos tendem a diminuir a resistência á corrosão. Os principais elementos de liga incluem o cobre, o magnésio, o silício, o manganês e o zinco. As ligas que não são tratáveis termicamente consistem em uma única fase, para as quais um aumento na resistência é obtido através do endurecimento por solução sólida. Outras ligas são tornadas termicamente tratáveis (capazes de serem submetidas a tratamento de endurecimento por precipitação), como resultado do processo de formação da liga. Em várias dessas ligas, o endurecimento por precipitação é devido à precipitação de dois elementos, que não o alumínio, para formar um composto intermetálico, tal com o $\mathrm{MgZn}_{2}$. 
Em geral, as ligas de alumínio podem ser divididas em ligas conformadas ou trabalhadas e ligas para fundição.

\subsubsection{Ligas conformadas ou trabalhadas}

As ligas conformadas passam por processos de laminação, extrusão, forjamento e estiramento. As mesmas são destinadas à fabricação de produtos semi-acabados, como laminados planos (placas, chapas e folhas), laminados não planos (tarugos, barras e arames), perfis extrudados e componentes forjados.

As ligas trabalhadas são subdivididas em duas classes:

- Ligas tratáveis termicamente: passam pelos processos de solubilização, precipitação, envelhecimento e/ou endurecimento.

- Ligas não tratáveis termicamente: As propriedades são alteradas apenas por trabalho a frio, ou seja, encruamento.

A fundição de peças de alumínio é feita em areia, sob pressão e precisão. Este grupo também é subdividido em duas classes:

- Ligas binárias - Com um elemento de liga adicionado (alumínio-cobre, alumínio-silício, alumínio-manganês, etc.).

- Ligas complexas - Com dois ou mais elementos de ligas adicionados (alumínio-cobre-silício, alumínio- cobre-silício-magnésio) (Maciel, 2013). 
2.1.2 Nomenclatura e simbologia dos tratamentos térmicos das ligas de alumínio Não existe um padrão internacional de nomenclatura para identificação das ligas de alumínio. Assim, cada associação, dentre as quais Alcan, DIN, ABNT e ASTM, adota um padrão de nomenclatura para identificação das ligas de alumínio. Usando o padrão ASTM, a ligas de alumínio são identificadas por meio de designações numéricas de quatro dígitos. O primeiro dígito indica o elemento ligante majoritário, conforme mostrado na tabela 1. O segundo elemento diferente de zero indica a modificação da liga original ou limites de impurezas. Os dois últimos dígitos são números arbitrários para diferenciar as várias ligas do grupo.

Tabela 1: Designações numéricas para identificação das ligas de alumínio.

Grupos de Liga

1XXX

2XXX

$3 X X X$

$4 X X X$

$5 X X X$

6XXX

7XXX
Elementos ligantes majoritários

Alumínio $99 \%$ de pureza

Cobre

Manganês

Silício 
As designações de tratamento térmico em ligas de alumínio são utilizadas em ligas trabalhadas ou fundidas, por meio de uma sequência de letras e números posteriores à especificação da liga e separados por um hífen. Cada dígito especifica o tipo e a sequência de tratamentos térmicos aplicados no material para conseguir a propriedade desejada através de transformações microestruturais (ASM Handbook, 1991).

A letra $\mathrm{T}$ é utilizada para indicar tratamentos térmicos em ligas onde a resistência se estabiliza em pouco tempo e sua designação segue da seguinte forma:

T1 - Aplicado em produtos conformados à alta temperatura em processos como fundição ou extrusão, e envelhecidos naturalmente.

T2 - Esta variação é utilizada em produtos trabalhados a quente, como laminação ou extrusão, e envelhecidos naturalmente.

T3 - É designado a produtos trabalhados a frio, que sofreram tratamento térmico de solubilização e envelhecimento natural.

T351 - Solução tratada, com alívio de tensões então a frio.

T4 - São produtos não trabalhados a frio depois do tratamento térmico e envelhecidos naturalmente.

T451 - Solução tratada e, em seguida, alívio de tensões.

T5 - Produtos não trabalhados a frio depois da conformação mecânica a altas temperaturas, e envelhecidos artificialmente.

T6 - Este grupo é designado a materiais que precisam obter estabilidades dimensionais e mecânicas através do tratamento térmico de solubilização e precipitação.

T651 - Tratada, com alívio de tensões, então envelhecidas artificialmente (tratamento térmico de precipitação). 
T7 - Aplicados em produtos conformados a frio, com tratamentos térmicos de precipitação, solubilização e envelhecimento artificial. É obtido o limite máximo de resistência à corrosão sob tensão e corrosão por exfoliação.

T8 - É aplicado a produtos trabalhados a frio depois dos tratamentos térmicos de precipitação, solubilização e envelhecimento artificial.

T9 - Produtos trabalhados a frio depois do tratamento térmico de precipitação e envelhecimento artificial.

T10 - Produtos com resfriamentos rápidos após a conformação mecânica a quente, como laminação ou extrusão, com propriedades mecânicas substancialmente melhoradas através do tratamento térmico de precipitação e envelhecimento artificial. (Maciel, 2013)

T451 - Tratamento térmico e alívio de tensões. 


\subsubsection{Ligas de Al da série $7 \mathrm{XXX}$}

2.1.3.1 Ligas de alumínio - zinco - magnésio

As liga de alumínio - zinco - magnésio pertencem à classe 7000, na qual a resistência é aumentada por tratamentos térmicos e são endurecidas por precipitação ou envelhecimento , tais como T7451, T7651, dentre outras. Essa liga tem como principais partículas de segunda fase $\mathrm{Al}_{7} \mathrm{Cu}_{2} \mathrm{Fe}, \mathrm{Mg}_{2} \mathrm{Si}$ e $\mathrm{Al}_{2} \mathrm{CuMg}$, como segue:

- $\mathrm{Al}_{7} \mathrm{Cu}_{2} \mathrm{Fe}: \mathrm{A}$ presença desse intermetálico é prejudicial aos estágios subsequentes de processamento, devido a partículas grossas do Fe, que podem afetar propriedades mecânicas. Essas partículas de $\mathrm{Fe}$ podem agir como concentradores de tensões, gerando trincas nas regiões adjacentes (Mazzer, 2013).

- $\mathrm{Mg}_{2} \mathrm{Si}$ : Essa partícula produz precipitados refinados e um endurecimento por precipitação em níveis satisfatórios, resultando no aumento da resistência da liga (Matsuda, 2000; Ringer, 1998).

- $\mathrm{Al}_{2} \mathrm{CuMg}$ : A presença do $\mathrm{Mg}$ e do Cu nesse intermetálico aumenta a resistência e reduz a densidade.

A liga $\mathrm{Al}$ da série $7 \mathrm{XXX}$ caracteriza-se pela alta resistência mecânica, alta tenacidade à fratura, boa resistência à corrosão e corrosão sob tensão (Luo, et al 2011) . Dentro da classe 7000 destacam-se algumas ligas, tais como AA7075, AA7475 e AA7050, dentre outras. Conforme já descrito na liga 2XXX, para a liga 7XXX a precipitação nas ligas de alumínio começa também com a formação das zonas GP, que são precipitados metaestáveis coerentes. 
De acordo com Ringer et al (1998) e Shen (2009), a provável sequência de precipitação da liga de alumínio $7 \mathrm{XXX}$ pode ser sumarizada da seguinte forma: SS $\rightarrow$ zona GP $\rightarrow \eta^{\prime} \rightarrow \eta\left(M \mathrm{Mn}_{2}\right)$. As fases GP e $\eta^{\prime}$ são as fases de precipitações principais, elas são responsáveis por conferir uma alta resistência à liga de alumínio 7050

Em 1943 desenvolveu-se a liga AA7075 para atender aos padrões da indústria aeroespacial. Essa liga foi o primeiro sucesso de uma liga de alumínio de alta resistência, contendo $0,40 \% \mathrm{Si}-0,50 \% \mathrm{Fe}-2 \% \mathrm{Cu}-0,30 \% \mathrm{Mn}-2,9 \% \mathrm{Mg}-028 \% \mathrm{Cr}$ $6,1 \% \mathrm{Zn}-0,20 \% \mathrm{Ti}$. Esta liga tinha boa resistência à corrosão sob tensão, devido à adição de cromo. Embora tenham surgido outras ligas que serão descritas abaixo, ela continua sendo a linha base, com um bom balanço das propriedades mecânicas requeridas para aplicações aeroespaciais (Alcoa).

A liga AA7475 foi desenvolvida para combinar alta resistência, boa tenacidade à fratura e resistência à propagação de trinca por fadiga e, em alguns casos, possui uma resistência à corrosão melhor que as ligas AA7075 e AA7475. Essa liga possui a seguinte composição química: $0,10 \% \mathrm{Si}-0,12 \% \mathrm{Fe}-1,9 \% \mathrm{Cu}-0,06 \% \mathrm{Mn}-2,6 \% \mathrm{Mg}$ 0,25\%Cr-6,2\%Zn-0,06\%Ti.(Alcoa)

A liga AA7050 desenvolvida pela ALCOA é uma das ligas mais usadas na indústria aeronáutica, uma vez que tem boa combinação entre resistência, resistência à corrosão sob tensão e tenacidade. Segundo Shen (2009), a liga AA7050 foi desenvolvida para ser a sucessora da liga AA7075, e possui alto teor de cobre e zinco. A diferença entre as ligas AA7050 e AA7075 está na adição de zircônio, em vez de cromo, como elemento inibidor de recristalização.

Na tabela 2 estão descritas as composições químicas da liga AA7050. 
Tabela 2: Composição química da liga AA7050 T(Alcoa).

\begin{tabular}{|c|c|c|c|c|c|c|c|c|c|}
\hline Si & $\mathrm{Fe}$ & $\mathrm{Cu}$ & Mn & Mg & $\mathrm{Cr}$ & $\mathrm{Zn}$ & $\mathrm{Ti}$ & $\mathrm{Zr}$ & Outros \\
\hline 0,12 & 0,15 & $2,02,7$ & 0,10 & $1,92,6$ & 0,04 & $\begin{array}{ll}5,7 & 6,7\end{array}$ & 0,06 & $\begin{array}{l}0,08 \\
0,115\end{array}$ & 0,15 \\
\hline
\end{tabular}

O alto teor de cobre, distribuição espacial e tamanho dos precipitados, conferem à liga 7050 uma alta resistência mecânica, uma boa resistência à corrosão e, por isso, são largamente usadas na indústria aeronáutica. A tabela 3 apresenta as propriedades mecânicas da liga AA7050-T7451 e são mostrados os valores de tenacidade à fratura, em que a melhoria da tenacidade é resultado da fração de volume controlado de partículas intermetálicas grosseiras e estrutura de grão não cristalizado. Outro fator que contribuiu para a melhoria da tenacidade foi o alto teor de zinco com baixo conteúdo de cobre.

Tabela 3: Propriedades mecânicas da liga AA7050-T7451 (Alcoa).

\begin{tabular}{cccccc}
\hline Liga & Espessura & Tensão de & Tensão de & $K_{I C}$ & Alongamento \\
& $(\mathbf{m m})$ & Resistencia & Escoamento & $\left(\right.$ MPam $\left.^{\mathbf{0 , 5}}\right)$ & $\%$ \\
& & $\begin{array}{c}\text { à tração } \\
(\mathbf{M P a})\end{array}$ & $(\mathbf{M P a})$ & & \\
\hline AA7050-T7451 & $6,35-50,80$ & 510 & 483 & 31,9 & 9 \\
\hline
\end{tabular}




\subsubsection{Ligas de Al da série $2 X X X$}

\subsubsection{Al-Cu-Mg}

As ligas de alumínio da série 2XXX são ligas que possuem o $\mathrm{Cu}$ e $\mathrm{Mg}$ como os principais elementos ligantes que aumentam a sua resistência. $\mathrm{O} \mathrm{Cu}$, além de aumentar a resistência, melhora as propriedades de fadiga, aumenta a resistência em temperaturas elevadas e mecanicabilidade. (Nafsin, 2013, Xiao, 2002).

As ligas da série $2 X X X$ têm baixa resistência à corrosão, em comparação às ligas de outras séries, que contêm uma menor quantidade de cobre. Elas são muito utilizadas em aplicações estruturais nas áreas aeronáuticas e aeroespaciais (Ghali, 2010).

Essas ligas são trabalhadas e reforçadas por meio de endurecimento por precipitação ou envelhecimento, que produz os precipitados por meio de um tratamento térmico e cujas partículas constituintes mais comuns são $\mathrm{Al}_{2} \mathrm{Cu}$ ou $\mathrm{Al}_{2} \mathrm{CuMg}$.

Conforme descrito por Ringer et al (1998), a precipitação nas ligas de alumínio começa com a formação das zonas GP, que são precipitados metaestáveis coerentes.

Ringer et al (1996) sugeriu que a série $2 X X X$, composta por três elementos Al-Cu-Mg, tem a provável sequência de precipitação: Solução sólida $\rightarrow$ Estagio préprecipitação $\rightarrow$ Zona GP $+\mathrm{S} \rightarrow \mathrm{S}\left(\mathrm{AL}_{2} \mathrm{CuMg}\right)$

A fase $S\left(\mathrm{Al}_{2} \mathrm{CuMg}\right)$ representa a fase de equilíbrio e constitui-se em partículas intermetálicas que conferem um endurecimento à liga e um aumento na resistência a mesma (Nafsin, 2013). 


\subsubsection{Al-Cu-Li}

O interesse no lítio está no fato de ser um excelente elemento ligante, é mais leve que os elementos metálicos conhecidos com densidade de $0,54 \mathrm{~g} / \mathrm{cm}^{3}$ e tem um número atômico 3 , pelo que somente o hidrogênio e o hélio são mais leves. Além das características citadas anteriormente, ele tem alta solubilidade com o alumínio, sendo que para cada $1 \%$ acrescido de lítio, a densidade do alumínio é reduzida em até 3\% e, simultaneamente, ele aumenta a rigidez ou o módulo de elasticidade em $6 \%$.

As pesquisas de Al-Li começaram nos Estados Unidos e na Alemanha, na década de 1920. Nessa mesma década, a Alemanha desenvolveu a primeira liga comercial de alumínio contendo lítio, cuja composição química era Al-12\%Zn-3\%Cu$0,6 \% \mathrm{Mn}-0,1 \% \mathrm{Li}$, mas, como outras ligas que não continham lítio apresentavam melhores propriedades, ela foi abandonada (Prasad, 2014).

Na década de 1950, a Alcoa Corporation desenvolveu uma liga alumínio-lítio de alta resistência. Essa liga foi denominada AA2020, cuja composição química era $\mathrm{Al}-4,5 \% \mathrm{Cu}-1,1 \% \mathrm{Li}-0,5 \% \mathrm{Mn}-0,2 \% \mathrm{Cd}$ e tinha alta resistência em temperaturas variando entre $150-200^{\circ} \mathrm{C}$. E em 1965, a então União Soviética, desenvolveu a liga AA1420 contendo Al -2\%Li-5,5\%Mg-0,1\%Zr (Prasad, 2014). Na década de 1980 são desenvolvidas as ligas AA2090, AA2091 e AA8090, dentre outras, denominadas segunda geração das ligas de alumínio - Litio.

A liga AA2050 dentre outras é uma liga da terceira geração da liga AL-LI-Cu, em que a composição química está descrita na tabela 4.

Tabela 4: Composição da liga AA2050 T84 (Alcoa)

\begin{tabular}{cccccccc}
\multicolumn{2}{c}{ Tabela 4: Composição da liga AA2050 T84 (Alcoa) } \\
\hline Liga & Li & Cu & Mg & Ag & Zr & Mn & Zn \\
& & & & & & & \\
\hline AA2050 T84 & 1 & 3,6 & 0,4 & 0,4 & 0,11 & 0,35 & 0,25 \\
& & & & & & & \\
\hline
\end{tabular}


Ela é caracterizada pelos melhoramentos na resistência à tração, tenacidade à fratura, resistência ao crescimento de trinca por fadiga, excelente resistência à corrosão sob tensão. (Hafley, 2011).

Além dos melhoramentos já citados no paragrafo anterior, ela apresenta uma menor densidade e um maior modo de elasticidade, quando comparada com as ligas convencionais $7 \mathrm{XXX}$ e 2XXX. Na tabela 5 estão as propriedades mecânicas da liga AA2050 T84, AA2024 T351, AA7050 T7451.

Tabela 5: Propriedades mecânicas das ligas AA2050 T84, AA2024 T351, AA7050 T7451(Alcoa)

\begin{tabular}{|c|c|c|c|c|c|c|}
\hline Liga & $\begin{array}{c}\sigma_{Y} \\
(M P a)\end{array}$ & $\begin{array}{c}\sigma_{u} \\
(M p a)\end{array}$ & $\begin{array}{c}E \\
(\mathrm{GPa})\end{array}$ & $\begin{array}{l}e_{T} \\
(\%)\end{array}$ & $\begin{array}{c}K_{I C} \\
\left(\mathrm{MPam}^{0,5}\right)\end{array}$ & Densidade \\
\hline AA2050-T84 & 441,26 & 489,52 & 75,15 & 3 & 42 & 2,71 \\
\hline AA2024-T351 & 296,5 & 434,37 & 73,8 & 6 & 30 & 2,77 \\
\hline AA7050-T7451 & 448,16 & 517,10 & 71 & 9 & 31 & 2,77 \\
\hline
\end{tabular}

As ligas de alumínio - lítio podem ter a resistência aumentada através de tratamentos térmicos e tratamento por envelhecimento artificial (Fendoni, 2009):

- Solubilização em alta temperatura para dissolver os elementos ligantes e obter uma única fase.

- Têmpera para obter uma solução sólida super-saturada (SSSS)

- Decomposição da SSSS com um tratamento por envelhecimento.

Como dito anteriormente a precipitação por endurecimento de ligas contendo lítio envolves várias fases metaestáveis. A figura 1 mostra esquematicamente as possíveis fases presentes nas ligas de Al-Li. 


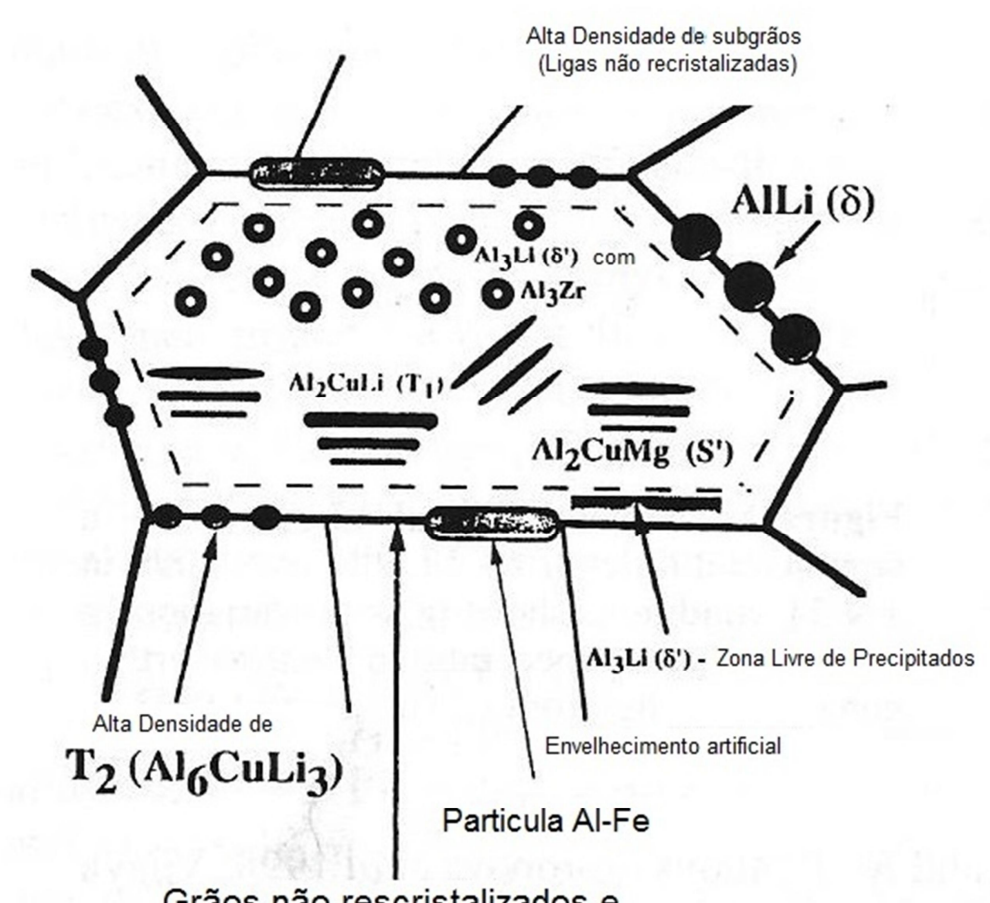

Grãos não rescristalizados e alongados

Anisotropia de grãos largos

Figura 1: Esquema mostrando as possíveis fases presentes na liga AL-Li AA8090 (Prasad et al 2003).

Abaixo estão as outras fases que podem se desenvolver durante a precipitação (Fendoni, 2009):

- $\delta(A l L i)$ - Precipitados provenientes da matriz. A fragilização e a susceptibilidade de corrosão sob tensão (CST) estão associadas a este precipitado.

- $\quad \delta^{\prime}\left(\mathrm{Al}_{3} \mathrm{Li}\right)$ - Precipita-se antes do resfriamento rápido. A partir da solubilização diminui a tenacidade e a ductilidade, devido à presença do $\mathrm{Li}$, que limita o deslizamento dos grãos e é passivo ao cisalhamento.

- $\theta(\mathrm{Al}-\mathrm{Cu})$ - É o precipitado de equilíbrio termodinâmico proveniente de $\theta^{\prime}$ e $\theta^{\prime \prime}$ e possui acentuada queda de dureza.

- $\quad \beta^{\prime}\left(A l_{3} Z r\right)$ - Devido à presença do Zircônio $(Z r)$, inibe a recristalização e possui microestrutura fina dispersa uniformemente na matriz, melhora as propriedades de fadiga do material e tenacidade. 
- $\quad S^{\prime}\left(A l_{2} C u M g\right)$ - Assim como $\delta^{\prime \prime}$ possui alta fração volumétrica na matriz, e não é afetada pelo Li, sua nucleação é difícil e ocorre preferencialmente nas discordâncias. A presença do Magnésio $(\mathrm{Mg})$ reduz a densidade e melhora a resistência .

- $\quad T_{1}\left(A I_{2} C u L i\right)$ - Esta fase é estável e sua nucleação ocorre nas ZGP ou em discordâncias. O aumento desse precipitado aumenta a resistência da liga.

- $\mathrm{T}_{2}\left(\mathrm{Al}_{2} \mathrm{CuLi}_{3}\right)$ - Rico em Cu é responsável pelas zonas livres de precipitados e pela fragilização do contorno de grão.

- Pequenas partículas dispersas de $\mathrm{MnAl}_{6}$ - O Manganês (Mn) tende a produzir fases intermetálicas onde somente $0,2-0,3 \%$ são solubilizados. Este componente pode nuclear partículas de precipitados $\delta$ '.

A adição de Magnésio $(\mathrm{Mg})$ e Prata $(\mathrm{Ag})$ em igual proporção tem grande efeito no surgimento dos demais precipitados e no aperfeiçoamento das propriedades de tensão e dobra a resistência ao escoamento do material. Quando há adição independente destes elementos o Mg auxilia na formação de precipitados T1, enquanto o Ag auxilia na formação de precipitados $\theta^{\prime}$ (MACIEL, 2013).

A presença de precipitados de cisalhamento ( $\delta$ ') e precipitados no contorno de grão (ס) associados com a zona livre de precipitados, conforme figura 2, faz desta liga frágil e susceptível á corrosão sob tensão (SCC). 


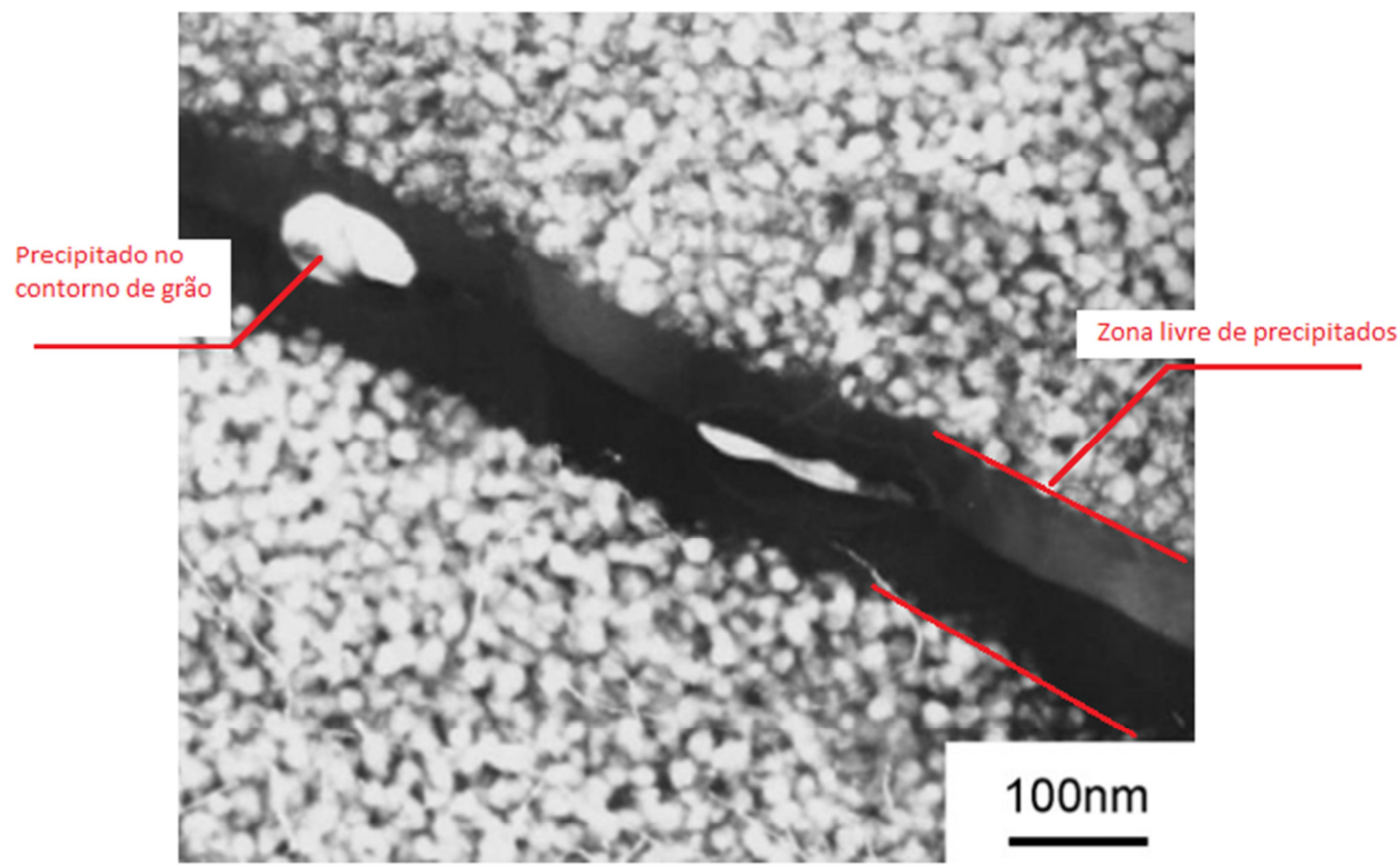

Figura 2: Precipitados no contorno de grão e zona livre de precipitados (Pasang, 2012). 


\subsection{Mecânica da fratura}

A metodologia tradicional de projeto utiliza-se dos conceitos de que um material carregado estaticamente é considerado seguro apenas se seu limite de escoamento for maior que as tensões aplicadas, desconsiderando-se, assim, a existência de defeitos nos materiais (Anderson, 2005).

O desenvolvimento dos estudos a respeito da Mecânica da Fratura iniciou-se quando os processos usuais de cálculo estrutural se tornaram insuficientes para explicar falhas de estruturas solicitadas por níveis de tensões abaixo das tensões admissíveis (Rosa, 2002).

O principal ponto de estudo da Mecânica da Fratura é o comportamento do material quando contém uma trinca. O processo de ruptura do material ocorre pelo crescimento dessa trinca, que pode ser um defeito inerente ao material e decorrente do processo de fabricação, como trincas de tratamento térmico, defeitos de soldagem, falhas internas em componentes fundidos, etc. Em outros casos, a trinca pode se desenvolver devido a uma solicitação dinâmica, como na nucleação de trincas de fadiga (Rosa, 2002).

A Mecânica da Fratura é usada para estimar os ciclos de propagação da trinca, relacionando a tensão aplicada com o tamanho da trinca. Assim, permite quantificar, de uma forma bastante precisa, os níveis admissíveis em que um componente com trincas pode operar, sem que venha a falhar (Rosa, 2002).

Griffith foi o primeiro a propor o critério de fratura, baseando-se num simples balanço de energia, aplicável somente na análise de trinca instável em materiais frágeis. Mais tarde, Irwin modificou esta teoria, estendendo-a a materiais dúcteis, propondo uma taxa de liberação de energia denominada $G$ que, alcançando seu valor crítico $G_{c}$, provoca a instabilidade da trinca (Anderson, 2005). 


\subsubsection{Teoria de Griffith}

No desenvolvimento da Teoria da Fratura, Griffith baseou-se na $1^{\circ}$ lei da Termodinâmica. Segundo sua teoria, uma trinca torna-se instável quando a energia disponível para o crescimento da trinca for suficiente para suplantar a energia de resistência do material à sua propagação, conforme figura 3. O modelo utilizado por Griffith foi uma placa infinita, como mostrado na figura 4, de espessura unitária, e que continha uma trinca passante de comprimento $2 a$, sujeita a uma tensão de tração uniforme, aplicada no infinito (Anderson, 2005; Hertzberg, 1989).

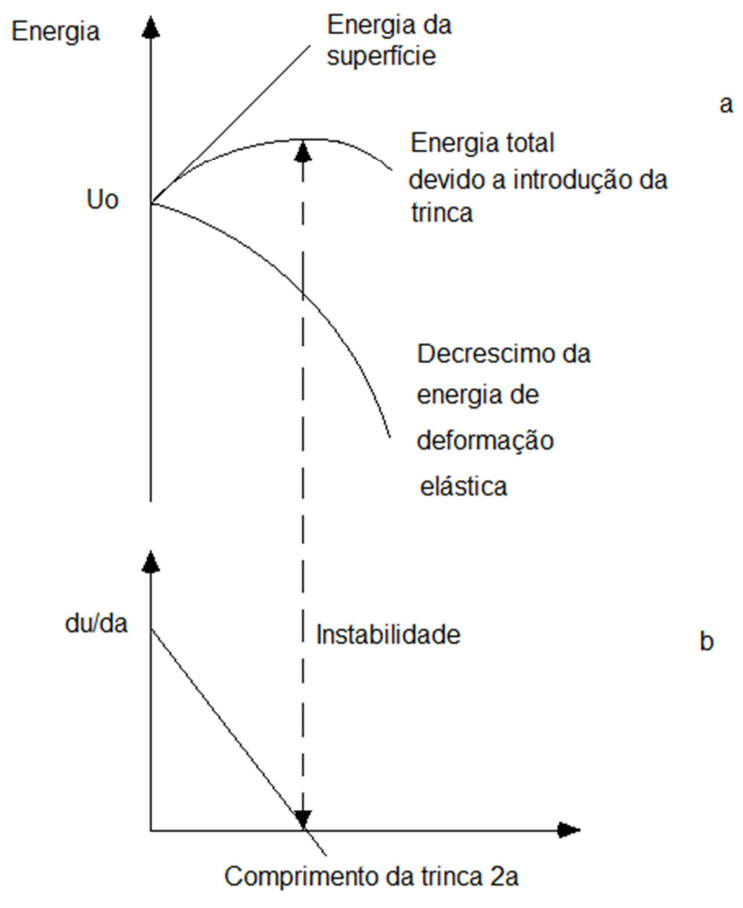

Figura 3. Balanço de energia de Griffith (Anderson, 2005)

Conforme descrito por Anderson (2005), a energia total $\left(U_{t}\right)$ de uma placa trincada pode ser escrita como:

$$
U_{T}=U_{e}+U_{s}
$$

Onde: 
$\left(U_{e}\right)=$ Energia elástica de uma placa não trincada.

$\left(U_{S}\right)=$ Mudança na energia elástica de superfície causada pela formação das superfícies da trinca.

Através da análise de tensão desenvolvida por Inglis, verificou-se que, para uma espessura unitária, o valor absoluto de $\left(U_{e}\right)$ é dado por:

$$
U_{e}=\frac{\pi \sigma^{2} a^{2}}{E}
$$

e a energia elástica da superfície por:

$$
U_{S}=4 a \gamma_{s}
$$

onde $\gamma_{s}$ é a energia de superfície por unidade de área (Anderson, 2005).

De acordo com Griffith, a trinca, ao propagar, aumentando seu comprimento de um valor " $d a "$, não provoca variação no valor de $U_{t}$. Assim,

$$
\partial \frac{\left(U_{S}-U_{e}\right)}{d a}=0
$$

ou derivando-se a Eq. 4 obtêm-se:

$$
4 \gamma_{s}-\frac{2 \pi \sigma^{2} a}{E}=0
$$

Para o estado plano de tensões, tem-se:

$$
\sigma=\sqrt{\frac{2 E \gamma_{s}}{\pi a}}
$$

Para o estado plano de deformação, tem-se:

$$
\sigma=\sqrt{\frac{2 E \gamma_{s}}{\left(1-v^{2}\right) \pi a}}
$$




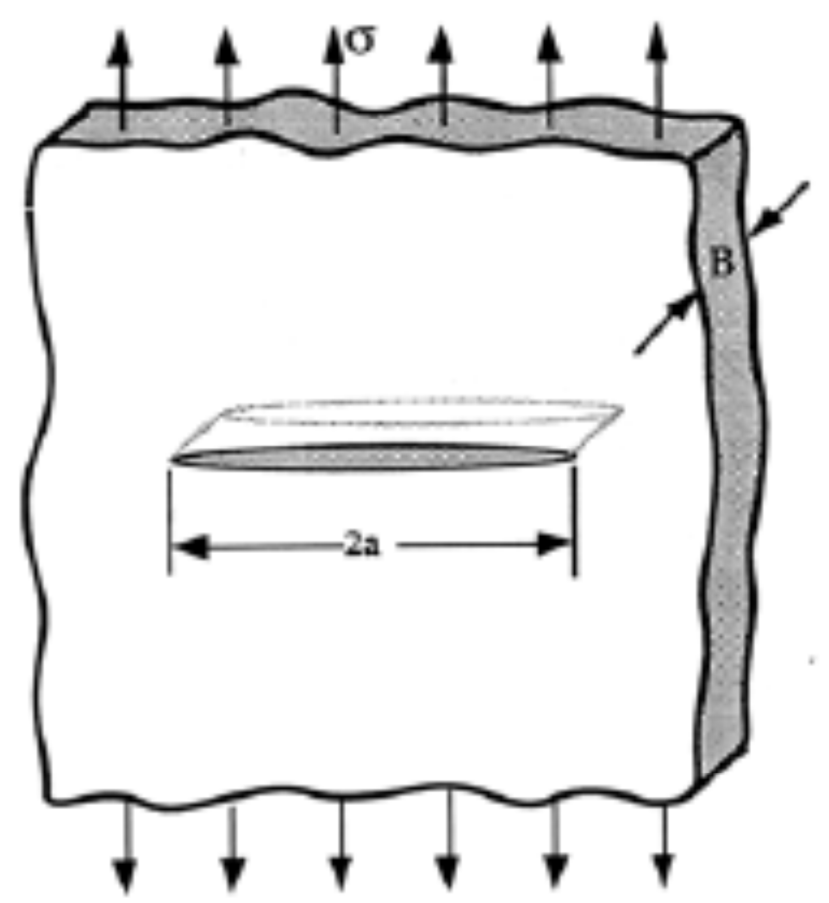

Figura 4. Modelo de Griffith (Anderson, 2005)

\subsubsection{Modificação da teoria de Griffith}

Em 1948, Irwin e Orowan modificaram a teoria de Griffith, estendendo-a a materiais capazes de se deformarem plasticamente. Assim, a Eq. 7 foi alterada para:

$$
\sigma=\left(\frac{2 E\left(\gamma_{s}+\gamma_{P}\right)}{\pi a}\right)^{\frac{1}{2}}
$$

Onde a resistência de um material à extensão da trinca é igual à energia de deformação plástica $\left(\gamma_{p}\right)$ mais a energia superficial elástica $\left(\gamma_{e}\right)$ (Anderson, 2005).

Para materiais dúcteis, a energia de deformação plástica é muito maior que a energia superficial elástica. 
Irwin, em 1956, propôs uma relação, utilizando a teoria de Griffith, que seria também utilizada para materiais deformáveis plasticamente. Foi definida a taxa de liberação de energia $(G)$, reescrevendo-se a Eq. 6 na forma:

$$
\frac{\pi \sigma^{2} a}{E}=2 \gamma_{e}
$$

Conforme mostrado na Eq. 9, o primeiro membro é denominado $G$ e representa a energia elástica por unidade de área superficial da trinca. G é uma medida de energia disponível para um aumento da extensão da mesma. O segundo membro representa a resistência do material à extensão da trinca (Anderson, 1995; Hertzberg, 1989; Farahmand,1997):

$$
G=\frac{\pi \sigma^{2} a}{E}
$$

Para ocorrer o crescimento instável da trinca, $G$ deve atingir o valor crítico $G_{c}$ :

$$
\begin{aligned}
& G_{C}=2 W_{f} \\
& w_{f}=\frac{\sigma^{2} \pi a}{2 E}
\end{aligned}
$$

Substituindo a eq. 12 na eq. 11 ,

$$
G=\frac{\sigma_{c}^{2} \pi a_{c}}{E}
$$

onde $w_{f}$ é a energia de fratura que poderia incluir efeitos de plasticidade, viscoelasticidade ou viscoplasticidade, dependendo do material. $G_{c}$ é a tenacidade à 
fratura, que pode ser medida através da tensão $\sigma_{c}$, necessária para fraturar uma placa contendo uma trinca de comprimento $2 a$.

\subsubsection{Mecânica da fratura elástica linear}

A mecânica da fratura linear elástica (MFLE) baseia-se na teoria da elasticidade, sendo aplicada em fraturas que ocorrem em materiais elásticos lineares. Ela não se aplica em materiais de comportamento não elástico. De um modo geral, a MFLE se aplica a materiais de comportamento frágil, onde o escoamento na ponta da trinca é muito pequeno (Anderson, 2005).

Através da MFLE podem ser estabelecidos campos de tensões na vizinhança da ponta da trinca, através uma relação com outros parâmetros, tais como: tensão nominal aplicada, tamanho, geometria e orientação da trinca. Utilizando todos estes parâmetros, é possível representar as propriedades da fratura através de um único parâmetro, chamado fator de intensidade de tensão, $K$ (Anderson, 2005; Farahmana, 1997). 


\subsubsection{Modos de abertura da ponta da trinca}

Os campos de tensões e modos de deslocamento na ponta da trinca podem ser classificados em três diferentes modos, dependendo da posição do plano da trinca em relação à tensão aplicada, como mostrado na figura 5 (Anderson, 2005).

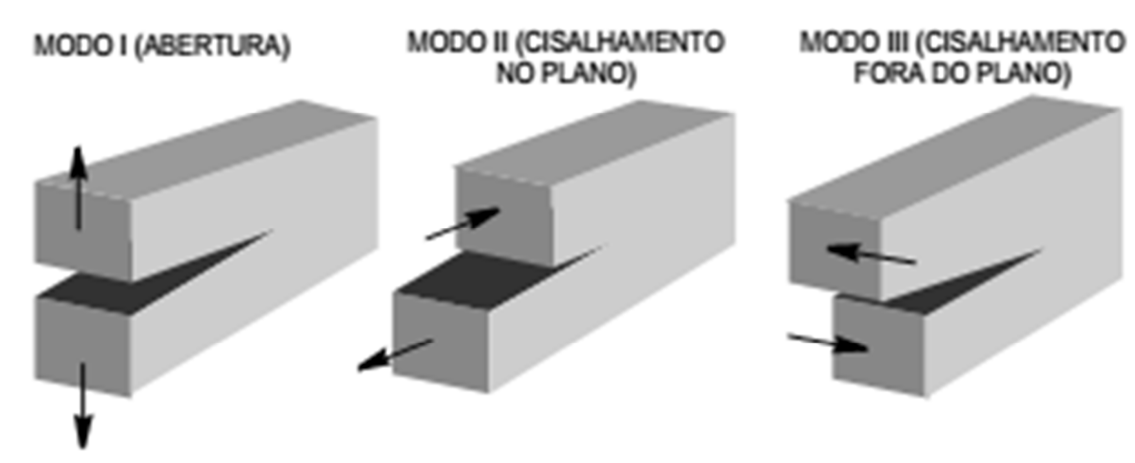

Figura 5. Modos de abertura da trinca (Anderson, 2005)

Modo I: É o modo onde a força principal é aplicada normal ao plano da trinca, tendendo a abri-la. Este carregamento é o modo mais utilizado nos projetos de Engenharia.

Modo II: Modo de deslizamento ou cisalhamento. As superfícies da trinca deslizam uma em relação à outra. A direção da força aplicada é paralela à superfície da trinca.

Modo III: Modo de rasgamento ou de cisalhamento transversal. As superfícies deslizam uma em relação à outra, e paralelamente à aresta da trinca. 


\subsubsection{Fator de intensidade de tensão}

Considerando os eixos de coordenadas polares como a origem na ponta da trinca, conforme figura 6, e assegurando um corpo trincado com características elásticas lineares, pode-se mostrar que o campo de tensões em torno da trinca é dado por (Hertzberg, 1989):

$$
\sigma_{i j}=\left(\frac{K}{\sqrt{r}}\right) f_{i j}(\theta)
$$

onde $\sigma_{i j}$ é o tensor de tensões, $k$ é uma constante e $f_{i j}$ é uma função adimensional de $\theta$. Os termos de ordem mais elevada dependem da geometria, mas, a solução para uma configuração específica contém um termo que é proporcional a $1 / \sqrt{r}$. Assim, quando $r=0$, a equação tende para uma singularidade na ponta da trinca. Quando $r=0$, o termo $1 / \sqrt{r}$ tende para o infinito e os demais termos permanecem finitos ou próximos de zero. As tensões em torno da trinca variam com $1 / \sqrt{r}$, independente da configuração tratada (Anderson, 2005).

Cada modo de carregamento produz uma singularidade $1 / \sqrt{r}$ na ponta da trinca. Desta maneira, as constantes $\mathrm{k}$ e $f_{i j}$ dependem do modo de carregamento. É conveniente substituir, neste ponto, $\mathrm{k}$ pelo Fator de Intensidade de tensão $K$, onde $K=k \sqrt{2 \pi}$. O fator de intensidade de tensão está de acordo com os modos de carregamento. Definindo o modo I, ter-se-á $K_{I}$. Então, o campo de tensões à frente da ponta da trinca será descrito como:

$$
\sigma_{y}=\frac{K_{I}}{\sqrt{2 \pi r}} \cos \frac{\theta}{2}\left(1+\sin \frac{\theta}{2} \sin \frac{3 \theta}{2}\right)
$$




$$
\begin{gathered}
\sigma_{x}=\frac{K_{I}}{\sqrt{2 \pi r}} \cos \frac{\theta}{2}\left(1-\sin \frac{\theta}{2} \sin \frac{3 \theta}{2}\right) \\
\tau_{x y}=\frac{K_{I}}{\sqrt{2 \pi r}} \cos \frac{\theta}{2} \sin \frac{\theta}{2} \cos \frac{3 \theta}{2}
\end{gathered}
$$

A espessura do corpo de prova definirá o estado de tensões na ponta da trinca. Se a chapa é fina, tal que a tensão na direção da espessura seja nula, isto é, $\sigma_{z}=0$, tem-se um estado plano de tensão. Se a chapa tem uma espessura considerável, em que a tensão não é desprezível, haverá uma restrição à deformação ao longo da espessura. Neste caso, tem-se a condição de estado plano de deformação:

$$
\sigma_{z}=v\left(\sigma_{x}+\sigma_{y}\right)
$$

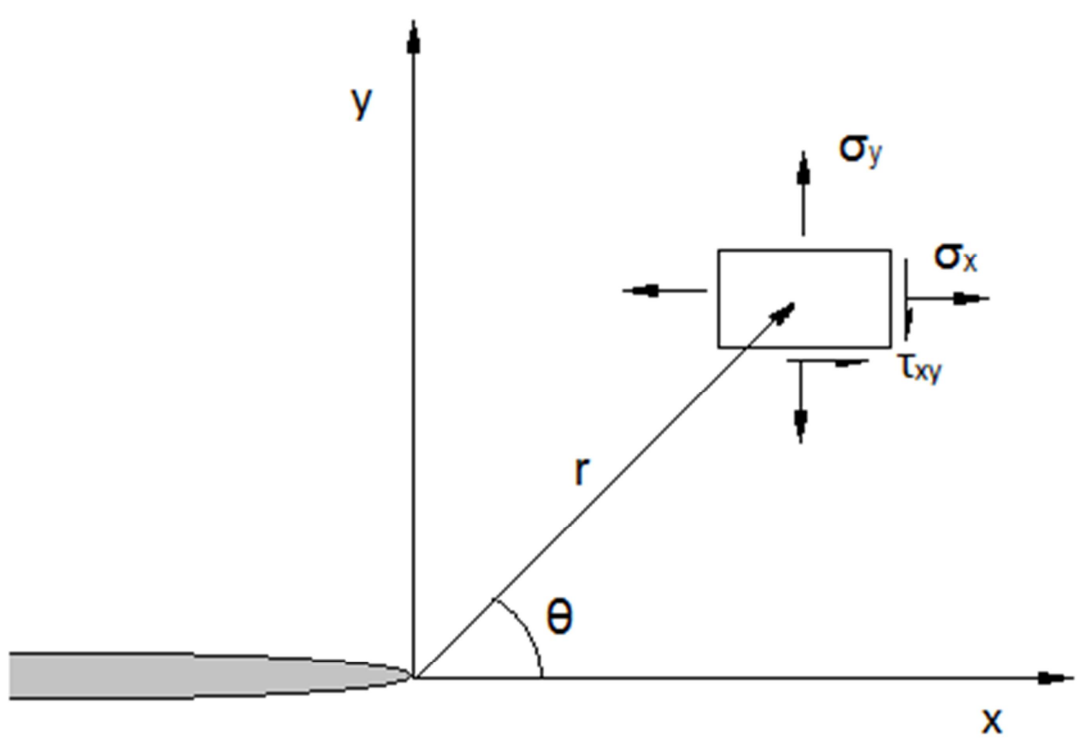

Figura 6. Tensões em torno da trinca (Anderson, 2005). 
A figura 7 é um gráfico esquemático de $\sigma_{y}$, onde se representam as tensões normais ao plano de trincas versus a distância da ponta da trinca. As equações eq. 19 a eq. 20 são validas em regiões próximas às trincas, onde a singularidade $1 / r$ domina o campo de tensões.

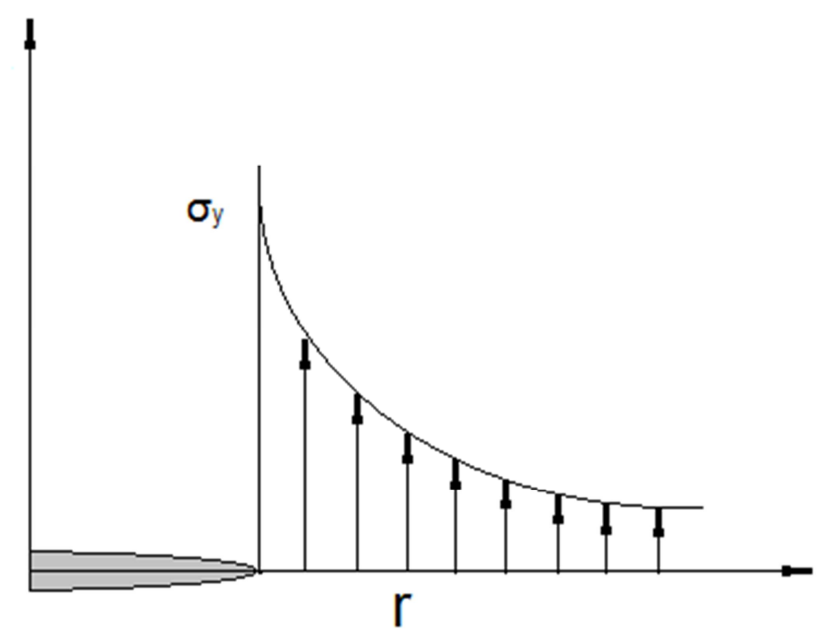

Figura 7. Tensões normais ao plano de trinca (Anderson, 2005).

O fator de intensidade de tensão define a magnitude das tensões na ponta da trinca. Se $K$ é constante, é possível determinar todos os componentes de tensão, deformação e deslocamento, como uma função de $r$ e $\theta$.

As equações citadas acima só valem para o caso de placa infinita: para o caso de corpos finitos, deve-se considerar um fator multiplicativo, chamado fator de forma $f(a / W)$, onde $W$ é a largura da placa, conforme equação 19:

$$
K_{I}=f(a / W) \sigma \sqrt{\pi a}
$$




\subsubsection{Tenacidade à fratura}

Assegurando que a falha de um material está associada a uma combinação de tensões e deformações, pode-se esperar que a propagação da trinca ocorra quando $K$ atingir ou exceder um valor crítico, conforme mostrado na Fig. 8. (Anderson, 2005; Godefroid, 1995; Dieter, 1981).

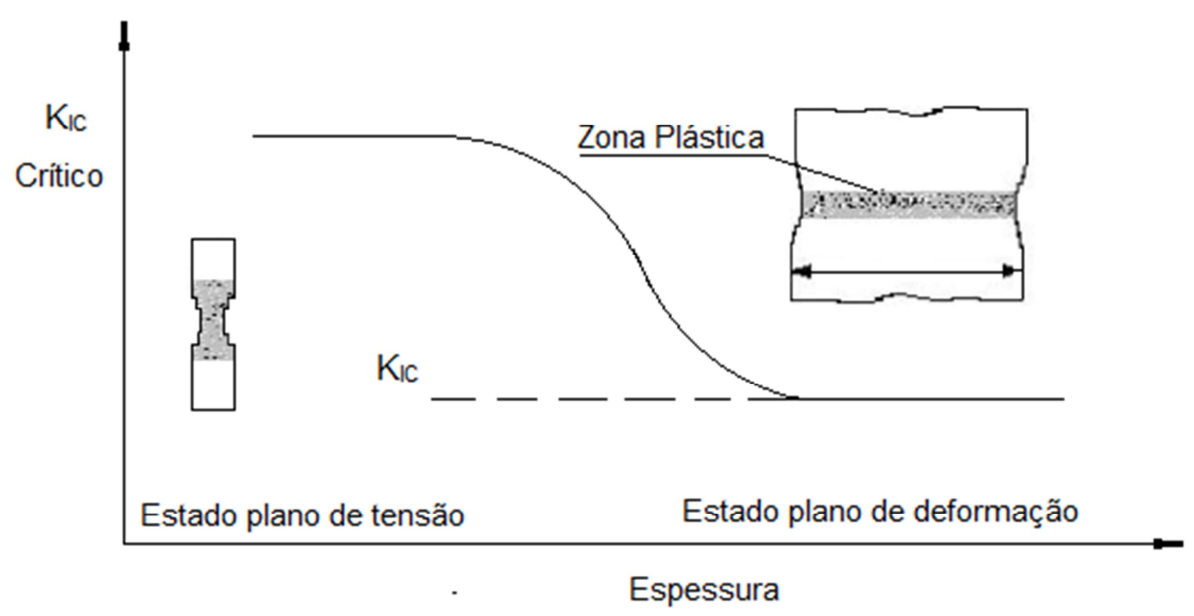

Figura 8. Tenacidade à fratura, valor crítico (Godefroid, 1995)

Em condições de estado plano de tensão, este valor crítico recebe a denominação de $K_{c}$. Ele corresponde ao valor máximo do fator de intensidade de tensão, em função da espessura do material. À medida que se aumenta a espessura do material, atinge-se o estado plano de deformação, e o valor de $K_{c}$ torna-se constante. Nesse ponto, o valor de $K_{c}$ pode ser considerado uma propriedade do material. Como os testes estão relacionados ao modo I, o valor crítico será utilizado com $K_{I c}$ (Anderson, 2005). Assim, $K_{I c}$ representa a resistência inerente do material à falha, na presença de uma trinca. De acordo com a norma ASTM E399, a determinação de $K_{I c}$ deverá obedecer aos seguintes critérios: 
$a, B,(W-a) \geq 2,5\left(\frac{K_{I c}}{\sigma_{e}}\right)^{2}$

onde $B$ é a espessura do material.

Assegura-se, através da Eq. 20, que o tamanho da zona plástica $r_{y}$ deva ser menor ou igual a 1/50 vezes as dimensões dos corpos-de-prova. Procura-se assim garantir a condição de deformação plana e um valor de $K_{I c}$ independente da espessura.

O gráfico da figura 8 apresenta uma diminuição aparente da tenacidade à fratura à medida que a espessura é reduzida, e essa diminuição corresponde, geralmente, a materiais em que a propagação é dúctil e para cada espessura apresentarão uma morfologia de crescimento de trinca diferente. Na figura 14 são mostradas as três morfologias de superfícies de fraturas para três tipos de espessuras diferentes. A figura 9a apresenta uma fratura predominantemente por cisalhamento, geralmente para placas finas ou chapas a $45^{\circ}$; a figura $9 \mathrm{~b}$ apresenta uma mistura de fratura por cisalhamento e fratura plana que ocorre em espessuras muitos largas; a figura 9c mostra a fratura de corpos de prova muito espessos, onde predomina a fratura plana. 


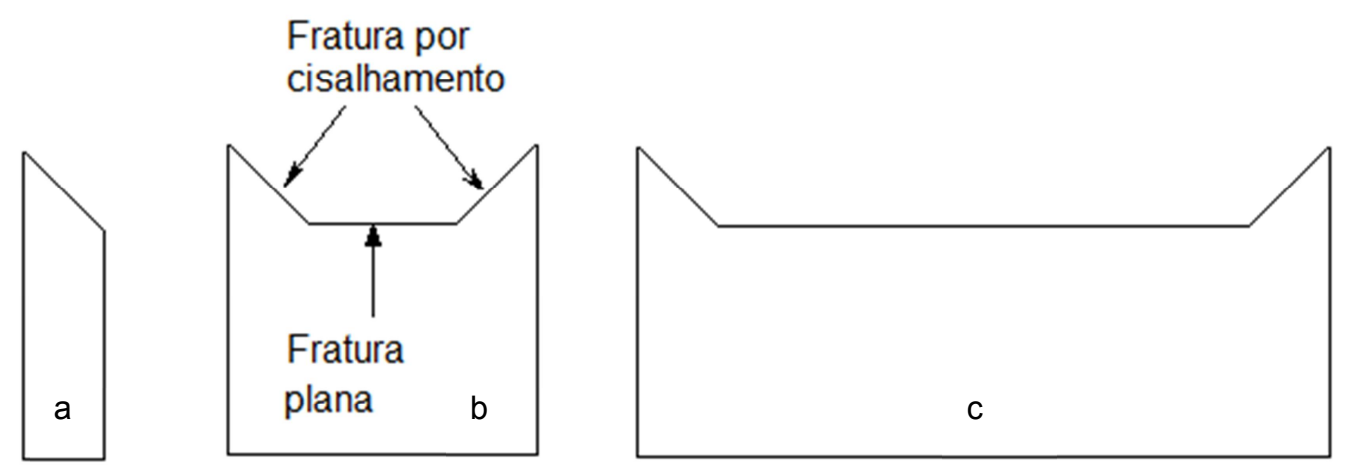

Figura 9. Efeito da espessura dos corpos de prova na morfologia da fratura para materiais que exibem crescimento de trinca dúctil. a) Fratura por cisalhamento; b) Fratura plana e por cisalhamento; c) Fratura predominante plana com uma pequena porção cisalhante.

Devido a essa propagação dúctil, pode ocorrer um tunelamento, que é o crescimento rápido da trinca pelo centro da placa, devido à alta triaxilidade $\mathrm{A}$ alta triaxilidade no centro da trinca produz bordas de cisalhamento devido à baixa triaxilidade nesta região, e o crescimento da trinca ocorre a $45^{\circ}$. Nas figuras 10 e 11 são mostrados o crescimento rápido da trinca no centro da placa devido a alta triaxilidade e baixa triaxilidade nas laterais, bem com a formação de arestas de cisalhamentos a $45^{\circ}$ e tunelamento da trinca.

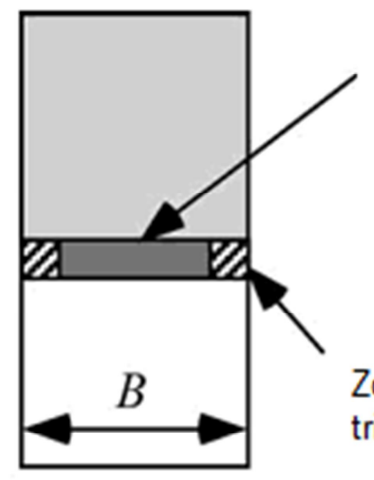

\section{Zona de alta triaxilidade}

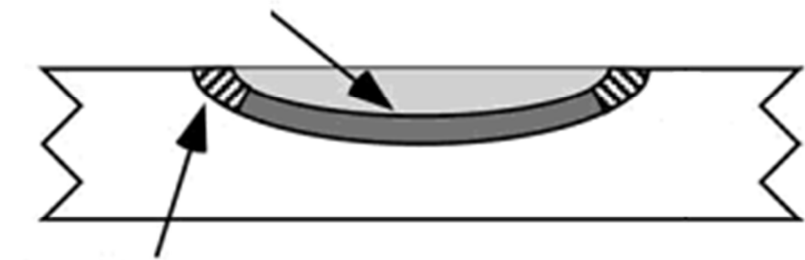

Zona de baixa triaxilidade

Figura 10. Crescimento rápido da trinca no centro do corpo de prova, devido à alta triaxilidade das tensões e o crescimento lento da trinca devido à baixa triaxilidade (Anderson, 2005). 


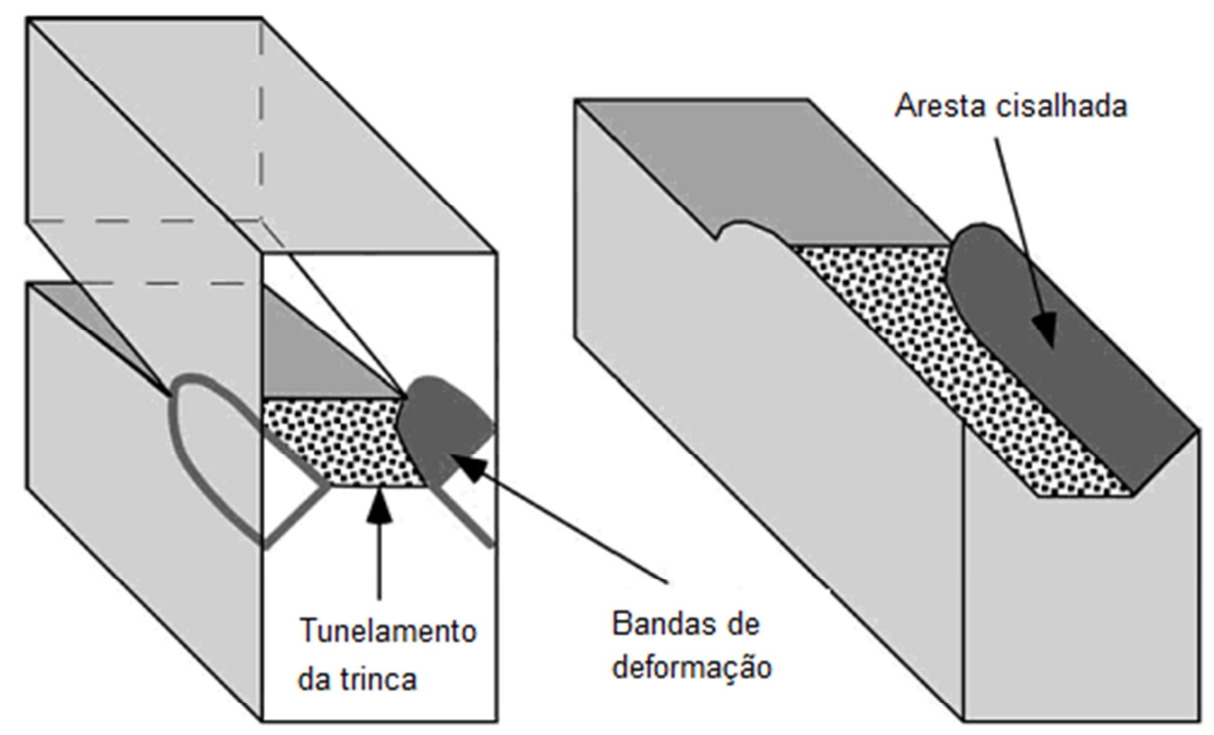

Figura 11. Formação das arestas de cisalhamento e tunelamento da trinca (Anderson, 2005).

\subsection{Curva $K_{R}$}

Conforme Heyer (1973), Krafft et al foi o primeiro a postular que para um dado material e com uma determinada espessura existe uma relação entre a trinca crescente e o fator de intensidade de tensão, ao qual foi denominado curva de resistência ao crescimento da trinca.

A curva $K_{R}$ caracteriza a resistência à fratura do material durante o período de extensão lenta e estável da trinca sob a influência do aumento de carga, o que resulta no aumento da zona plástica à frente da trinca. Através da curva $K_{R}$, descreve-se a variação completa de $K_{I C}$, em que se observa o crescimento estável e instável da trinca.

Para saber quando ocorre a instabilidade através da curva $K_{R}$, existem dois métodos para montar a curva $K_{R}$, pelo controle da carga e pelo controle do deslocamento. No controle de carga, $K$ vai aumentando até que a carga máxima 
tangencie a curva $K_{R}$, onde ocorre a instabilidade da trinca, como pode ser observado na figura 12.

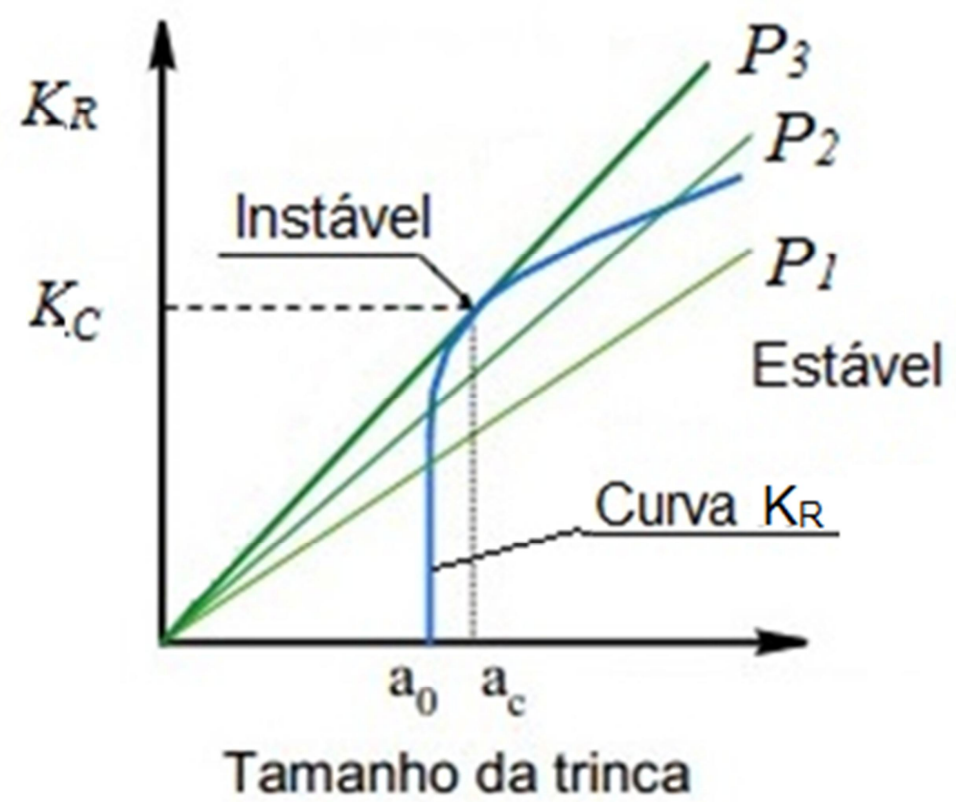

Figura 12: Representação esquemática da curva $K_{R}$ e curvas das tensões aplicadas para predizer a instabilidade da trinca (Anderson, 2005).

No deslocamento controlado, conforme figura $13, K$ vai diminuindo à medida que a trinca vai crescendo. Comparando estes dois métodos, constata-se que o deslocamento controlado tende a alcançar uma maior estabilidade em relação ao método de carga controlada. 


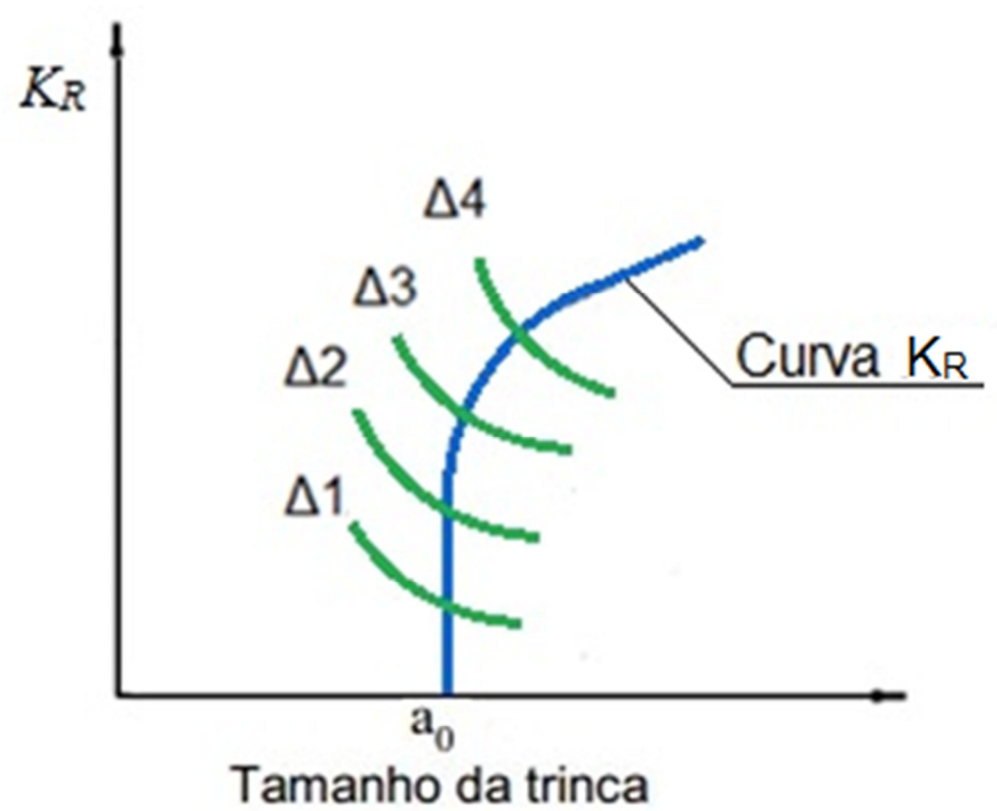

Figura 13. Deslocamento controlado (Anderson, 2005).

A geometria da curva $K_{R}$, ou seja, a constatação de que um material terá uma curva que vai aumentando, ou se a curva será plana, depende do comportamento do material. Esse comportamento em maior ou menor grau depende da configuração da estrutura da trinca.

Quando acontece de a curva ser plana, o material é frágil ou linear, como mostrado na figura 14. Isto ocorre por causa da energia superficial que é uma propriedade que não varia. Para a curva não linear ela pode assumir várias formas, devido à relação material dúctil ou não linear acompanhado de uma fratura.

Num material que se propaga por clivagem, a curva $K_{R}$ é geralmente instável, devido ao material próximo à ponta da trinca ter altas taxas de deformação elástica que supre as deformações plásticas. Assim, a resistência ao crescimento da trinca por clivagem é menor que a resistência inicial no início da fratura. 


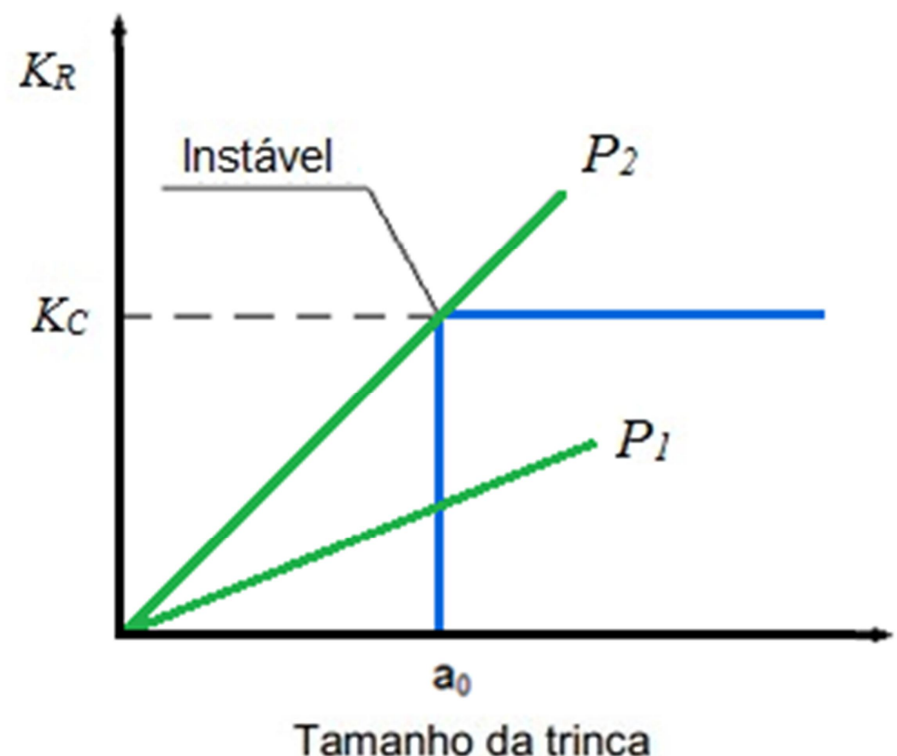

Figura 14: Comportamento frágil do material (Anderson, 2005).

Os crescimentos estável e instável da trinca podem ocorrer da seguinte forma:

\section{Estável:}

$K_{R}$

e

$$
\frac{d G}{d a} \leq \frac{d R}{d a}
$$

Instável:

$$
\frac{d G}{d a} \geq \frac{d R}{d a}
$$




\subsection{Fadiga}

A fadiga é uma redução gradual da capacidade de carga do componente, pela ruptura lenta do material, consequência do avanço quase infinitesimal das fissuras que se formam no seu interior. Este crescimento ocorre para cada flutuação do estado de tensões. As cargas variáveis fazem com que, ao menos em alguns pontos, haja deformações plásticas também variáveis com o tempo. Estas deformações levam o material a uma deterioração progressiva, dando origem à trinca, a qual cresce até atingir um tamanho crítico, suficiente para a ruptura final, em geral brusca, apresentando características macroscópicas de uma fratura frágil (Rosa, 2002).

Em geral, o processo de fadiga consiste de três estágios distintos: (1) nucleação, onde a trinca se inicia em algum ponto de alta concentração de tensão; (2) propagação, durante a qual essa trinca avança em cada ciclo de tensões; (3) ruptura final, ocorre rapidamente, uma vez que a trinca atingiu o tamanho crítico.

\subsubsection{Nucleação e Propagação}

A trinca nucleada que se forma e propaga para a falha é formada através de movimentos de deslocações que produz planos de deslizamento na superfície do material, conforme figura 15. Estes planos de deslizamento surgem já nos primeiros ciclos do carregamento, e com o prosseguimento da solicitação, novos planos vão se formando, para acomodar as novas deformações plásticas, pois, devido ao encruamento do material, cada plano atua uma única vez, apenas durante meio ciclo. Deste modo, o conjunto de planos de deslizamento forma uma banda de deslizamento, onde ocorrerá a trinca (Lee, Y.-L, et al, 2005). 


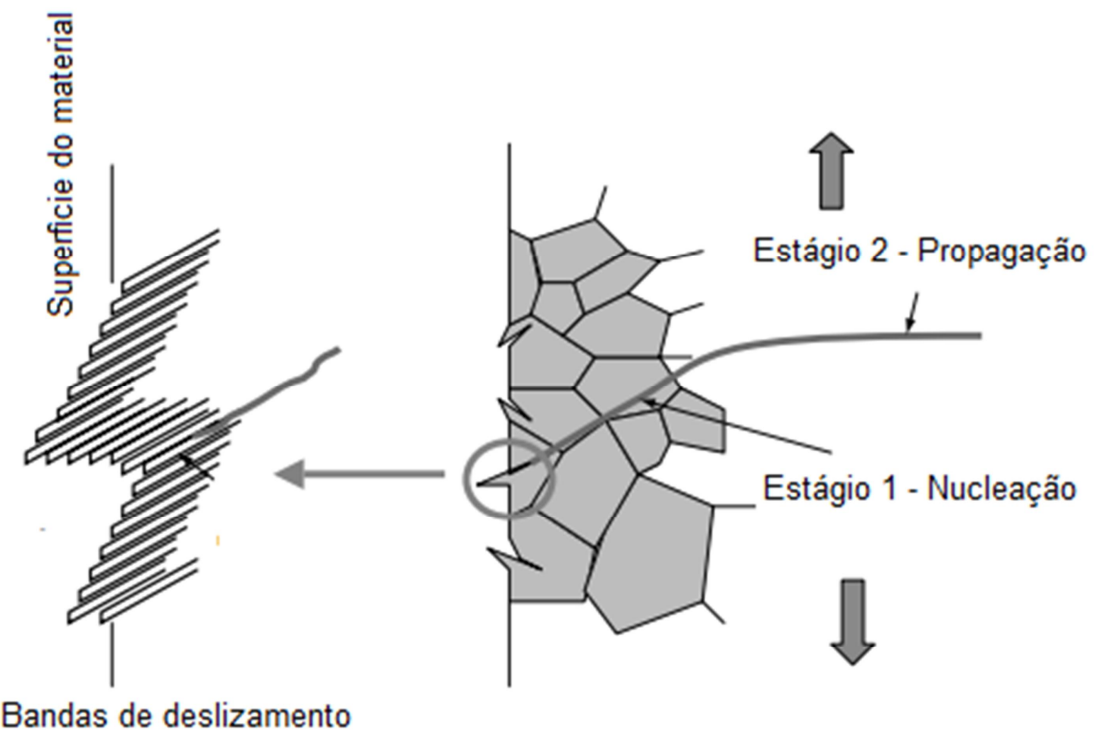

Figura 15. Formação das bandas de deslizamento pela solicitação cíclica e seu aspecto. Estágios de propagação de uma trinca de fadiga. (Lee, Y.-L, et al, 2005).

As trincas crescem mais rapidamente na fase de propagação que na fase de nucleação, gerando grandes áreas fraturadas e cobertas por estrias, conforme figura 16.

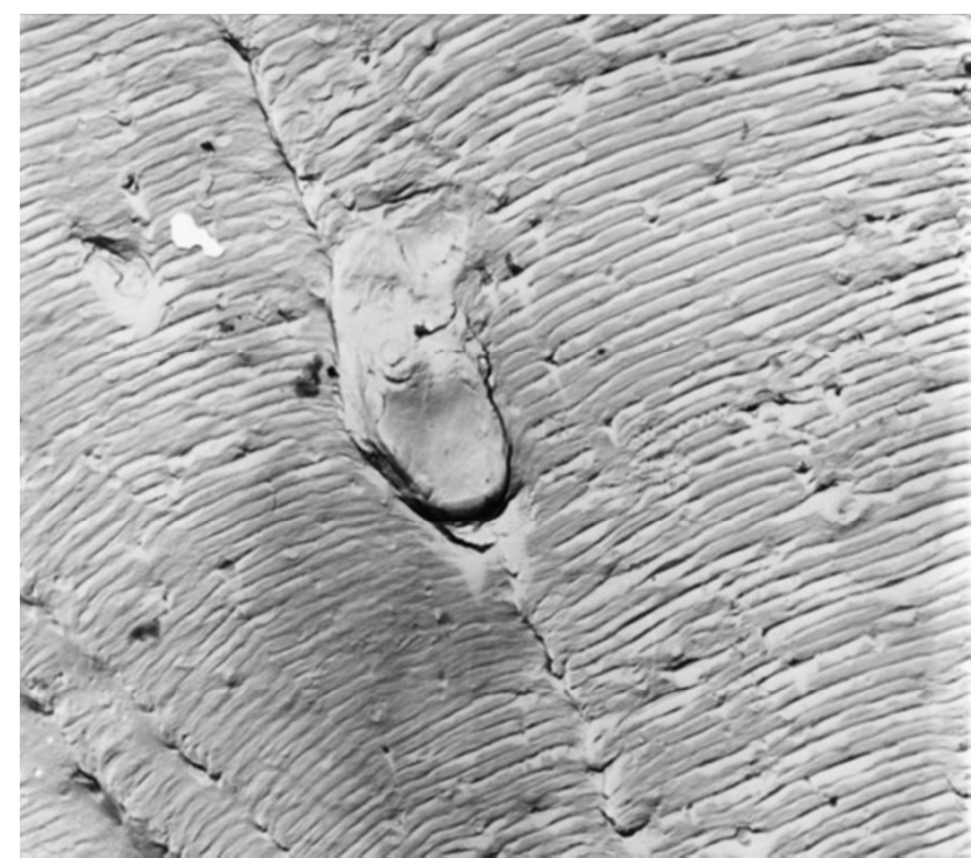

Figura 16. Estrias (Schijve, 2003). 
O mecanismo de formação de estrias é um processo repetitivo de arredondamento plástico e afilamento da extremidade da trinca, onde ocorre a formação de estrias em materiais dúcteis. Esse mecanismo de formação de estrias pode ser observado na figura 17 pelo modelo de Laird.

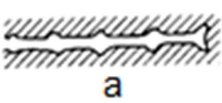

a

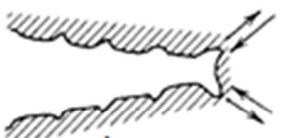

b

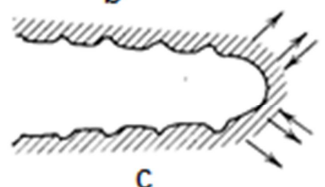

$\mathrm{C}$
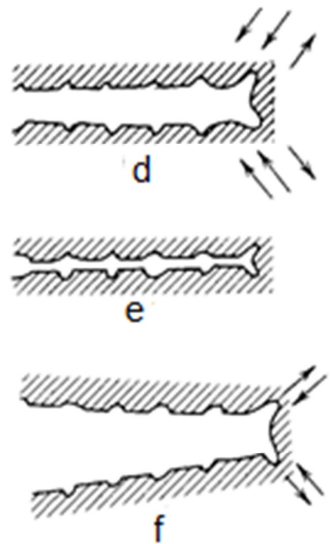

Figura 17. Mecanismo de propagação de trinca por fadiga, processo repetitivo de arredondamento plástico e afilamento da extremidade da trinca; (Callister Junior, 2002)

Em que representam:

(a) Carga compressiva zero ou máxima - trinca fechada;

(b) Carga de tração pequena, ocorrendo á formação de entalhes duplos, orientados a $45^{\circ}$.

(c) Ocorrência de arredondamento, devido às cargas trativas;

(d) Durante o processo de compressão, as deformações cisalhantes são invertidas, ocorrendo, assim, novamente, um processo de afilamento na ponta da trinca com entalhe duplo.

(e) Fechamento total da trinca com formação de estrias.

(f) Repetição de todo o processo para a formação de estrias. 
Quando a trinca no estágio de propagação atinge seu comprimento crítico, a seção não trincada não pode mais suportar a carga, ocorrendo assim a falha catastrófica, na figura 18.

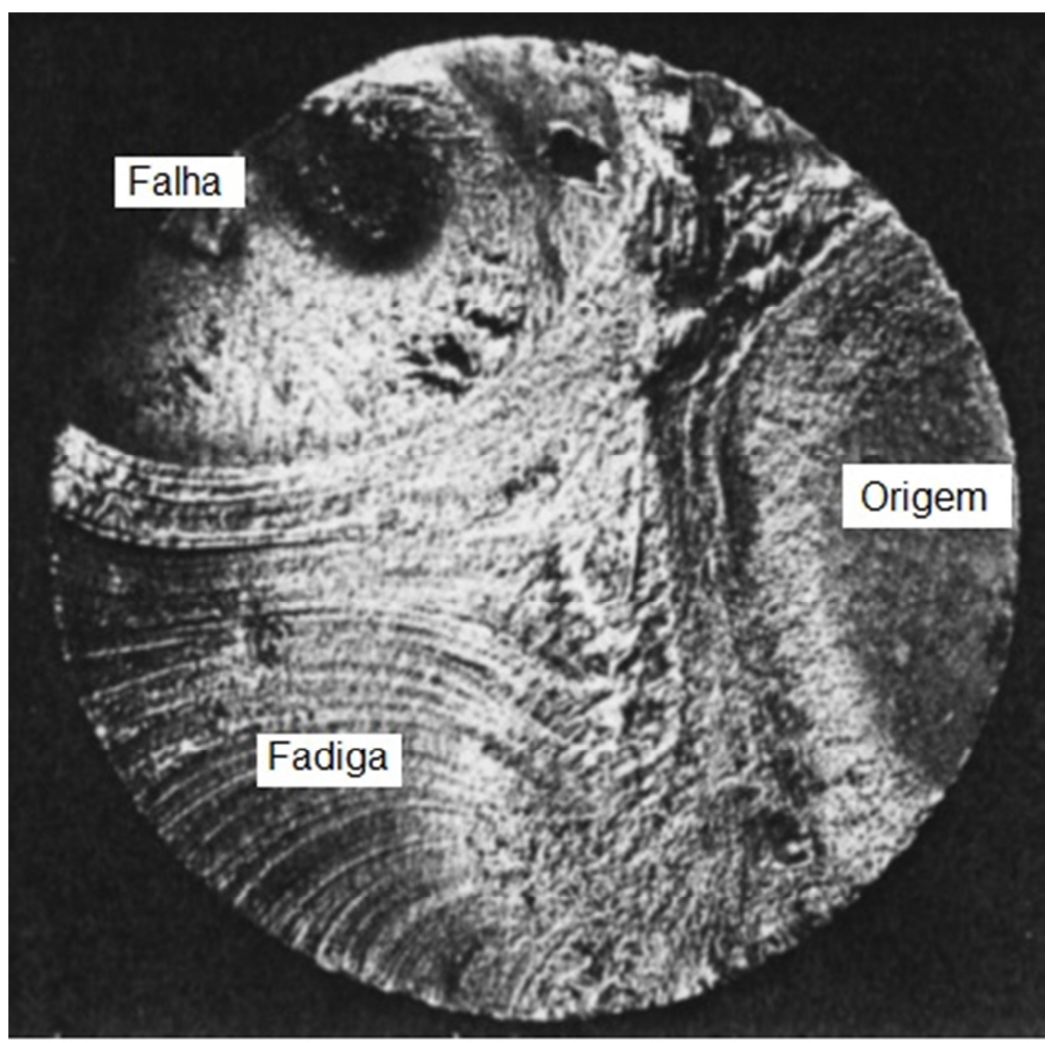

Figura 18. Falha Catastrófica (Schijve, 2003). 
2.4.2 Propagação por trinca de fadiga baseada na mecânica da fratura elástica linear

Segundo Forth et al (2003) e Mirzaei, o crescimento da trinca por fadiga nos materiais é tipicamente quantificado pela taxa de crescimento da/dN, devido ao carregamento e à mecânica da fratura elástica linear, $\Delta K$, ou seja, fator de intensidade de tensão.

Como citado anteriormente, a taxa de propagação da trinca é medida em termos de crescimento de trinca por ciclo de carga e depende principalmente do fator de intensidade de tensão, que é definido pelas equações 24 e 25 .

$\Delta K=K_{\max }-K_{\min }$

$\Delta K=f \Delta \sigma \sqrt{\pi a}=>f\left(\sigma_{\max }-\sigma_{\min }\right) \sqrt{\pi a}$

Onde,

$f=$ Fator geométrico

$\Delta \sigma=$ Tensão uniaxial

$a=$ Comprimento da trinca.

Na figura 19 apresenta-se um gráfico em uma escala dupla logarítmica, onde é plotado taxa de propagação da trinca $d a / d N$ em função do fator de intensidade de tensão. Como pode ser observado, segundo Lawson, (1999), nesse gráfico, o mesmo apresenta três estágios de propagação, região I, II e III.

○ Região I é conhecida como região crescimento de trinca macroscópica por fadiga Threshold em cisalhamento (modo II). Essa região tem um estágio de crescimento de trinca o qual se caracteriza por uma assíntota, que é o fator de intensidade de tensão Threshold, $\Delta K_{t h}$. Isto implica que se $\Delta K$ é menor que $\Delta K_{t h}$, o crescimento da trinca será 
desacelerado e assegurará que nenhum crescimento de trinca por fadiga ocorrerá. Os valores de $\Delta K_{t h}$ para ligas de alumínio varia de 35MPa.m $\mathrm{m}^{0,5}$, dependendo do valor de R.(Lee, 2005)

○ Região II é o estágio de crescimento linear da trinca, que é caracterizada como região de Paris, conforme equação 26. Essa equação é desenvolvida um duplo log-log que dá uma relação linear, no qual $\mathrm{C}$ e o expoente $\mathrm{m}$ são constantes do material, com $\mathrm{m}$ representando a inclinação da curva. Para obter os valores de C e m, utiliza-se o método dos mínimos quadrados, conforme equações 27, 28 e 29, que podem ser adotadas para ajustar os dados de fadiga no gráfico Log-Log (Lawson, 1999).

$\frac{d a}{d N}=C \Delta K^{m}$

$\log (d a / d N)=\log (C)+m \log (\Delta K)$

$Y=A+X B$

$Y=\log \left(\frac{d a}{d N}\right), X=\log (\Delta K), A=\log (C)$, e $B=m$

- Região III, essa região como a região I, tem um estagio de crescimento como uma assíntota. Ela é a região do limite superior da curva e é caracterizada pela taxa de crescimento da trinca acelerada e instável, onde a instabilidade e aceleração acontecem porque $K_{\max }=K_{c}$, Isto significa que $K_{\max }$ alcança um valor crítico que conduz à falha completa do material. 


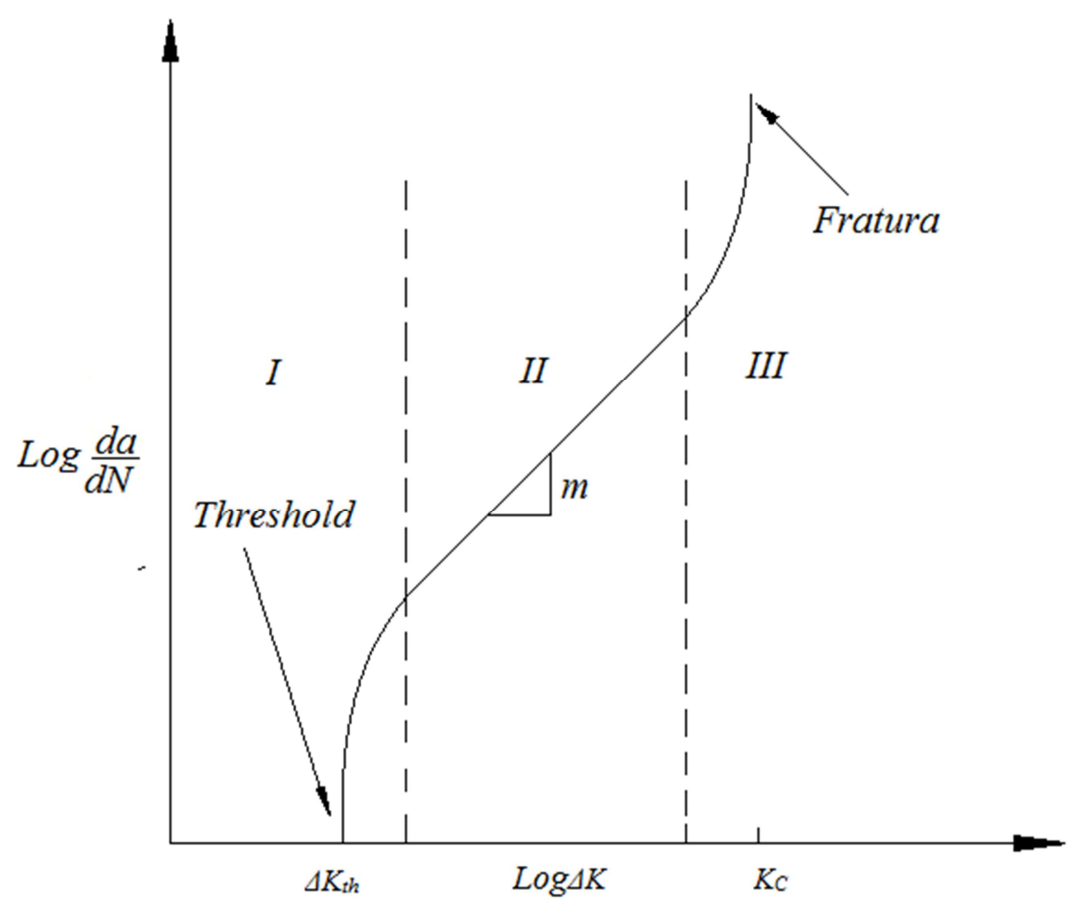

Figura 19. Taxa de crescimento da trinca da/dN plotado em função do fator de intensidade de tensão $\Delta K$ (Anderson, 2005).

Embora a equação de Paris seja a mais utilizada, ela não leva em conta o efeito de $R$ que, quanto maior, maior será a velocidade de propagação da trinca, conforme figura 20 e, ao mesmo tempo, não considera as regiões I e III. Assim, são necessárias equações diferentes para valores diferentes de $R$. 


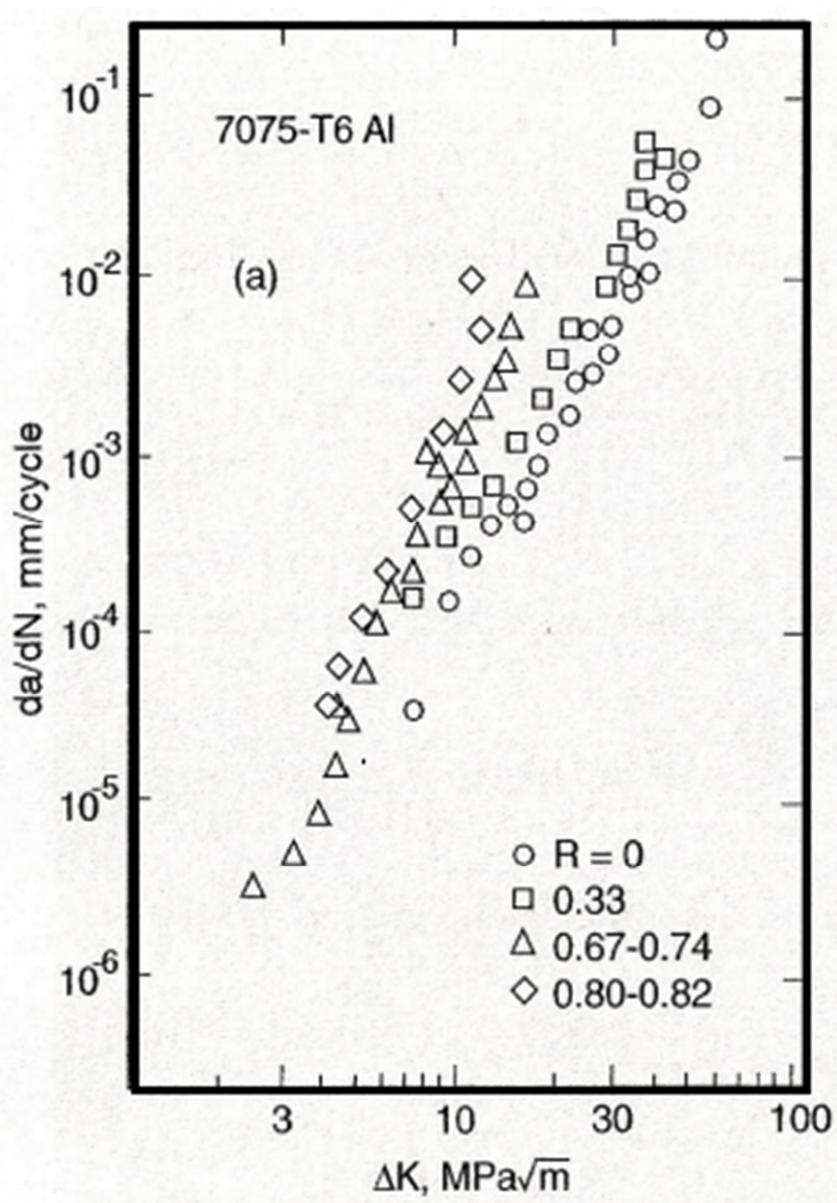

Figura 20. Gráfico evidenciando o efeito da razão de tensões na taxa de propagação da trinca (Dowling, 2007).

Segundo Maddox, (1975), várias expressões foram desenvolvidas para tentar superar estes problemas. Forman postulou a seguinte equação, levando em conta a razão de carga $\mathrm{R}$ através do termo $(1-R)$ e a região III através do termo $\left(K_{c}-K_{\max }\right)$ no denominador. Assim, quando $K_{\max }$ aproxima-se do $K_{c}$ ocorre uma fratura rápida e instável.(Pan et al) .

$\frac{d a}{d N}=\frac{C_{2}(\Delta K)^{m 2}}{(1-R)\left(K_{C}-\Delta K\right)}$

Onde: 
$\frac{d a}{d N}(1-R) K_{c}-\Delta K=C_{2}(\Delta K)^{m 2}$

Assim,

$Q=C_{2}(\Delta K)^{m 2}$

Substituindo a equação 32 na equação 31 ter-se-á:

$Q=\frac{d a}{d N}(1-R) K_{C}-\Delta K$

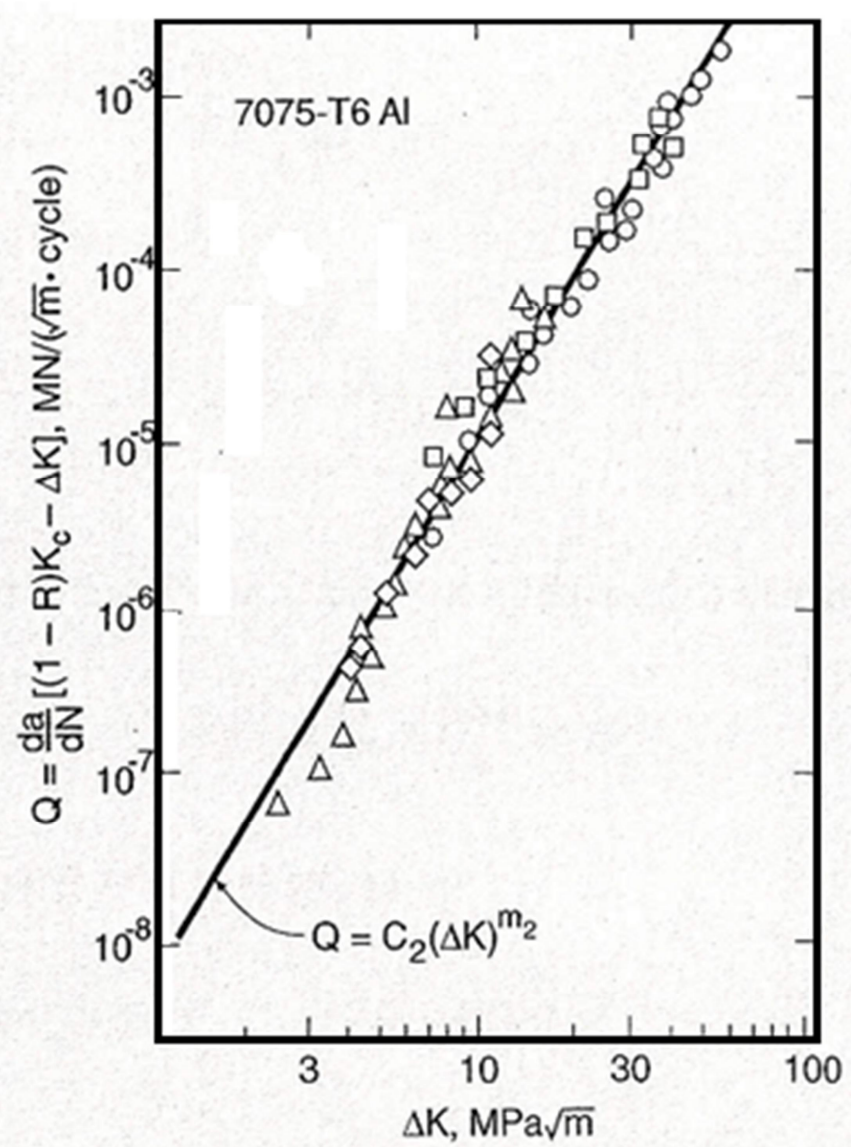

Figura 21.Correlação entre as combinações de dados de $\Delta K$ e $\mathrm{R}$ utilizando a equação de Forman. 
Conforme descrito por Maddox, (1975), Pearson modificou a equação de Forman, uma vez que o mesmo utilizava corpos de prova com espessura fina, 2,5mm. Pearson realizou ensaios com corpos de prova para ensaio de flexão com espessura de $12,7 \mathrm{~mm}$. Assim, o modo de falha era mantido no estado plano de deformação. Estes resultados não ficavam de acordo com os ensaios realizados com os corpos de prova de espessura de $2,5 \mathrm{~mm}$, em que o modo de falha seria no estado plano de tensão. Assim, Pearson modicou a equação de Forman, alterando o $K_{C}$ por $K_{I C}$ e elevou o denominador a 0,5 , gerando um gráfico, conforme figura 22 , similar ao gráfico de Forman, mostrado na figura 2.

$\frac{d a}{d N}=\frac{C_{2}(\Delta K)^{m 2}}{\left[(1-R) K_{I C}-\Delta K\right]^{0,5}}$

Onde

$$
\begin{aligned}
& \frac{d a}{d N}\left[(1-R) K_{I C}-\Delta K\right]^{0,5}=C_{2} \Delta K^{m 2} \\
& Q=C_{2}(\Delta K)^{m 2}
\end{aligned}
$$

Substituindo a equação 36 na equação 35 ter-se-á:

$$
Q=\frac{d a}{d N}\left[(1-R) K_{I C}-\Delta K\right]^{0,5}
$$




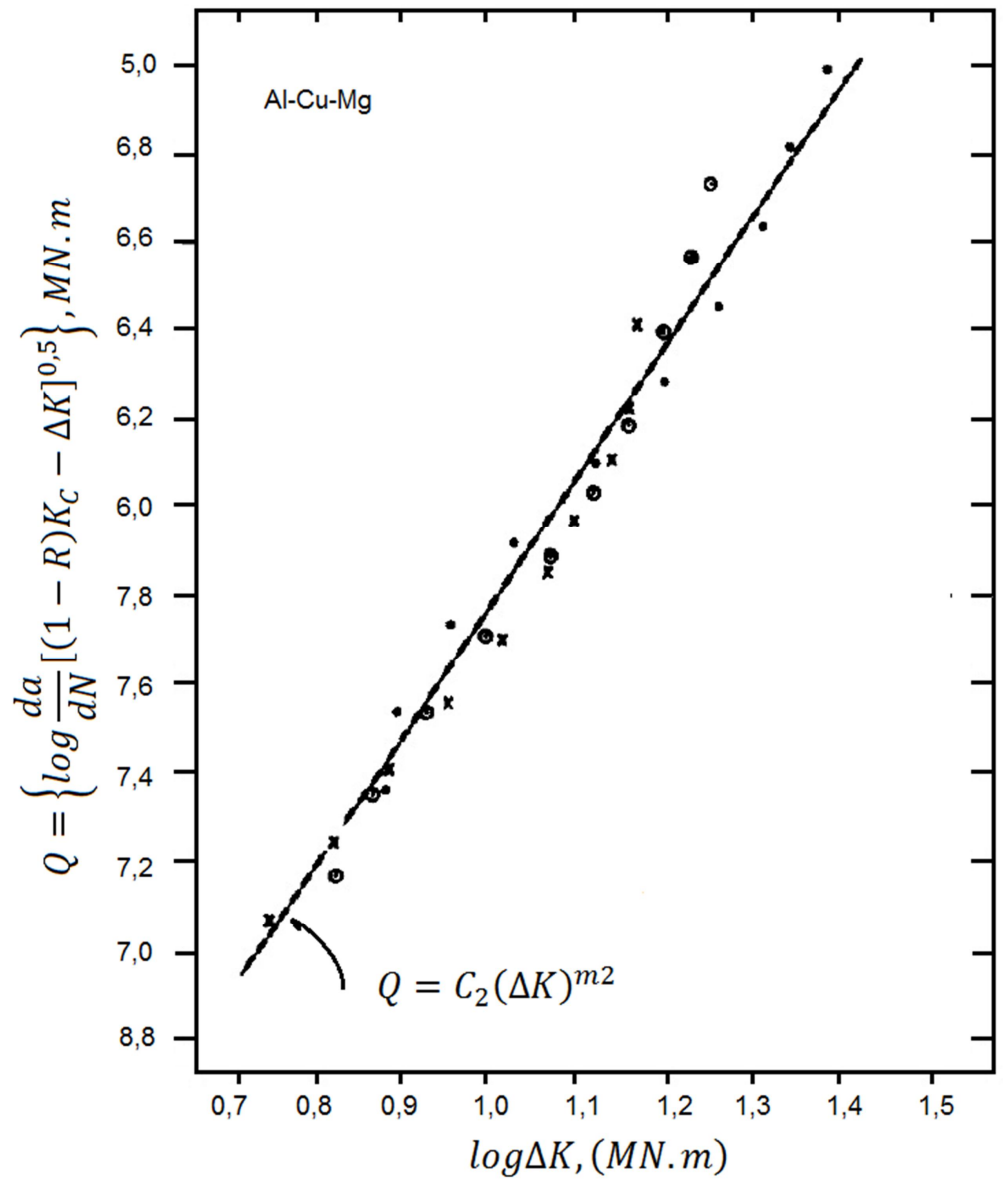

Figura 22. Correlação entre as combinações de dados de $\Delta K$ e $\mathrm{R}$ utilizando a equação de Pearson (Pearson, 1972).

Como pode ser observado na figura 20 , a equação de Paris evidencia o efeito da razão de tensões, na taxa de propagação, mostrando exatamente que uma cresce mais do que a outra. Segundo Dowling, (2007), no caso das equações de Formam e Pearson, para um determinado material, o sucesso das mesmas se deve às combinações dos valores de $K$ e $R$, que resultam em uma linha reta num gráfico $\log -\log$ de $Q$ versus $K$, conforme figuras 21 e 22. Assim, tendo-se a curva pode-se calcular a taxa de propagação para qualquer $R$. 


\section{MATERIAIS E MÉTODOS}

Neste capitulo serão apresentados os ensaios, os procedimentos para a realização dos ensaios de tração, tenacidade à fratura, fadiga em temperatura ambiente e temperatura criogênica e caracterização microestrutural.

A figura 23 mostra o fluxograma detalhando a sequência dos ensaios realizados.

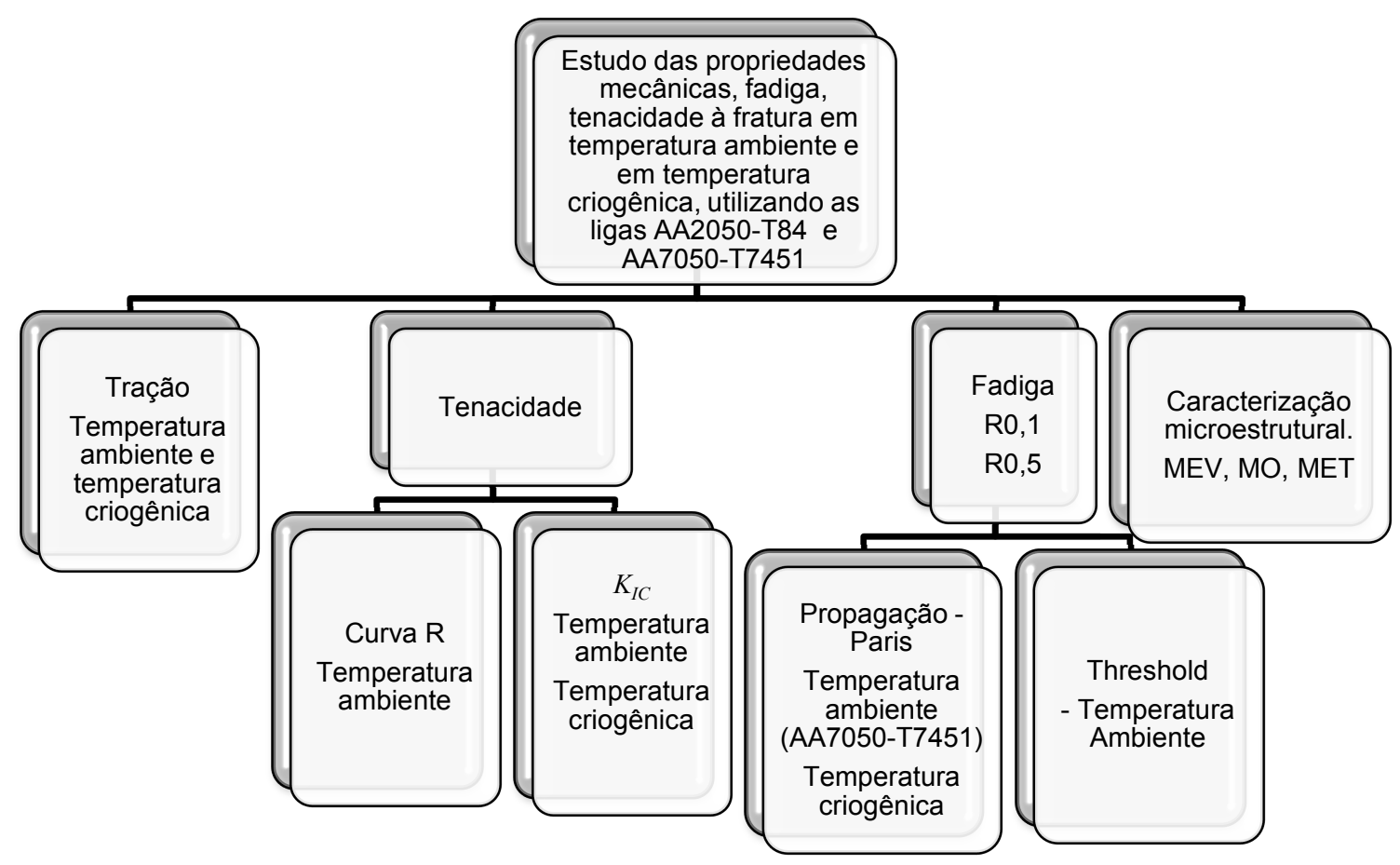

Figura 23. Fluxograma detalhando sequência dos ensaios realizados. 


\subsection{Materiais}

Foram estudadas duas ligas de Al de alta resistência, sendo uma da família 2XXX e outra da família $7 \mathrm{XXX}$, ambas fornecidas pela Embraer. Da família $2 \mathrm{XXX}$ foi escolhida a liga denominada de AA2050 (AL-Cu-Li), cedida em forma de placa laminada nas dimensões $800 \times 550 \times 50 \mathrm{~mm}$ e tratadas termicamente na condição T84. A liga da série $7 X X X$ escolhida foi a liga AA7050, cedida na forma de placa nas dimensões de 1000 x 1000 x 50mm, tratada na condição T7451.

As composições químicas encontradas foram comparadas com as composições descritas nas normas ou fornecidas pelo fabricante. Conforme tabela 6, têm-se as composições químicas de cada material utilizado para os ensaios.

Tabela 6. Composição química das ligas de alumínio (\%peso)

\begin{tabular}{|c|c|c|c|c|c|c|c|c|c|c|c|}
\hline Ligas & $\mathrm{Cu}$ & Mg & Mn & $\mathrm{Zn}$ & $\mathrm{Fe}$ & $\mathrm{Ti}$ & Si & $\mathrm{Cr}$ & Al & $\mathbf{L i}$ & $\mathbf{Z r}$ \\
\hline AA2050-T84 & 3,54 & 0,31 & 0,37 & 0,02 & 0,06 & 0,03 & 0,03 & $20^{*}$ & Base & 0,87 & 0,08 \\
\hline AA7050-T7451 & 2,25 & 1,896 & 0,01 & 6,02 & 0,05 & 0,03 & 0,04 & 0,01 & Base & ND & 0,10 \\
\hline
\end{tabular}

*ppm (parte por milhão) 


\subsection{Análises metalográficas}

Os materiais possuem grãos com várias características, dentre as quais podese citar o tamanho e a forma, que são apenas duas características da microestrutura. Essas microestruturas são estudadas por meio de análises metalográficas que utilizam microscopia ótica ou eletrônica. Os grãos constituintes possuem dimensões microscópicas com diâmetros que podem ser da ordem de micra.

A análise microestrutural tem a finalidade de examinar os diversos elementos estruturais e os defeitos que influenciam nas propriedades mecânicas dos materiais. Esses exames devem ser realizados para assegurar que as associações entre as propriedades mecânicas e a estrutura, bem como os defeitos, sejam compreendidos de forma apropriada.

\subsubsection{Microscópio ótico}

As análises microestruturais foram realizadas por meio de análises micrográficas em três direções. Para ambas as ligas estudadas foram realizados cortes nas direções longitudinal (L), transversal (T) e topo (S), conforme figura 24.

O método para preparação das amostras para as análises microestruturais constituiu em cortar as mesmas por meio de disco abrasivo sob refrigeração. Logo após, as mesmas foram embutidas em resinas e posteriormente lixadas, utilizando lixa de granulometria 120, 220, 320, 400, 600, 800, 1200 e 2000 mesh. Por fim foram polidas com pasta de diamante de $1 \mu \mathrm{m}$ de acordo com a norma ASTM E 3. 


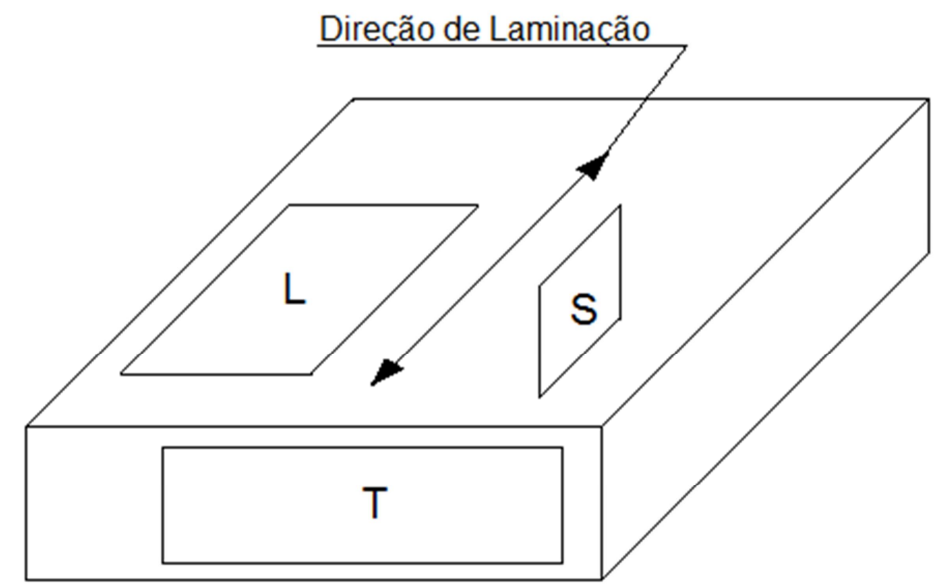

Figura 24. Desenho esquemático mostrando as direções observadas

As amostras foram observadas e fotografadas utilizando microscópio ótico Olympus BX41M-LED, no qual foi acoplada uma câmera digital de alta resolução (5,0 Mpixels).

O reagente de Keller foi utilizado para realizar o ataque metalográfico, por meio de imersão em todas as amostras. A composição do reagente é apresentada na tabela 7.

Tabela 7. Composição química do reagente de Keller

\begin{tabular}{cc}
\hline $\mathrm{HF}(\mathbf{4 8})$ & $\mathbf{2} \mathrm{ml}$ \\
\hline $\mathrm{HCl}$ concentrado & $3 \mathrm{ml}$ \\
$\mathrm{HNO}_{3}$ concentrado & $5 \mathrm{ml}$ \\
& $100 \mathrm{ml}$ \\
\hline Água destilada
\end{tabular}




\subsubsection{Microscópio eletrônico de varredura (MEV)}

Para análises metalográficas de elementos mais finos e menores utilizou-se a microscopia eletrônica de varredura (MEV) e análise por energia dispersiva de raio $\mathrm{x}$ (EDX), onde procurou-se identificar os precipitados com grande influência na fadiga e tenacidade à fratura.

Para execução dessas análises utilizou-se um microscópio eletrônico de varredura (MEV) da marca Marca FEI, modelo Impec 50, com feixe de elétrons 10kV e WD 10mm, em corpos de prova sem ataque químico.

\subsubsection{Microscópio eletrônico de transmissão (MET)}

O microscópio eletrônico de transmissão foi utilizado para detalhar as características da microestrutura. Assim, para executar o ensaio, foram preparadas amostras metálicas ou lâminas finas com espessura igual ou maior que $100 \mu \mathrm{m}$, conforme descrito abaixo (Afonso, 2008).

1. A preparação das laminas é de forma direta, consistindo no corte da amostra a partir de sólidos (metálicos e cerâmicos). O procedimento consiste em cortar uma chapa, utilizando um disco de corte de diamante e, através de um lixamento grosseiro, com lixa de granulometria \#320, garantir uma espessura de $500 \mu \mathrm{m}$ e, depois um lixamento mais fino, utilizando uma lixa de granulometria \#600, até a

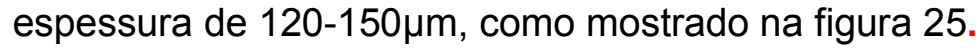




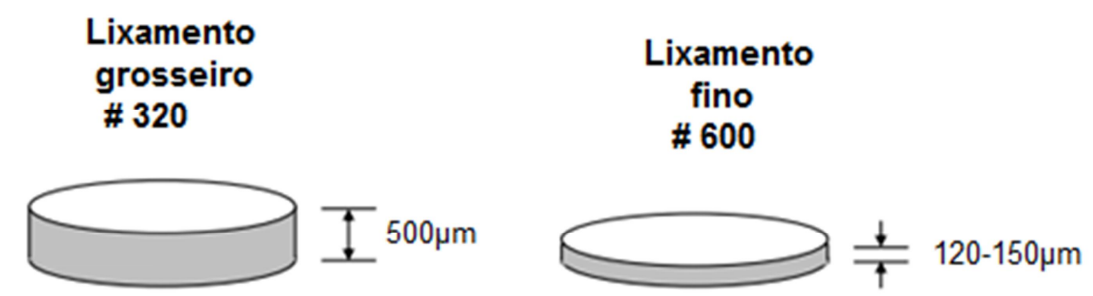

Figura 25 - Preparação da lâminas corte e lixamento.

2. Conforme mostrado na figura 26 , logo após obter a chapa com a espessura entre $120-150 \mu \mathrm{m}$, a amostra é estampada, de modo a obter um disco com diâmetro de $3 \mathrm{~mm}$. Posteriormente, o disco é lixado com lixa grana \#2000 e polido com suspensão de alumina $\left(\mathrm{Al}_{2} \mathrm{O}_{3}\right)$ até a espessura entre $70-100 \mu \mathrm{m}$.

\section{Estampagem \\ $\varnothing=3 \mathrm{~mm}$}

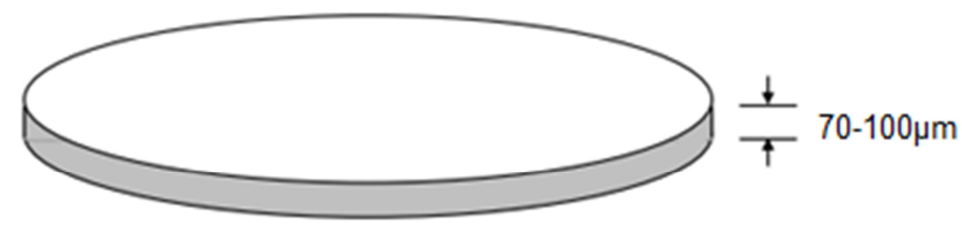

Figura 26. Estampagem e polimento.

3. Na etapa subsequente, conforme figura 27 , é produzida uma calota esférica no centro do disco (dimpling), através de um polimento, até garantir uma espessura entre $5-20 \mu \mathrm{m}$.

\section{Calota esférica}

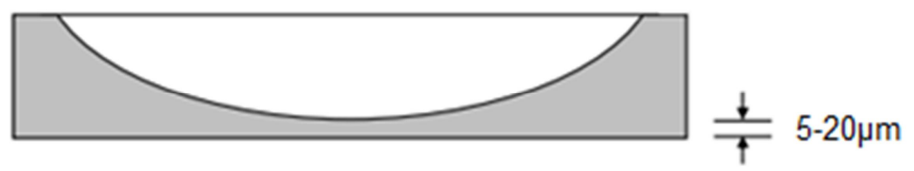

Figura 27. Calota esférica. 
4. Na última etapa, como mostrado na figura 28 , é executado um polimento iônico (Ion milling), para garantir a espessura menor ou igual a $100 \mu \mathrm{m}$.

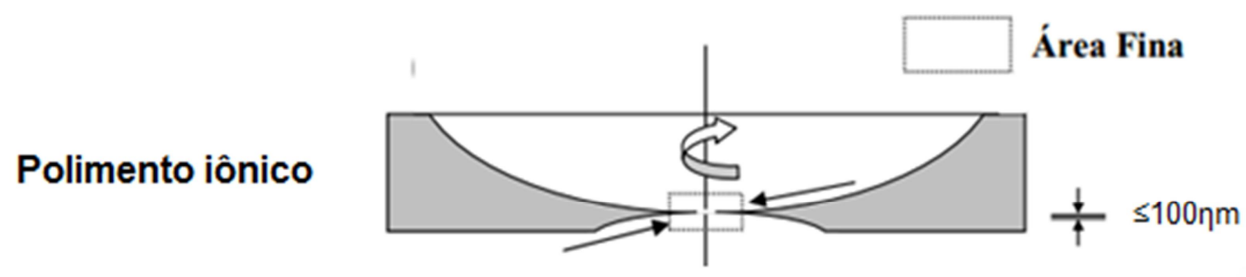

Figura 28 - Etapa final da lâmina, através do polimento iônico.

\subsection{Ensaio de tração}

Os ensaios de tração foram realizados conforme norma ASTM E8 -13 ${ }^{\mathrm{a}}$, com o objetivo de determinar as propriedades mecânicas dos materiais nas direções longitudinal $(\mathrm{L})$ e transversal $\mathrm{T}$, nas temperaturas ambiente e criogênica $-54^{\circ} \mathrm{C}$.

Foram determinados o limite de escoamento para a $0,2 \%$ de deformação plástica $\left(\sigma_{0,2}\right)$, limite de resistência à tração $\left(\sigma_{r}\right)$, módulo de elasticidade $(E)$ e alongamento total $\left(\varepsilon_{t}\right)$. A geometria e tamanho dos corpos de prova utilizados são apresentados nas figuras 29 e 30 .

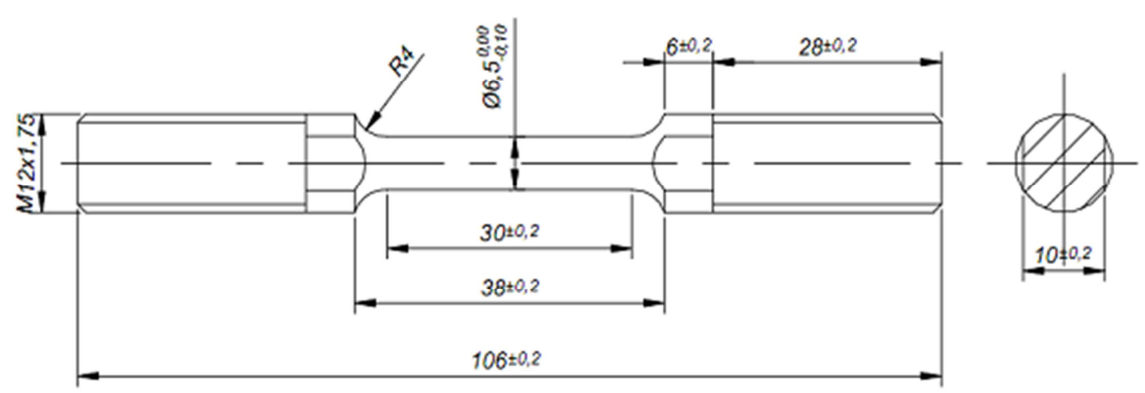

Figura 29. Geometria e dimensões dos corpos de prova obtidos para as ligas de AA2050-T84 e AA7050-T7451 para os ensaios a $-54^{\circ} \mathrm{C}$. Dimensões em $\mathrm{mm}$. 


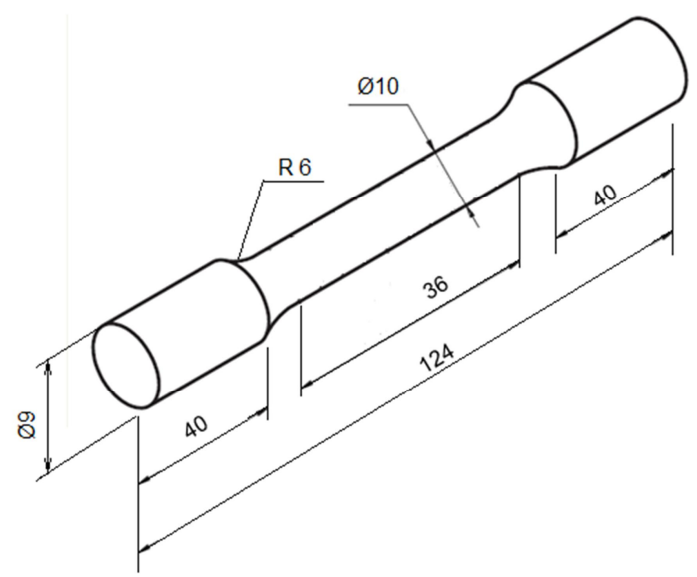

Figura 30. Geometria e dimensões dos corpos de prova obtidos para as ligas de AA2050-T84 e AA7050-T7451 para os ensaios em temperatura ambiente. Dimensões em mm.

\subsection{Ensaio de tenacidade à fratura}

Os ensaios de tenacidade à fratura foram realizados para determinação de $K_{I C}$ ou $K_{C}$ em temperatura ambiente e a $-56^{\circ} \mathrm{C}$, conforme a norma ASTM E399-12. A liga utilizada para o ensaio foi AA7050-T7451 e foram confeccionados corpos de prova do tipo compacto em tração, $\mathrm{C}(\mathrm{T})$, conforme figura 31 , que foram usinados nas direções (T-L) e (L-T), de acordo com a figura 32. 

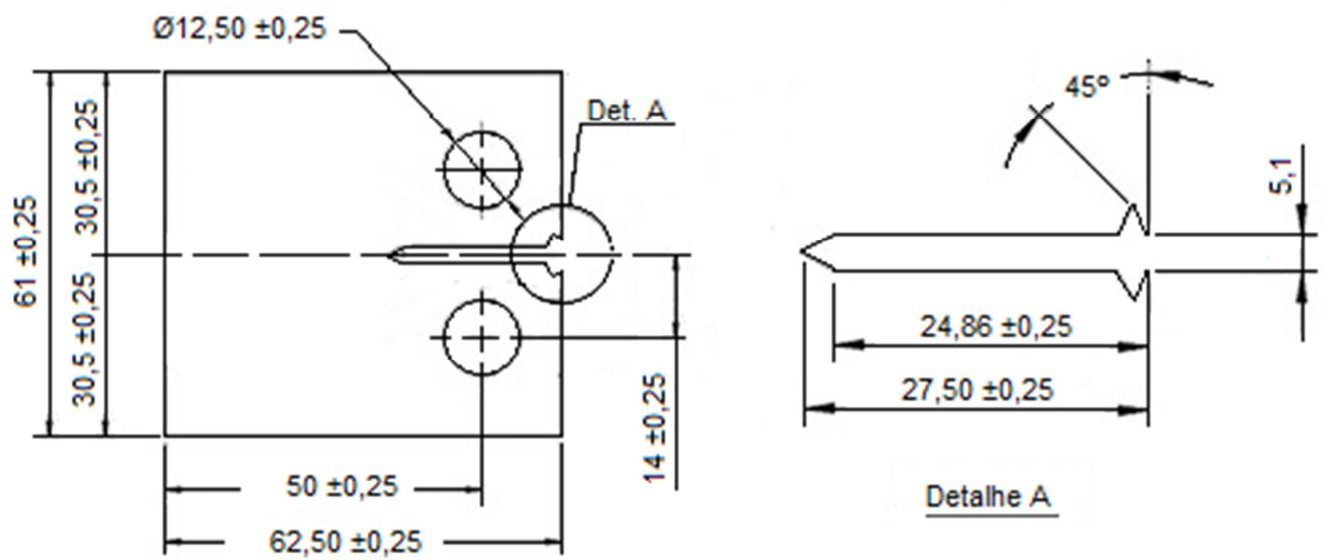

Detalhe A

Espessura: $25 \pm 0,25$

Figura 31. Desenho do corpo de prova $\mathrm{C}(\mathrm{T})$ tirado do centro da placa com espessura de 25mm. Dimensões em mm.

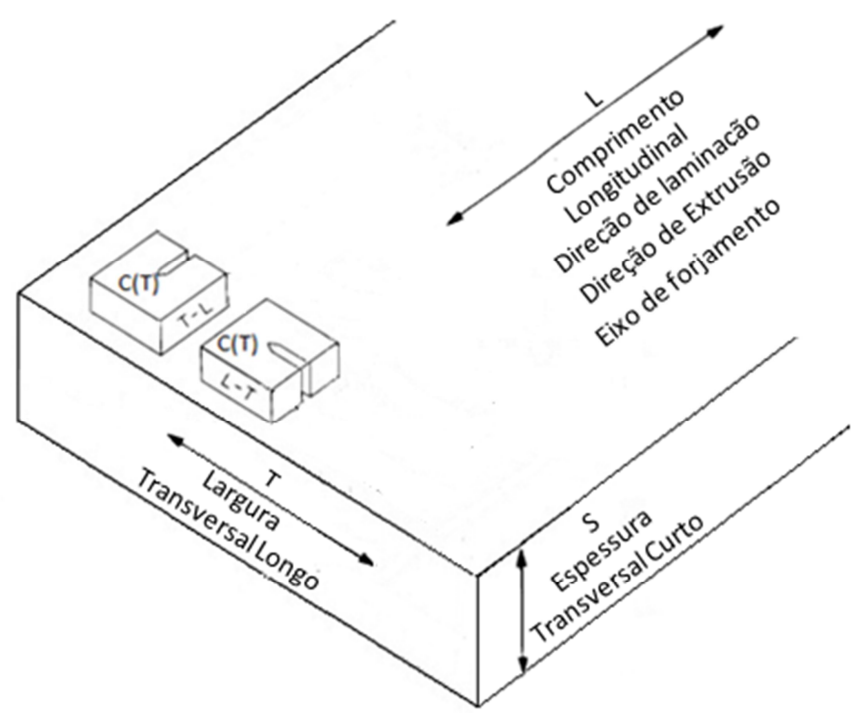

Figura 32. Esquema mostrando a configuração da retirada dos corpos de prova, tipo $C(T)$ (ASTM E399-12). 
Para a realização dos ensaios de $K_{I C}$ da liga AA7050-T7451 utilizou-se três corpos de prova para cada direção.

Para a realização da pré-trinca e dos ensaios em temperatura ambiente utilizou-se uma máquina servo hidráulica MTS Landmark, modelo 370.10, que possui garras em que o corpo de prova é fixado com pinos, conforme figura 33 . Porém, para o ensaio em temperatura criogênica $\left(-54^{\circ} \mathrm{C}\right)$, utilizou-se a máquina MTS 810 de $250 \mathrm{KN}$, com uma câmara com nitrogênio líquido para o resfriamento criogênico, conforme figura 34, seguindo os mesmos princípios do ensaio em temperatura ambiente.

O crescimento da trinca foi mensurado usando a técnica da variação da flexibilidade elástica, utilizando um extensômetro tipo "clip on gauge" montado no entalhe do corpo de prova, como mostra a Figura 33.

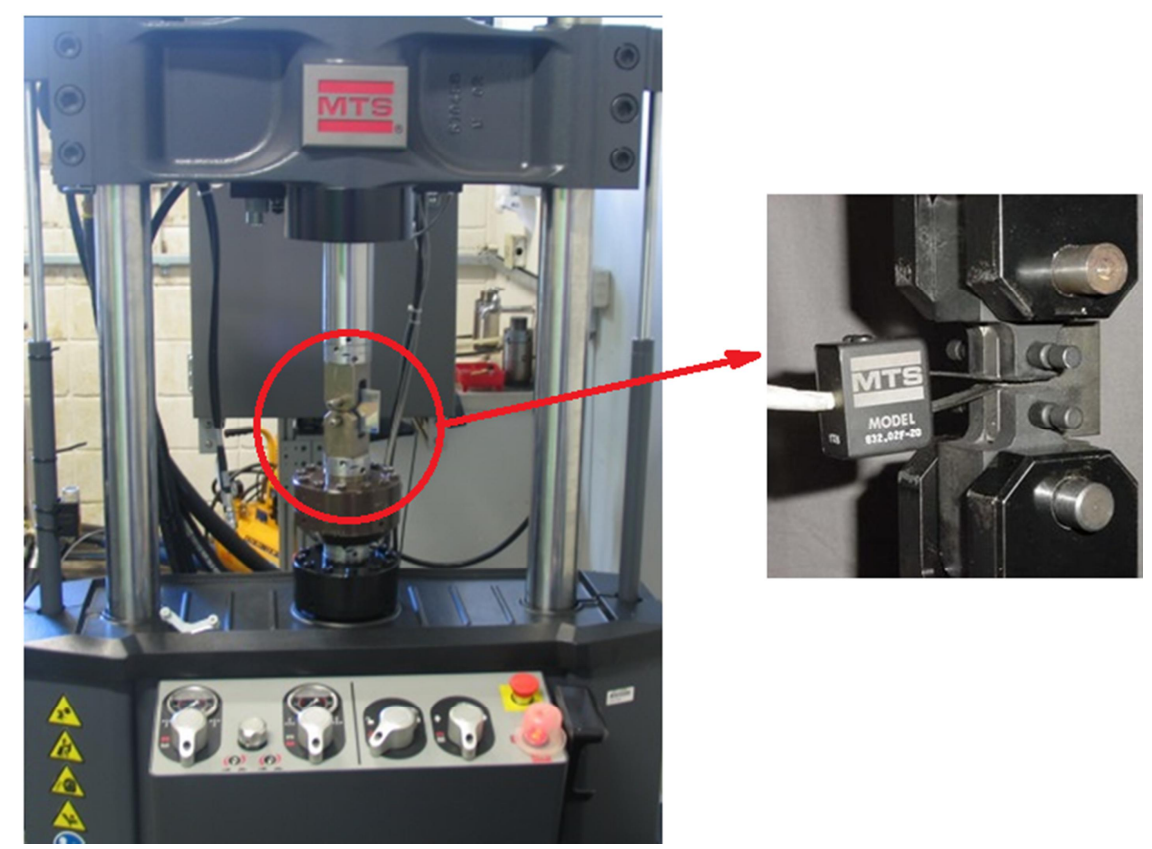

Figura 33. Corpo de prova acoplado na máquina durante ensaio de tenacidade à fratura. 


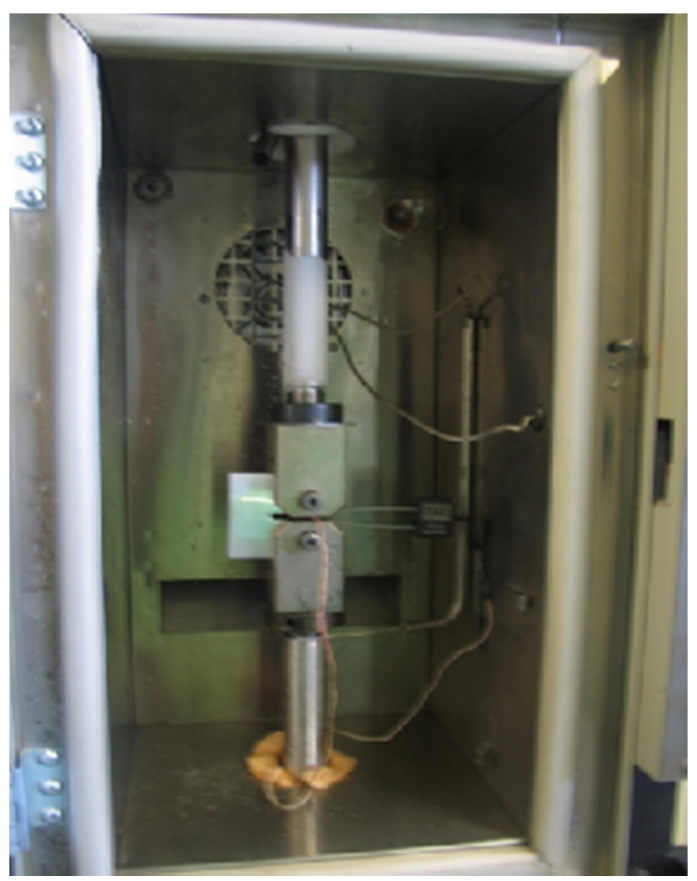

Figura 34. Corpo de prova montado para ensaio em baixa temperatura $\left(T=-54^{\circ} \mathrm{C}\right)$

A tabela 8 mostra os parâmetros utilizados para a execução da pré-trinca em temperatura ambiente e na temperatura a $-54^{\circ} \mathrm{C}$, para a liga $\mathrm{AA} 7050-\mathrm{T} 7451$, com frequência de $15 \mathrm{~Hz}$ e razão entre cargas de $R=0,1$. $O$ comprimento da pré-trinca também foi mensurado utilizando a mesma técnica descrita acima.

Tabela 8. Parâmetros utilizados para execução de pré-trinca nos corpos de prova do ensaio de tenacidade à fratura da liga AA7050-T7451

\begin{tabular}{|c|c|c|c|c|c|}
\hline$a(m m)$ & $\triangle K(M P a \sqrt{m})$ & $P_{\max }(K N)$ & $P_{\min }(K N)$ & $P_{\text {med }}(K N)$ & $P_{a}(K N)$ \\
\hline 23,41 & 25 & 14,71 & 1,47 & 8,09 & 6,62 \\
\hline 23,48 & 20 & 11,8 & 1,18 & 6,47 & 5,29 \\
\hline 25,02 & 18 & 10,59 & 1,06 & 5,82 & 4,77 \\
\hline
\end{tabular}


Após o ensaio, as superfícies de fratura foram separadas e o valor do tamanho da trinca foi obtido para o calculo de $K_{Q}$, conforme as equações abaixo e foram realizadas as verificações, conforme exigido pela norma ASTM E399-12.

Para o corpo de prova do tipo $\mathrm{C}(\mathrm{T})$ :

$$
\begin{aligned}
& \mathrm{K}_{\mathrm{Q}}=\frac{\mathrm{P}_{\mathrm{Q}}}{\sqrt{\mathrm{BB}_{\mathrm{N}}} \sqrt{\mathrm{W}}} * \mathrm{f}\left(\frac{\mathrm{a}}{\mathrm{w}}\right) \\
& f\left(\frac{a}{w}\right)=\frac{2+\frac{a}{w}}{\left(1-\frac{a}{w}\right)^{\frac{3}{2}}}\left[0,886+4,64\left(\frac{a}{w}\right)-13,32\left(\frac{a}{W}\right)^{2}+14,72\left(\frac{a}{w}\right)^{3}-5,60\left(\frac{a}{w}\right)^{4}\right]
\end{aligned}
$$

Onde:

$K_{Q}=$ Fator de Intensidade de tensão:

$P=$ Carga aplicada no corpo de prova;

$B=$ Espessura do corpo de prova;

$B_{N}=$ Espessura do corpo de prova entre as raízes dos entalhes laterais;

$W=$ Largura;

$a=$ Comprimento da trinca;

$f\left(\frac{a}{w}\right)=$ Fator Geométrico. 
3.4.1 Ensaios de tenacidade à fratura na temperatura ambiente

Na tabela 9 estão os dados de taxa de carregamento e controle de carga da liga AA7050-T7451, nas direções L-T e T-L.

Tabela 9. Taxas de carregamento para cada corpo de prova extraído nas direções L-T e T-L utilizados nos ensaios de tenacidade $\left(K_{I c}\right)$ em temperatura ambiente da liga AA7050-T7451

\begin{tabular}{|c|c|c|c|c|c|}
\hline \multirow[b]{2}{*}{ CP } & \multirow{2}{*}{$\begin{array}{c}\text { Taxa } \\
\left(\frac{M P a \sqrt{m}}{s}\right)\end{array}$} & \multicolumn{2}{|c|}{ L-T } & \multicolumn{2}{|c|}{ T-L } \\
\hline & & $a_{0}(\mathrm{~mm})$ & $P(K N / \min )$ & $a_{0}(\mathrm{~mm})$ & $P(K N / \mathrm{min})$ \\
\hline 1 & 1 & 24,4 & 17,45 & 25,46 & 19,2 \\
\hline 2 & 1 & 25,1 & 17,48 & 26,24 & 17,47 \\
\hline 3 & 1 & 24 & 17,42 & 25,4 & 17,44 \\
\hline
\end{tabular}

\subsubsection{Ensaios de tenacidade à fratura na temperatura criogênica}

Na Tabela 10 estão os dados de taxa de carregamento e controle de carga da liga AA7050-T7451 na temperatura criogênica, nas direções L-T e T-L.

Tabela 10. Taxas de carregamento para cada corpo de prova extraído nas direções L-T e T-L utilizados nos ensaios de tenacidade $\left(K_{I c}\right)$ em temperatura criogênica da liga AA7050-T7451

\begin{tabular}{|c|c|c|c|c|c|}
\hline \multirow{2}{*}{ CP } & \multirow{2}{*}{$\begin{array}{c}\text { Taxa } \\
\left(\frac{M P a \sqrt{m}}{s}\right)\end{array}$} & \multicolumn{2}{|c|}{ L-T } & \multicolumn{2}{|c|}{ T-L } \\
\hline & & $a_{0}(\mathrm{~mm})$ & $P(K N / \min )$ & $a_{0}(\mathrm{~mm})$ & $P(K N / \min )$ \\
\hline 1 & 1 & 22,76 & 36 & 23,65 & 33 \\
\hline 2 & 1 & 22,85 & 36 & 23,48 & 34 \\
\hline 3 & 1 & 22,21 & 30,6 & 25,02 & 32 \\
\hline
\end{tabular}




\subsection{Curva $K_{R}$}

Os ensaios para determinação da Curva $\mathrm{K}_{R}$ foram realizados conforme norma ASTM E561-10, para verificar a resistência do material ao crescimento da trinca. A máquina utilizada para o ensaio foi a mesma do ensaio de tenacidade à fratura em temperatura criogênica.

Os ensaios foram realizados em temperatura ambiente, utilizando-se as ligas AA2050-T84 e AA7050-T7451, que foram usinadas nas direções L-T e T-L.

Os corpos de prova utilizados para o ensaio foram do tipo tração compacto $\mathrm{C}(\mathrm{T})$, conforme figura 35 . E o crescimento da trinca foi mensurado usando a técnica da variação da flexibilidade elástica, utilizando um extensômetro tipo "clip on gauge" montado no entalhe do corpo de prova, como mostra a figura 33.

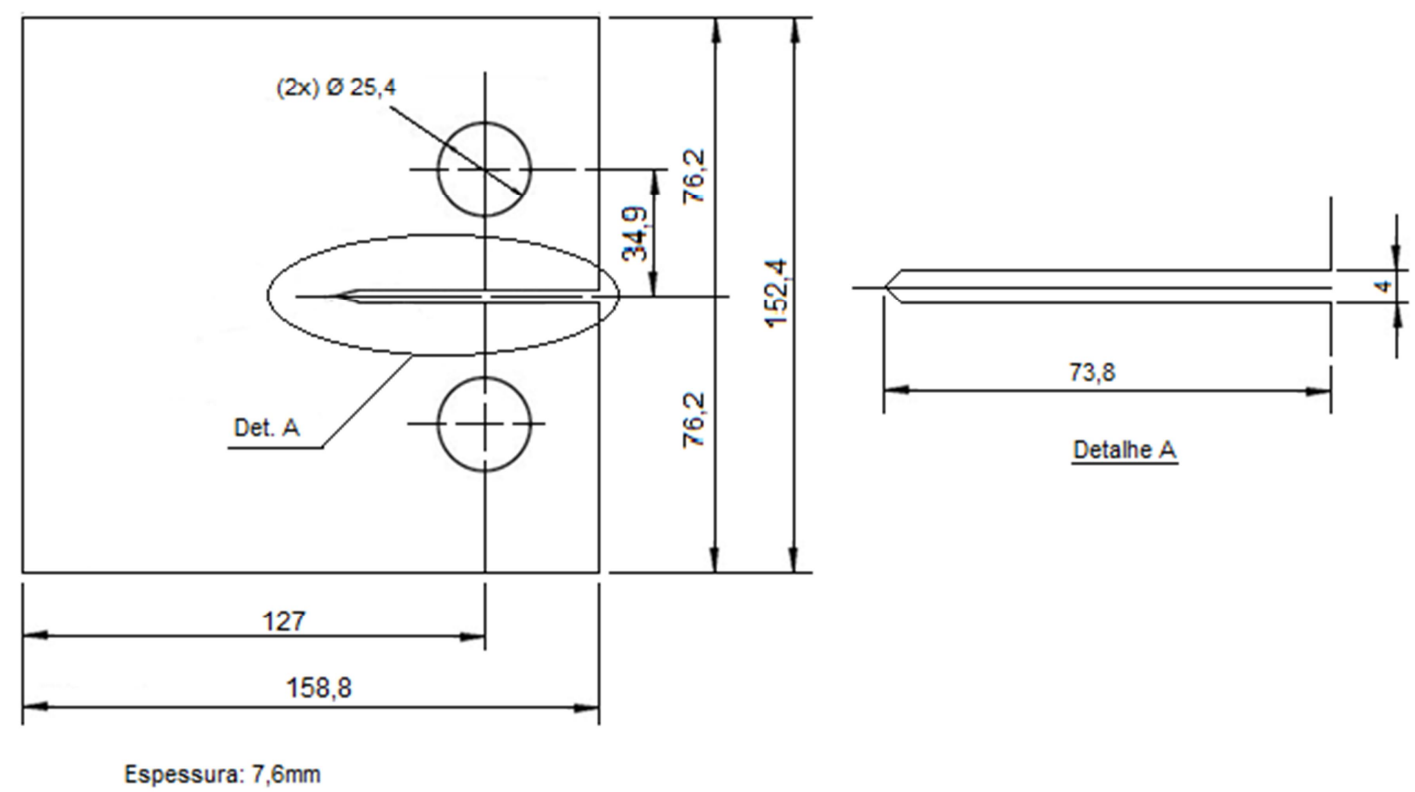

Figura 35. Desenho do corpo de prova $C(T)$ para determinação da Curva $K_{R}$. Dimensões em $\mathrm{mm}$. 
3.6 Propagação de trinca por fadiga em temperatura ambiente e criogênica

Os ensaios de propagação de trinca por fadiga em temperatura ambiente e criogênica $\left(-54^{\circ} \mathrm{C}\right)$ foram executados conforme norma ASTM E647-13. Porém, os ensaios realizados na temperatura ambiente levaram em consideração a região I (Threshold) e a região II (Paris). Os ensaios em temperatura criogênica $\left(-54^{\circ} \mathrm{C}\right)$ foram realizados apenas na região II (Paris), uma vez que a determinação do $K$ limite (Threshold) da região I não compunha o escopo do projeto, considerando-se a demora do ensaio e a necessidade de grande quantidade de nitrogênio.

Para a realização dos ensaios foram utilizadas as ligas AA2050-T84 e AA7050- T7451, confeccionadas nas direções L-T e T-L. Os corpos de prova confeccionados foram os de tração compacto $\mathrm{C}(\mathrm{T})$, cujo desenho e as dimensões são mostrados na figura 36. A execução dos ensaios de fadiga variaram de acordo com os seguintes parâmetros: razão de carga, direção de propagação da trinca e temperatura para o período de propagação. A tabela 6 ilustra as condições do ensaio realizado e a quantidade de corpos de prova das ligas AA7050-T7451.
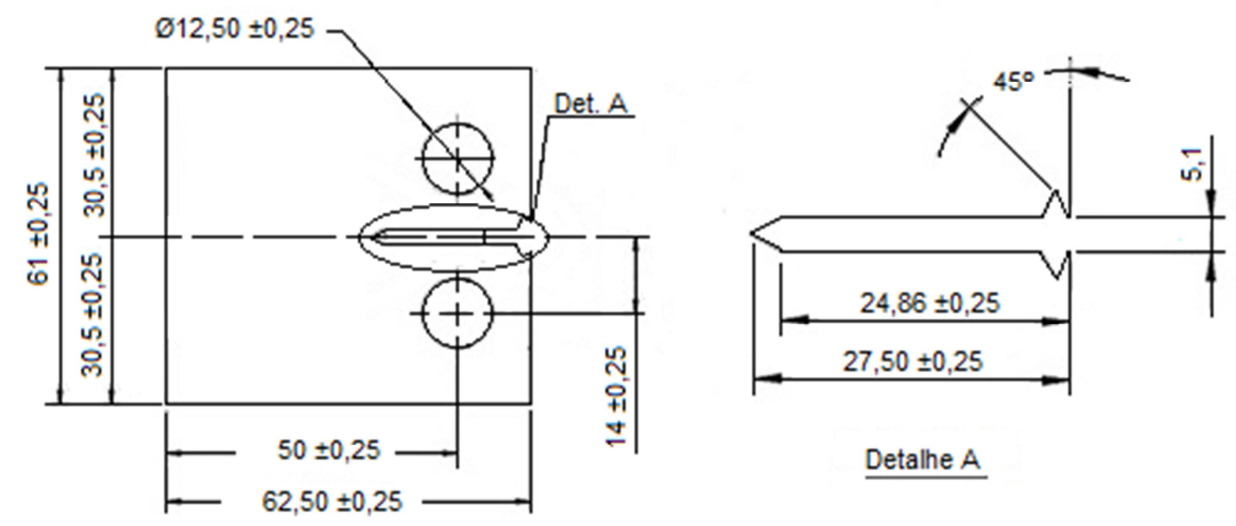

Espessura: $5 \mathrm{~mm}$

Figura 36. Esquema da geometria e dimensões, realizado em CAD, dos corpos de prova do tipo $\mathrm{C}(\mathrm{T})$. Dimensões em $\mathrm{mm}$. 
Tabela 11. Matriz de ensaio de fadiga para a liga AA7050-T7451

\begin{tabular}{|c|c|c|c|c|}
\hline & Configuração & Curvas & CDP & Total \\
\hline \multirow{5}{*}{ FCG } & $\mathrm{da} / \mathrm{dN}$ L-T $5 \mathrm{~mm}$ & R 0,1 (RTA e LTA) & 2 & \multirow{3}{*}{4} \\
\hline & $\mathrm{da} / \mathrm{dN}$ L-T $5 \mathrm{~mm}$ & R 0,5 (RTA e LTA) & 2 & \\
\hline & $\mathrm{da} / \mathrm{dN}$ T-L $5 \mathrm{~mm}$ & R 0,1 (RTA e LTA) & 2 & \\
\hline & & & & \multirow[t]{2}{*}{4} \\
\hline & $\mathrm{da} / \mathrm{dN}$ T-L $5 \mathrm{~mm}$ & R 0,5 (RTA e LTA) & 2 & \\
\hline
\end{tabular}

Os ensaios foram realizados em uma máquina servo-hidráulica MTS 810, de 250 KN de capacidade e uma câmara MTS ENVIRONMENTAL 651, para ensaios em temperatura a $-54^{\circ} \mathrm{C}$, conforme figuras 26 e 27 , utilizando uma onda senoidal e frequência de $15 \mathrm{~Hz}$. 


\section{RESULTADOS E DISCUSSÕES}

\subsection{Análise Microestrutural}

\subsubsection{Liga AA7050-T7451}

A figura 37 apresenta uma micrografia ótica da liga AA7050-T7451, mostrando grãos bastante alongados (empanquecados) e a texturização no sentido da laminação bastante acentuada. Conforme Prasard (2014), essa texturização e forte deformação estão relacionadas com a adição de zircônio na composição química.

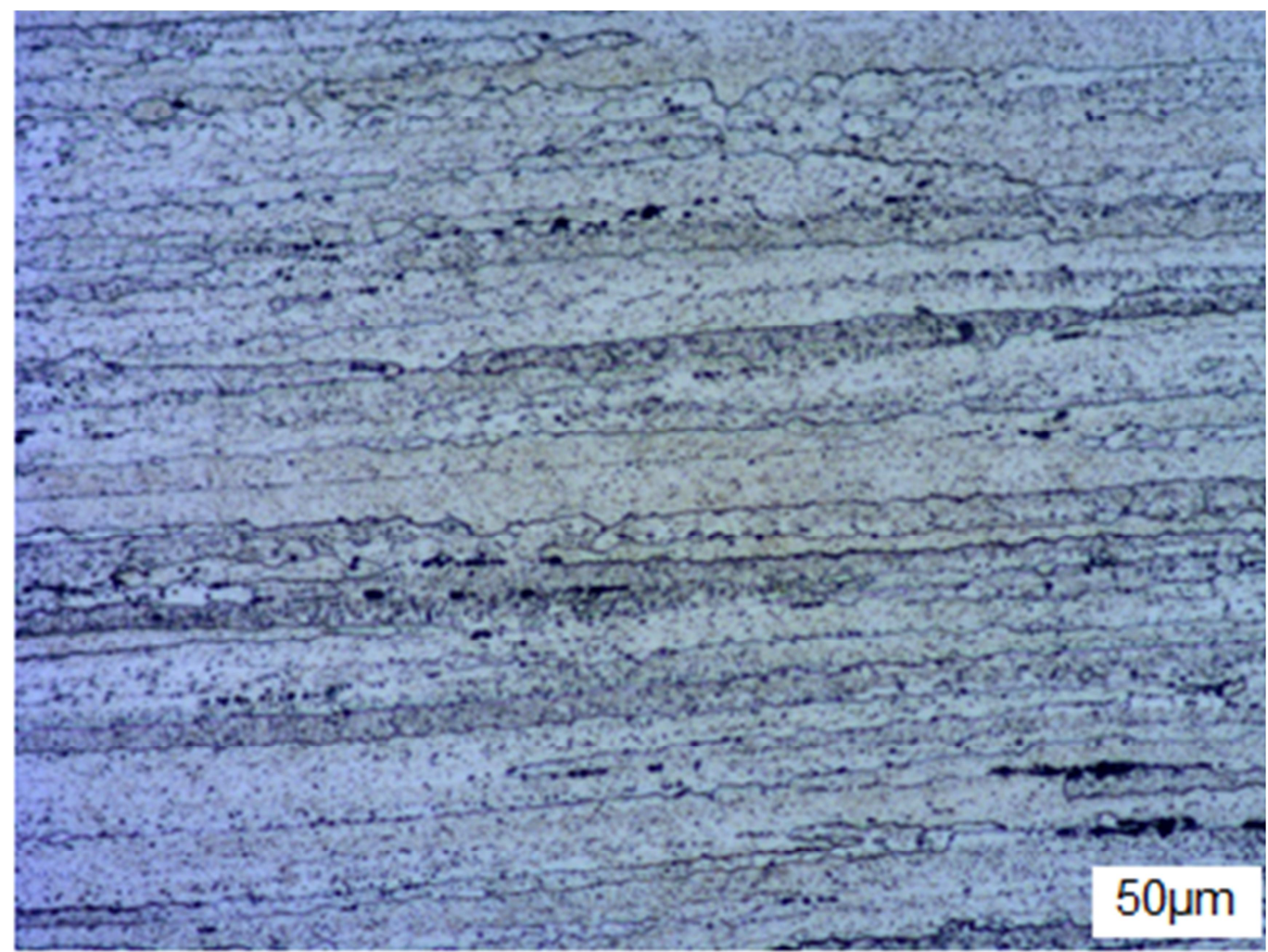

Figura 37. Micrografia ótica mostrando a microestrutura da liga AA7050-T7451 
A figura $38(a, b)$ apresenta uma microestrutura da liga AA7050-T7451 em temperatura ambiente, que consiste de uma matriz a-Al com grãos alongados e alinhados na direção de laminação, observados através de um microscópio eletrônico de varredura - MEV.

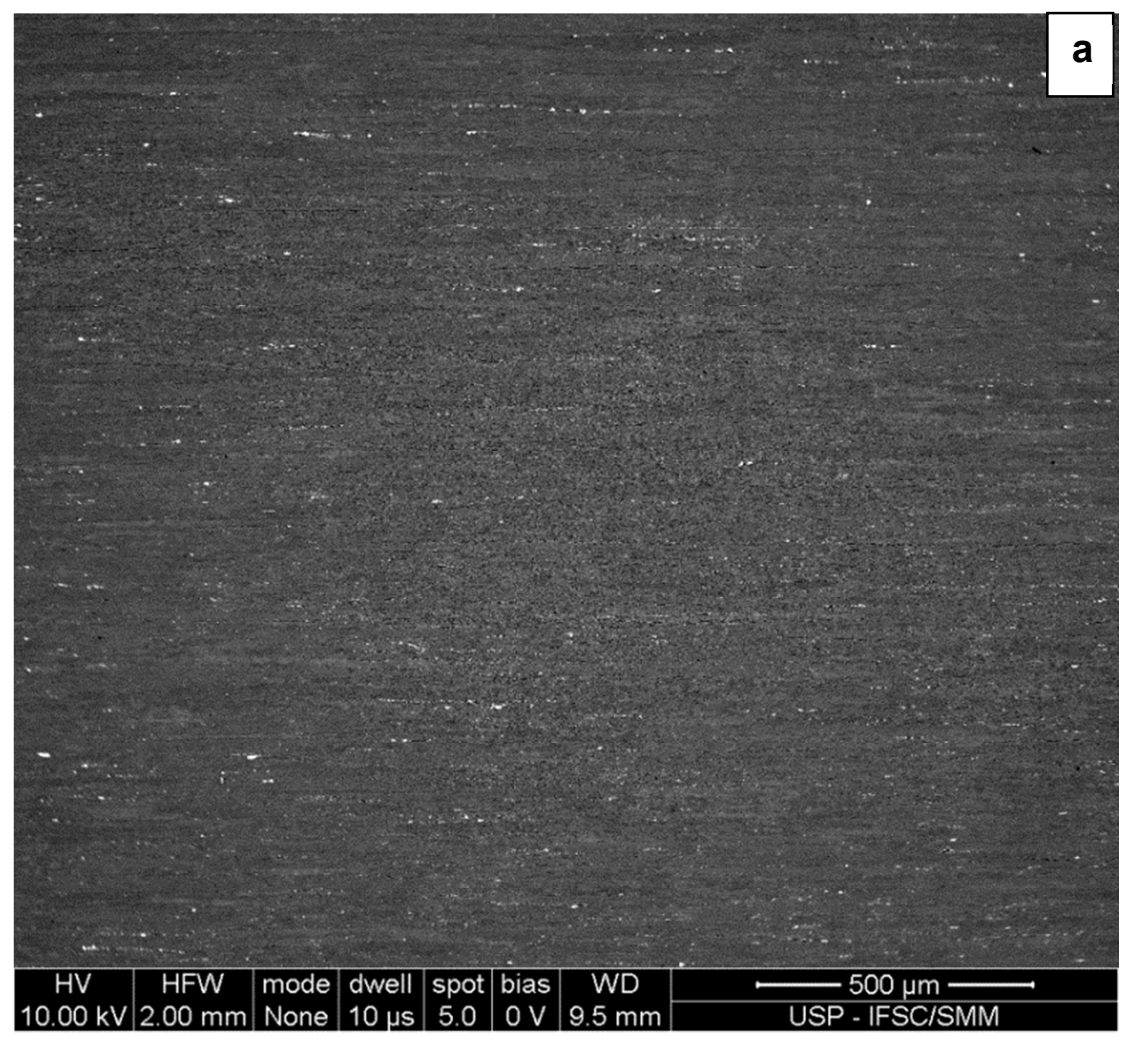




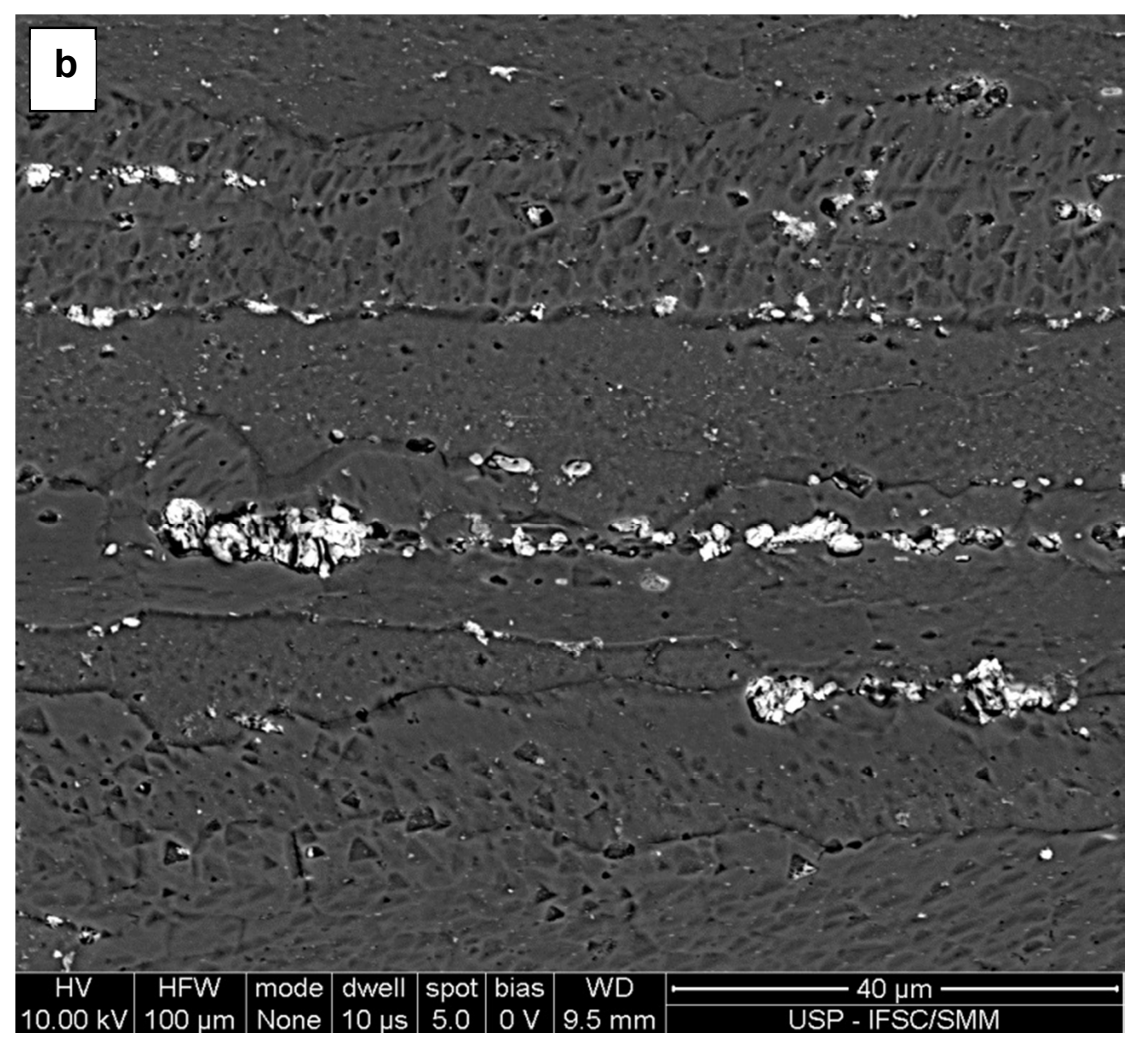

Figura 38. Micrografia dos grãos e dos precipitados na direção longitudinal da liga AA7050T7451

A figura 39 apresenta algumas partículas constituintes dispersas que foram analisadas em duas áreas distintas, por meio da técnica espectroscopia de raios- $X$ por dispersão de energia (EDX). Como pode ser observado, detectou-se uma grande porcentagem de $\mathrm{Cu}$ em ambas as áreas analisadas. 


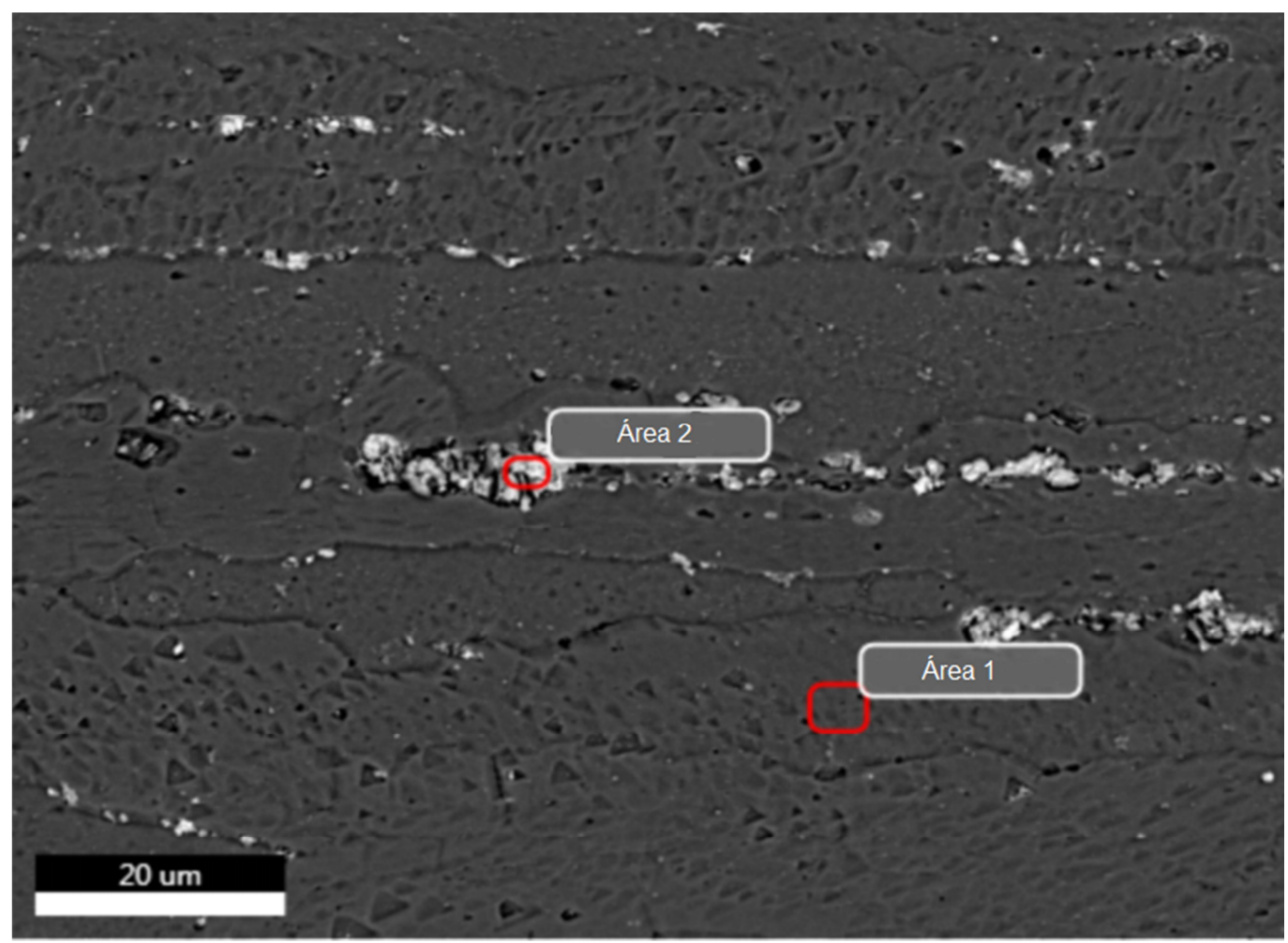

Área 1

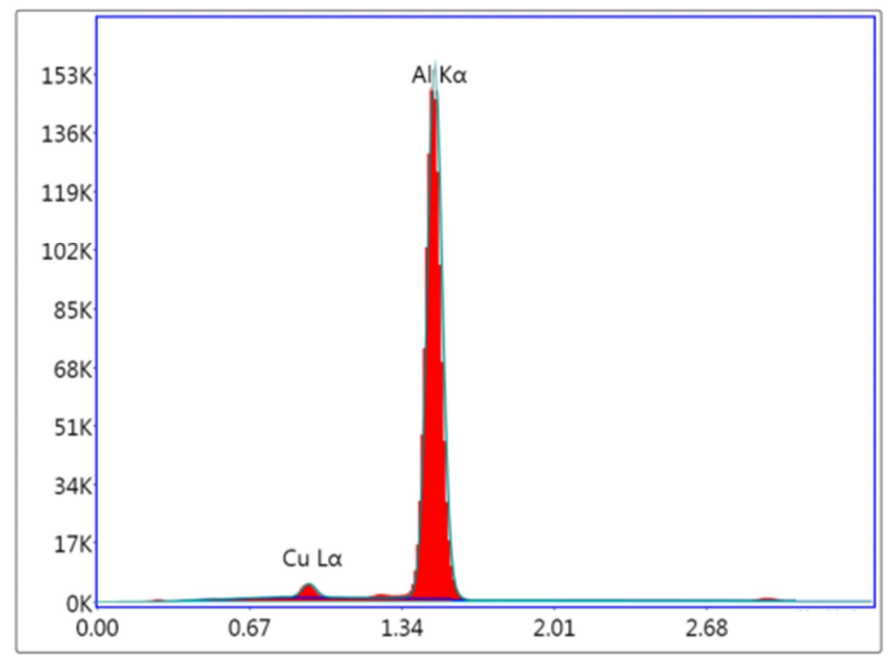

Elemento \% (wt) \% (at)

\begin{tabular}{ccc}
\hline $\mathrm{Cu}$ & 2,82 & 1,22 \\
$\mathbf{A l}$ & 97,18 & 98,78 \\
\hline
\end{tabular}


Área 2

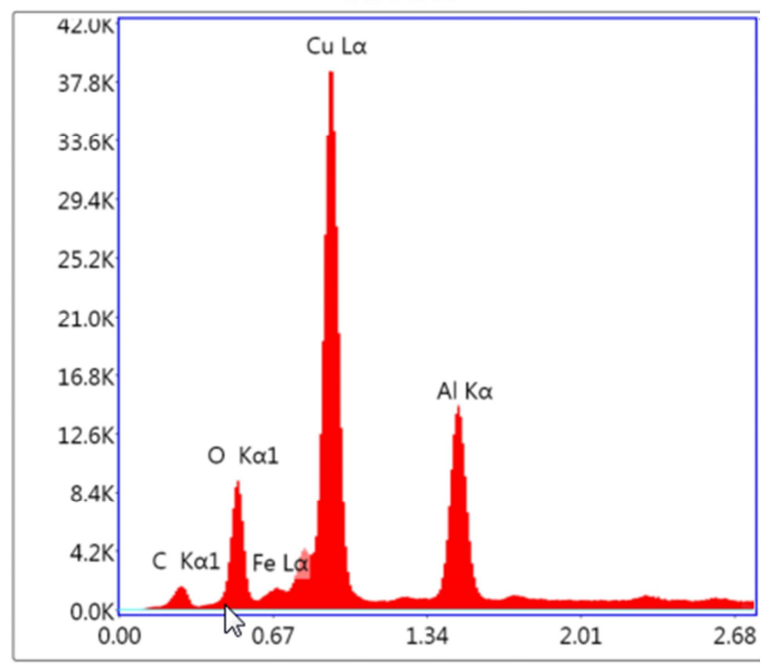

\begin{tabular}{lll}
\hline Elemento & $\%$ (wt) & \% (at) \\
\hline C & 7,78 & 21,90 \\
O & 9,99 & 21,11 \\
Fe & 0,32 & 0,19 \\
Cu & 63,58 & 33,83 \\
Al & 18,33 & 22,97 \\
\hline
\end{tabular}

Figura 39. Análise por espectroscopia de raio-X por dispersão de energia em precipitados incoerentes da liga AA7050-T7451

Como descrito anteriormente, no item 2.1.3, a presença da partícula constituinte $\mathrm{Cu}$ é benéfica, porque melhora as propriedades mecânicas através do intermetálico $\mathrm{Al}_{2} \mathrm{CuMg}$.

A figura 40 mostra uma micrografia realizada por um microscópio eletrônico de transmissão de varredura (METV), na qual podem ser observados, em escala nanométrica, precipitados finos e homogêneos dentro dos grãos, e precipitados grosseiros ao longo dos contornos dos grãos. 

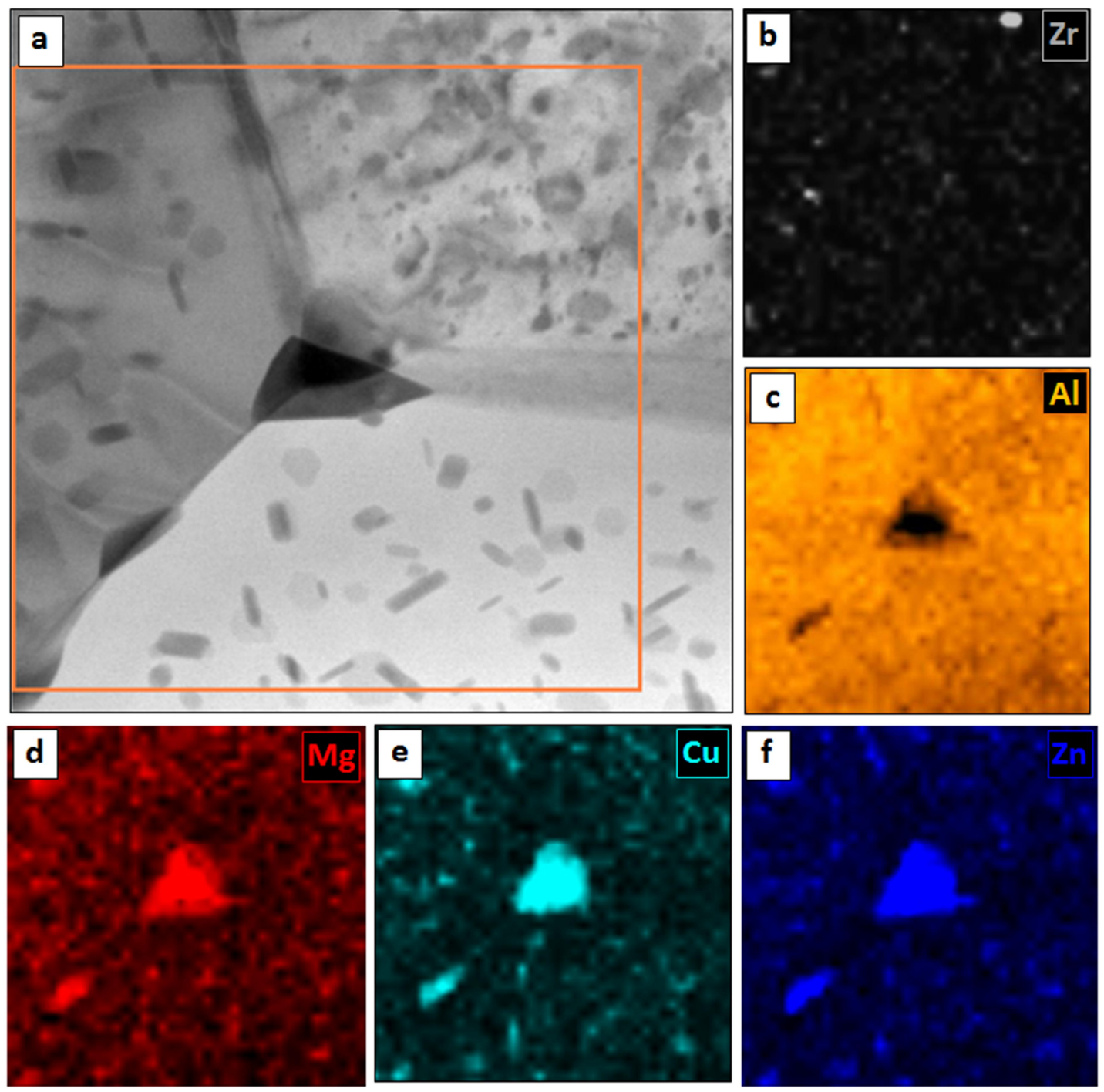

Figura 40.( a) Micrografia de microscopia eletrônica de transmissão por varredura (METV) mostrando, em sinal de campo claro, precipitados finos dentro dos grãos, e precipitados grossos nos contornos de grãos, e os respectivos mapeamentos elementares de raios-X através de EDX: (b) Zr, (c) Al, (d) Mg, (c) Cu, (d) Zn. 


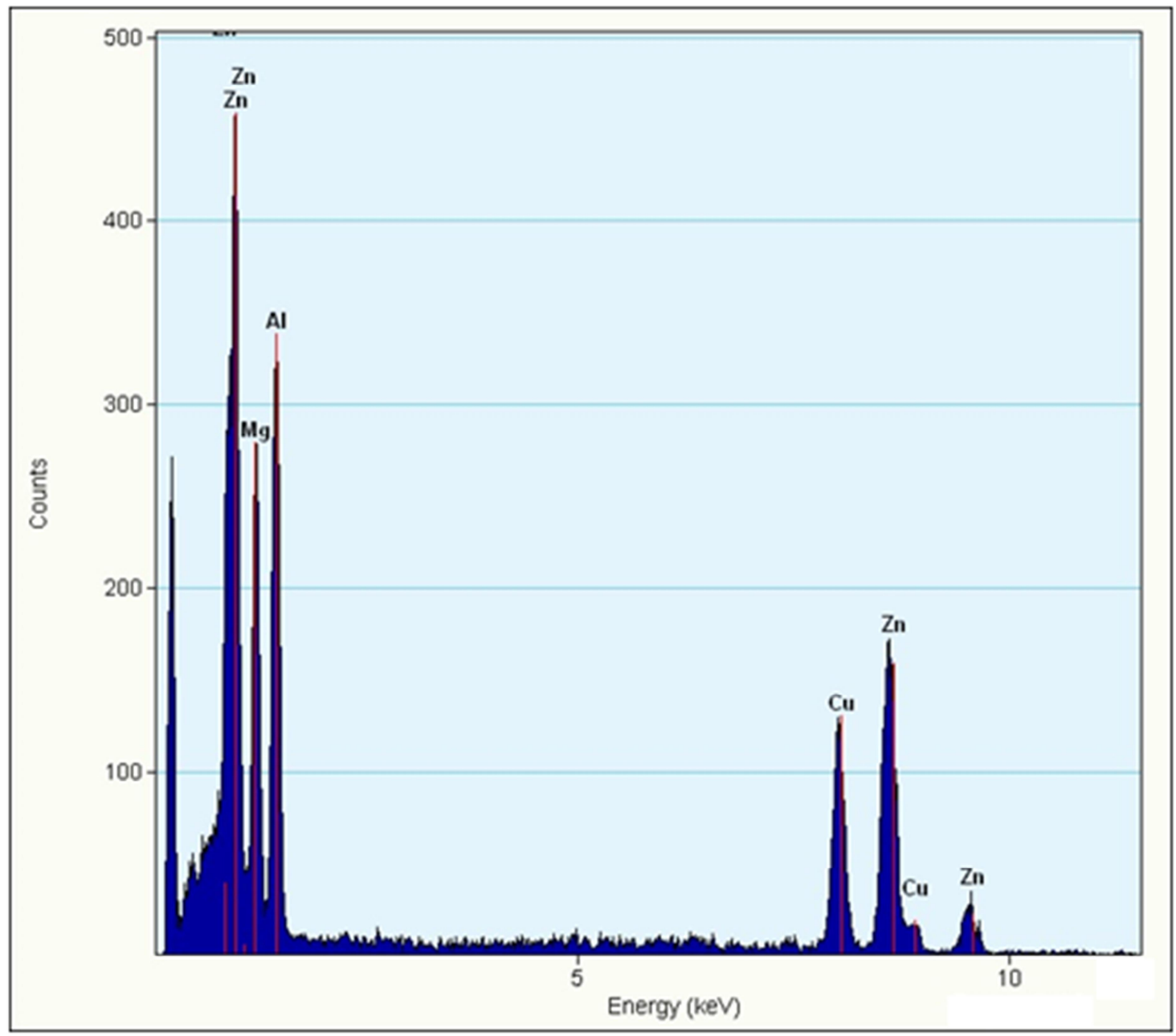

Figura 41. Análise de espectroscopia de raio-X por dispersão de energia (EDX) do precipitado no contorno de grão.

A figura 41 é uma análise realizada por espectroscopia por dispersão de energia (EDS) para saber a porcentagem de cada elemento que compõe o precipitado no contorno de grão em relação à figura 40. Como pode ser observado, detectou-se uma grande porcentagem de $\mathrm{Zn}$ e $\mathrm{Mg}$ no contorno de grão,

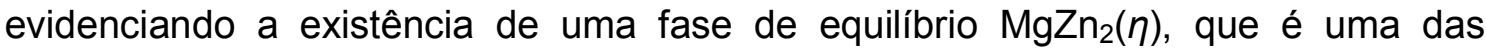
principais fases para melhorar as propriedades mecânicas. 
$\mathrm{Na}$ Figura 42 são mostrados os precipitados nanométricos alongados da fase $\eta$ ' e coexistem na microestrutura também as zonas GP. A fase $\eta^{\prime}$ possui estrutura cristalina hexagonal (hcp), com parâmetros de rede $a=0.496 \mathrm{~nm}$, e $c=1.403 \mathrm{~nm}$.
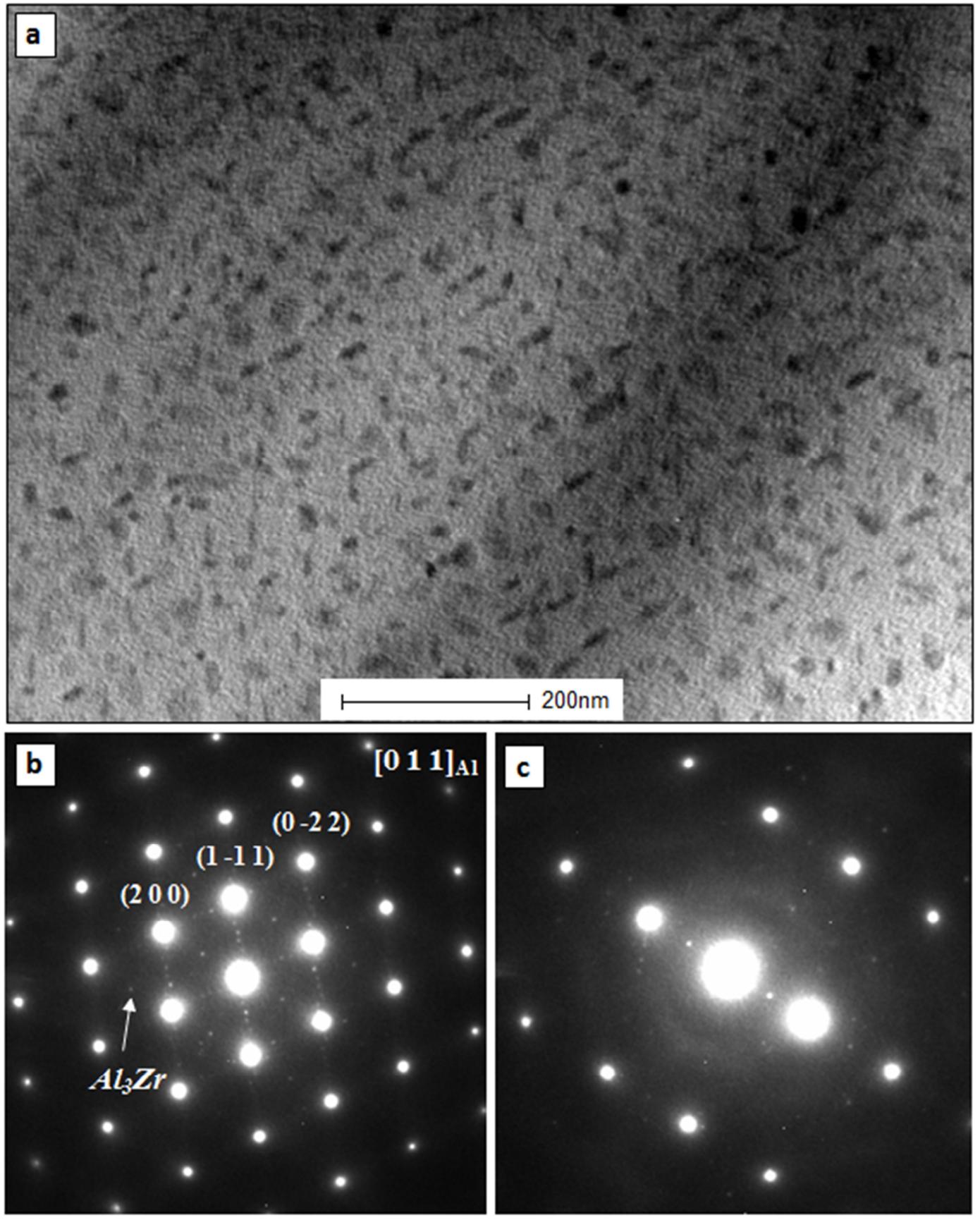

Figura 42. Micrografia de MET (microscopia eletrônica de transmissão) (a) imagem de campo claro (CC) mostrando precipitados nanoméricos e (b) difração de elétrons de área selecionada (DEAS) na orientação [011] e (c) DEAS em eixo de zona qualquer, mostrando spots da matriz de Al e dos precipitados. 
Os precipitados nanométricos citados na figura 42 estão em torno de $\sim 10 \mathrm{~nm}$, distribuídos uniformemente na matriz, na imagem do MET, na orientação <011> em campo claro (Bright field - BF). Estes precipitados muito finos são as chamadas zonas GP, os quais são formados pela nucleação homogênea na solução sólida supersaturada (Kai et al, 2009).

Como pode ser observado também na figura 42, modo MET, há precipitados nanométricos esféricos da fase $\mathrm{Al}_{3} \mathrm{Zr}$, conhecidos como dispersoides (com estrutura cristalina de célula unitária cúbica) dispersos na matriz de Al-cfc em imagens de campo claro (CC). Os dispersoides inibem a recristalização, melhorando a tenacidade do material, como descrito no item 2.1.4.

A ocorrência destes precipitados de $\mathrm{Al}_{3} \mathrm{Zr}$ pode ser confirmada através da análise da figura 40 e, por meio da microscopia eletrônica de transmissão por varredura (METV), em sinal de campo claro e respectivos mapeamentos elementares realizados pela espectroscopia por dispersão de energia (EDS): (b) Zr, (c) Al, (d) Mg, (c) Cu, (d) Zn, mostrando a composição de precipitados nos contornos do grão (maiores) e no interior do grão (menores) na escala nanométrica.

$\mathrm{Na}$ imagem de microscopia eletrônica de transmissão de alta resolução (METAR), da Fig. 43 a, b, é possível ver precipitados na faixa de $3 \mathrm{~nm}$ que são aglomerados de átomos ("clusters") referentes às zonas GP. As zonas GPI são coerentes com a matriz da fase Al-cfc, com ordenamento interno de átomos de $\mathrm{Zn}$ e $\mathrm{Al} / \mathrm{Mg}$ nos planos [001 $]_{\mathrm{Al}-\mathrm{cfc}}$, e são formadas em uma ampla faixa de temperaturas de tratamentos térmicos de envelhecimento, desde a temperatura ambiente (TA) até $140-150^{\circ} \mathrm{C}$, independentemente da temperatura de têmpera (resfriamento rápido a partir de alta temperatura). Geralmente, ambos os tipos de zonas GP (GPI e GPII) 
podem ser formadas como precursoras para a precipitação das fases metaestáveis $\eta$.

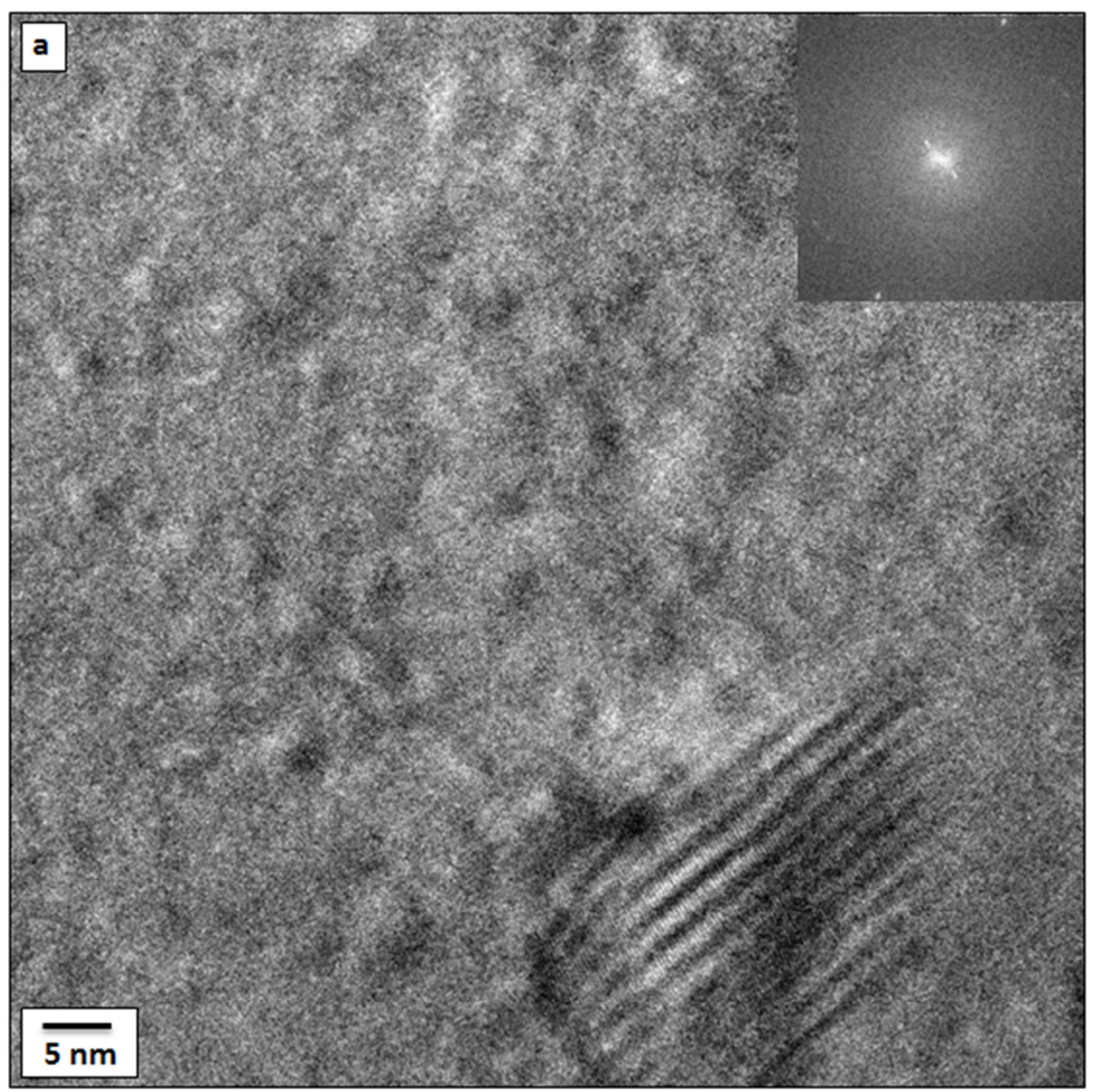




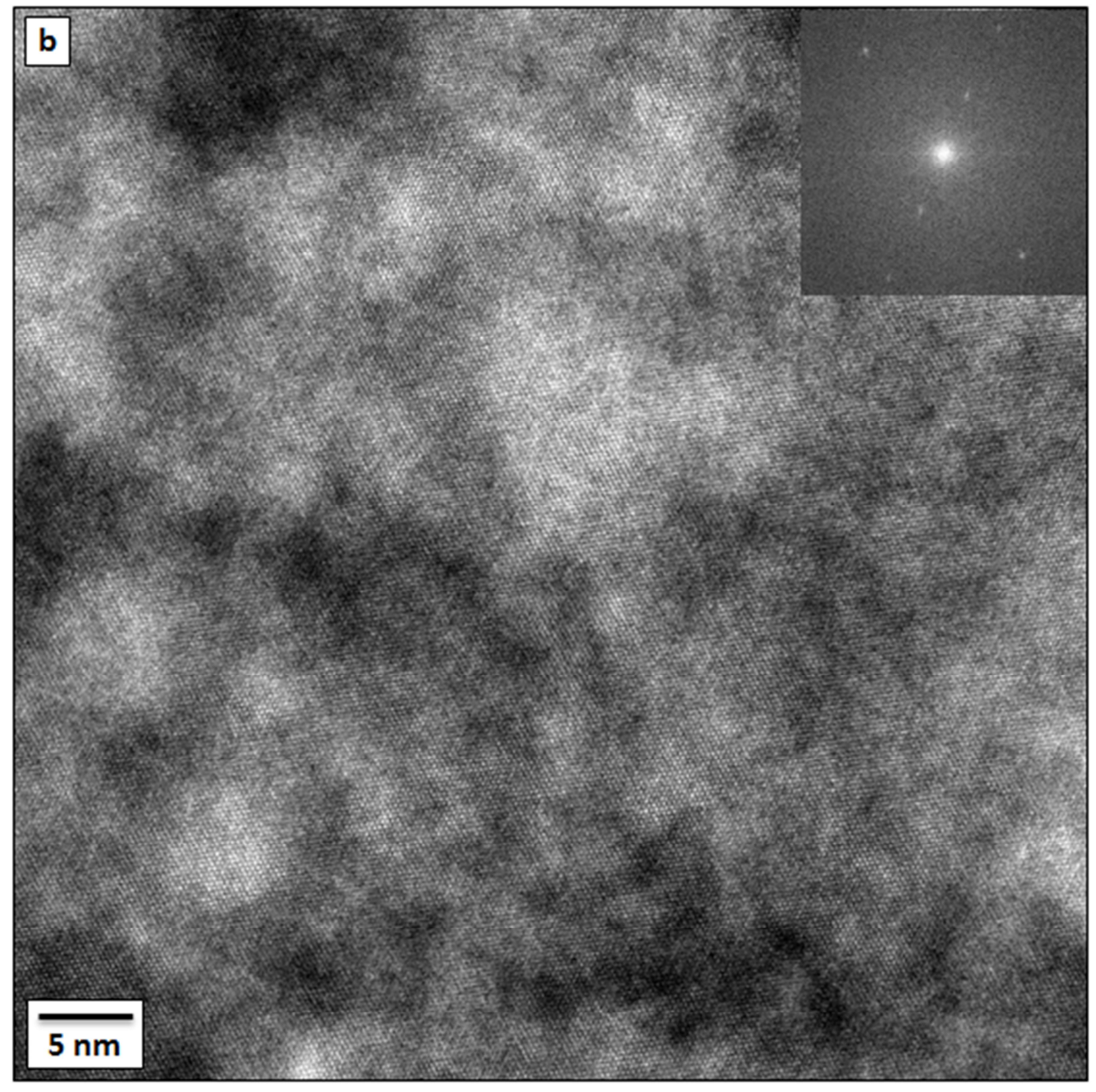

Figura 43. Micrografias de HRTEM (microscopia eletrônica de transmissão de alta resolução) (a) e (b), mostrando, na escala atômica, precipitados nanométricos no interior do grão (intragranulares) e respectivos spots na transformada de Fourier (TF) no canto superior direito de cada imagem. 


\subsubsection{Liga AA 2050-T84}

A figura 44 apresenta uma micrografia da liga AA2050-T84 com grãos bastante alongados e uma forte texturização no sentido da laminação, muito acentuada. Essa forte texturização é devido à deformação também causada pelo zicornio, conforme relatado por Prasad (2014).

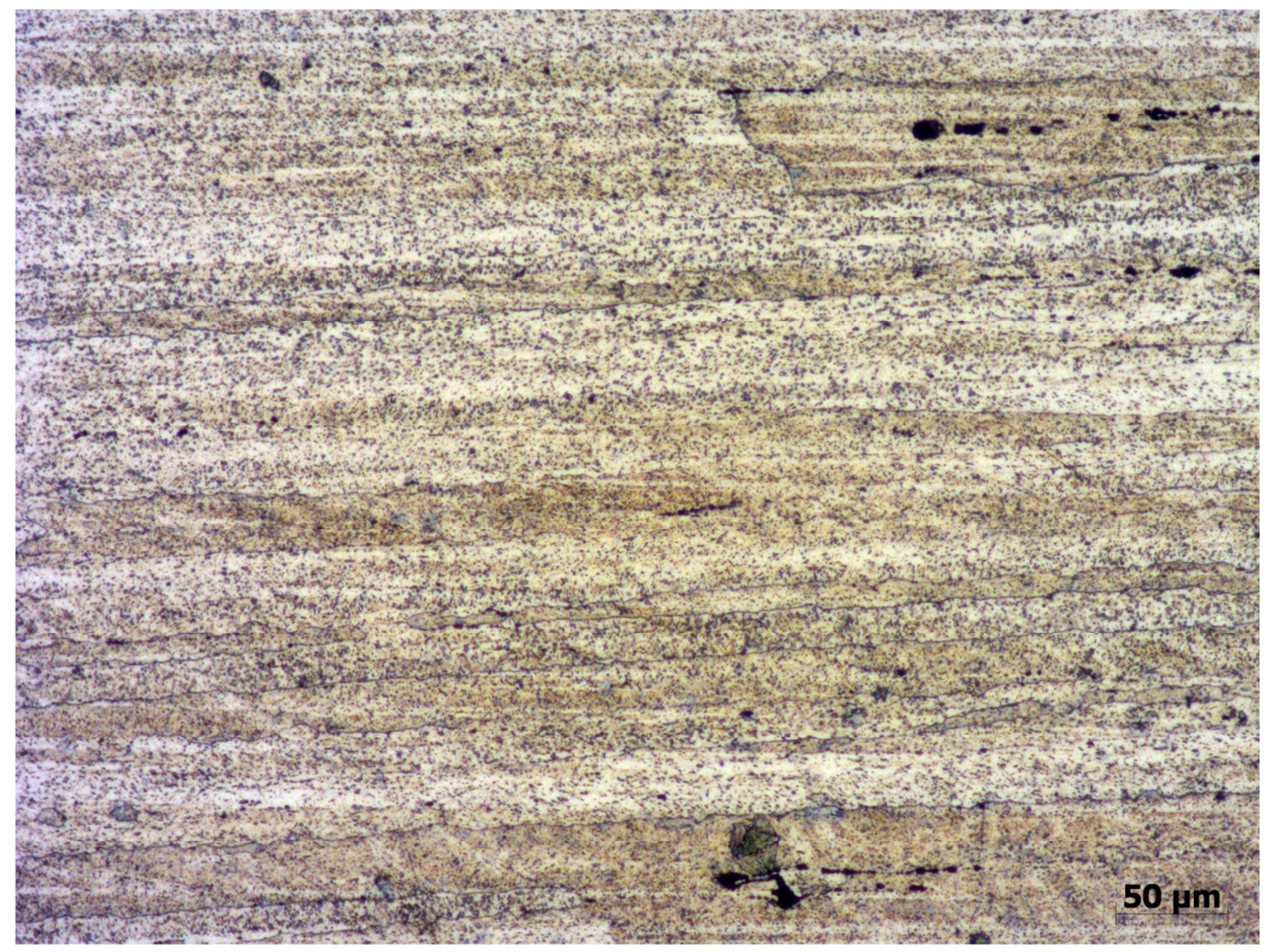

Figura 44. Micrografia ótica mostrando a microestrutura da liga AA2050-T7451

A figura 45 apresenta uma microestrutura da liga AA2050-T84, em temperatura ambiente, que consiste de uma matriz a-Al. Assim como na microestrutura da liga AA7050-T7451, apresentada na figura 38, grãos alongados e precipitados estão alinhados na direção de laminação, observados através de um microscópio eletrônico de varredura - MEV. 

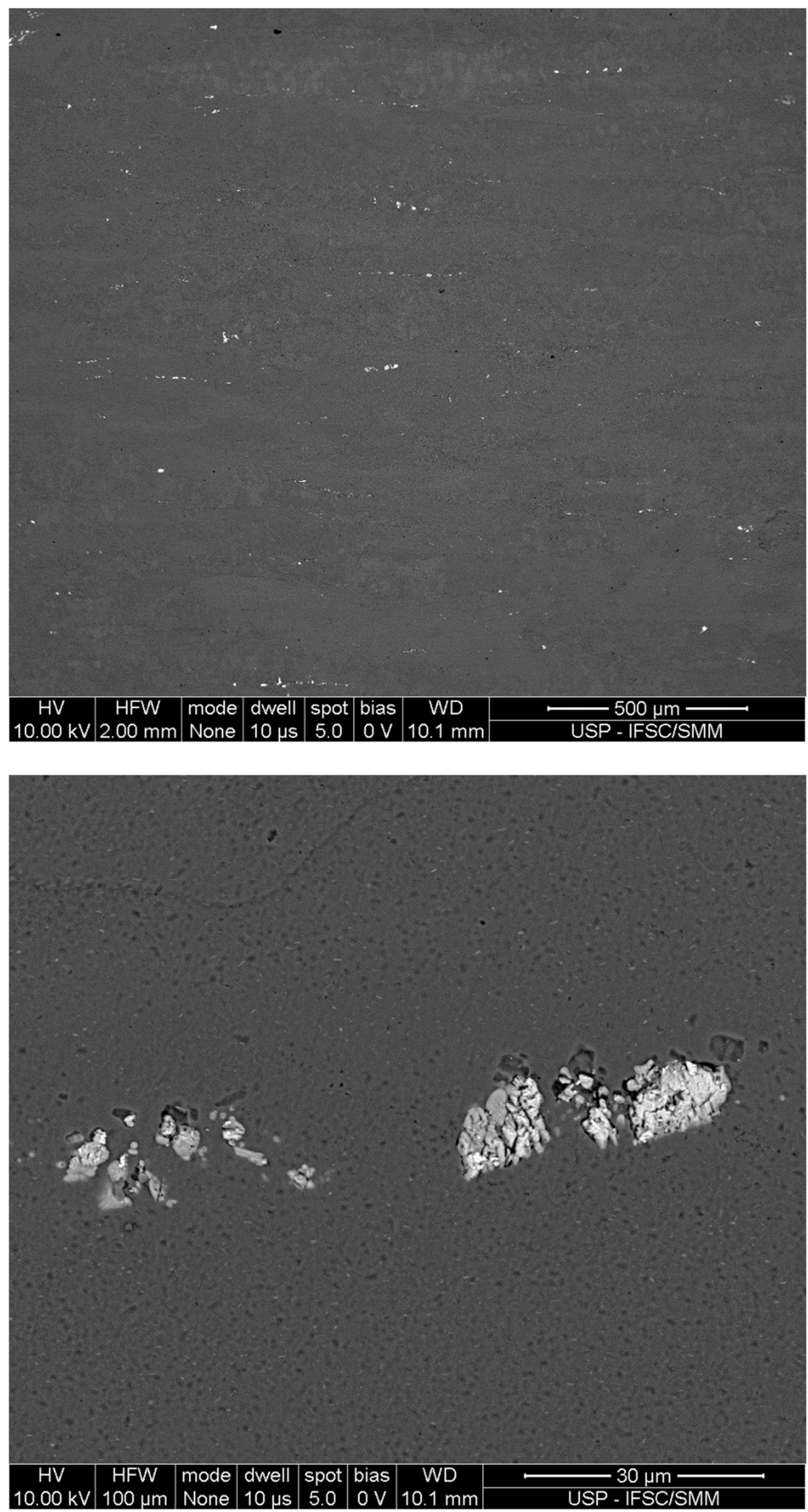

Figura 45. Micrografia dos grãos e dos precipitados na direção longitudinal da liga AA2050T84 
A figura 46 apresenta uma micrografia da superfície analisada, por meio da técnica de espectroscopia de raio-X por dispersão de energia, em duas áreas selecionadas, apresentando partículas de segunda fase alinhadas na direção de laminação.

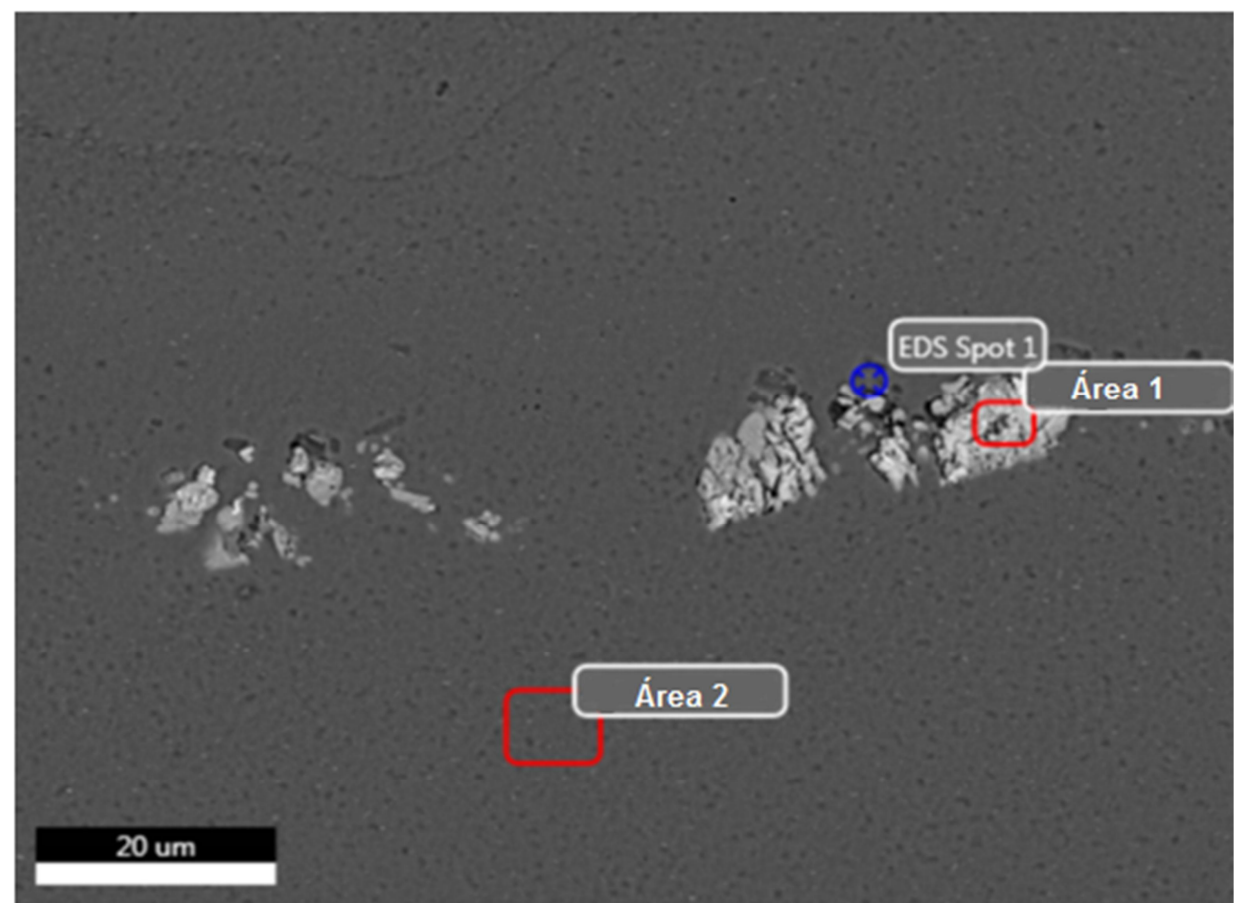

\section{Área 1}

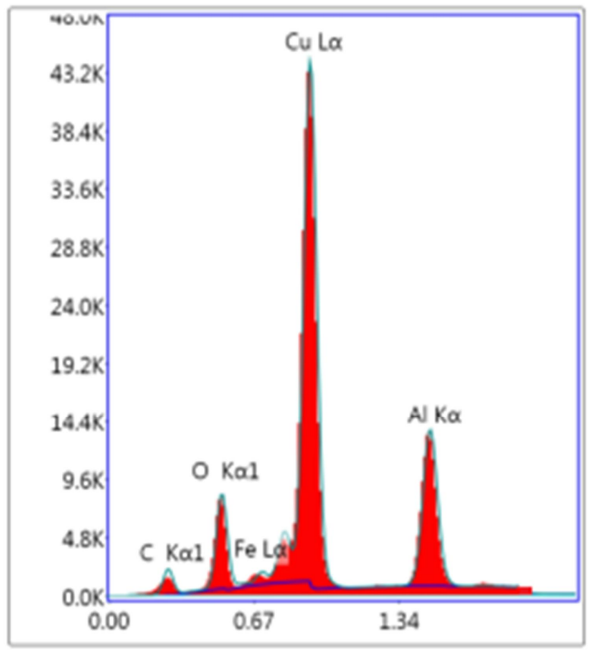

\begin{tabular}{ccc}
\hline Elemento & $\%$ (wt) & $\%$ (at) \\
\hline $\mathbf{C}$ & 6,56 & 19,08 \\
\hline $\mathbf{O}$ & 8,21 & 18,67 \\
\hline $\mathbf{F e}$ & 0,59 & 0,39 \\
\hline $\mathbf{C u}$ & 68,38 & 39,15 \\
\hline Al & 16,25 & 21,91 \\
\hline
\end{tabular}




\section{EDS Spot 1}

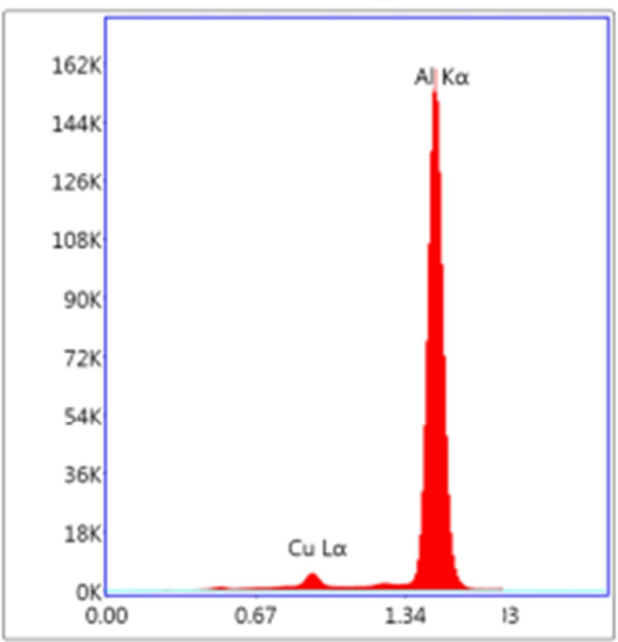

$$
\text { Elemento } \% \text { (wt) } \% \text { (at) }
$$

\begin{tabular}{ccc}
\hline Cu & 2,42 & 1,04 \\
Al & 97,58 & 96,96
\end{tabular}

Área 2

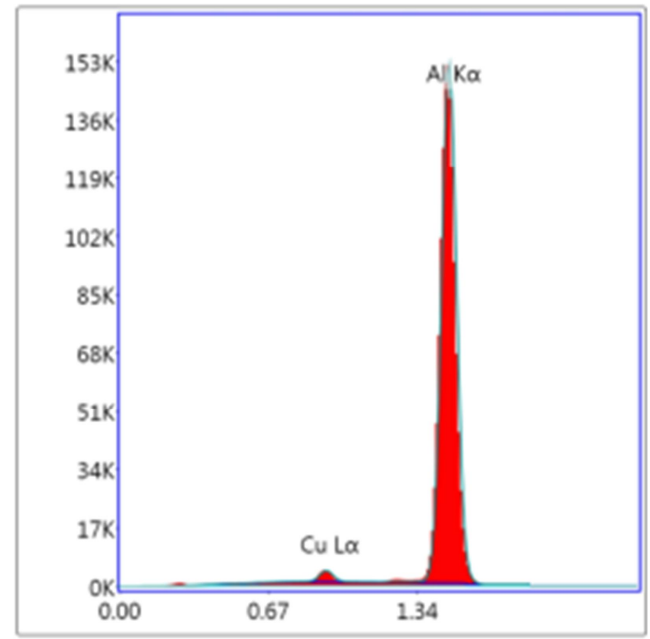

\begin{tabular}{ccc}
\hline Elemento & $\%$ (wt) & \% (at) \\
\hline Cu & 2,64 & 1,14 \\
Al & 97,36 & 98,86 \\
\hline
\end{tabular}

Figura 46. Análise por espectroscopia de raio-X por dispersão de energia em precipitados incoerentes da liga AA7050-T7451 
Como pode ser observado na figura 46 , através dos gráficos e porcentagem dos elementos ligantes, gerados pela análise por espectroscopia de raio-X por dispersão de energia, o cobre se destaca como elemento ligante majoritário. O cobre aumenta a resistência por meio das fases $S^{\prime}\left(\mathrm{Al}_{2} \mathrm{CuMg}\right),\left(\mathrm{Al} \mathrm{I}_{2} \mathrm{CuLi}\right)$ e $\left(\mathrm{Al}_{2} \mathrm{Cu}\right)$. E segundo Miller et al (1986), em ligas onde $S^{\prime}\left(\mathrm{Al}_{2} \mathrm{CuMg}\right)$ é a segunda fase dominante, nenhuma zona livre de precipitado são formadas em contorno de ângulo baixo.

A figura 47a apresenta uma micrografia do microscópio eletrônico de transmissão (MET), mostrando os contornos dos grãos. E a figura 47b apresenta uma análise de espectroscopia de raio-X por dispersão de energia (EDX), dando conta dos elementos majoritários que compõem a liga metálica de Al 2050, à exceção do Li, que não pode ser detectado.

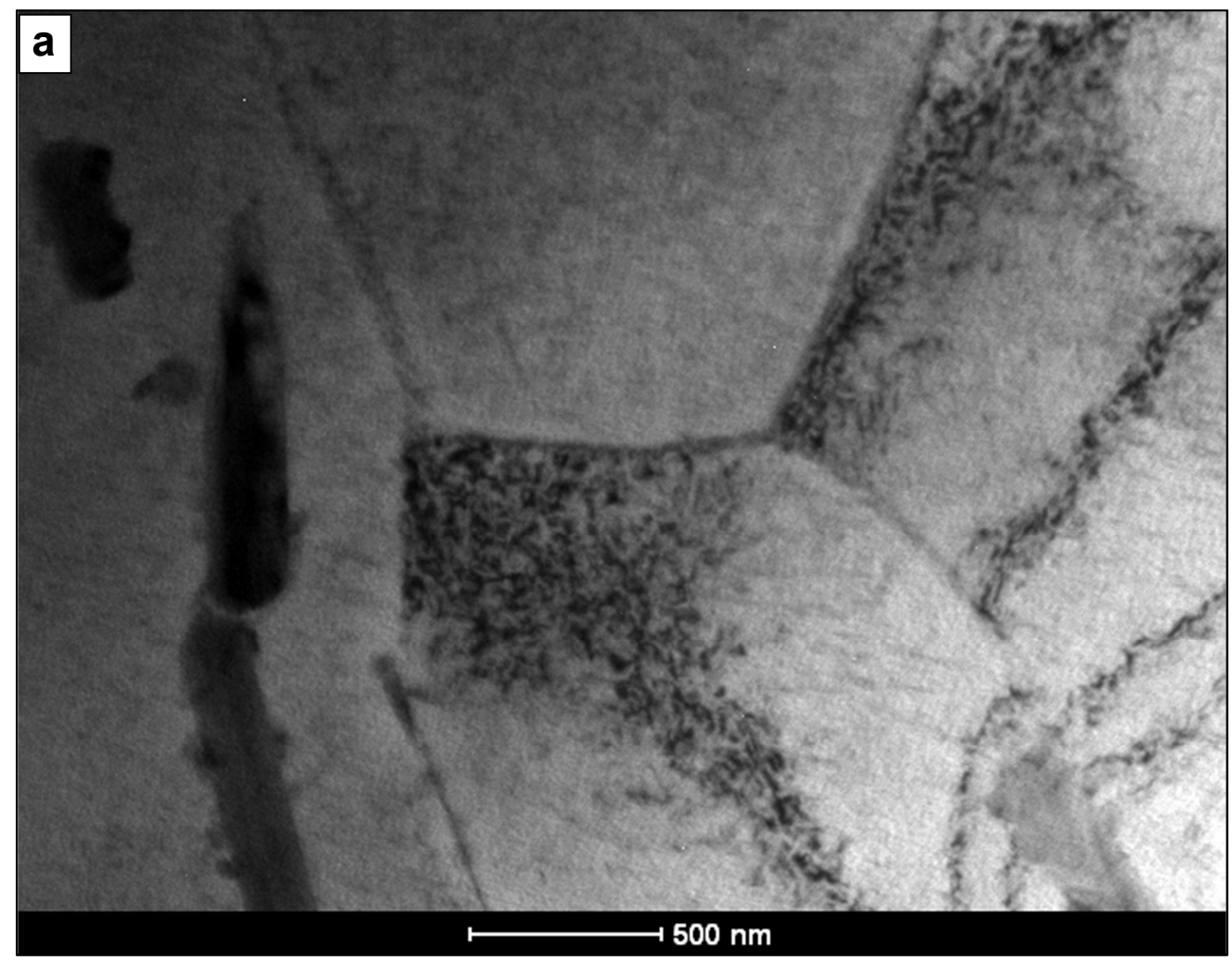




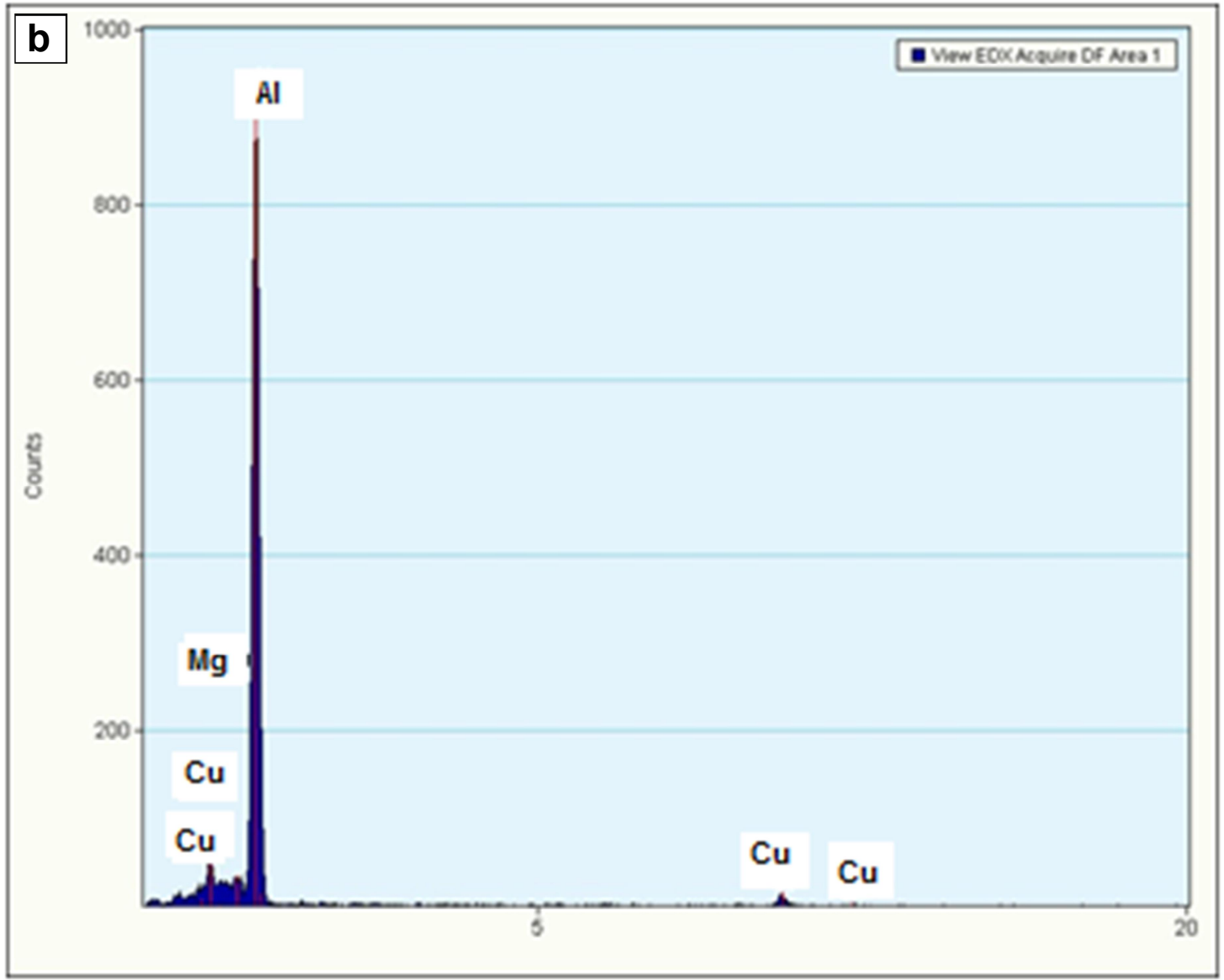

Figura 47. Micrografia de MET (microscopia eletrônica de transmissão) (a) em campo claro (CC) e (b) análise de EDX geral, mostrando elementos majoritários que compõem a liga metálica de Al AA2050-T84 (exceto o Li que não pode ser detectado).

A figura $47 \mathrm{~b}$ apresenta o $\mathrm{Cu}$ e $\mathrm{Mg}$ como os principais elementos ligantes majoritários. O acréscimo de $\mathrm{Mg}$ e $\mathrm{Cu}$ resulta no precipitado intermetálico S'( $\left.\mathrm{Al}{ }_{2} \mathrm{CuMg}\right),\left(\mathrm{Al}{ }_{2} \mathrm{CuLi}\right)$, que melhora a resistência mecânica e minimiza a formação da zona livre de precipitados (Jata et al, 1986). 

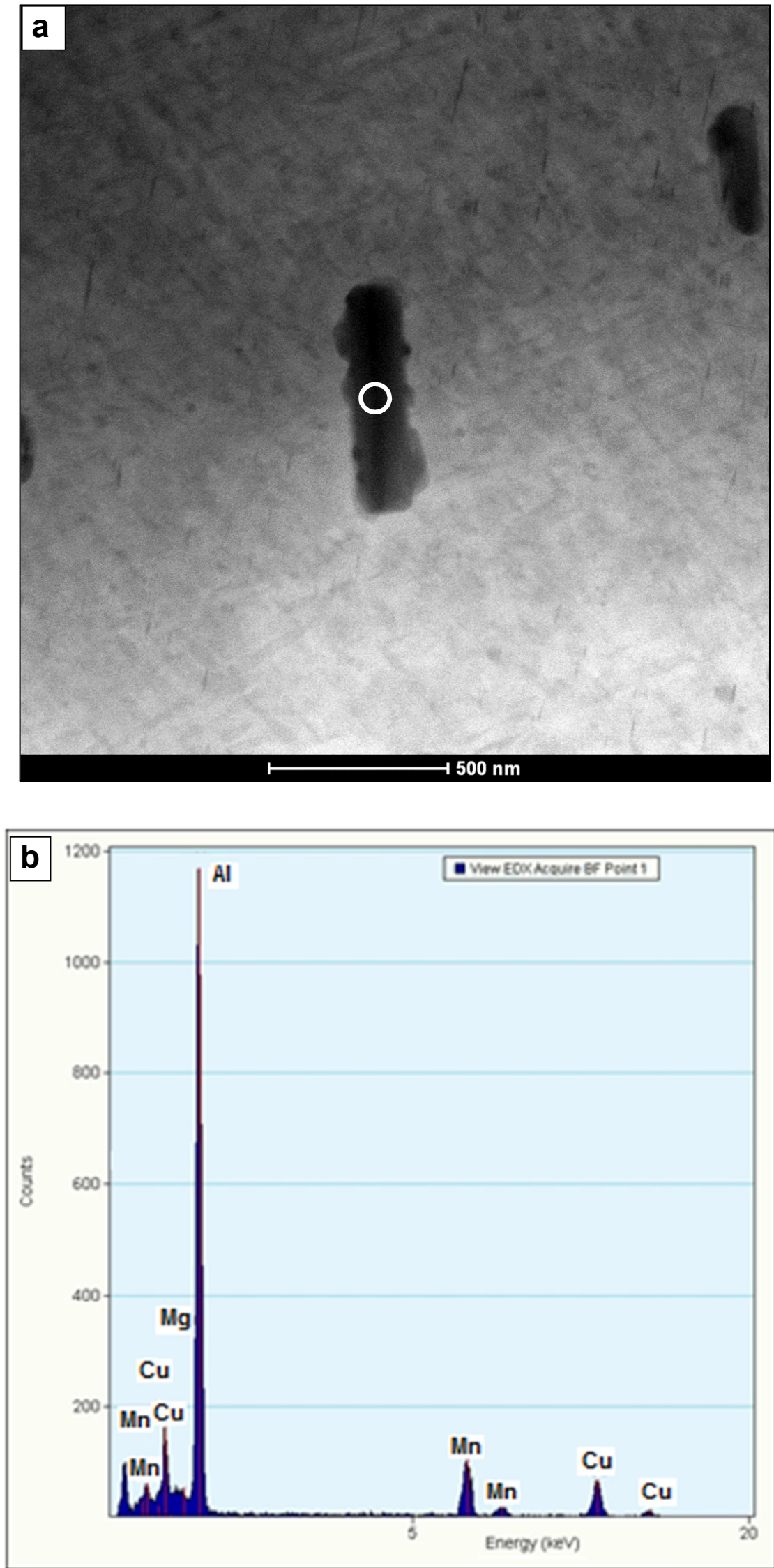

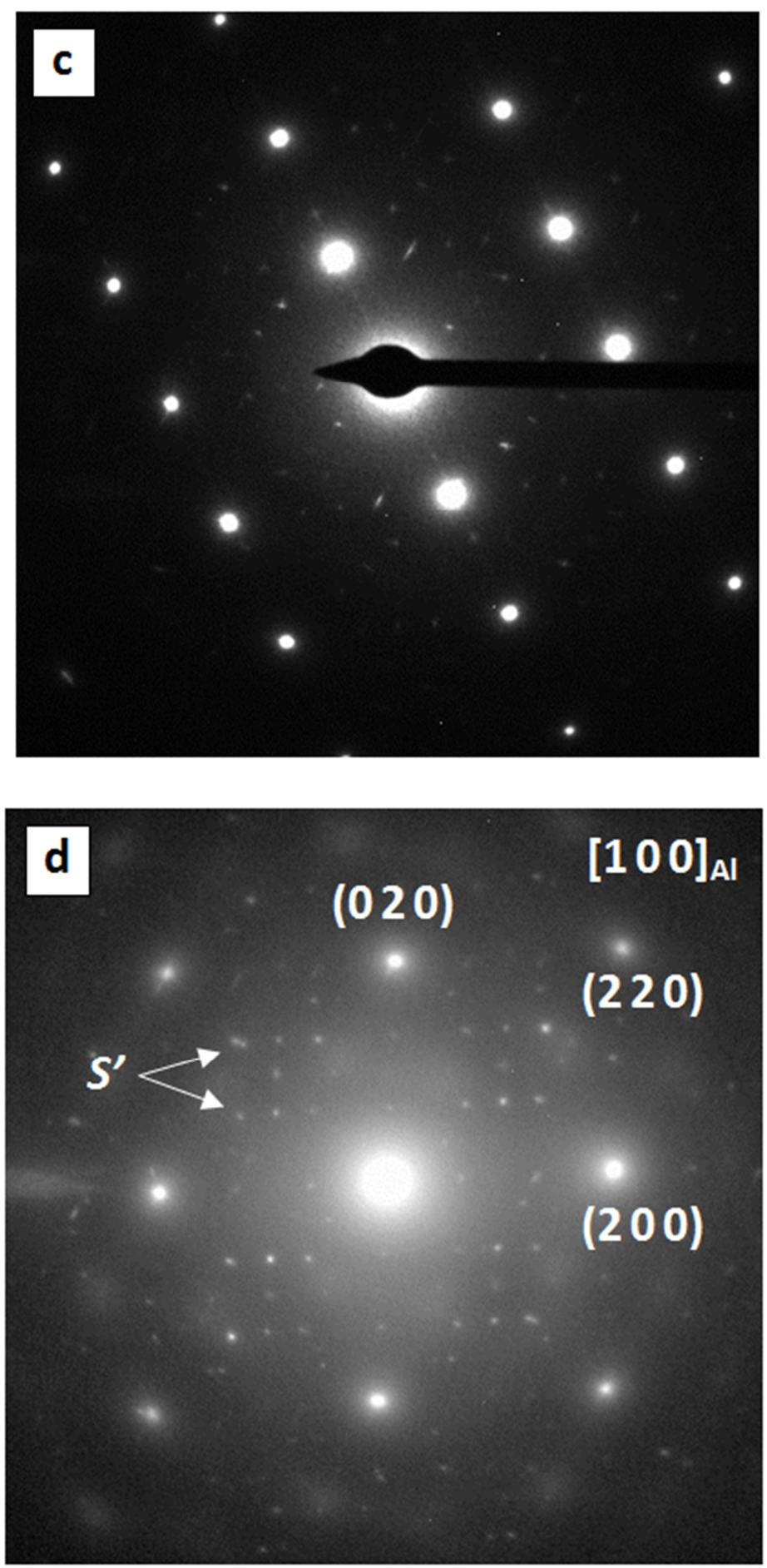

Figura 48. Micrografia de MET (microscopia eletrônica de transmissão) (a) em campo claro (BF) e respectiva (b) análise de EDX da região circular do precipitado com formato retangular. Padrões de difração de elétrons de área selecionada (DEAS) no eixo de zona (c) da matriz [Al-fcc] e (d) $\left[\begin{array}{lll}1 & 0 & 0\end{array}\right]_{\mathrm{Al}-\mathrm{fcc}}$ mostrando spots da fase intermetálica $S^{\prime}$. 
Conforme mostrado na figura 47, o Cu e Mg são os principais elementos ligantes, o que resulta no precipitado intermetálico $S^{\prime}\left(\mathrm{Al}_{2} \mathrm{CuMg}\right)$. Isso pode ser comprovado nas figuras $48 \mathrm{a}$ e b onde um precipitado S', identificado com um círculo branco, em nanoescala, dentro de um grão e sua respectiva análise de espectroscopia de raio-X por dispersão de energia (EDX), mostrando os elementos majoritários que compõem o mesmo, exceto o Li, que não pode ser detectado. Para confirmar a presença da fase S' foram realizados difração de elétrons da área selecionada na matriz [Al-fcc] na orientação [100] $]_{A l l}$, mostrando os spots da fase intermetálica S', conforme figuras 48c e 48d.

A presença do precipitado S' produz barreiras que restringem os movimentos de discordâncias que promove uma deformação mais homogênea e aumenta a resistência da liga.

A figura 49 mostra micrografia realizada no microscópio eletrônico de transmissão por varredura (a) em sinal de campo escuro (DF - Dark Field) e (b) em sinal de campo claro (BF - Bright field). Como pode ser observado, há uma zona livre de precipitados no contorno de grão e precipitados intragranulares em escala nanométrica.

Segundo Deng (2014) e Radmilovic et al (1988), a zona livre de precipitados está relacionada com a exclusão de átomos ao redor do contorno de grãos. Isso ocorre devido à presença do $\mathrm{Li}$, que reduz o número de vacâncias móveis, dificultando a formação de precipitados nos contornos de grãos (Deng, 2014).

As propriedades de fratura podem ser afetadas pela presença da zona livre de precipitados Devido à ductilidade, podem ocorrer deformações localizadas que, por sua vez, ocasionarão deslocamentos que podem acumular nos contorno de grãos, resultando numa concentração de tensão que poderá nuclear uma trinca. 
Com relação aos precipitados intragranulares, segundo Jun-zhou (2010), os mesmos oferecem mais resistência ao crescimento da trinca do que a zona livre de precipitados e os precipitados nos contornos de grãos.
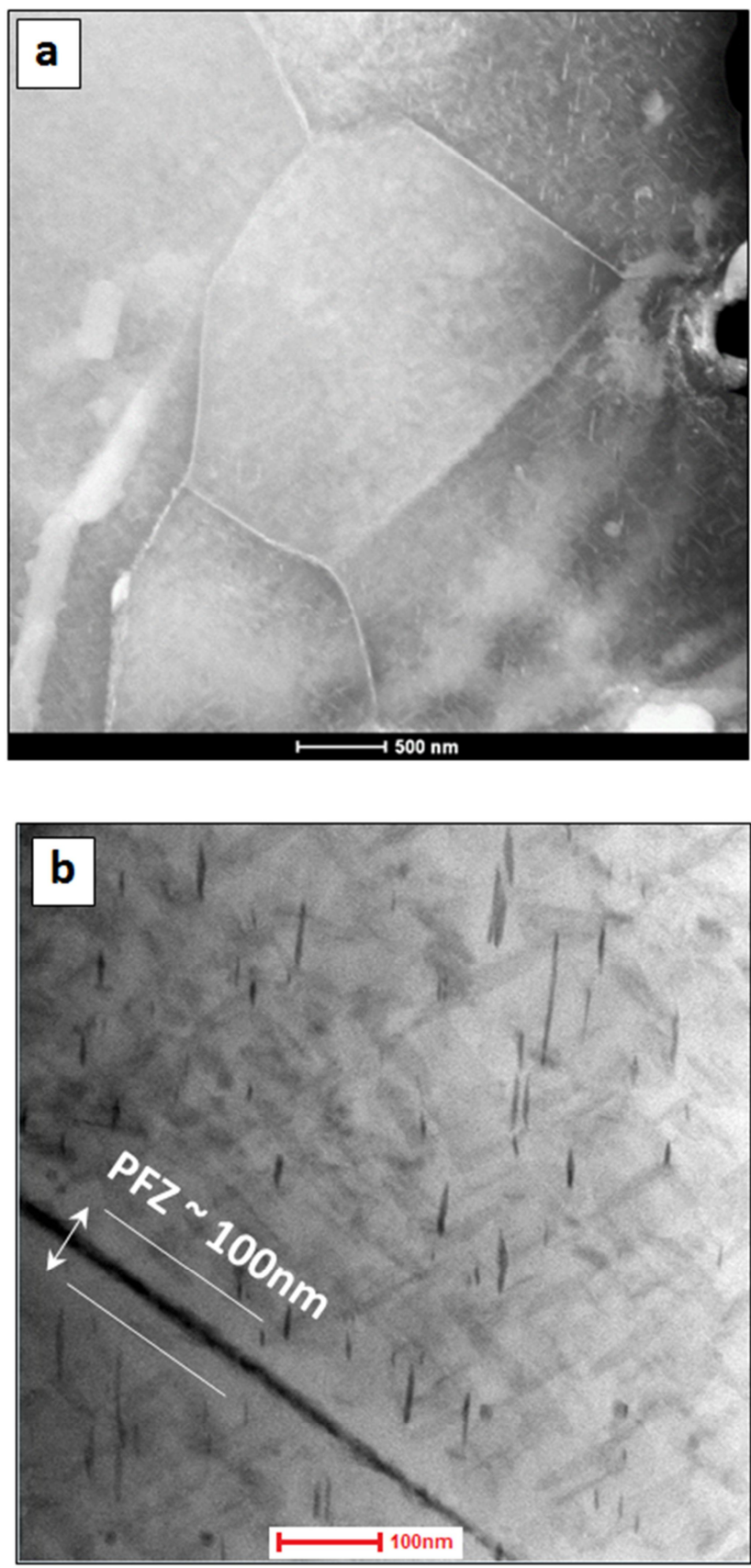

Figura 49. Micrografia de METS (a) em sinal de campo escuro (DF - "dark field") e (b) em sinal de campo claro (BF - "bright field"), mostrando região livre de precipitados (PFZ) no contorno de grão e precipitados intragranulares na escala nanométrica. 
A figura 50 mostra Micrografia de METV (microscópio eletrônico de transmissão por varredura) em sinal de campo claro (DF _ "dark field") e respectivos mapeamentos elementares de raios-X através de EDX, na qual se mostra a composição dos precipitados nos contornos de grãos (maiores) e no interior do grão (menores) na escala nanométrica.

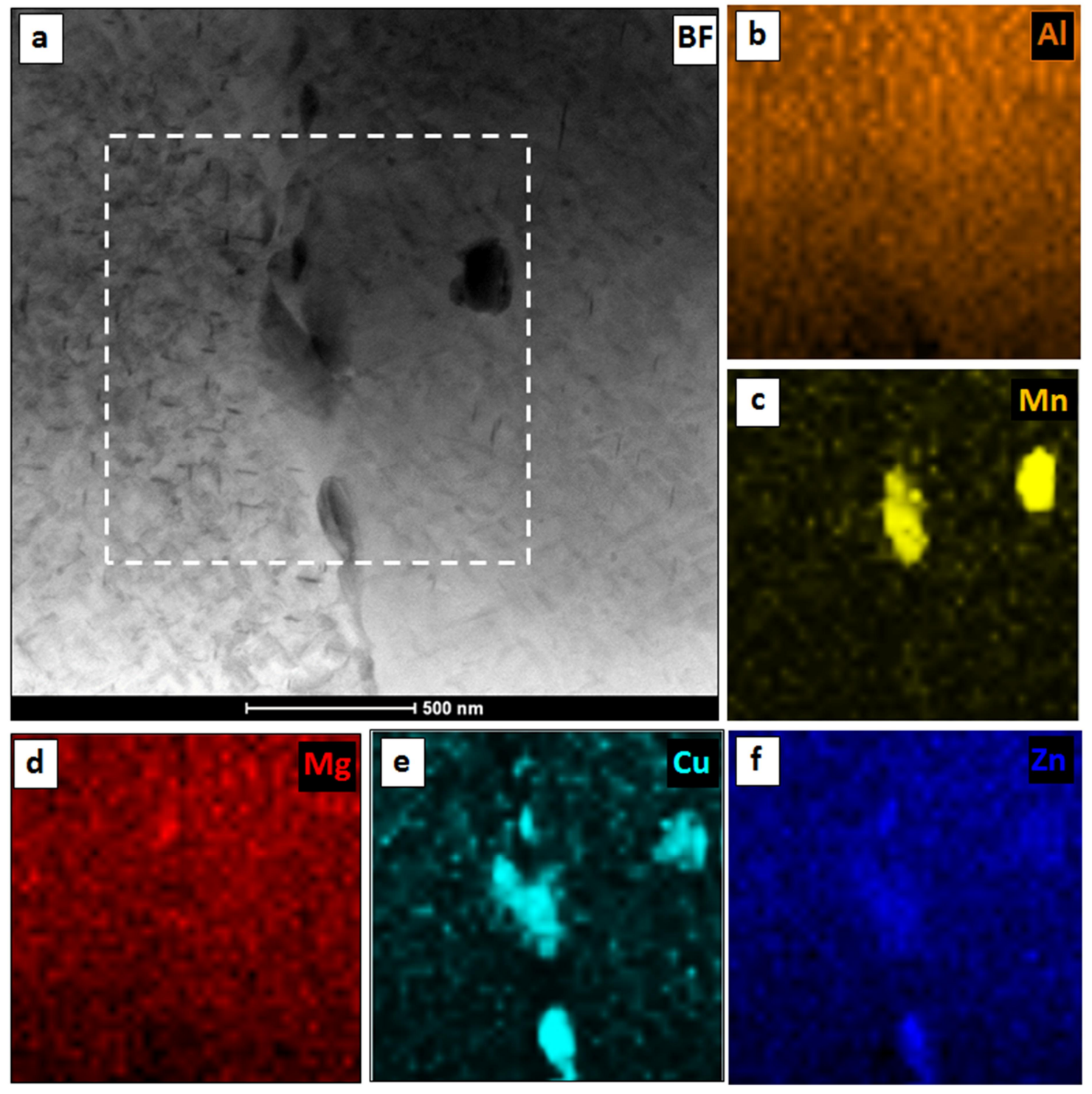

Figura 50. Micrografia de (a) METV (microscopia eletrônica de transmissão por varredura) em sinal de campo claro (BF - "bright field") e respectivos mapeamentos elementares de raios-X através de EDS: (b) Al, (c) Mn, (d) Mg, (c) Cu, (d) Zn, mostrando a composição de precipitados nos contornos de grão (maiores) e no interior do grão (menores) na escala nanométrica. 
A existência do precipitado intermetálico S' e de alguns dispersoides, como $\mathrm{Al}_{20} \mathrm{Cu}_{2} \mathrm{Mn}_{3}, \mathrm{Al}_{12} \mathrm{Mg}_{2} \mathrm{Cr}$, podem ser comprovados na figura 50, que realça $\mathrm{Mg}, \mathrm{Cu}, \mathrm{Zn}$ e Mn. 


\subsection{Ensaio de tração}

As tabelas 12 a 15 apresentam os resultados do limite de resistência à tração, limite de escoamento, módulo de Young, percentual de alongamento e a redução de área, determinados segundo a norma ASTM E8-13 para as duas ligas estudadas, conforme seguem.

Tabela 12. Resultados dos ensaios de tração da liga AA7050-T7451 em temperatura ambiente $\left(23^{\circ} \mathrm{C}\right)$.

\begin{tabular}{|c|c|c|c|c|c|}
\hline CP's & $\begin{array}{c}\sigma_{\mathrm{r}} \\
(\mathrm{MPa})\end{array}$ & $\begin{array}{c}\sigma_{0,2} \\
(\mathrm{MPa})\end{array}$ & $\begin{array}{c}E \\
(\mathrm{GPa})\end{array}$ & RA\% & $\% A L$ \\
\hline 1 & 529,7 & 473 & 67 & 38 & 11,1 \\
\hline 2 & 52,9 & 475,1 & 68 & 31,79 & 11,9 \\
\hline 3 & 528,4 & 474,5 & 67 & 35,86 & 11,6 \\
\hline 4 & 552,6 & 464,7 & 52 & 35,35 & 11,8 \\
\hline 5 & 527,6 & 474,2 & 68 & 37,49 & 12,4 \\
\hline Média & 533,6 & 472,3 & 64 & 35,10 & 11,8 \\
\hline Desvio Padrão & 9,4 & 3,9 & 6,21 & 2,44 & 0,4 \\
\hline
\end{tabular}


Tabela 13. Resultados dos ensaios de tração da liga AA7050-T7451 em temperatura

\begin{tabular}{|c|c|c|c|c|c|}
\hline CP's & $\begin{array}{c}\sigma_{\mathrm{r}} \\
(\mathrm{MPa})\end{array}$ & $\begin{array}{c}\sigma_{0,2} \\
(\mathrm{MPa})\end{array}$ & $\begin{array}{c}\mathrm{E} \\
(\mathrm{GPa})\end{array}$ & RA $\%$ & $\% A L$ \\
\hline 1 & 597,1 & 532,9 & 73,1 & 27,8 & 14 \\
\hline 2 & 578,1 & 515,2 & 66,2 & 36,5 & 12,7 \\
\hline 3 & 593 & 525 & 72,1 & 36,5 & 13,9 \\
\hline 4 & 588,8 & 523,9 & 72,8 & 26,2 & 13 \\
\hline Média & 589 & 524 & 71 & 32 & 13 \\
\hline Desvio Padrão & 8,2 & 7,2 & 3,3 & 5,5 & 0,6 \\
\hline
\end{tabular}

Os resultados dos ensaios de tração para a liga AA7050-T7451 em temperatura ambiente, conforme tabela 12, estão muito similares aos resultados encontrados por Rossino et al (2010). O limite de escoamento e o limite de resistência encontrados por Rossino et al (2010) foram respectivamente 454MPa e $513 \mathrm{MPa}$, numa diferença de $4 \%$ em relação aos resultados deste trabalho. Com relação ao módulo de elasticidade, Rossino et al (2010) encontrou 73GPa, resultando numa diferença de $14 \%$ em relação aos resultados obtidos neste trabalho.

As tabelas 14 e 15 apresentam os resultados dos ensaios de tração da liga AA2050-T84 em temperaturas ambiente e criogênica.

Os resultados obtidos em temperatura ambiente, conforme tabela 15, estão muito similares aos resultados encontrados por Hafley et al (2011), em que o limite 
de escoamento e o limite de resistência e módulo de elasticidade foram respectivamente $468,15 \mathrm{MPa}$ e $515,73 \mathrm{MPa}$ e $75,8 \mathrm{GPa}$, numa diferença de menos de $1 \%$ em relação aos resultados obtidos neste trabalho.

Com relação aos ensaios realizados em temperatura criogênica, conforme tabela 15 , os valores não foram muito similares aos resultados obtidos por Hafley et al (2011), com exceção do limite de escoamento. O limite de escoamento obtido por Hafley foi de 544MPa, o limite de resistência 630MPa, e o módulo de elasticidade foi de $84,8 \mathrm{GPa}$, numa diferença de menos de $1 \%$ para o limite de escoamento, $11 \%$ em relação ao limite de resistência e $16 \%$ em relação ao módulo de elasticidade, neste trabalho. Contudo, cabe ressaltar que, no ensaio em temperatura criogênica realizado por Hafley, a temperatura utilizada foi de $-196^{\circ} \mathrm{C}$, enquanto que neste trabalho foi de $-54^{\circ} \mathrm{C}$.

Tabela 14. Resultados dos ensaios de tração da liga AA2050-T84 em temperatura ambiente

\begin{tabular}{|c|c|c|c|c|c|}
\hline CP's & $\begin{array}{c}\sigma_{\mathrm{r}} \\
(\mathrm{MPa})\end{array}$ & $\begin{array}{c}\sigma_{0,2} \\
(\mathrm{MPa})\end{array}$ & $\begin{array}{c}E \\
(\mathrm{GPa})\end{array}$ & RA\% & $\% A L$ \\
\hline 1 & 501,7 & 461,5 & 76,4 & 35,2 & 9 \\
\hline 2 & 520,4 & 480,4 & 75 & 30,3 & 12,9 \\
\hline 3 & 520,8 & 483,5 & 75 & 31,9 & 10,5 \\
\hline 4 & 504,2 & 466,9 & 73,8 & 36 & 13,2 \\
\hline 5 & 508,2 & 469,9 & 73,2 & 33,6 & 13,3 \\
\hline Média & 511 & 472 & 75 & 33 & 12 \\
\hline Desvio Padrão & 9 & 9,3 & 1,2 & 2,34 & 1,93 \\
\hline
\end{tabular}


Tabela 15. Resultados dos ensaios de tração da liga AA2050-T84 em temperatura criogênica

\begin{tabular}{|c|c|c|c|c|c|}
\hline CP's & $\begin{array}{c}\sigma_{\mathrm{LRT}} \\
(\mathrm{MPa})\end{array}$ & $\begin{array}{c}\sigma_{0,2} \\
(\mathrm{MPa})\end{array}$ & $\begin{array}{c}E \\
(\mathrm{GPa})\end{array}$ & RA\% & $\% A L$ \\
\hline 1 & 565 & 529,9 & 73 & 26,8 & 12 \\
\hline 2 & 574,4 & 540,2 & 76,6 & 23,9 & 12,7 \\
\hline 3 & 562,7 & 531,1 & 72,2 & 30,2 & 13,5 \\
\hline 4 & 552,5 & 514,7 & 68,1 & 41,3 & 12,9 \\
\hline 5 & 573,7 & 536,1 & 76,1 & 33,8 & 11,8 \\
\hline Média & 566 & 530 & 73 & 31 & 12 \\
\hline Desvio Padrão & 9 & 9,7 & 3,4 & 6,8 & 0,7 \\
\hline
\end{tabular}

Comparando-se os resultados entre as tabelas 12 e 14, obtidos em temperatura ambiente, observa-se que a liga AA7050-T7451 tem um limite de resistência $\left(\sigma_{\mathrm{r}}\right)$ maior em $4 \%$ em relação ao Limite de resistência $\left(\sigma_{\mathrm{r}}\right)$ da liga AA2050-T84. Mas, com relação ao módulo de elasticidade (E), a liga AA2050-T84 apresenta uma rigidez maior em 17\% em relação à liga AA7050-T7451.

Com relação às comparações entre as tabelas 13 e 15, as diferenças foram bem pequenas, podendo-se dizer que foram muito similares, com limite de resistência $\left(\sigma_{r}\right)$ da liga AA7050-T7451 4\% maior em relação à liga AA2050-T84. O limite de escoamento $\left(\sigma_{0,2}\right)$ e o módulo de elasticidade da liga AA2050-T84 resultou maior em 1 e 2,80\% em relação à liga AA7050-T7451. 


\subsection{Tenacidade à fratura}

Na tabela 16 estão os resultados dos ensaios de tenacidade à fratura para as ligas AA2050-T84, realizados por Maciel (2013), e AA7050-T7451 em temperatura ambiente.

Tabela 16. Resultados dos Ensaios de Tenacidade à fratura em temperatura ambiente $\left(23^{\circ} \mathrm{C}\right)$ entre as Ligas AA7050-T7451 X AA2050-T84

\begin{tabular}{|c|c|c|c|c|}
\hline \multirow[b]{2}{*}{ CP'S } & \multicolumn{2}{|c|}{ AA7050-T7451 } & \multicolumn{2}{|c|}{ AA2050-T84 } \\
\hline & $\begin{array}{l}K_{I C}(\mathrm{~L}-\mathrm{T}) \\
\mathrm{MPam}^{0,5}\end{array}$ & $\begin{array}{l}K_{I C}(\mathrm{~T}-\mathrm{L}) \\
\text { MPam }^{0,5}\end{array}$ & $\begin{array}{l}K_{I C}(\mathrm{~L}-\mathrm{T}) \\
\mathrm{MPam}^{0,5}\end{array}$ & $\begin{array}{l}K_{I C}(\mathrm{~T}-\mathrm{L}) \\
\text { MPam }^{0,5}\end{array}$ \\
\hline 1 & 45 & 36,9 & 40,5 & 34,3 \\
\hline 2 & 45,8 & 40,5 & 40,7 & 32 \\
\hline 3 & 43,4 & 36,6 & 44,4 & 31,2 \\
\hline Média & 44,7 & 38 & 41,9 & 32,5 \\
\hline io Padrão & 1,22 & 2,17 & 2,20 & 1,61 \\
\hline
\end{tabular}

Os resultados obtidos em temperatura ambiente, conforme tabela 16, entre as direções L-T e T-L da liga AA7050-T7451, dão conta de que, na direção L-T, os valores de $K_{I C}$ são $17 \%$ maior do que na direção T-L. Essa diferença entre as direções revela uma anisotropia do material, que está de acordo com os ensaios realizados por Wei et al (2014), segundo os quais, para a direção L-T e T-L, foram encontrados os valores $K_{I C}=30 \mathrm{MPam}^{0,5}$ e $K_{I C}=23.8 \mathrm{MPam}^{0,5}$. Segundo Wei et al (2014), essa diferença está relacionada com as características dos grãos recristalizados. 
Com relação à liga AA2050-T84, seguindo a tabela 16, verifica-se também uma maior tenacidade na direção L-T, em que os valores de $K_{I C}$ são $28 \%$ maior do que na direção T-L. Como ocorre com a liga AA7050-T7451, a liga AA2050-T84 apresenta um material anisotrópico. A anisotropia da liga AA2050-T84 está de acordo com os ensaios realizados por Hafley et al (2011), assim como os valores encontrados nas direções L-T e T-L, com $K_{I C}=42 \mathrm{MPam}^{0,5}$ e $K_{I C}=28 \mathrm{MPam}^{0,5}$. Segundo Zakharov (2003), essa característica anisotrópica da liga Al-Li provavelmente se deve ao fato da estrutura não rescristalizada. Segundo Venkateswara et al (1988), outro possível fator que pode contribuir para uma maior tenacidade da liga AA2050-T84 na direção L-T, em relação à liga T-L, é o fato de que há incidência de delaminações perpendiculares ao plano da trinca. Essas delaminações são responsáveis pelo aumento da tenacidade.

Segundo Domont (2003), outro fator que poderia explicar a anisotropia das ligas em relação à tenacidade à fratura seriam as texturas cristalográfica e morfológica produzidas pelo processo de laminação, associada com a zona livre de precipitado, mais a distribuição espacial das partículas constituintes. Esses fatores dão direção preferencial para propagação de trinca intragranular e uma anisotropia plástica intrínseca do material. Assim, a tenacidade à fratura é anisotrópica dentro da placa.

Comparando os resultados da tabela 16, entre as ligas na direção L-T, constata-se que são similares, com uma pequena vantagem para a liga AA7050T7451, de 6\%. Com relação à direção T-L, a vantagem da liga AA7050-T7451 é maior em 17\%. Essa superioridade da liga AA7050-T7451, com relação à tenacidade à fratura, provavelmente se deve a uma maior quantidade de zircônio, que inibe a recristalização, aumentando a tenacidade 
Tabela 17. Resultados dos Ensaios de Tenacidade à fratura em temperatura criogênica $\left(-54^{\circ} \mathrm{C}\right)$ entre as Ligas AA7050-T7451 e AA2050-T84

\begin{tabular}{|c|c|c|c|c|}
\hline \multirow{3}{*}{ CP'S } & \multicolumn{2}{|c|}{ AA7050-T7451 } & \multicolumn{2}{|c|}{ AA2050-T84 } \\
\hline & $K_{I C}(\mathrm{~L}-\mathrm{T})$ & $\overline{K_{I C}(\mathrm{~T}-\mathrm{L})}$ & $K_{I C}(\mathrm{~L}-\mathrm{T})$ & $K_{I C}(\mathrm{~T}-\mathrm{L})$ \\
\hline & $\mathrm{MPam}^{0,5}$ & $\mathrm{MPam}^{0,5}$ & $\mathrm{MPam}^{0,5}$ & $\mathrm{MPam}^{0,5}$ \\
\hline 1 & 39,84 & 31,37 & 40,6 & 31,9 \\
\hline 2 & 35,23 & 33,37 & 39,4 & 34,2 \\
\hline 3 & 39,28 & 33,94 & - & 33,1 \\
\hline Média & 38,12 & 32,89 & 40 & 33,1 \\
\hline Desvio Padrão & 2,05 & 1,10 & 0,85 & 1,15 \\
\hline
\end{tabular}

Em relação à tabela 17, que apresenta os resultados em temperatura criogênica, comparando as direções L-T e T-L, da liga AA7050-T7451, constata-se que há uma tenacidade à fratura maior em $17 \%$ na direção L-T.

Com relação à liga AA2050-T84, a mesma também apresenta, na direção L-T, um $K_{I C}$ maior em $21 \%$ em relação à direção T-L. Os resultados obtidos em temperatura criogênica para a liga AA2050-T84 estão bastante similares aos resultados encontrados por Hafley et al (2011), nos quais, nas direções L-T e T-L, encontrou-se $K_{I C}=35,68 \mathrm{MPam}^{0,5}$ e $K_{I C}=30,98 \mathrm{MPam}^{0,5}$. Deve-se levar em consideração que a temperatura criogênica, para o ensaio de Hafley et al (2011), foi de $-190^{\circ} \mathrm{C}$, enquanto que, a deste trabalho, foi de $-54^{\circ}$.

Comparando os resultados da tabela 17 , na temperatura criogênica, entre as ligas AA7050-T7451 e AA2050-T84, observa-se que os valores são muito similares, 
com uma leve superioridade da liga AA2050-T84 de 5\%, na direção L-T, e menos de $1 \%$, na direção T-L.

\subsection{Curva $K_{R}$}

A figura 51 apresenta a comparação entre as orientações L-T e T-L, atráves da curva $K_{R}$ versus $\Delta a$. Como pode ser observado, a orientação L-T é mais íngreme, ou seja, ela tem uma maior resistência à propagação da trinca, em relação à orientação T-L.

Observa-se também, no gráfico da figura 51, que a orientação T-L tem uma tendência de comportamento frágil, conforme figura 14.

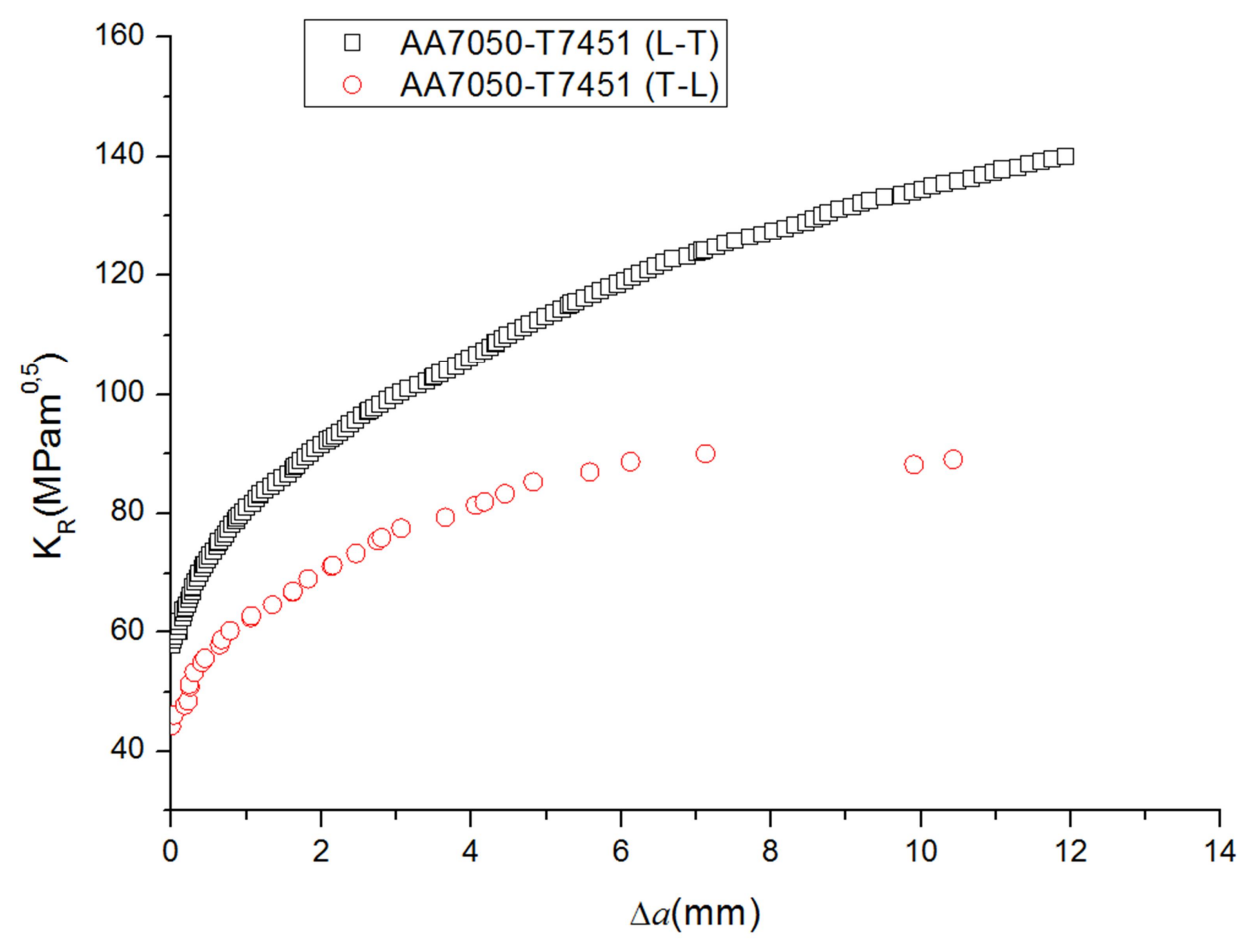

Figura 51. Curva $K_{R}$ versus $\Delta a$ da liga AA7050-T7451 nas direções L-T e T-L. 
Essa superioridade da direção L-T poder ser comprovada através da tabela 16, na qual o fator de intensidade de tensão $K_{I C}=44,7 \mathrm{MPam}^{0,5}$ na direção L-T é maior do que o fator de intensidade de tensão $K_{I C}=38 \mathrm{MPam}^{0,5}$ na direção T-L.

A figura 52, mostra a curva $K_{R}$ versus $\Delta a$ para a liga AA2050-T84, observando-se um comportamento similar ao gráfico da liga AA7050-T7451 da figura 51, onde a direção L-T tem uma maior resistência em relação à direção T-L. Essa diferença pode ser comprovada também através da tabela 16, na qual o fator de intensidade de tensão $K_{I C}=41,9 \mathrm{MPam}^{0,5}$ na direção L-T é maior do que o fator de intensidade de tensão $K_{I C}=32,5 \mathrm{MPam}{ }^{0,5}$ na direção T-L.

.Comparando os gráficos das figuras 51 e 52, observa-se uma diferença mais significativa entre as direções L-T e T-L, para a liga AA2050-T84, em relação à liga AA7050-T7451. Essa diferença pode ser comprovada na tabela 16, em que a diferença entre L-T e T-L, para a liga AA7050-T7451, é de 17,63\% e, em relação à liga AA2050-T84, a diferença é 28,92\%. 


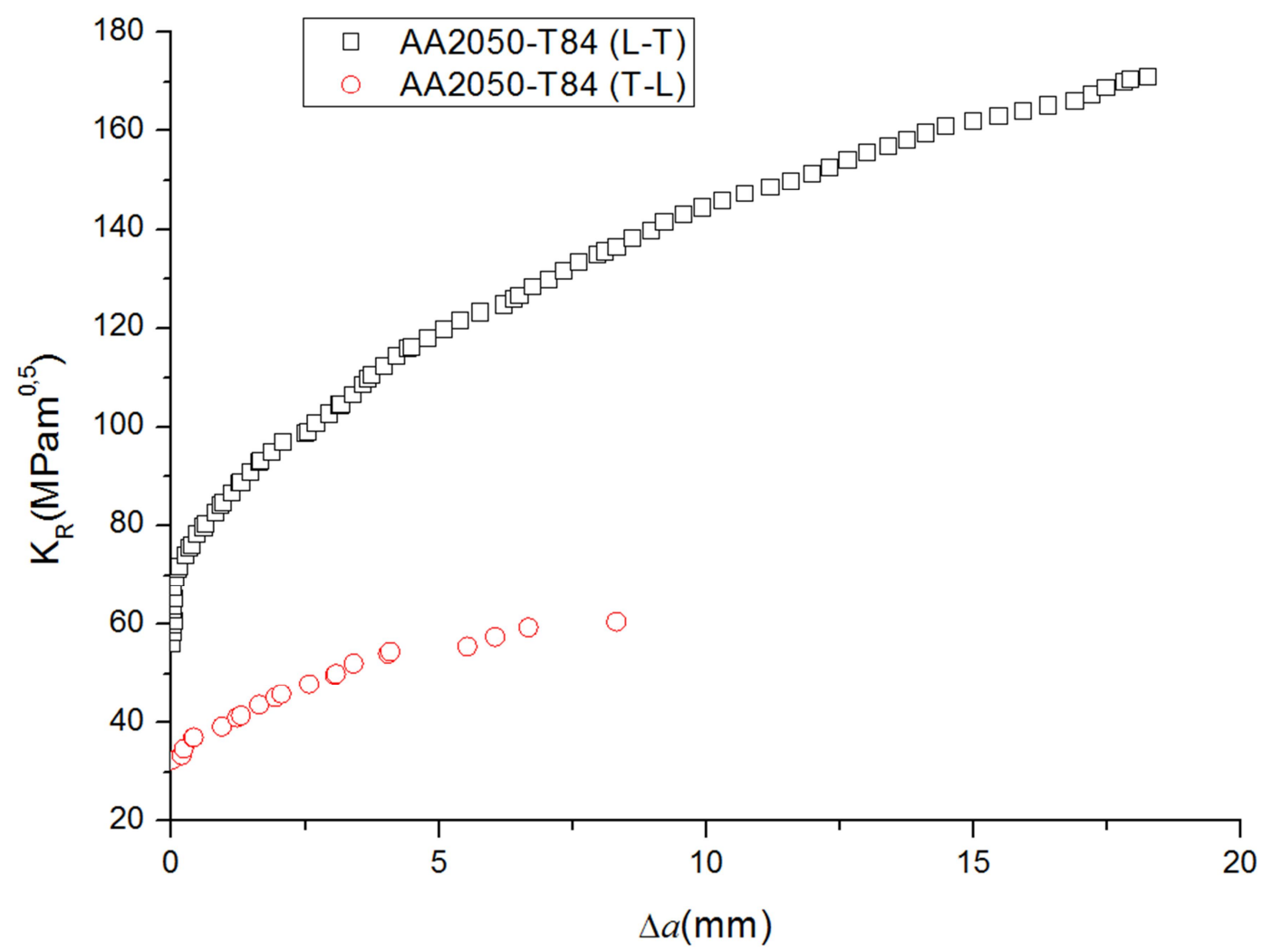

Figura 52. Curva $\mathrm{K}_{\mathrm{R}}$ versus $\Delta a$ da liga AA2050-T84 nas direções L-T e T-L.

A figura 53 apresenta uma comparação entre as ligas AA7050-T7451 e AA2050-T84, ambas na direção L-T. Observa-se que ambas apresentam uma curva de resistência similar, com uma vantagem mínima para liga AA2050-T84. Essa diferença mínima pode ser comprovada na tabela 16, a qual revela que a liga AA7050-T7451 tem $K_{I C}$ maior em 6\%, em relação à liga AA2050-T84, na direção L$\mathrm{T}$. 


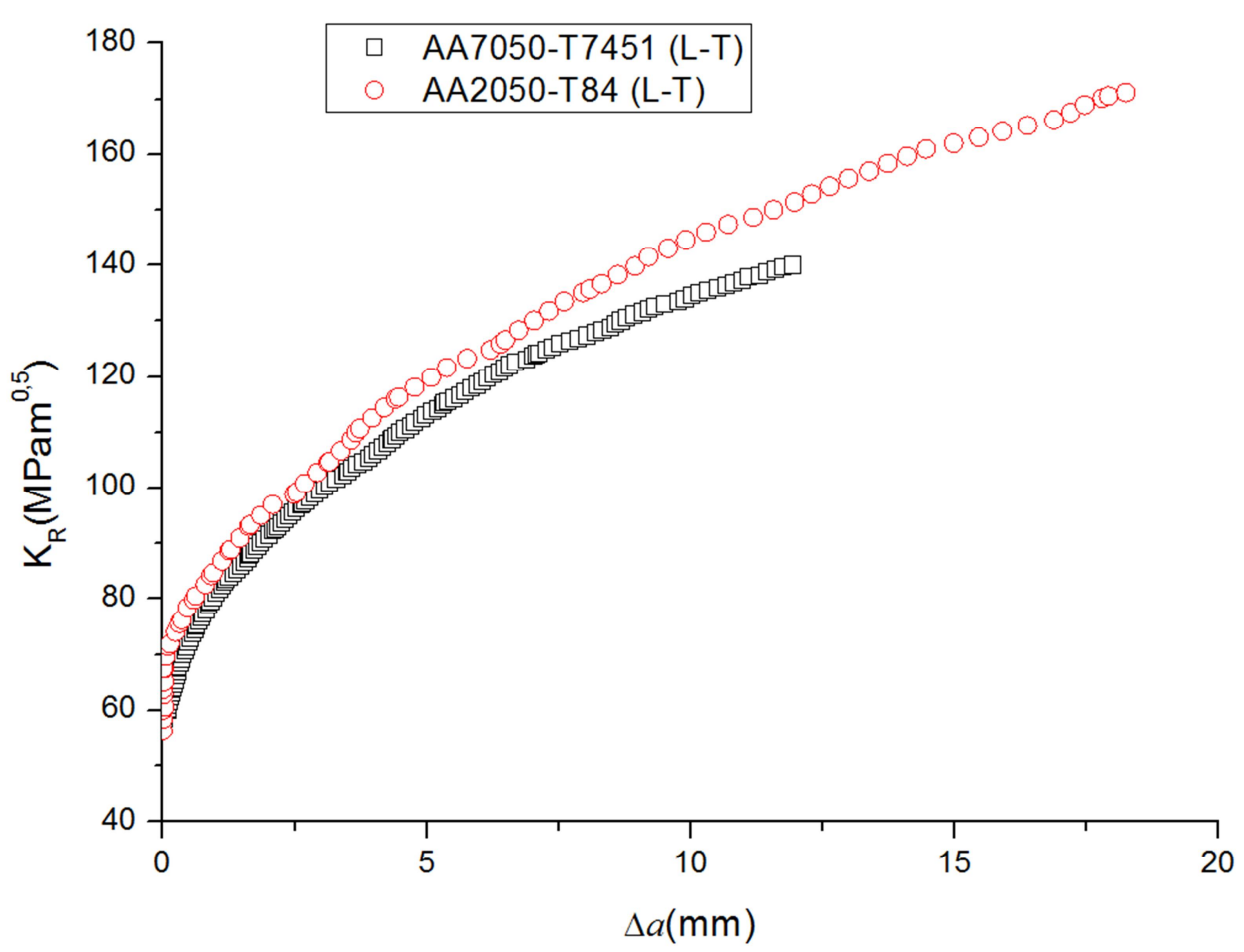

Figura 53. Curva $\mathrm{K}_{\mathrm{R}}$ versus $\Delta a$ das ligas AA2050-T84 e AA7050T7451 na direção L-T

A figura 54 apresenta também uma comparação entre as ligas AA7050-T7451 e AA2050-T84, porém na direção T-L. Neste caso, verifica-se uma resistência mais significante para a liga AA7050-T7451. E essa diferença pode ser comprovada também através da tabela 16 , em que a liga AA7050-T7451, na direção T-L, tem $K_{I C}$ 17\% maior, em relação à AA2050-T84, na mesma direção. 


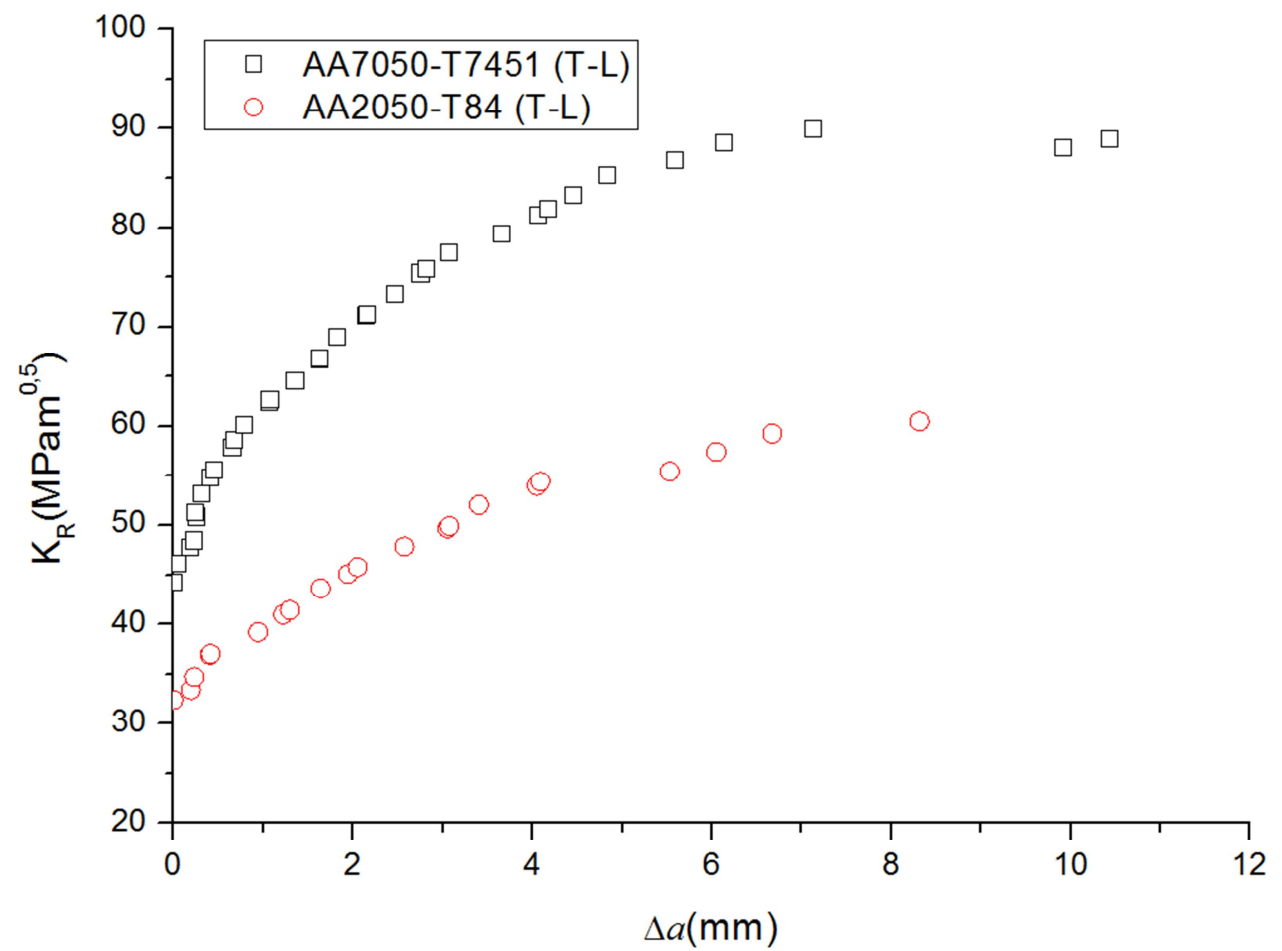

Figura 54. Curva R comparativa entre as ligas AA2050T84 e AA7050-T7451 na direção T-L. 


\subsection{Ensaio de Fadiga}

Nas figuras 55 a 56 são apresentados os gráficos de propagação da trinca na temperatura ambiente e na temperatura criogênica, $-54^{\circ} \mathrm{C}$, para a liga $\mathrm{AA} 7050-$ T7451, comparando-se as diferentes taxas de carga $R$, mas, mantendo-se as mesmas direções, segundo modelo de Paris. Como pode ser observado, em ambos os gráficos a direção com R0,5 tem uma taxa de propagação de trinca maior que $\mathrm{R} 0,1$.

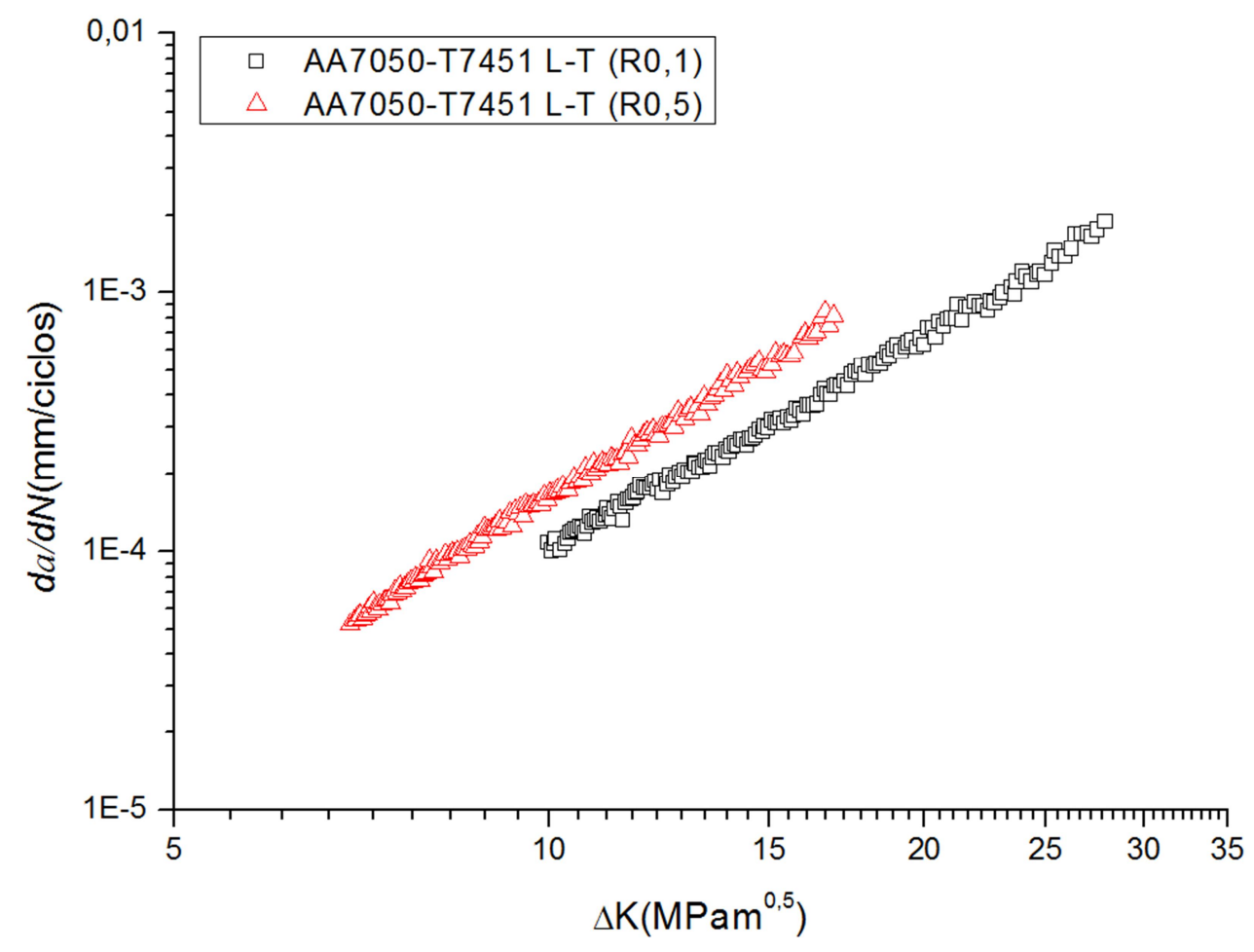

Figura 55. Ensaio de propagação com R0,1 e R0,5 na direção L-T para as ligas AA7050T7451 na temperatura ambiente, usando-se o modelo de Paris. 


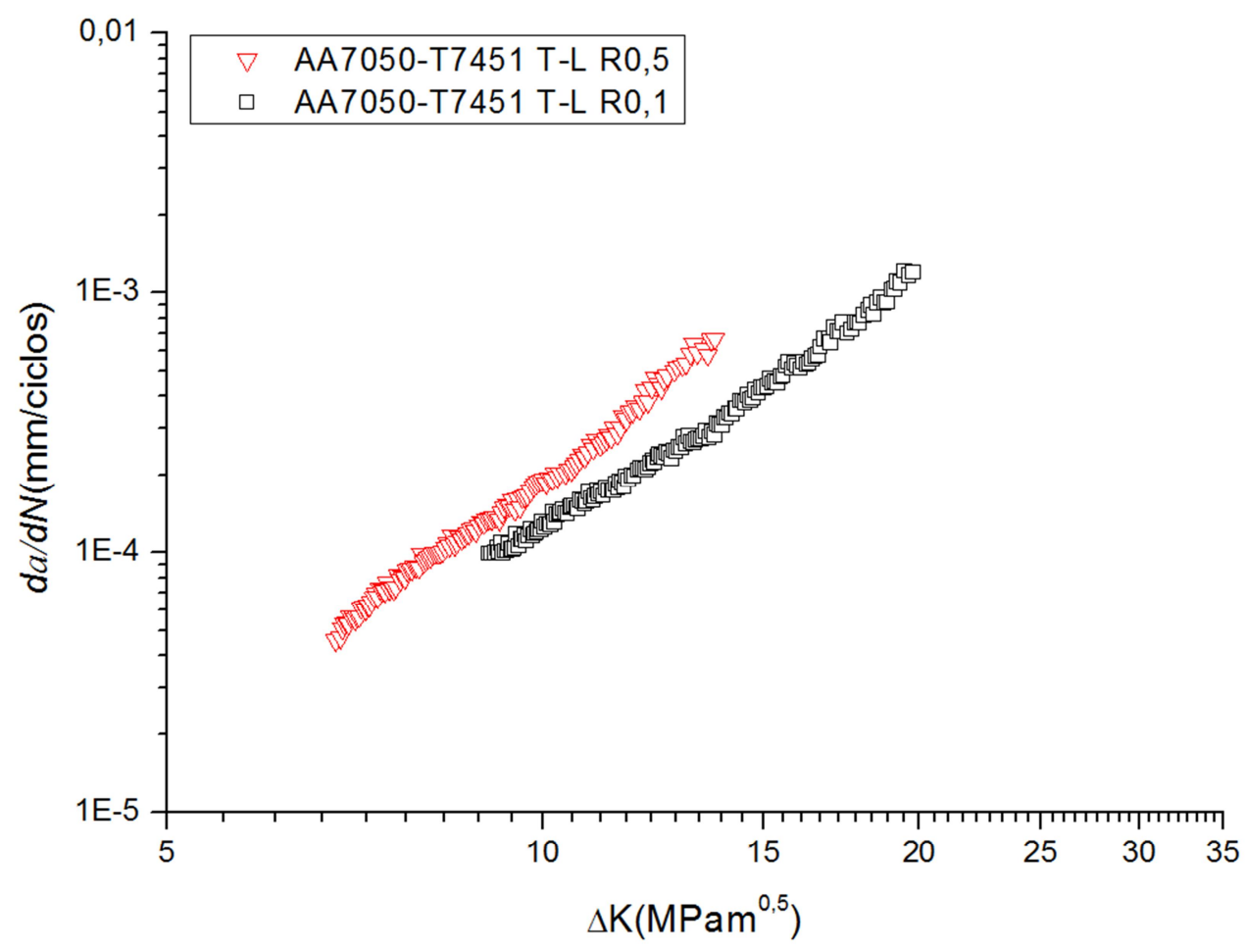

Figura 56. Ensaio de propagação com R0,1 e R0,5 na direção T-L para as ligas AA7050T7451 na temperatura ambiente, usando-se modelo de Paris. 


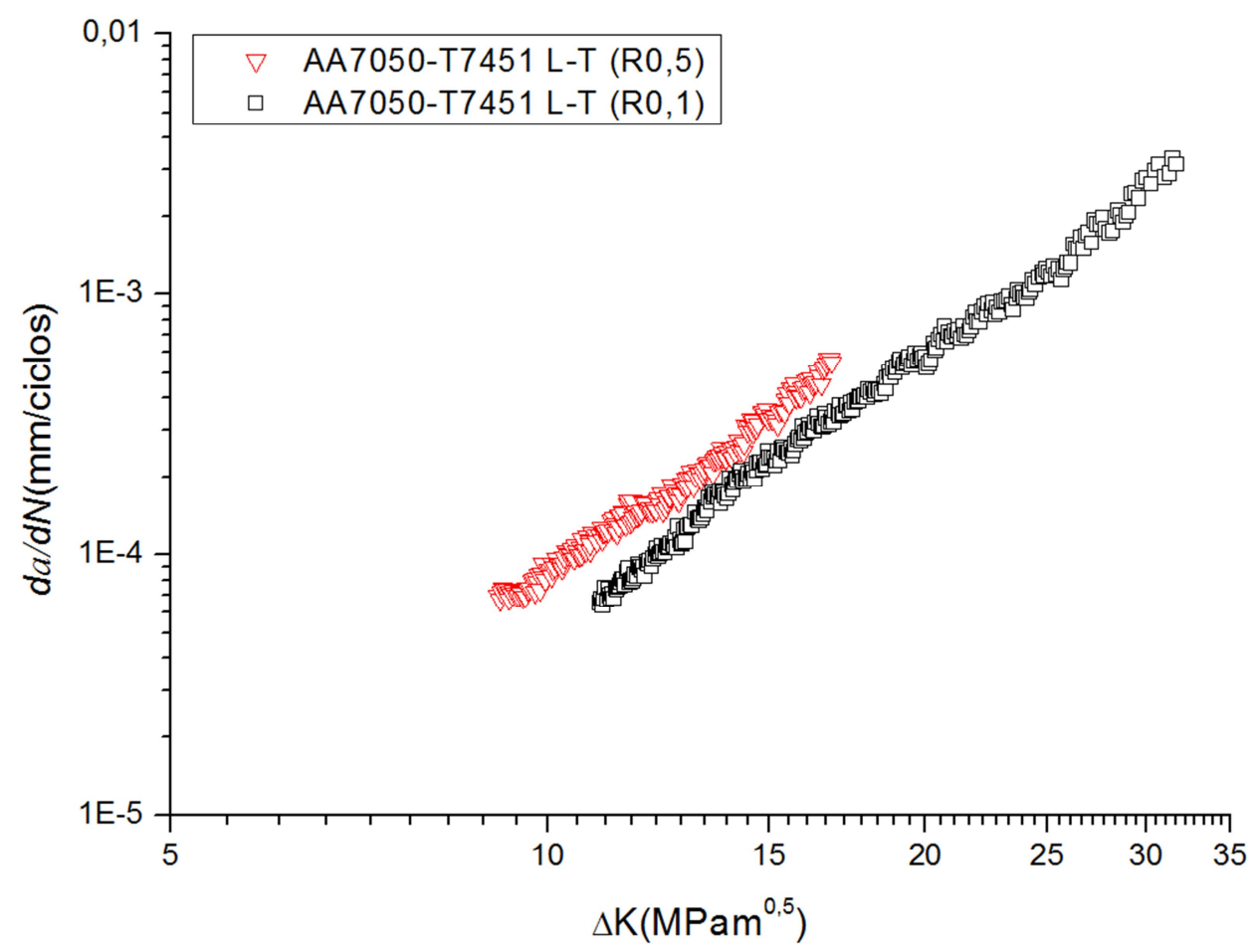

Figura 57. Ensaio de propagação com R0,1 e R0,5 na direção L-T para as ligas AA7050-T7451 em temperatura criogênica, usando-se modelo de Paris.

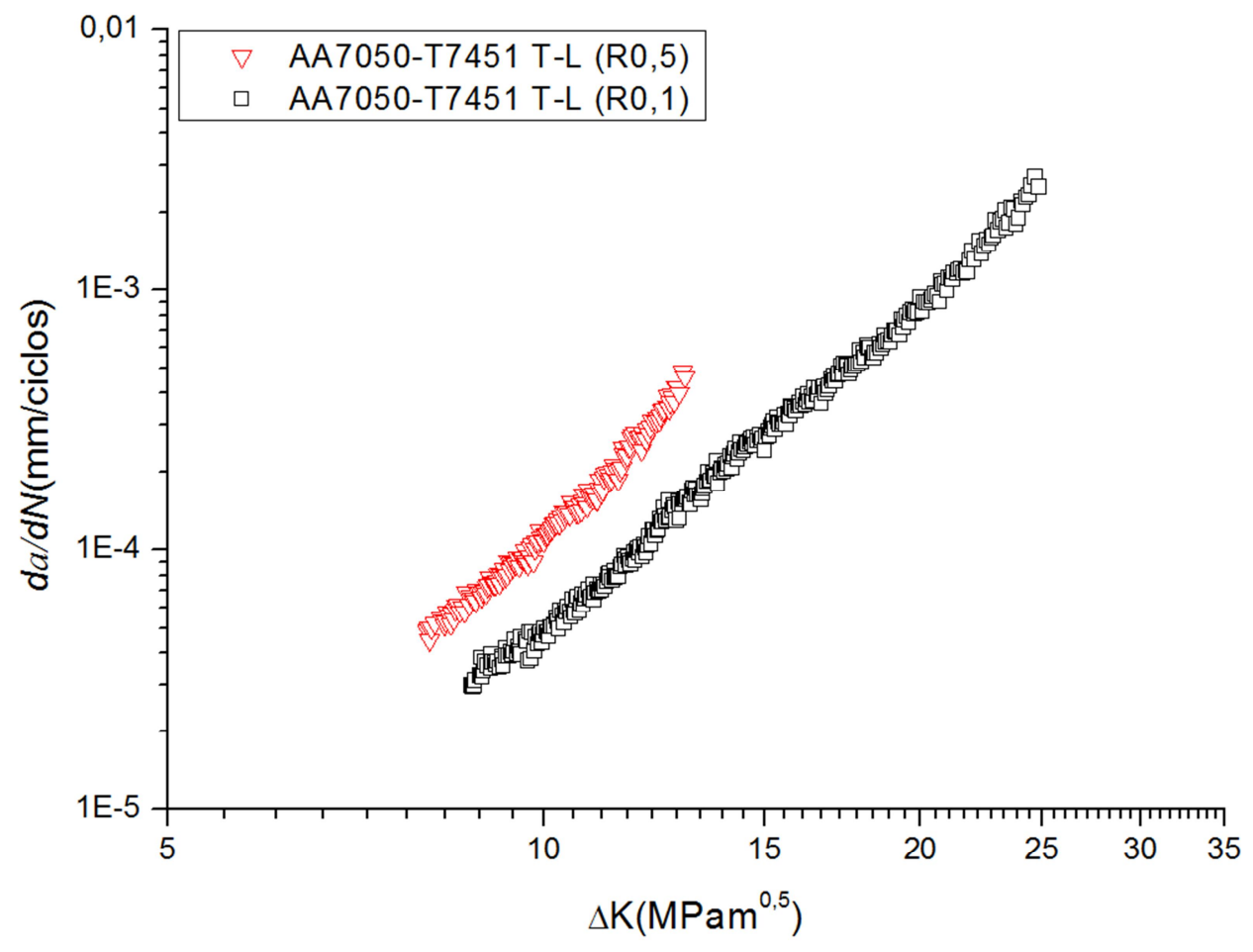

Figura 58. Ensaio de propagação com R0,1 e R0,5 na direção T-L para as ligas AA7050T7451 em temperatura criogênica, usando-se modelo de Paris. 
As figuras 57 e 58 apresentam os gráficos para temperatura criogênica ($54^{\circ} \mathrm{C}$ ), novamente revelando que a razão de carga $\mathrm{R} 0,5$ é mais sensível, ou seja, tem uma maior taxa de propagação em relação a $\mathrm{R} 0,1$.

As Tabelas 18 e 19 representam os resultados dos parâmetros da equação de Paris, obtidos dos ensaios de propagação de trinca por fadiga, para a liga de alumínio estudada. Os valores de $\mathrm{m}$ representam o coeficiente angular da reta de regressão linear, e C é o coeficiente encontrado pela extensão da linha reta para $\Delta \mathrm{K}$ $=1$.

Tabela 18. Resumo dos resultados obtidos dos ensaios de propagação de trinca por fadiga em temperaturas ambiente e criogênica para a liga Al-Cu AA 7050-T7451 e para $R=0,1$.

\begin{tabular}{|c|c|c|c|c|c|c|}
\hline & Direção & $\begin{array}{l}\text { Condições de } \\
\text { temperatura }\end{array}$ & $\mathbf{m}$ & $\mathrm{C}\left(\frac{\mathrm{mm} / \mathrm{ciclo}}{(M P a \sqrt{m})^{m}}\right)$ & Paris & $\mathbf{R}^{2}$ \\
\hline & L-T & & 2,72 & 1,89E-07 & $d a / d N=1,89 \mathrm{E}-07(\Delta \mathrm{K})^{2,72}$ & 0,99654 \\
\hline & T-L & $\operatorname{Ar}\left(23^{\circ} \mathrm{C}\right)$ & 3,14 & 8,87E-08 & $d a / d \mathrm{~N}=8,87 \mathrm{E}-08(\Delta \mathrm{K})^{3,14}$ & 0,99264 \\
\hline & L-T & & 3,50 & 1,63E-08 & $d a / d N=1,63 \mathrm{E}-08(\Delta \mathrm{K})^{3,50}$ & 0,9944 \\
\hline & T-L & & 4,17 & 3,37E-09 & $d a / d N=3,37 \mathrm{E}-09(\Delta \mathrm{K})^{4,17}$ & 0,9966 \\
\hline
\end{tabular}


Tabela 19. Resumo dos resultados obtidos dos ensaios de propagação de trinca por fadiga em temperaturas ambiente e criogênica para a liga Al-Cu AA 7050-T7451 e para R =0,5.

\begin{tabular}{|c|c|c|c|c|c|c|}
\hline & Direção & $\begin{array}{l}\text { Condições de } \\
\text { temperatura }\end{array}$ & $\mathbf{m}$ & $\mathrm{C}\left(\frac{\mathrm{mm} / \mathrm{cicllo}}{(M P a \sqrt{\boldsymbol{m}})^{m}}\right)$ & Paris & $\mathbf{R}^{2}$ \\
\hline & L-T & \multirow{3}{*}{$\operatorname{Ar}\left(23^{\circ} \mathrm{C}\right)$} & 2,98 & $1,68 \mathrm{E}-07$ & $d a / d N=1,68 \mathrm{E}-07(\Delta \mathrm{K})^{2,98}$ & 0,99714 \\
\hline & $T-L$ & & 3,58 & $5,12 \mathrm{E}-08$ & $d a / d N=5,12 \mathrm{E}-08(\Delta \mathrm{K})^{3,58}$ & 0,99295 \\
\hline & L-T & & 3,38 & 3,49E-08 & $d a / d N=3,49 \mathrm{E}-08(\Delta \mathrm{K})^{3,38}$ & 0,98656 \\
\hline & $\mathrm{T}-\mathrm{L}$ & Criogenia $\left(54^{\circ} \mathrm{C}\right)$ & 4,62 & $2,78 \mathrm{E}-9$ & $d a / d N=2,78 \mathrm{E}-09(\Delta \mathrm{K})^{4,62}$ & 0,98564 \\
\hline
\end{tabular}

Observa-se, nas tabelas 18 e 19, que a direção T-L apresenta um maior valor de m, ou seja, uma maior inclinação da reta em comparação com a direção L-T. Essa inclinação mostra que a direção T-L é mais sensível à razão de carga, tanto na temperatura ambiente quanto na temperatura criogênica. Essa sensibilidade maior representa uma maior velocidade de propagação da trinca. Esse maior valor de crescimento de trinca ocorre devido à direção dos grãos, que estão alongados numa única direção, resultando numa barreira energética menor nessa direção, para a trinca percorrer.

Essa resistência à propagação da trinca mais elevada na direção L-T pode ser comprovada na curva $K_{R}$ da figura 53 .

Outra constatação que pode ser verificada nas tabelas 18 e 19 são os valores de $m$ na temperatura criogênica maiores em relação ao $m$ na temperatura ambiente. Isso mostra que a reta para a temperatura criogênica é mais inclinada, assim, a tendência seria que a velocidade de propagação da trinca fosse maior em relação à temperatura ambiente. Porém, o que se observa, no gráfico da figura 59, é que a 
curva na condição criogênica apresenta-se ligeiramente abaixo da curva na condição ambiente. Segundo Liaw e Logsdon (1985), esse aumento da resistência à propagação da trinca, através da diminuição da temperatura, é devido a um processo termicamente ativado, à luz de um modelo dinâmico de discordância. Em outras palavras, na ponta da trinca, a energia térmica ativada para mover as discordâncias sobre as barreiras diminui com a diminuição da temperatura, resultando em um aumento da resistência à propagação de trinca em fadiga, para temperaturas mais baixas.

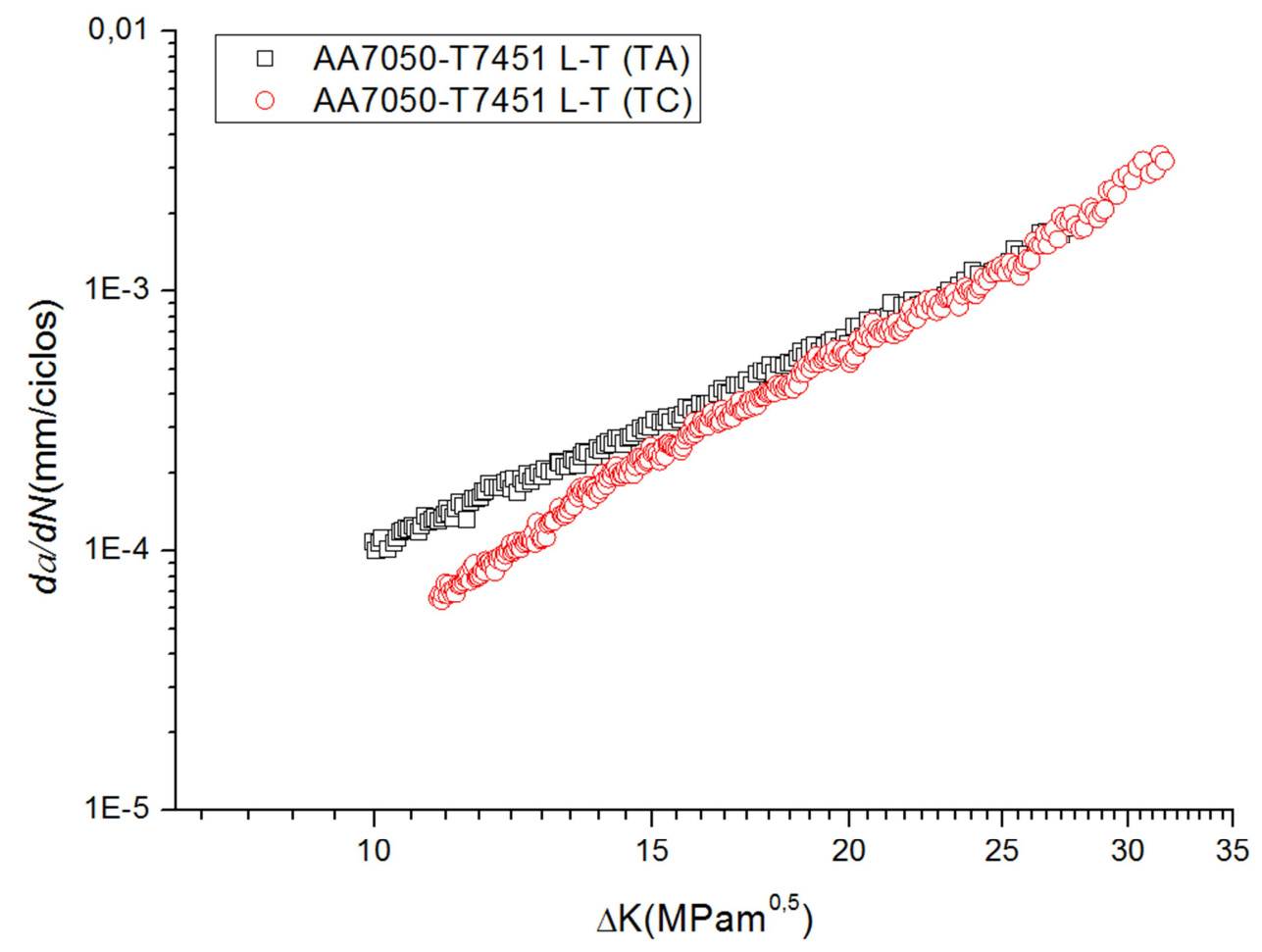

Figura 59. Efeito da temperatura na resistência a propagação da trinca da liga AA7050T7451, usando-se modelo de Paris com R0,1. 
As figuras 60 e 61 apresentam os resultados relativos à liga AA2050-T84, na temperatura ambiente, usando-se o método de Paris, comparando-se as mesmas direções e alterando-se a razão de carga. Como pode se observar, as direções L-T e $\mathrm{T}$-L, com R0,5, apresentam uma velocidade de propagação maior que $\mathrm{R} 0,1$. Os resultados apresentados seguem os mesmos resultados da liga AA7050-T7451, em que a liga é sensível a $R$, utilizando-se o método de Paris.

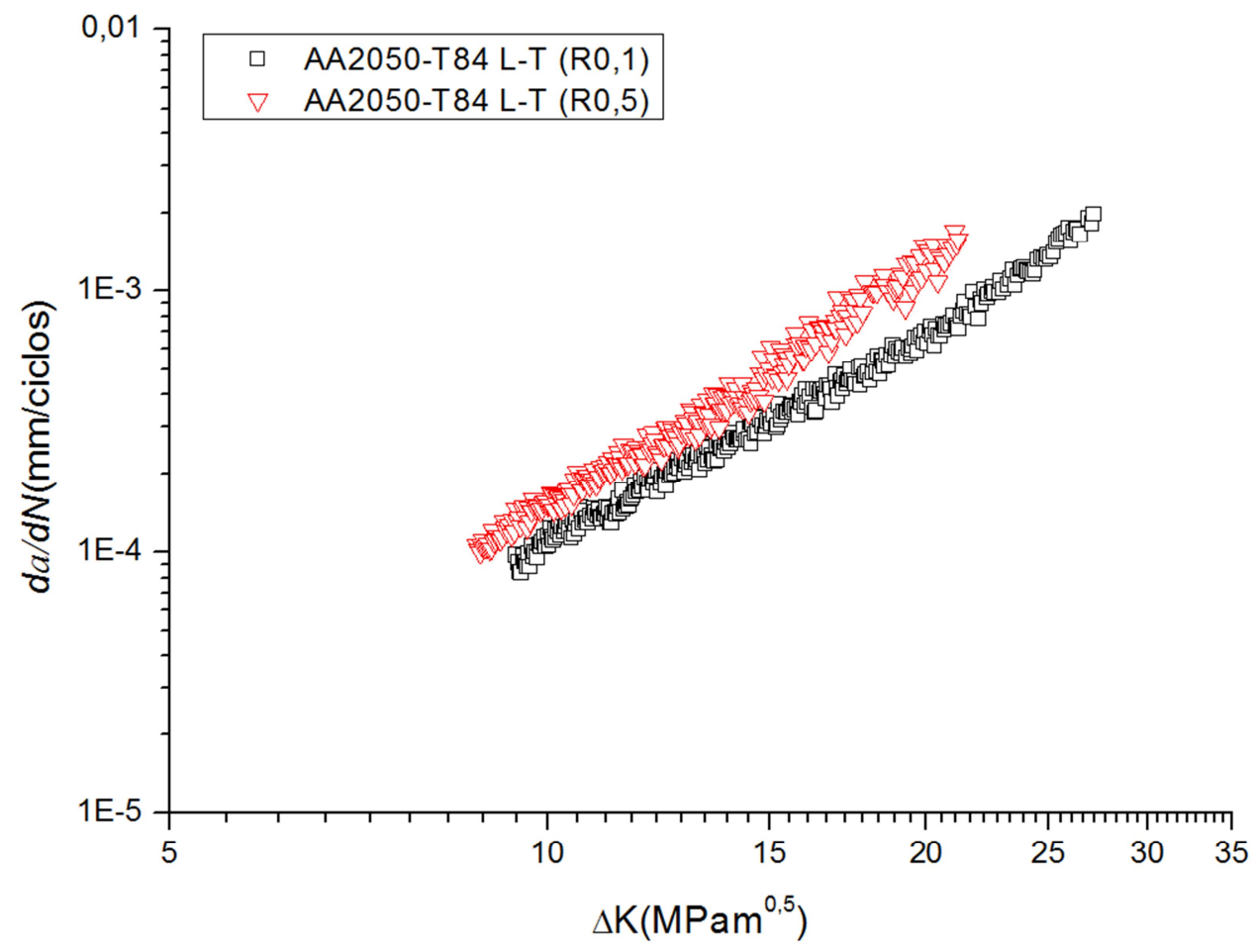

Figura 60. Efeito da razão de carga na taxa de propagação da trinca da liga AA2050-T84, na direção L-T, na temperatura ambiente, usando-se modelo de Paris. 


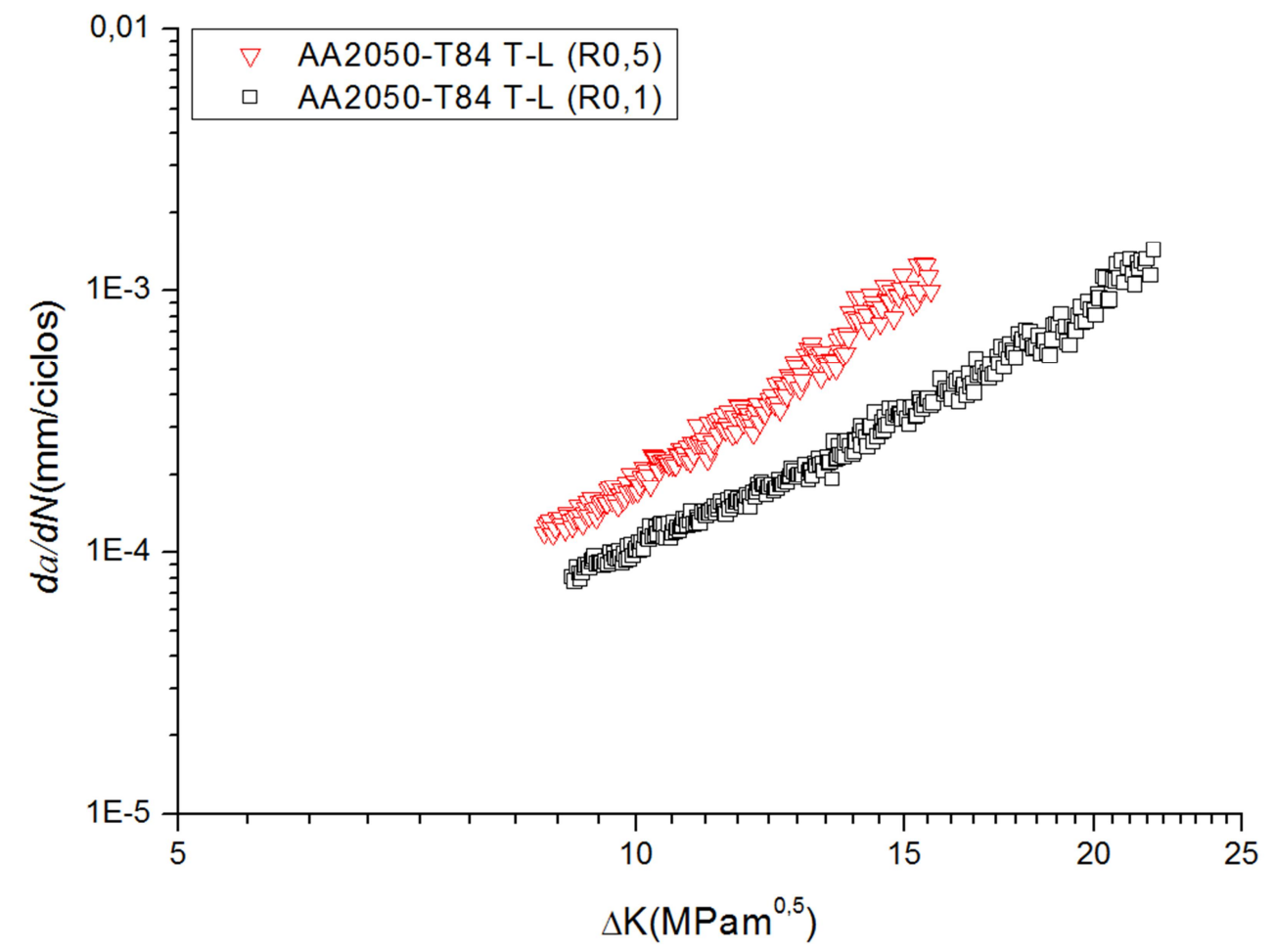

Figura 61. Efeito da razão de carga na taxa de propagação da trinca da liga AA2050-T84, na direção T-L, na temperatura ambiente, usando-se modelo de Paris. 
As figuras 62 e 63 apresentam os resultados relativos à liga AA2050-T84, comparando-se as mesmas direções em temperatura criogênica, usando também o modelo de Paris. Como pode ser observado nos gráficos anteriores, a razão de carga R0,5 apresenta uma taxa de propagação de trinca maior.

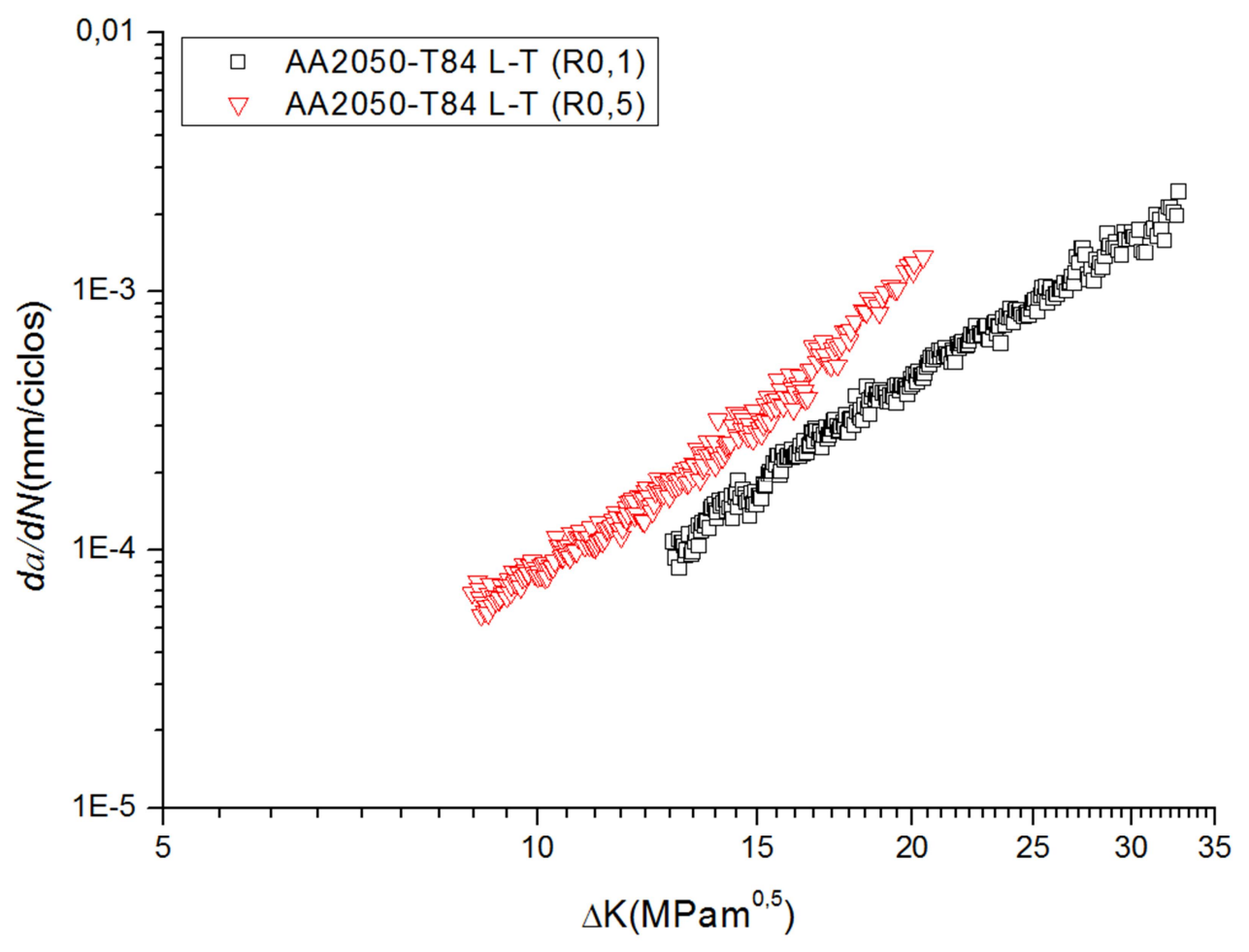

Figura 62. Efeito da razão de carga na taxa de propagação da trinca da liga AA2050-T84, na direção L-T, na temperatura criogênica, usando-se modelo de Paris. 


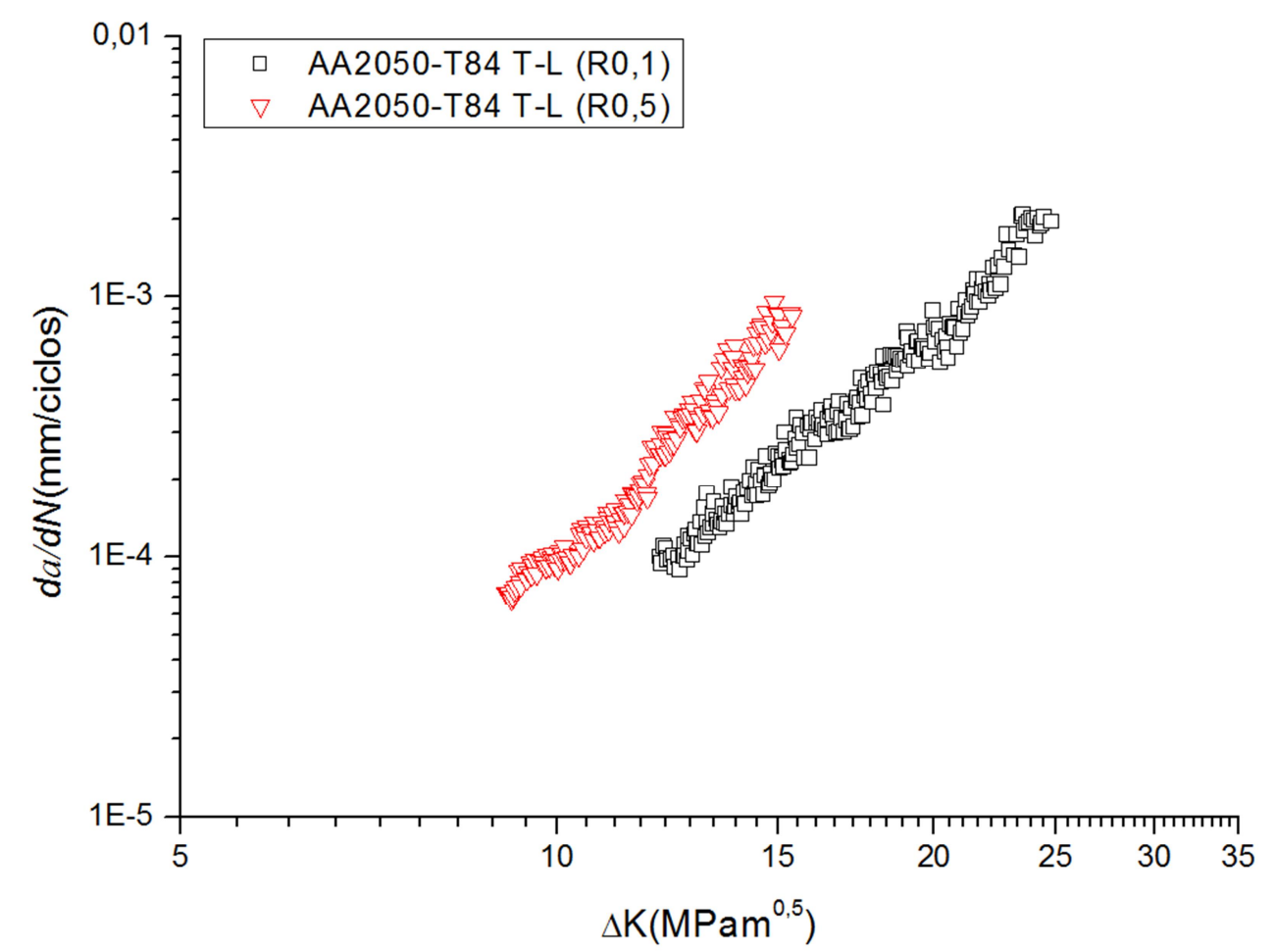

Figura 63. Efeito da razão de carga na taxa de propagação da trinca da liga AA2050-T84, na direção T-L, na temperatura criogênica, usando-se modelo de Paris.

As Tabelas 20 e 21 representam os resultados dos parâmetros da equação de Paris obtidos dos ensaios de propagação de trinca por fadiga, para a liga de alumínio AA2050-T84. Os valores de m representam o coeficiente angular da reta de regressão linear, e C é o coeficiente encontrado pela extensão da linha reta para $\Delta K$ $=1 \mathrm{MPa} \cdot \mathrm{m}^{1 / 2}$. Os resultados dos ensaios em ar foram realizados por Bonazzi (2013).

Observa-se que na direção T-L, assim como na liga AA7050-T7451, há um valor de m maior em relação à direção L-T, ou seja, uma maior inclinação da reta em comparação com a direção L-T. Observa-se que na direção T-L, assim como na liga AA7050-T7451, há um valor de m maior em relação à direção L-T, ou seja, uma maior inclinação da reta em comparação com a direção L-T. Essa inclinação mostra que a direção T-L é mais sensível à razão de carga, tanto na temperatura ambiente quanto na temperatura criogênica. Essa sensibilidade maior representa uma maior 
velocidade de propagação da trinca. Esse maior valor de crescimento de trinca ocorre devido à direção dos grãos, que estão alongados numa única direção, sendo a barreira energética menor nessa direção, para a trinca percorrer.

Essa resistência à propagação da trinca mais elevada na direção L-T pode ser comprovada na curva R da figura 54.

Tabela 20. Resumo dos resultados obtidos dos ensaios de propagação de trinca por fadiga, em temperaturas ambiente e criogênica, para a liga Al-Li AA 2050-T84 e para $\mathrm{R}=0,1$.

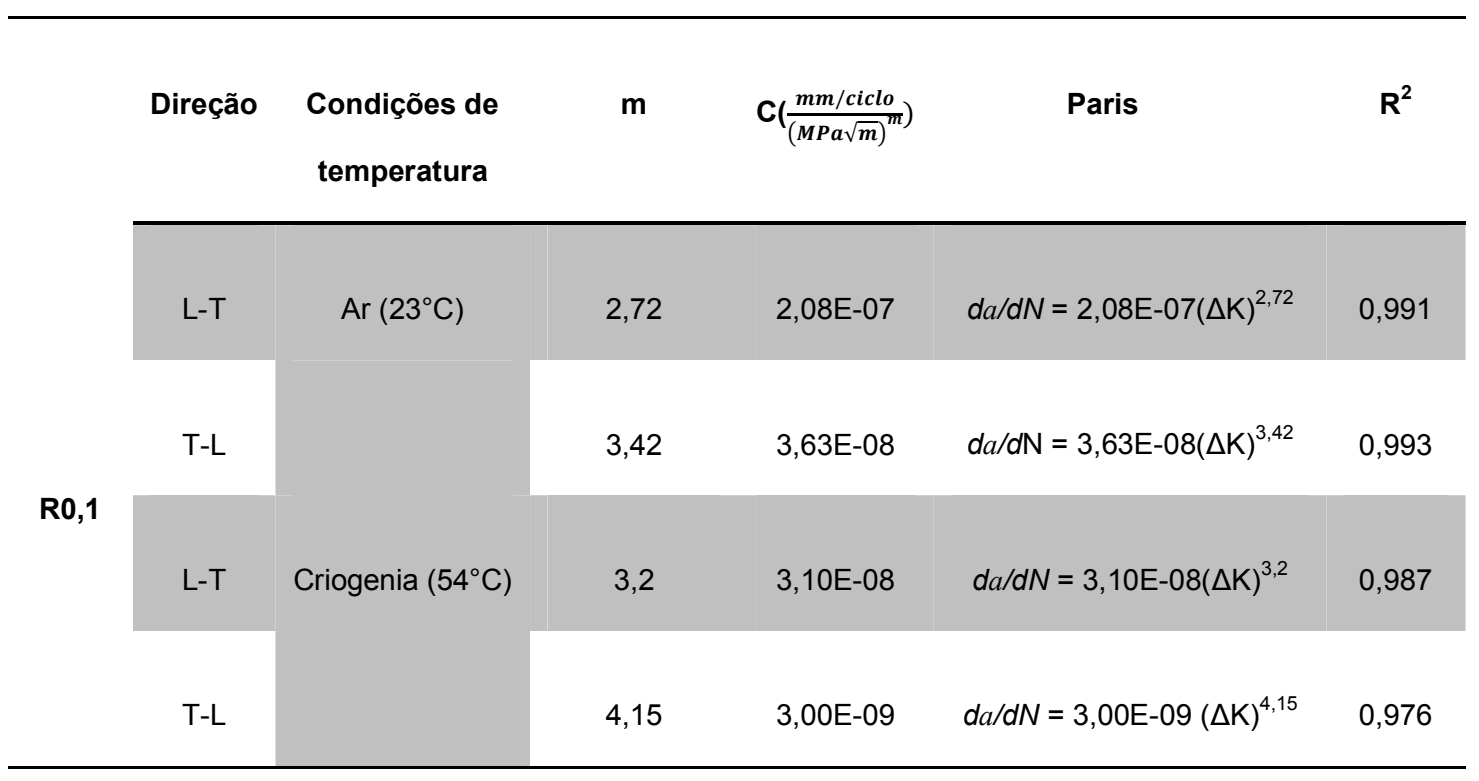


Tabela 21. Resumo dos resultados obtidos dos ensaios de propagação de trinca por fadiga em temperatura ambiente e criogênica para a liga Al-Li AA 2050-T84 e para $R=0,5$.

\begin{tabular}{|c|c|c|c|c|c|c|}
\hline \multirow{5}{*}{0,5} & Direção & $\begin{array}{l}\text { Condições de } \\
\text { temperatura }\end{array}$ & $\mathbf{m}$ & C $\left.\frac{m m / \text { ciclo }}{(M P a \sqrt{m})^{m}}\right)$ & Paris & $\mathbf{R}^{2}$ \\
\hline & L-T & \multirow[b]{2}{*}{$\operatorname{Ar}\left(23^{\circ} \mathrm{C}\right)$} & 3,09 & 1,19E-07 & $d a / d N=1,19 \mathrm{E}-07(\Delta \mathrm{K})^{3,09}$ & 0,991 \\
\hline & $\mathrm{T}-\mathrm{L}$ & & 4,00 & $1,88 \mathrm{E}-08$ & $d a / d N=1,88 \mathrm{E}-08(\Delta \mathrm{K})^{4,00}$ & 0,993 \\
\hline & L-T & \multirow{2}{*}{ Criogenia $\left(54^{\circ} \mathrm{C}\right)$} & 3,78 & 1,13E-08 & $d a / d N=1,13 \mathrm{E}-08(\Delta \mathrm{K})^{3,78}$ & 0,987 \\
\hline & T-L & & 4,92 & 1,18E-09 & $d a / d N=1,18 \mathrm{E}-09(\Delta \mathrm{K})^{4,92}$ & 0,976 \\
\hline
\end{tabular}

Assim com nas tabelas 18 e 19, pode-se verificar que, nas tabelas 20 e 21, que os valores de $\mathrm{m}$ na temperatura criogênica são maiores em relação a $\mathrm{m}$ na temperatura ambiente. Isso mostra que a reta para a temperatura criogênica é mais inclinada. Assim, a tendência seria que a velocidade de propagação da trinca fosse maior em relação à temperatura ambiente. Mas, seguindo a mesma tendência do gráfico da figura 59 , observa-se que, no gráfico da figura 64 , a curva na condição criogênica apresenta-se abaixo da curva na condição ambiente. Segundo Liaw e Logsdon (1985), esse aumento da resistência à propagação da trinca, através da diminuição da temperatura, é devido a um processo termicamente ativado, à luz de um modelo dinâmico de discordância. Em outras palavras, na ponta da trinca a energia térmica ativada para mover as discordâncias sobre as barreiras diminui com a diminuição da temperatura, resultando em um aumento da resistência à propagação de trinca em fadiga, para temperaturas mais baixas. 


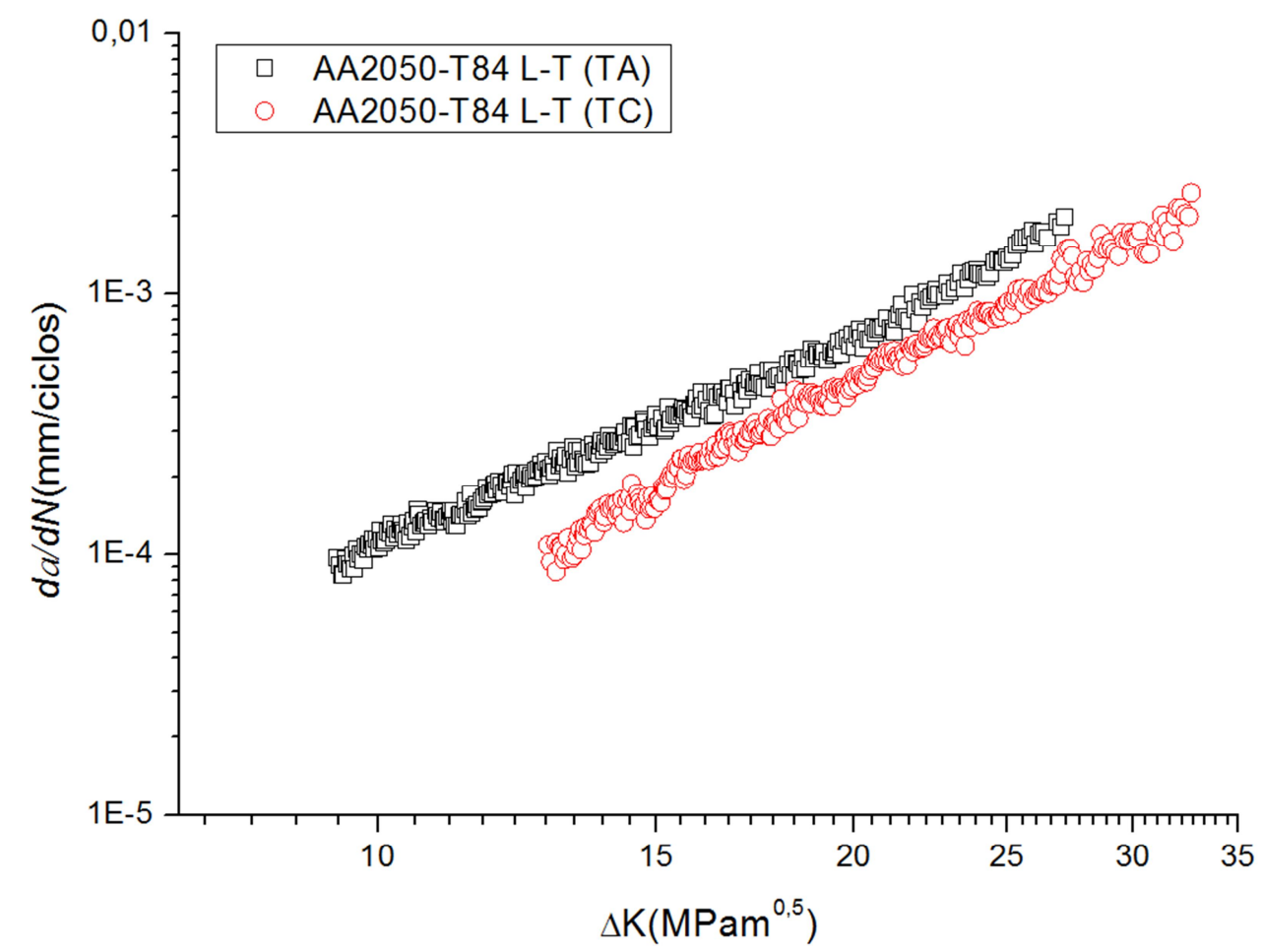

Figura 64. Efeito da temperatura na resistência à propagação da trinca da liga AA2050-T84, usando-se o modelo de Paris com R0,1.

Observa-se que, quando se compara as inclinações de m entre as direções LT versus T-L, tanto para a liga AA7050-T7451 quanto para a liga AA2050-T84, esta apresenta uma maior diferença entre as direções L-T versus T-L. Essa diferença pode ser comprovada nos gráficos das figuras 51 e 52 .

Comparando os valores de $m$ da liga AA7050-T7451 com os valores de $m$ da liga AA2050-T84, nas tabelas 18, 19, 20 e 21, observa-se que ambas as ligas possuem inclinações muito próximas, ou seja, possuem a mesma resistência à propagação da trinca. Isto pode ser comprovado através das figuras 65 e 66 . 


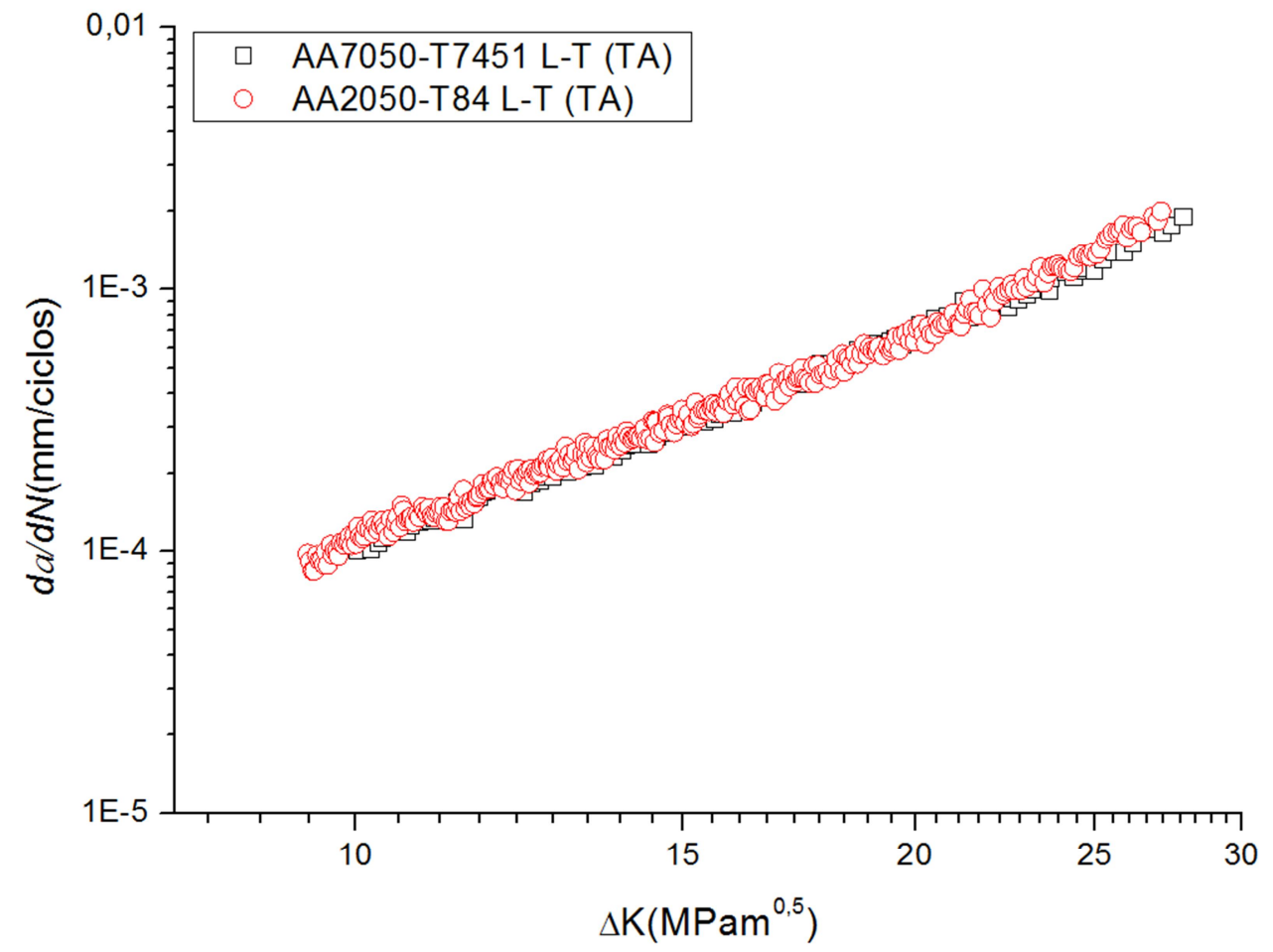

Figura 65. Comparação entre as ligas AA7050-T7451 e AA2050-T84, usando-se o modelo de Paris, em temperatura ambiente, com R0,1.

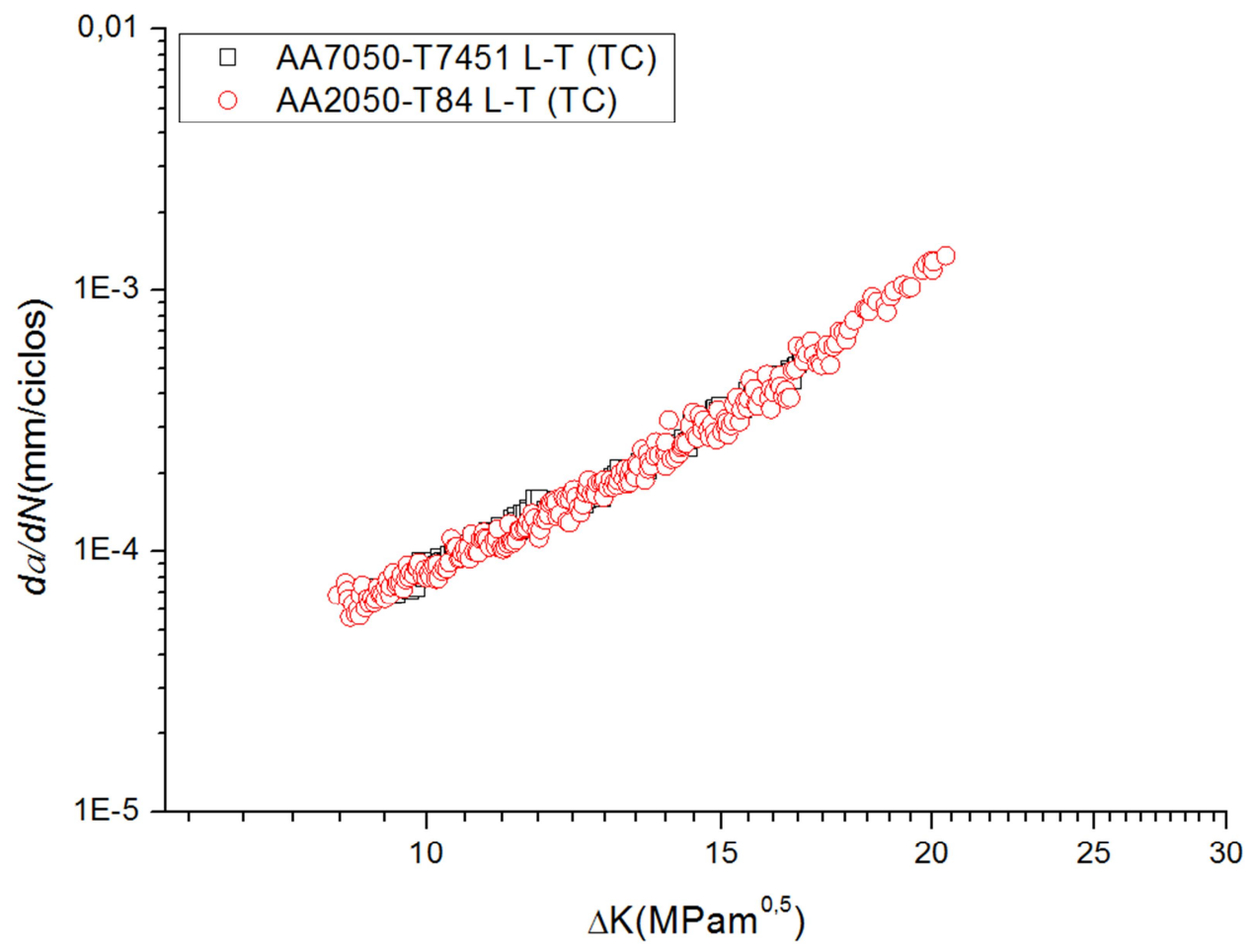

Figura 66. Comparação entre as ligas AA7050-T7451 e AA2050-T84, usando-se o modelo de Paris, em temperatura criogênica, com R0,5. 
Nas figuras 67 - 70 são mostrados os gráficos baseados no modelo de Pearson, para a liga AA7050-T7451, nas quais todas as curvas mostraram excelentes correlações, tanto para temperatura ambiente quanto para temperatura criogênica, com exceção do gráfico da figura 69.

No geral, os gráficos das figuras citadas acima apresentam bons ajustes, estando de acordo com modelo de Pearson, citado no item 2.4.2, em que, tendo-se a curva, pode-se calcular a taxa de propagação da trinca para qualquer $R$.

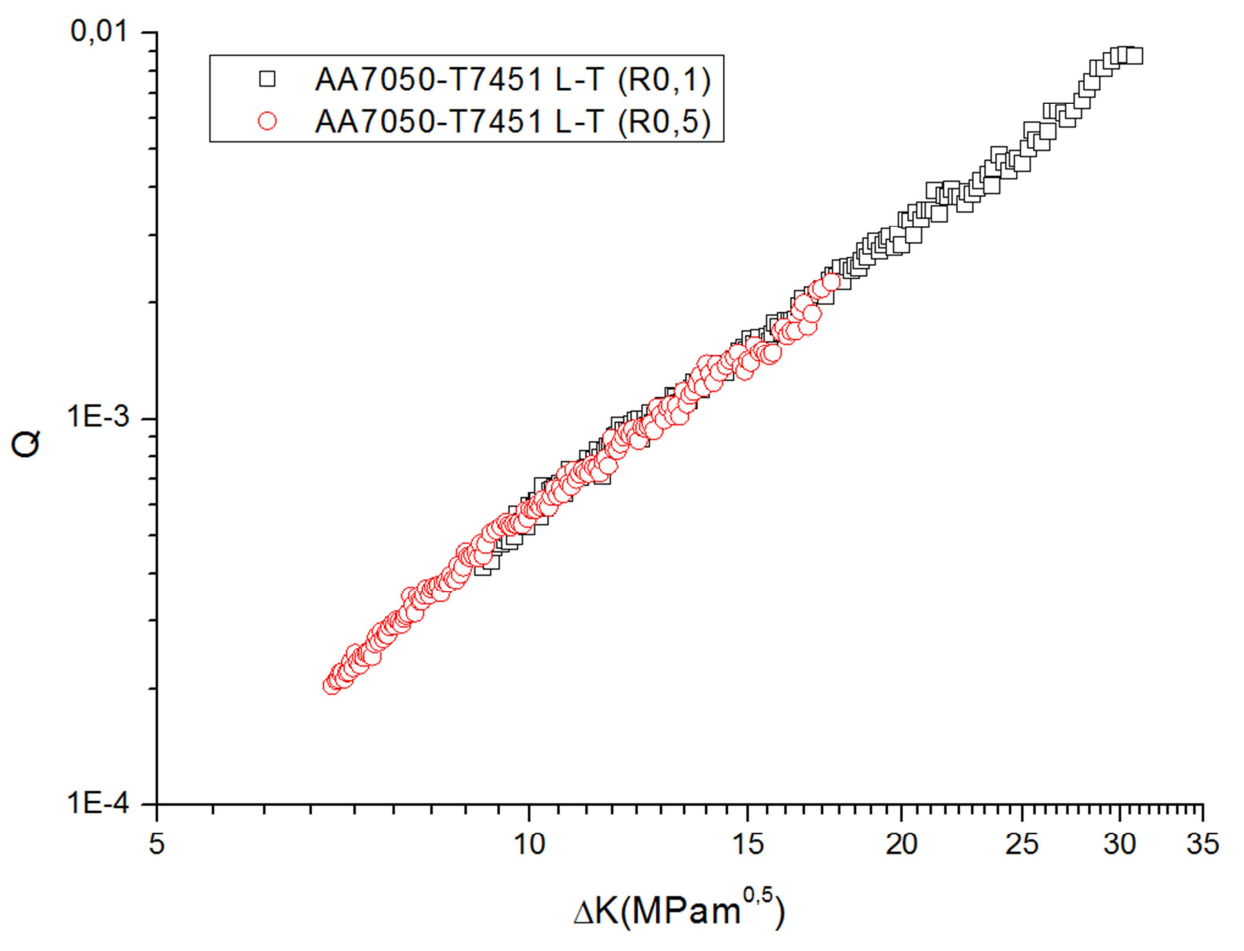

Figura 67. Ensaio de propagação com R0,1 e R0,5, na direção L-T, em temperatura ambiente, para a liga AA7050T7451, utilizando-se modelo de Pearson. 


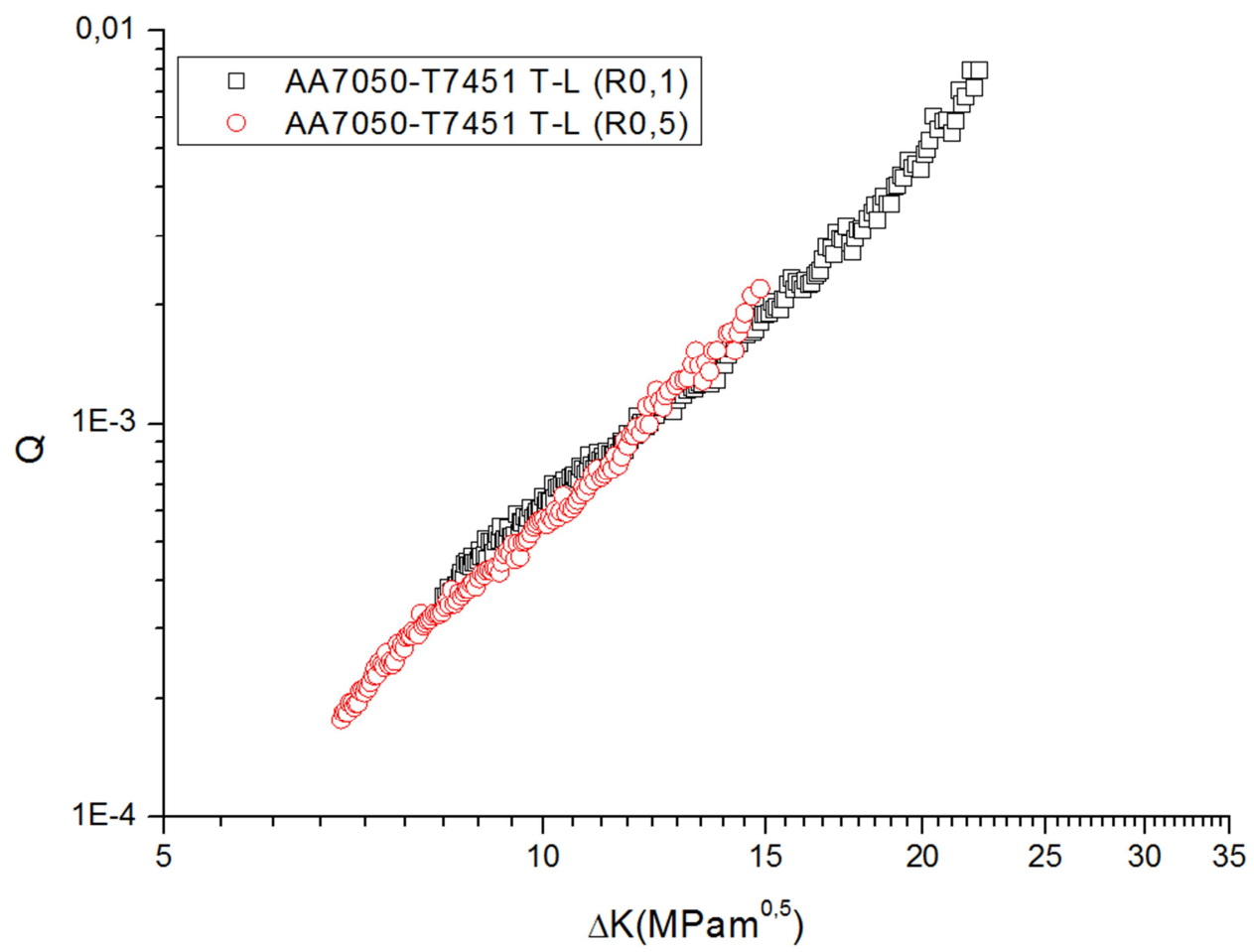

Figura 68. Ensaio de propagação com R0,1 e R0,5, na direção T-L, em temperatura ambiente, para a liga AA7050T7451, utilizando-se o modelo de Pearson.

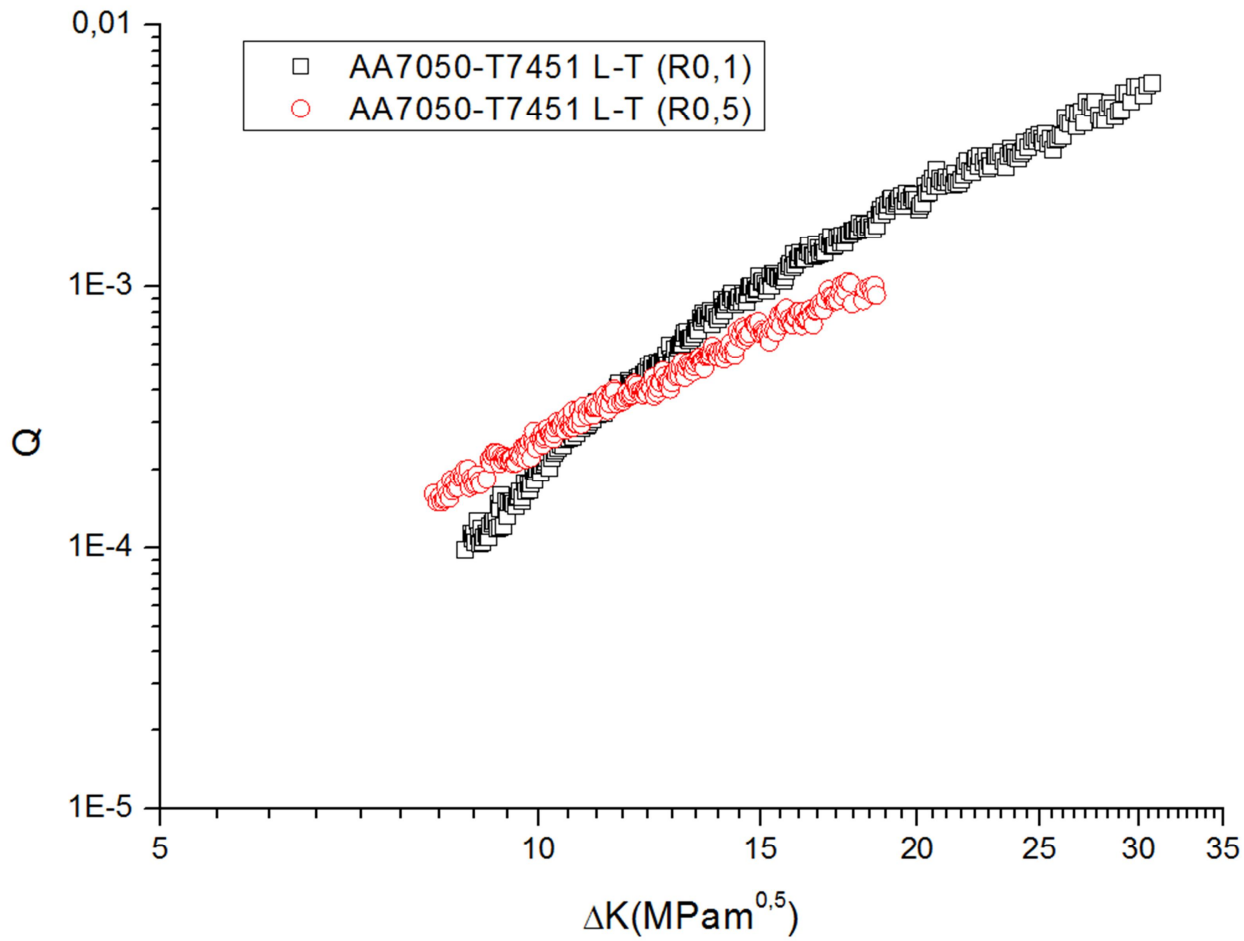

Figura 69. Ensaio de propagação com R0,1 e R0,5, na direção $L-T$, em temperatura criogênica, para a liga AA7050T7451, utilizando-se modelo de Pearson. 


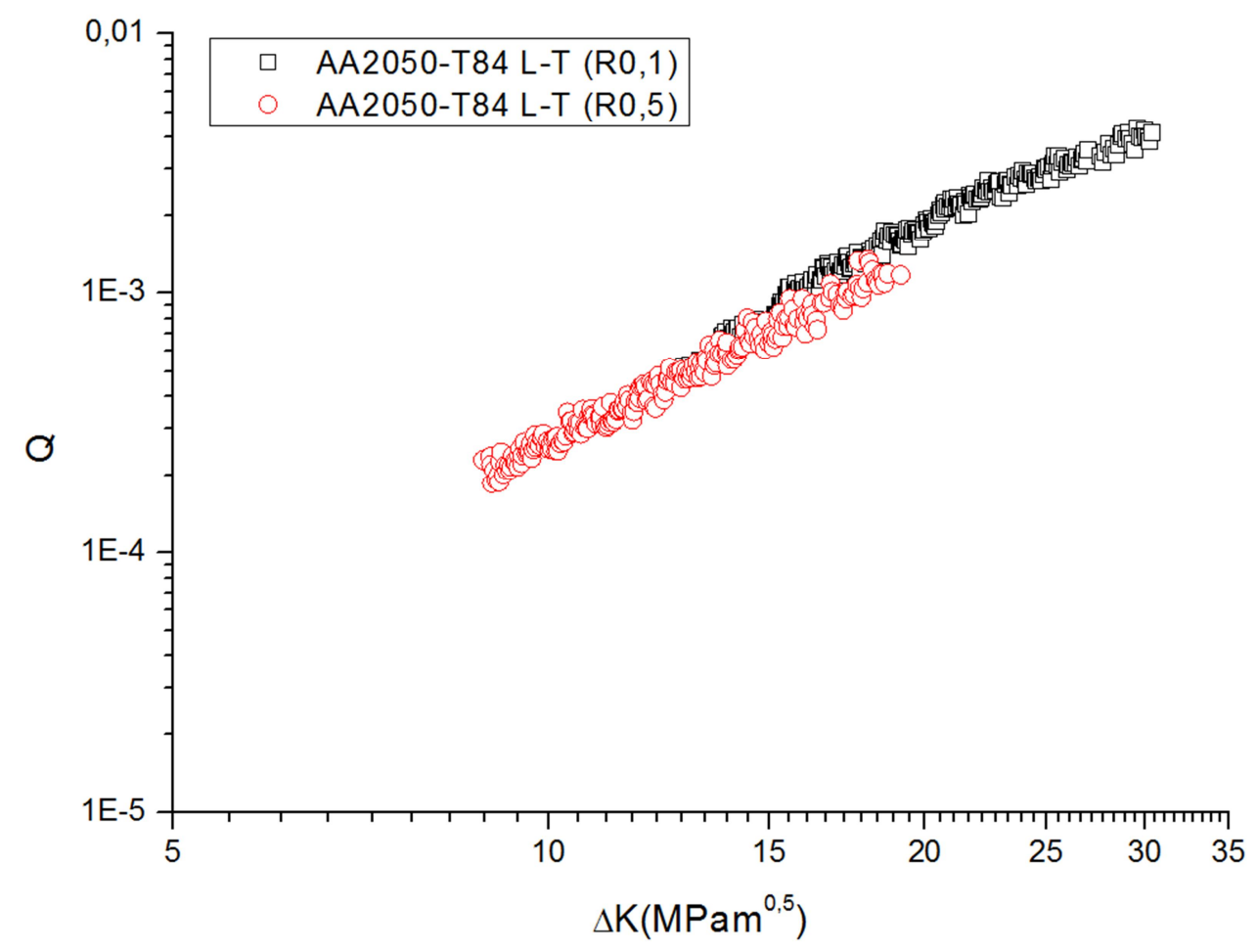

Figura 70. Ensaio de propagação com R0,1 e R0,5, a direção L-T, em temperatura criogênica, para a liga AA7050T7451, utilizando-se modelo de Pearson. 
As Tabelas 22 e 23 representam os resultados dos parâmetros do modelo de Pearson, obtidos dos ensaios de propagação de trinca por fadiga, para a liga de alumínio AA7050-T7451. Os valores de m representam o coeficiente angular da reta de regressão linear, e C é o coeficiente encontrado pela extensão da linha reta para $\mathrm{K}=1 \mathrm{MPa} \cdot \mathrm{m}^{1 / 2}$.

Tabela 22. Resumo dos resultados obtidos dos ensaios de propagação de trinca por fadiga, em temperaturas ambiente e criogênica, para a liga Al-Cu AA 7050-T7451 e para $\mathrm{R}=0,1$.

\begin{tabular}{|c|c|c|c|c|c|c|}
\hline & Direção & $\begin{array}{l}\text { Condições de } \\
\text { temperatura }\end{array}$ & $\mathbf{m}$ & $\mathrm{C}\left(\frac{\mathrm{mm} / \mathrm{ciclo}}{(\mathrm{MPa} \sqrt{m})^{m}}\right)$ & Pearson & $\mathbf{R}^{2}$ \\
\hline & L-T & \multirow{4}{*}{ Criogenia $\left(54^{\circ} \mathrm{C}\right)$} & 2,4 & $2,27 \mathrm{E}-06$ & $\frac{d a}{d N}=\frac{2,27 \times 10^{-6}(\Delta K)^{2,4}}{\left[(1-R) K_{c}-\Delta K\right]^{0,5}}$ & 0,99351 \\
\hline \multirow[t]{3}{*}{ Ro,1 } & T-L & & 2,90 & $7,66 \mathrm{E}-07$ & $\frac{d a}{d N}=\frac{7,66 \times 10^{-7}(\Delta K)^{2,90}}{\left[(1-R) K_{c}-\Delta K\right]^{0,5}}$ & 0,99378 \\
\hline & L-T & & 2,35 & $1,44 \mathrm{E}-07$ & $\frac{d a}{d N}=\frac{1,44 \times 10^{-7}(\Delta K)^{2,35}}{\left[(1-R) K_{c}-\Delta K\right]^{0,5}}$ & 0,98619 \\
\hline & T-L & & 3,4 & $7,90 \mathrm{E}-08$ & $\frac{d a}{d N}=\frac{7,90 \times 10^{-8}(\Delta K)^{3,4}}{\left[(1-R) K_{c}-\Delta K\right]^{0,5}}$ & 0,98015 \\
\hline
\end{tabular}


Tabela 23. Resumo dos resultados obtidos dos ensaios de propagação de trinca por fadiga, em temperaturas ambiente e criogênica, para a liga Al-Li AA 7050-T7451 e para R =0,5.

$\begin{array}{cccccc}\text { Direção } & \text { Condições de } & \text { m } & \mathbf{C}\left(\frac{m m / \text { ciclo }}{(\operatorname{MPa} \sqrt{m})^{m}}\right) & \text { Paris } & \mathbf{R}^{2} \\ \text { temperatura } & & & \end{array}$

R0,5

\begin{tabular}{|c|c|c|c|c|c|}
\hline L-T & & 2,47 & $1,86 \mathrm{E}-06$ & $\mathrm{da} / \mathrm{dN}=1,86 \mathrm{E}-06(\Delta \mathrm{K})^{2,47}$ & 0,99351 \\
\hline T-L & $\operatorname{Ar}\left(23^{\circ} \mathrm{C}\right)$ & 3,05 & $5,12 \mathrm{E}-07$ & $\mathrm{da} / \mathrm{dN}=5,12 \mathrm{E}-07(\Delta \mathrm{K})^{3,05}$ & 0,99378 \\
\hline L-T & Criogenia $\left(54^{\circ} \mathrm{C}\right)$ & 2,35 & $1,14 \mathrm{E}-06$ & $\mathrm{da} / \mathrm{dN}=1,14 \mathrm{E}-06(\Delta \mathrm{K})^{2,35}$ & 0,98619 \\
\hline T-L & & 2,74 & $3,82 \mathrm{E}-07$ & $\mathrm{da} / \mathrm{dN}=3,82 \mathrm{E}-07(\Delta \mathrm{K})^{3,82}$ & 0,98015 \\
\hline
\end{tabular}

Nas figuras 71 - 74 também são mostrados os gráficos baseados no método de Pearson para a liga AA2050-T84. Assim com na liga AA7050-T7451, todas as curvas também mostraram excelentes ajustes, tanto para temperatura ambiente quanto para temperatura criogênica.

Os gráficos das figuras citadas acima apresentam bons ajustes, como já realçado, estando de acordo com a equação de Pearson, citada no item 2.4.2, segundo a qual, tendo-se a curva, pode-se calcular a taxa de propagação da trinca para qualquer $R$, contrariamente à equação de Paris, que não é uma função da razão de carga e, portanto, nesta, serão necessárias várias equações diferentes, para vários $\mathrm{R}$ diferentes. 


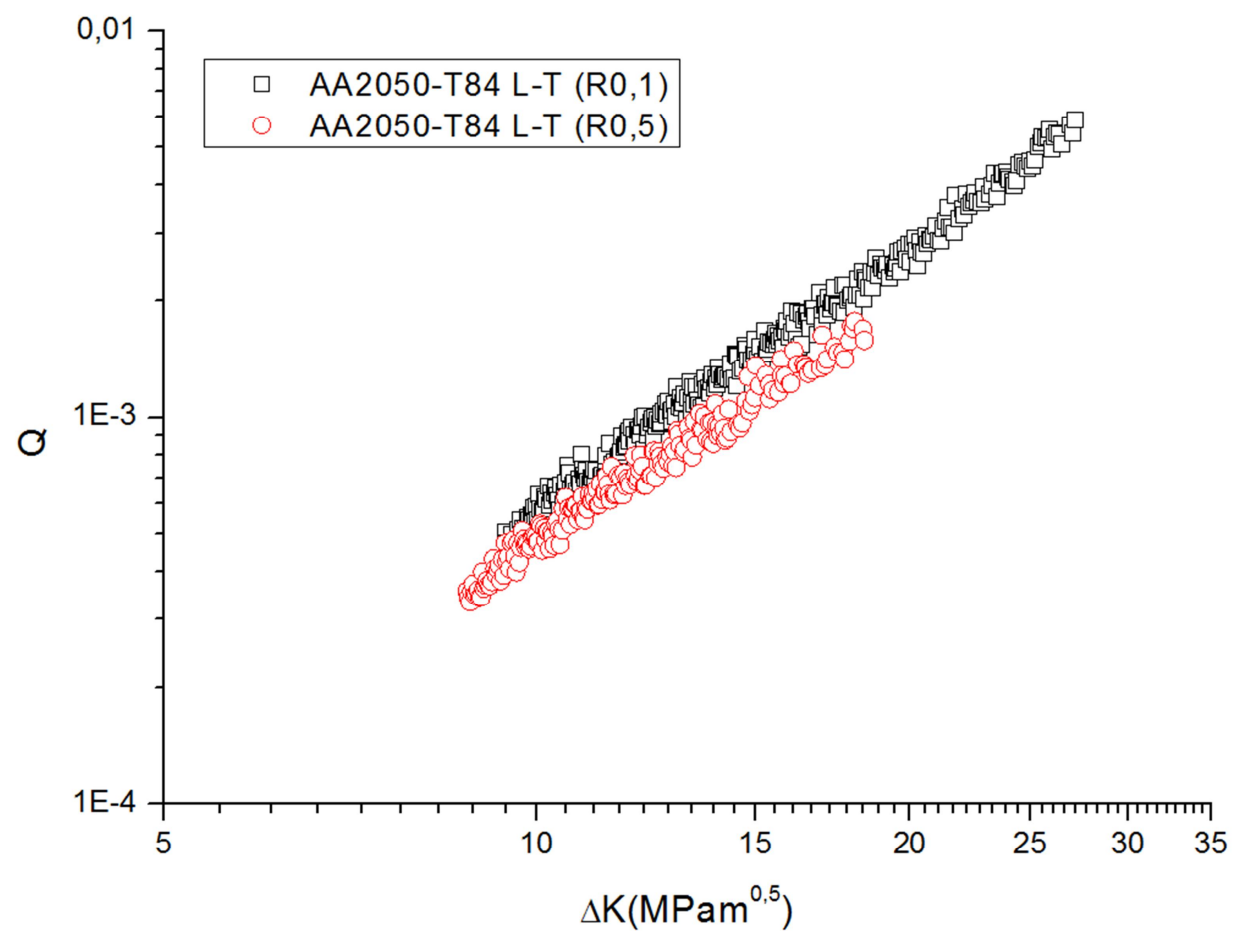

Figura 71. Ensaio de propagação com R0,1 e R0,5, na direção L-T, em temperatura ambiente, para a liga AA2050T7451, utilizando-se método de Pearson. 


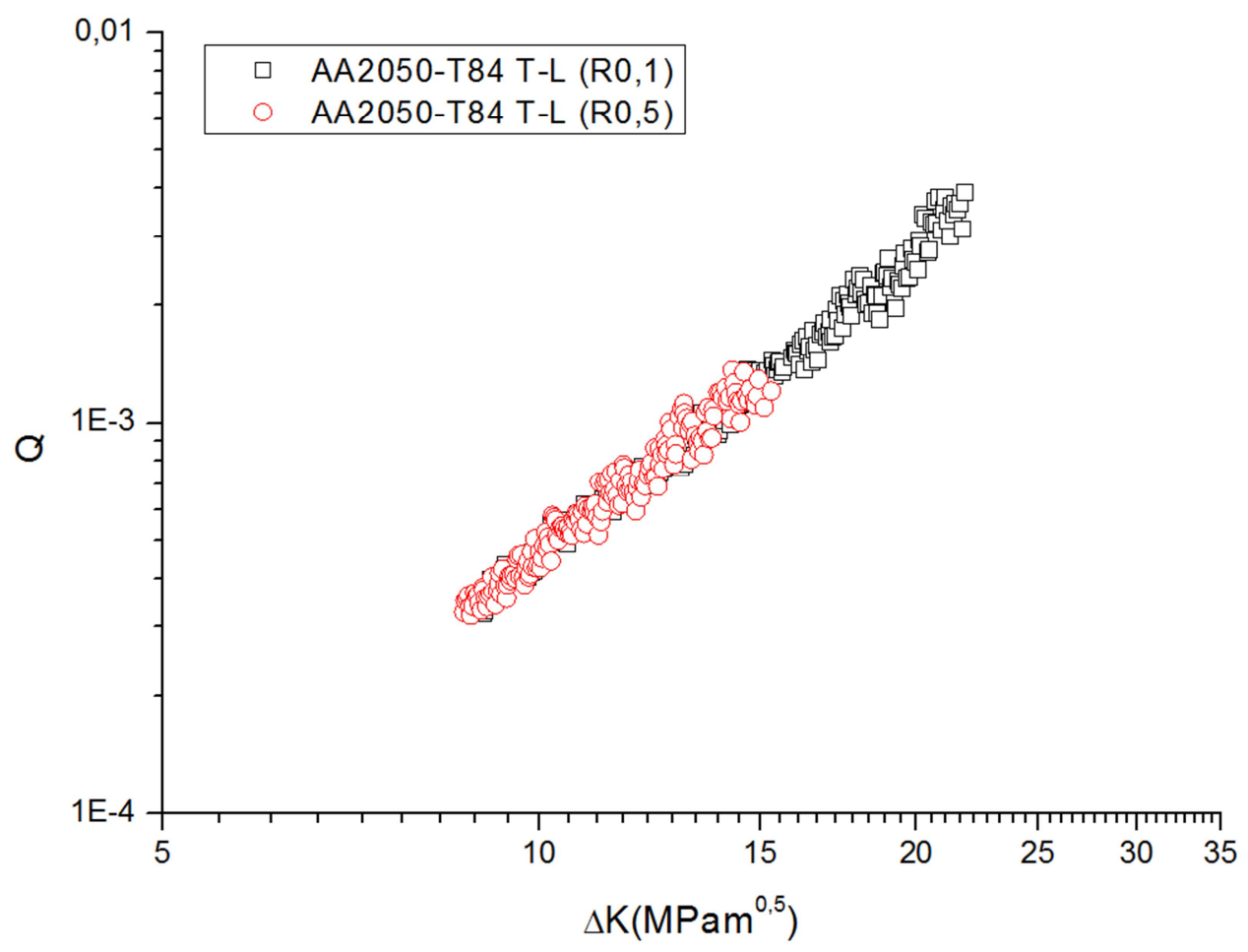

Figura 72. Ensaio de propagação com R0,1 e R0,5, na direção T-L, em temperatura ambiente, para a liga AA2050T7451, utilizando-se método de Pearson.

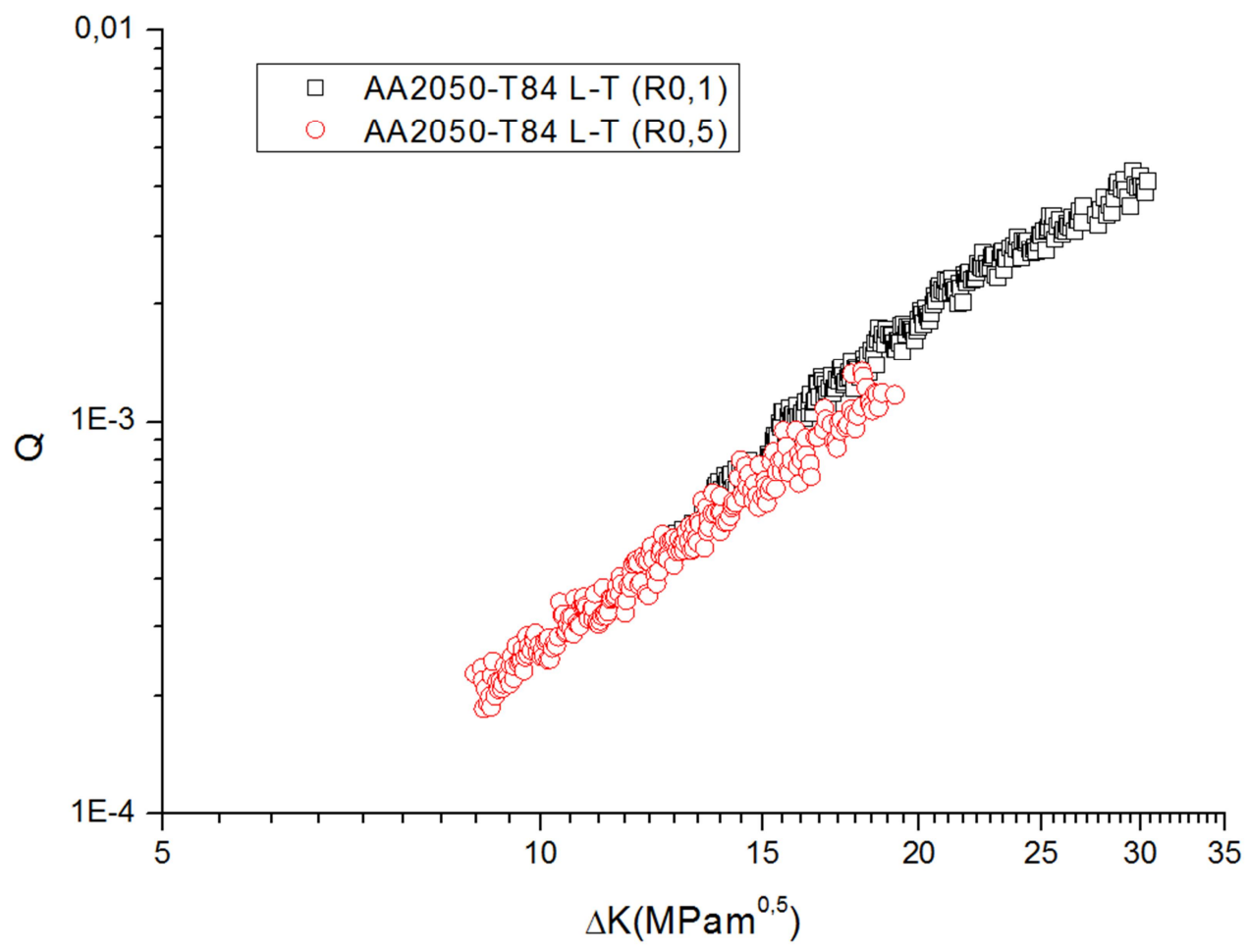

Figura 73. Ensaio de propagação com R0,1 e R0,5, na direção L-T, em temperatura criogênica, para a liga AA2050T7451, utilizando-se método de Pearson. 


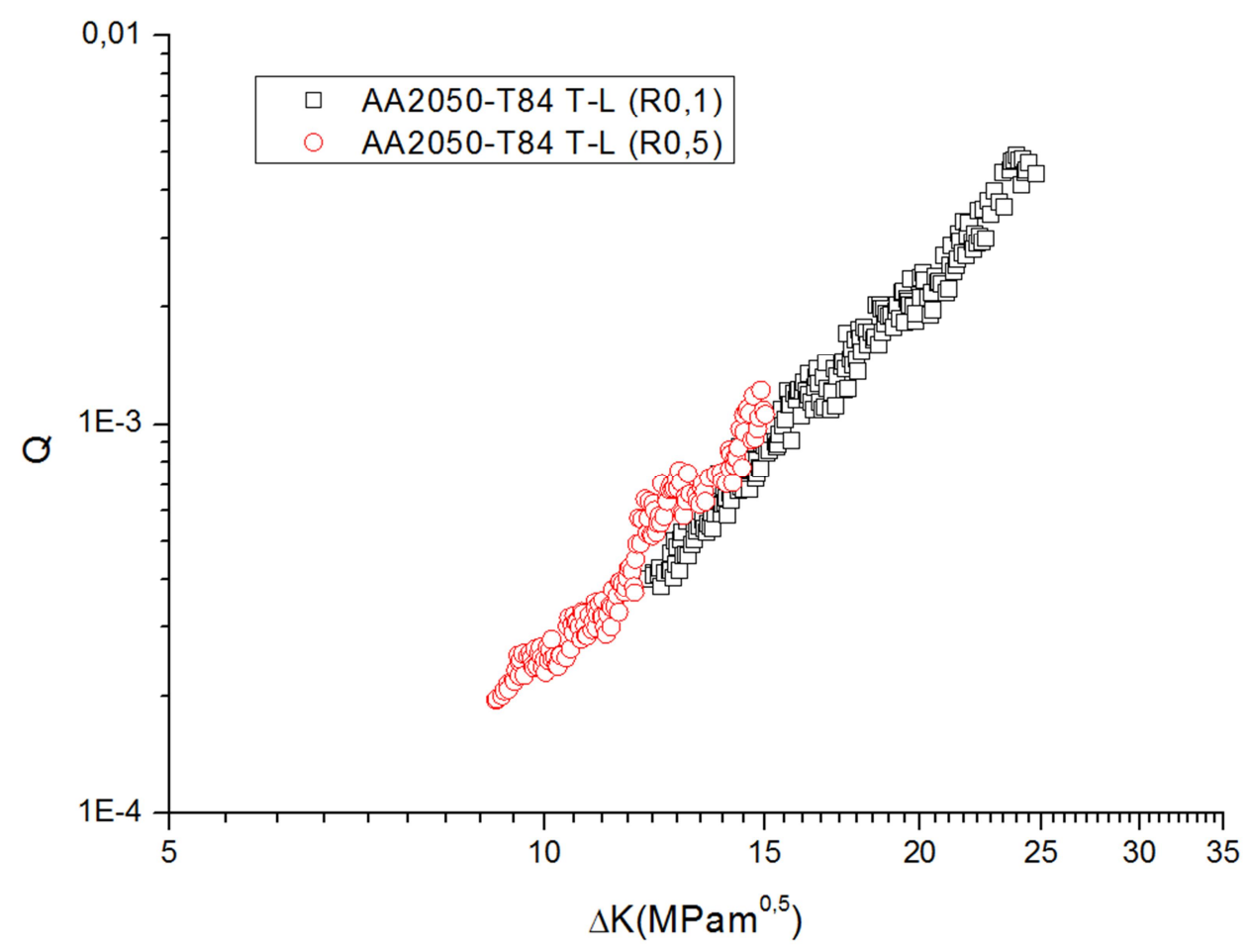

Figura 74. Ensaio de propagação com R0,1 e R0,5, na direção T-L, em temperatura criogênica, para a liga AA2050T7451, utilizando-se método de Pearson. 
As Tabelas 24 e 25 representam os resultados dos parâmetros do modelo de Pearson, obtidos dos ensaios de propagação de trinca por fadiga, para a liga AA 2050-T84. Os valores de m representam o coeficiente angular da reta de regressão linear, e C é o coeficiente encontrado pela extensão da linha reta para $K=1$ MPa.m ${ }^{1 / 2}$

Tabela 24, Resumo dos resultados obtidos dos ensaios de propagação de trinca por fadiga, em temperaturas ambiente e criogênica, para a liga Al-Li AA 2050-T84 e para $R=0,1$.

\begin{tabular}{|c|c|c|c|c|c|c|}
\hline & Direção & $\begin{array}{l}\text { Condições de } \\
\text { temperatura }\end{array}$ & $\mathbf{m}_{2}$ & $\mathrm{C}_{2}\left(\frac{\mathrm{mm} / \mathrm{ciclo}}{(\mathrm{MPa} \sqrt{m})^{m}}\right)$ & Pearson & $\mathbf{R}^{2}$ \\
\hline & L-T & & 2,27 & 3,05E-06 & $\frac{d a}{d N}=\frac{3,05 \times 10^{-6}(\Delta K)^{2,27}}{\left[(1-R) K_{c}-\Delta K\right]^{0,5}}$ & 0,99164 \\
\hline R0,1 & T-L & $\operatorname{Ar}\left(23^{\circ} \mathrm{C}\right)$ & 2,57 & $1,22 \mathrm{E}-06$ & $\frac{d a}{d N}=\frac{1,22 \times 10^{-6}(\Delta K)^{2,57}}{\left[(1-R) K_{c}-\Delta K\right]^{0,5}}$ & 0,98759 \\
\hline & L-T & & 2,46 & 1,07E-06 & $\frac{d a}{d N}=\frac{1,07 \times 10^{-6}(\Delta K)^{2,46}}{\left[(1-R) K_{c}-\Delta K\right]^{0,5}}$ & 0,97551 \\
\hline & T-L & Criogenia $\left(54^{\circ} \mathrm{C}\right)$ & 3,43 & 7,70E-08 & $\frac{d a}{d N}=\frac{7,70 \times 10^{-8}(\Delta K)^{3,43}}{\left[(1-R) K_{c}-\Delta K\right]^{0,5}}$ & 0,97937 \\
\hline
\end{tabular}


Tabela 25. Resumo dos resultados obtidos dos ensaios de propagação de trinca por fadiga, em ar e em criogenia, para a liga Al-Li AA 2050-T84 e para $\mathrm{R}=0,5$.

\begin{tabular}{|c|c|c|c|c|c|c|}
\hline & Direção & $\begin{array}{l}\text { Condições de } \\
\text { temperatura }\end{array}$ & $\mathbf{m}_{2}$ & $\mathrm{C}_{2}\left(\frac{m m / c i c l o}{(M P a \sqrt{m})^{m}}\right)$ & Pearson & $\mathbf{R}^{2}$ \\
\hline & L-T & $\operatorname{Ar}\left(23^{\circ} \mathrm{C}\right)$ & 2,1028 & 3,77E-06 & $\frac{d a}{d N}=\frac{3,77 \times 10^{-6}(\Delta K)^{2,102}}{\left[(1-R) K_{c}-\Delta K\right]^{0,5}}$ & 0,97553 \\
\hline \multirow[t]{3}{*}{ R0,5 } & T-L & \multirow{3}{*}{ Criogenia $\left(54^{\circ} \mathrm{C}\right)$} & 2,49757 & 1,48E-06 & $\frac{d a}{d N}=\frac{1,48 \times 10^{-6}(\Delta K)^{2,4975}}{\left[(1-R) K_{c}-\Delta K\right]^{0,5}}$ & 0,95779 \\
\hline & L-T & & 2,40314 & 1,05E-06 & $\frac{d a}{d N}=\frac{1,05 \times 10^{-6}(\Delta K)^{2,403}}{\left[(1-R) K_{c}-\Delta K\right]^{0,5}}$ & 0,97502 \\
\hline & T-L & & 3,55796 & 6,95E-08 & $\frac{d a}{d N}=\frac{6,95 \times 10^{-8}(\Delta K)^{3,557}}{\left[(1-R) K_{c}-\Delta K\right]^{0,5}}$ & 90,94882 \\
\hline
\end{tabular}

Observa-se que os coeficientes de $\mathrm{m}$ e $\mathrm{C}$ obtidos pelo modelo de Paris diferem dos coeficientes $\mathrm{m}_{2}$ e $\mathrm{C}_{2}$ de Pearson.

Os gráficos das figuras 75 e 76 apresentam as curvas completas da taxa de propagação da trinca $(\mathrm{d} a / \mathrm{dN})$, em função da variação da intensidade de tensão $(\Delta \mathrm{K})$ da liga AA7050-T7451. Observa-se que, tanto para o gráfico da figura 75 , quanto para a figura 76 , na região do threshold com R0,1, apresenta-se uma maior resistência à propagação da trinca com uma taxa de crescimento menor, com $\Delta \mathrm{K}=2,66 \mathrm{MPam}^{0,5}$ e $3,5 \mathrm{MPam}^{0,5}$. 


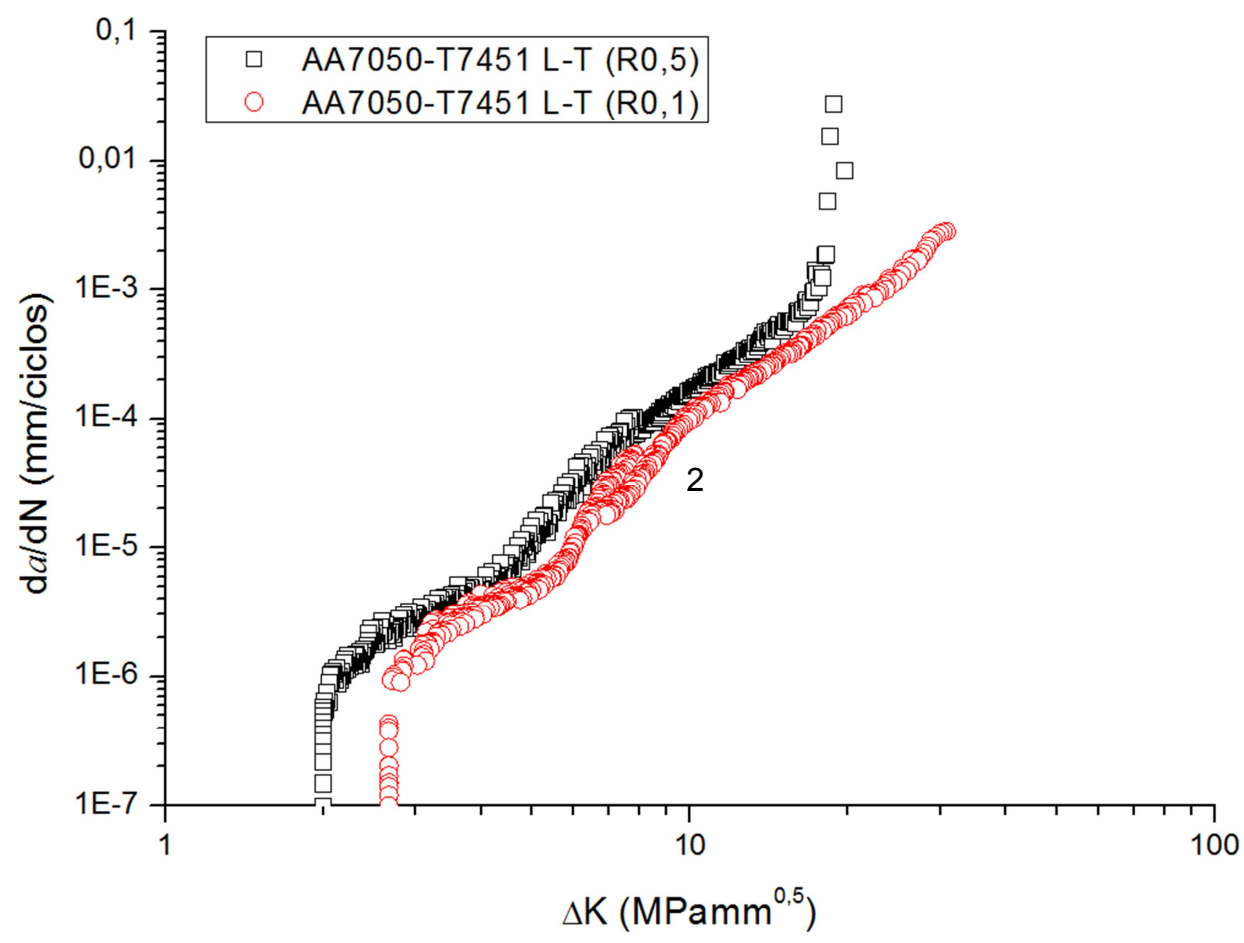

Figura 75. Ensaio de threshold comparativo entre R0,1 e R0,5, na direção L-T, em temperatura ambiente, para a liga AA7050T7451.

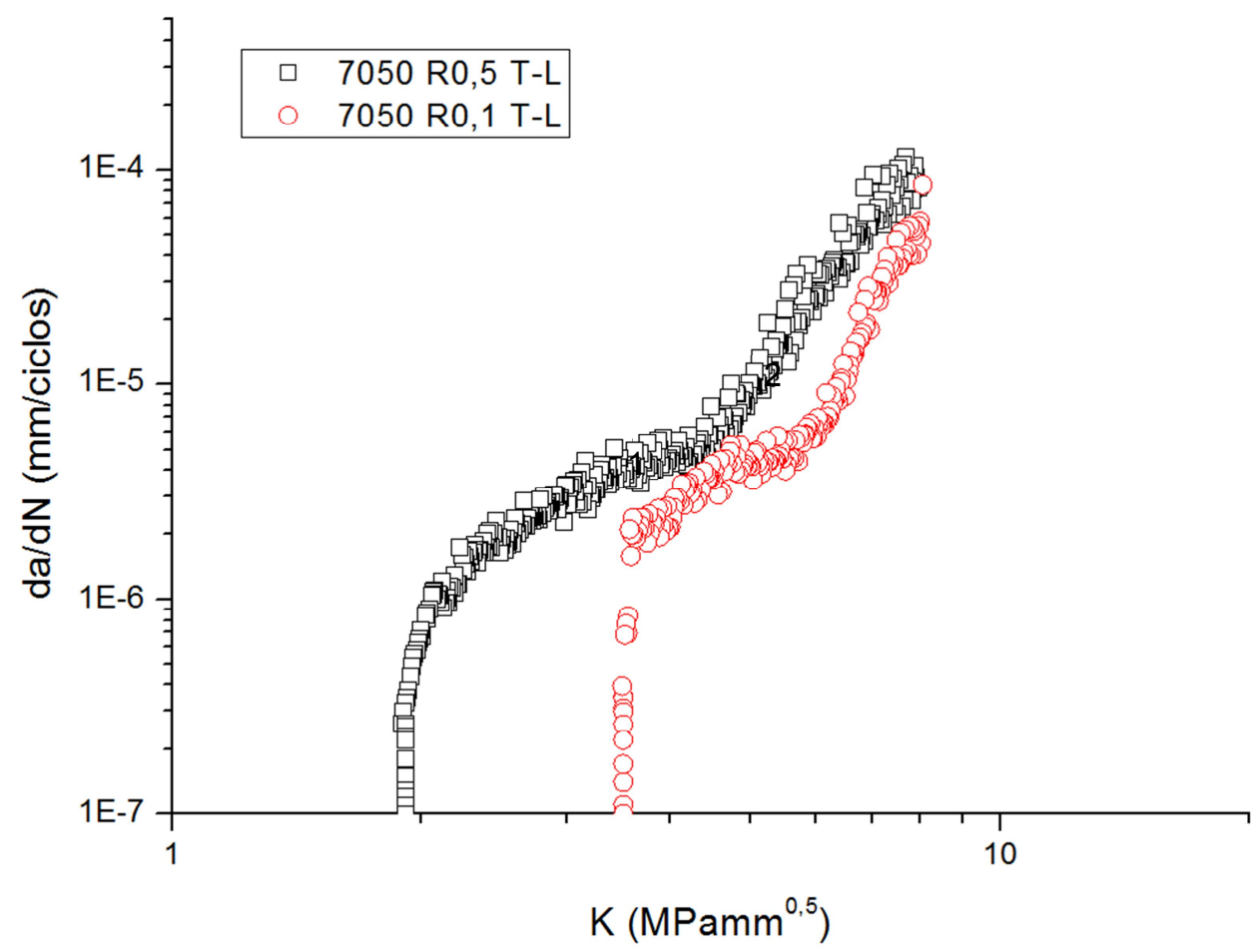

Figura 76. Ensaio de threshold comparativo entre R0,1 e R0,5, na direção T-L, em temperatura ambiente, para a liga AA7050T7451. 
O gráfico da figura 77 mostra a curva completa da taxa de propagação da trinca $(d a / d N)$, em função da variação da intensidade de tensão $(\Delta K)$ da liga AA2050-T84. Ela apresenta o mesmo resultado do gráfico da figura 76, no qual a razão de carga $\mathrm{R} 0,1$ apresenta uma maior resistência à propagação da trinca, com uma taxa de crescimento da trinca menor, com $\Delta \mathrm{K}=2,96 \mathrm{MPam}^{0,5}$, contra uma $\Delta \mathrm{K}=1,89 \mathrm{MPam}^{0,5}$ para $\mathrm{R} 0,5$.

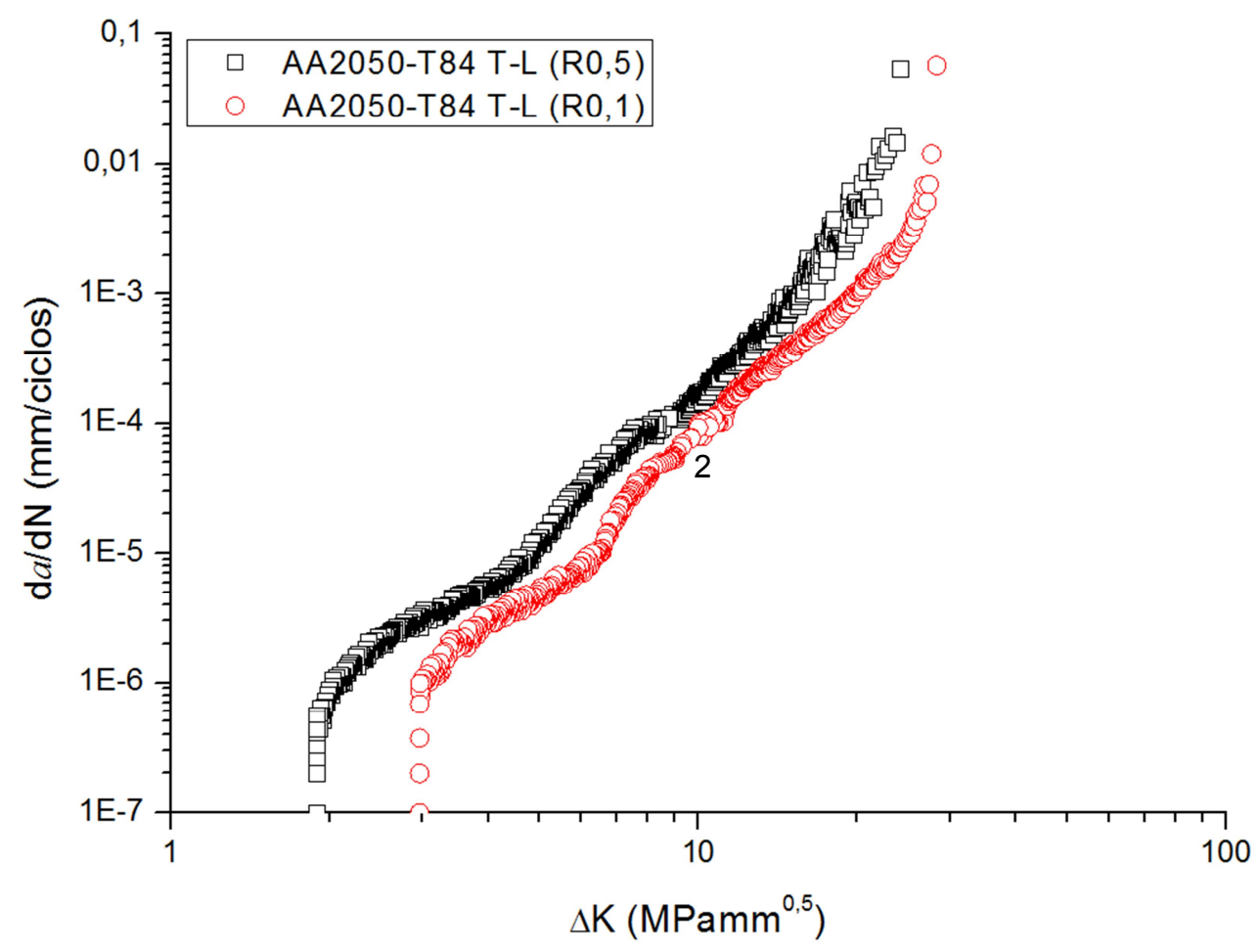

Figura 77. Ensaio de threshold comparativo entre R0,1 e R0,5, na direção T-L, em temperatura ambiente, para a liga AA2050T84. 
$\mathrm{Na}$ figura 78 apresenta-se o gráfico comparativo entre as curvas das ligas AA7050-T7451 e AA2050-T84, na direção T-L, com R0,1. Observa-se que a liga AA7050-T7451 tem uma maior resistência à propagação da trinca com $\Delta \mathrm{K}=3,5 \mathrm{MPam}^{0,5}$ em relação à liga $\mathrm{AA2050-T84} \Delta \mathrm{K}=2,96 \mathrm{MPam}^{0,5}$. Porém, na região de Paris, ambas as ligas têm a tendência de ter o mesmo comportamento. Os resultados na região de Paris estão em concordância com os resultados dos ensaios de Lequeu (2009).

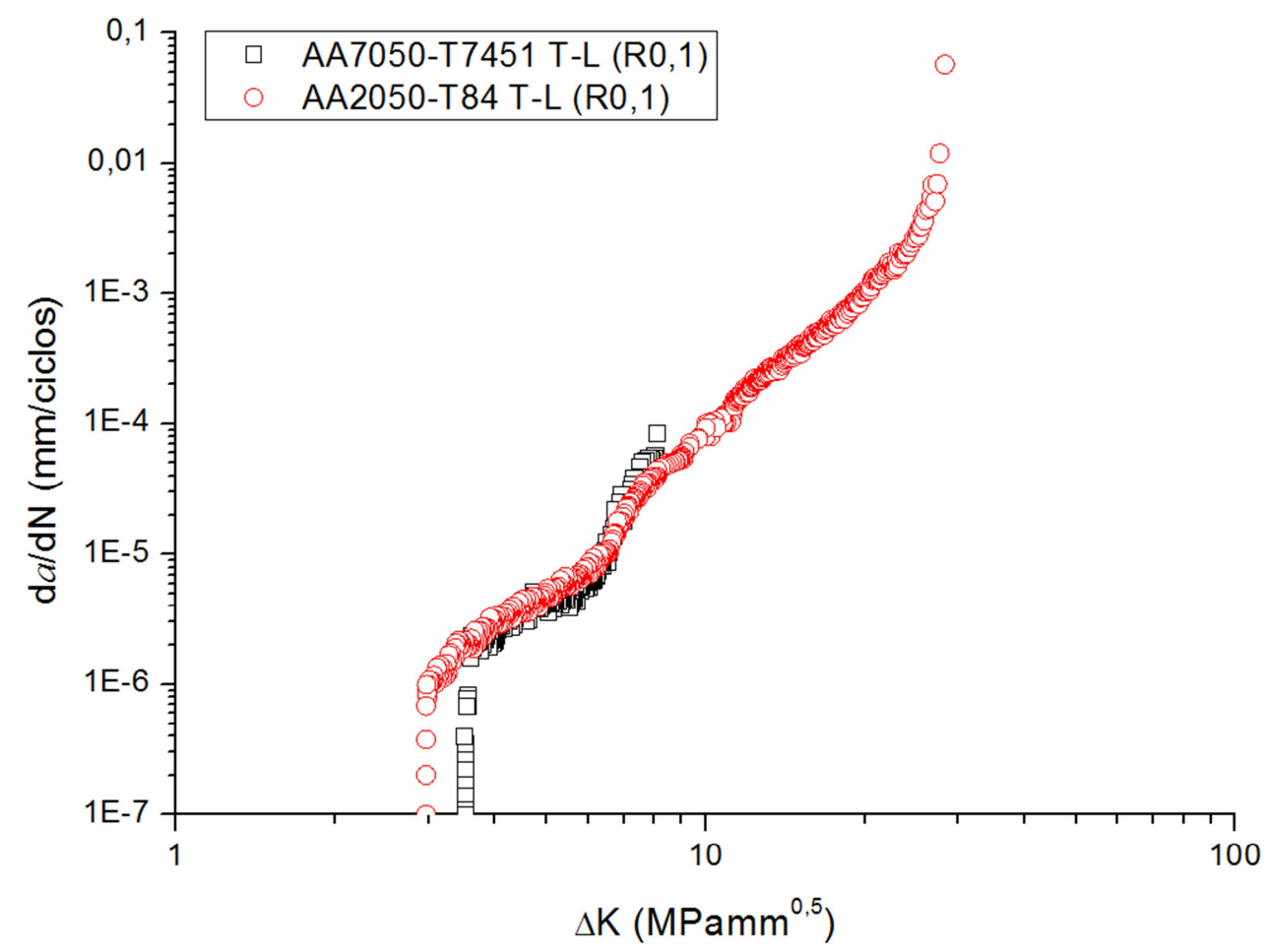

7Figura 78. Ensaio de threshold comparativo entre as ligas AA7050-T7451 e AA2050-T84, na direção T-L, com R0,1, em temperatura ambiente. 


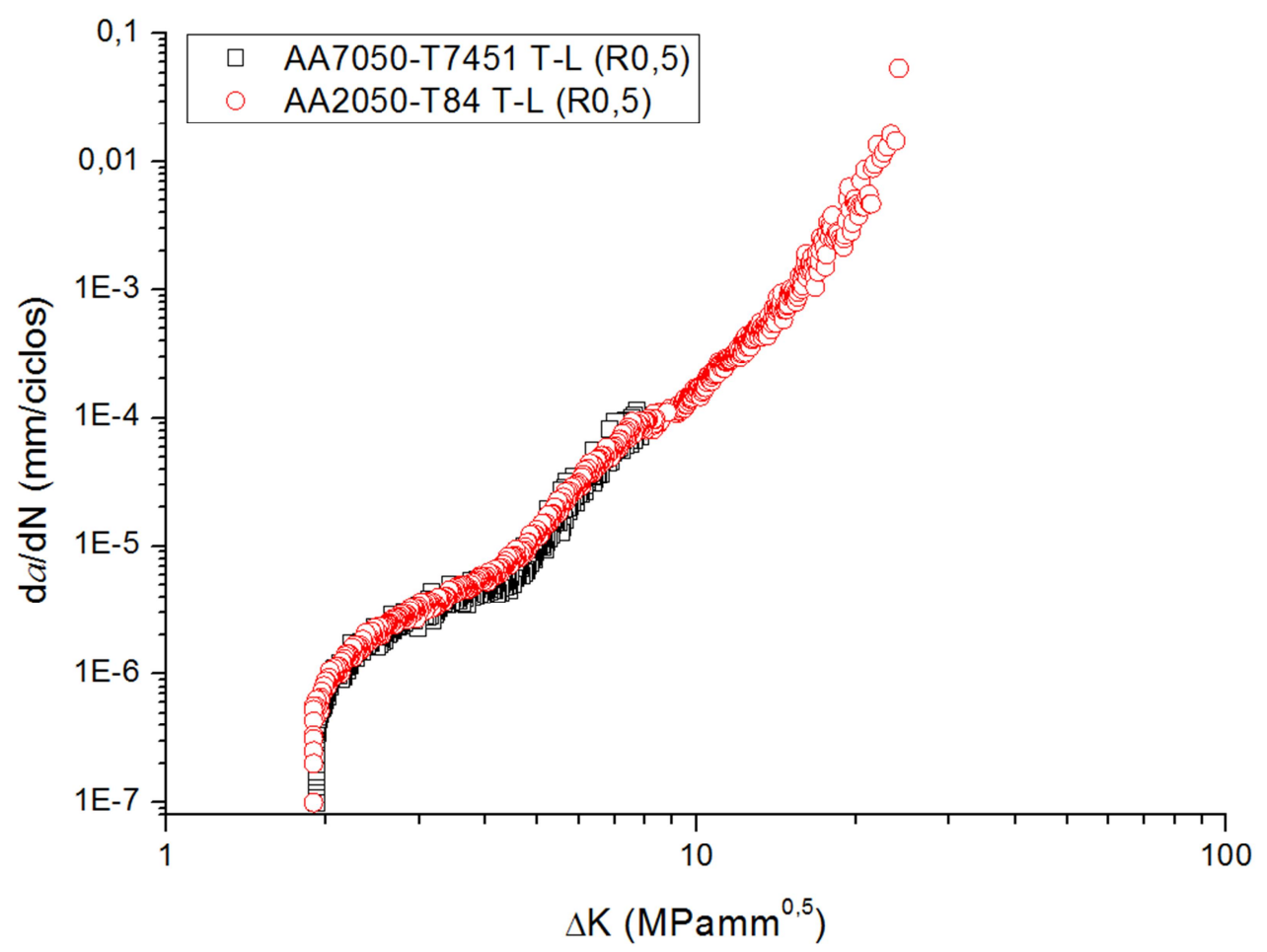

Figura 79. Ensaio de threshold comparativo entre as ligas AA7050-T7451 e AA2050-T84, na direção T-L, com R0,5, em temperatura ambiente.

A figura 79 apresenta o gráfico comparativo entre as curvas das ligas AA7050-T7451 e AA2050-T84, na direção T-L, com R0,5. Observa-se que as curvas apresentam os mesmos comportamentos, nas regiões threshold e Paris, e estão de acordo com os ensaios realizados por Lequeu (2009).

Observa-se que, em todos os gráficos das figuras $75-79$, há uma região de plateau, ou região de transição, onde há um decréscimo na taxa de propagação da trinca. Ela é uma região intermediária, que fica entre a região threshold e a região de Paris, em que há uma mudança na inclinação, como pode ser observado na figura 80 , entre os pontos 1 e 2 .

Conforme descrito por Richard et al (2012), essa região de transição é conhecida como crescimento de trinca por fadiga em ambiente assistido, ou seja, 
sofre a ação de algum meio ativo, como umidade do ar, vapor de água etc, porque a microestrutura é muito sensível à umidade.

Segundo Henaff et al (2007), esse comportamento é atribuído à fragilização por hidrogênio na ponta da trinca, resultante de uma sequência de processos, como segue:

- Acesso de meios a ponta da trinca;

○ Dissociação de superfície e produção de hidrogênio.

- Hidrogênio entra e transporta para a ponta da trinca:

○ Reação de fragilização.

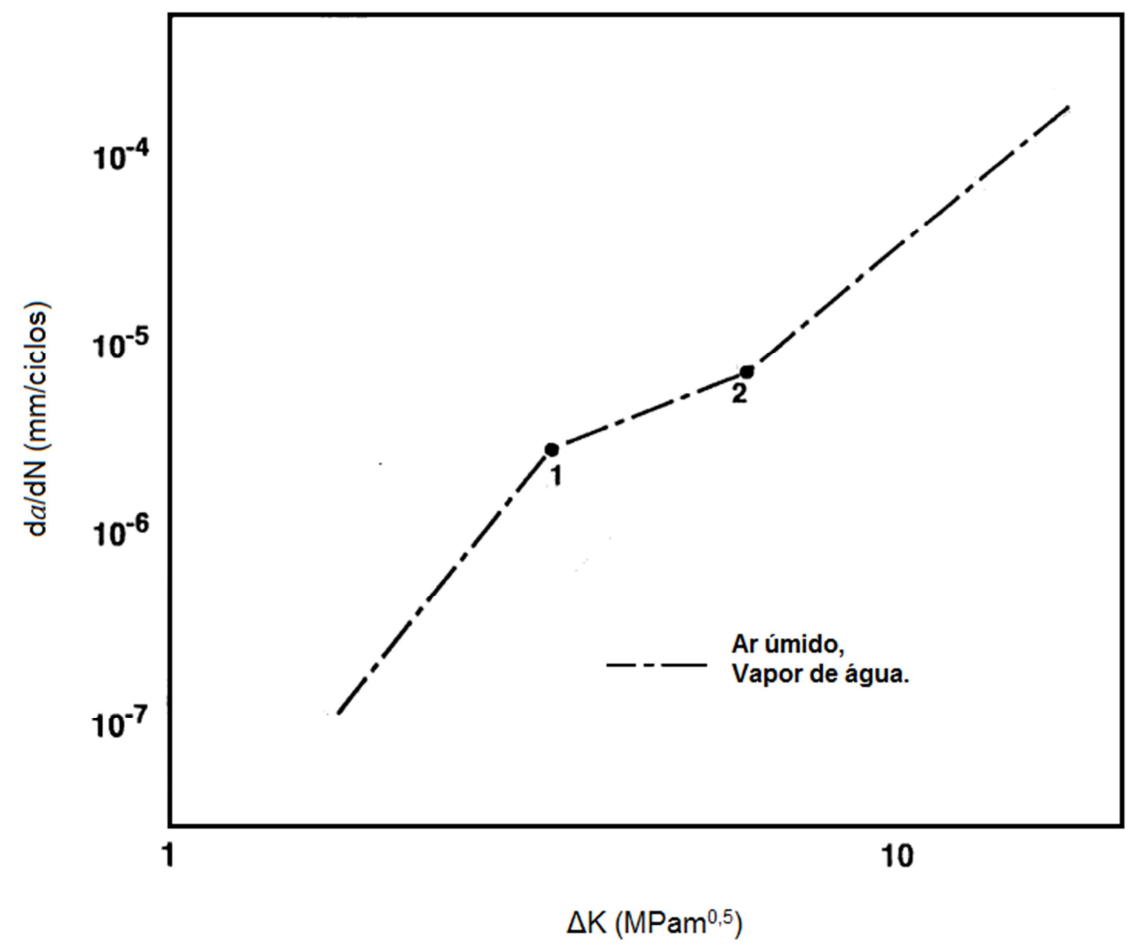

Figura 80. Gráfico mostrando o efeito do ambiente em uma curva da/dN versus $\Delta \mathrm{K}$ (Plascik et al, 1993). 
Segundo Plascik (1993), Hénaff et al (2007) e SlaviK et al (1992), para não ocorrer essa região de transição, ou para que não ocorra perda na resistência ao crescimento de trinca por fadiga, deve-se realizar os ensaios em ambientes inertes, ou seja, no vácuo.

A figura 81 apresenta um gráfico com várias curvas, de várias ligas, sem a região de transição no vácuo. Pode-se observar que todas as curvas não apresentam as regiões de transição.

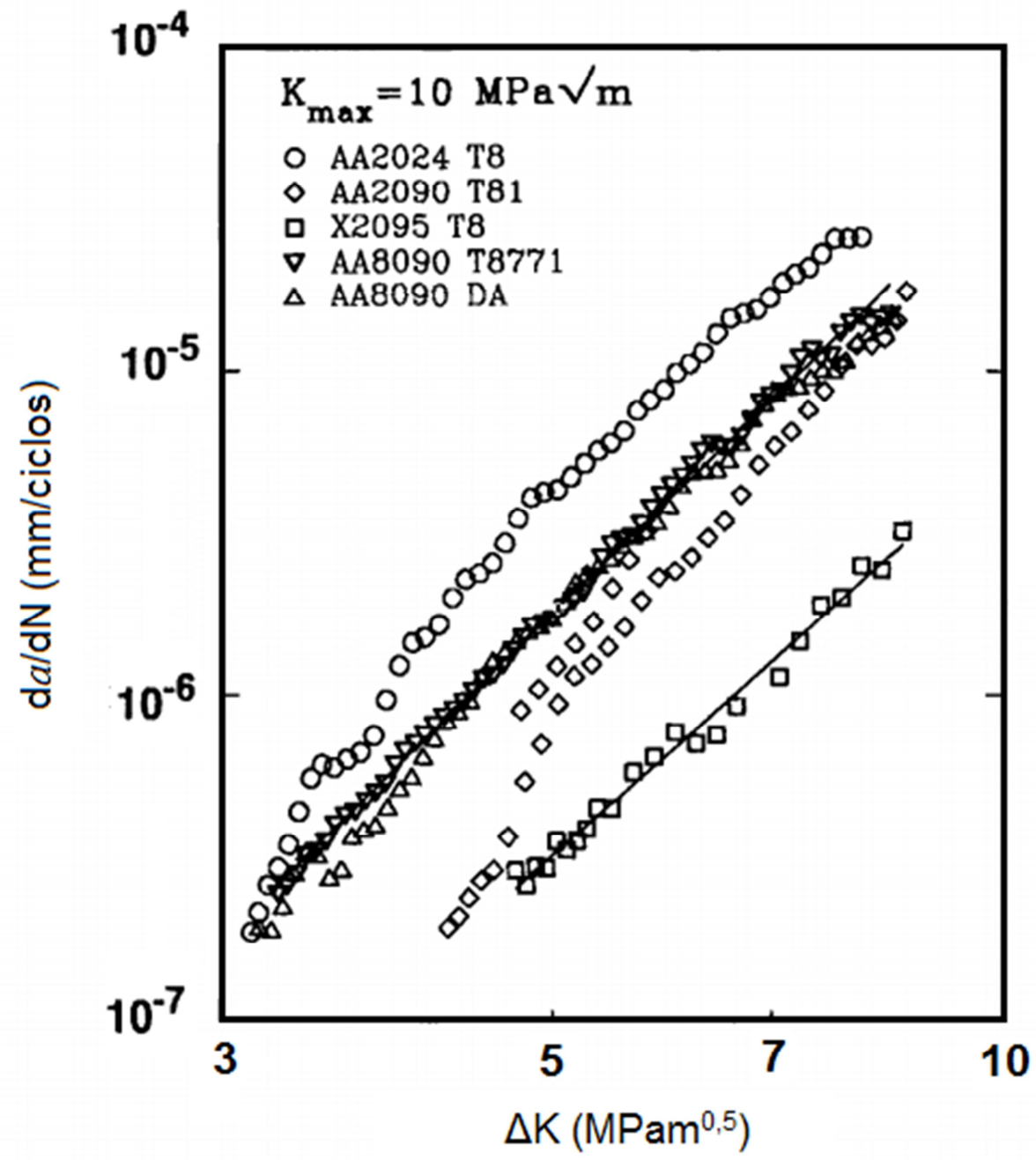

Figura 81. Taxa de crescimento da trinca por fadiga intrínseco da liga Al-Li-Cu-Mg, no vácuo (Slavik et al, 1993). 


\section{CONCLUSÃO}

Observou-se que ambas as ligas, AA7050-T7451 e AA2050-T84, apresentaram anisotropia nas propriedades de tenacidade à fratura e fadiga, segundo os ensaios realizados, numa correspondência com os estudos/artigos aqui referidos.

Conforme observado, no ensaio de tração, a liga AA7050-T7451 apresenta uma menor resistência ao escoamento em relação à liga AA2050-T84. Porém, com relação ao limite de resistência, a liga AA2050-T84 apresenta um limite maior.

A liga AA2050-T84 apresenta uma maior rigidez em relação à liga AA7050T7451, devido ao seu módulo de elasticidade ser maior.

A análise microestrutural mostrou que a liga AA7050-T7451 tem uma maior tenacidade à fratura, provavelmente devido à maior adição de zircônio.

Para a temperatura criogênica, a liga AA2050-T84 tem uma tenacidade similar à da liga AA7050-T7451.

A tenacidade poderia ser maior se a liga AA2050-T84 não tivesse tantas ocorrências de zonas livres de precipitados, que estão relacionadas com a ductilidade da liga 2000, contendo Lítio.

Com relação aos resultados dos ensaios da curva $K_{R}$, as ligas AA7050-T7451 e AA2050-T84 apresentam uma maior resistência á propagação da trinca na direção L-T do que na direção T-L.

Ambas as ligas, na direção T-L, apresentam comportamento plano, ou seja, com características frágeis.

A comparação entre as ligas AA7050-T7451 e AA2050-T84, através das curvas de resistência ou curva $R$ na direção L-T, mostram que ambas as ligas apresentam uma curva de resistência muito similar. 
A comparação entre as ligas AA7050-T7451 e AA2050-T84, na direção T-L, demonstrou que a liga AA7050-T7451 apresenta uma maior resistência, muito provavelmente devido à presença de dispersoides $\mathrm{Al}_{3} \mathrm{Zr}$, que melhoram a tenacidade.

Nos ensaios de fadiga, observou-se que quanto maior $R$, mais rápida é a taxa de propagação da trinca.

Através do modelo de Paris, a direção T-L revelou-se mais sensível à razão de carga, nas temperaturas ambiente e criogênica, do que a direção L-T.

Através do modelo de Pearson, as curvas apresentaram boas concordâncias, podendo-se prever qual seria a taxa de propagação para qualquer $\mathrm{R}$, com uma precisão de 95\%.

Nos ensaios de threshold, comparando-se as mesmas direções, ambas as ligas mostraram que à razão de carga $\mathrm{R} 0,1$, a trinca tem uma resistência maior para se propagar.

Observou-se que, nos gráficos de ensaios de threshold, em ambas as ligas, há uma região de transição entre o threshold e a região de Paris. Essa região é ocasionada devido à umidade do ar, sendo conhecida como crescimento de trinca por fadiga em ambiente assistido.

Comparando-se as ligas através do ensaio de threshold, constatou-se que as ligas AA7050-T7451 e AA2050-T84 têm um comportamento muito similar. 


\section{REFERÊNCIAS}

AFONSO, C.R.M. (2008). "Procedimento para preparação de amostras metálicas (lâminas finas) para TEM através do PIPS". Laboratório de Microscopia Eletrônica -LME/LNLS. 2008.

ALCOA :Alloy $\mathbf{7 0 5 0}$ plate and sheet. Disponível em: https://www.alcoa.com/mill products/catalog/pdf/alloy7050techsheetrev.pdf. Acesso em: $02 a b r i l 2015$.

ALCOA. Alloy $\mathbf{7 0 7 5}$ plate and sheet. Disponível em: https://www.alcoa.com/mill products/catalog/pdf/alloy7075techsheet.pdf. Acesso em: 02 abril2015.

ALCOA. Alloy 7475 plate and sheet. Disponível em: https://www.alcoa.com/mill products/catalog/pdf/alloy7475techplatesheet.pdf. cesso em: $02 a b r i l 2015$.

AMERICAN SOCIETY FOR TESTING AND MATERIALS, 2013, "Standard Test Methods for Tension Testing of Metallic Materials", ASTM E8-13a, Philadelphia.

AMERICAN SOCIETY FOR TESTING AND MATERIALS, 2011, "Standard Guide for Preparation of Metallographic Specimens”, ASTM E3, Philadelphia.

AMERICAN SOCIETY FOR TESTING AND MATERIALS ASTM E 647 (2013). Standard Method for Measurement of Fatigue Crack Growth Rates. Philadelphia.

AMERICAN SOCIETY FOR TESTING AND MATERIALS ASTM E 399 (2012). Test Method for Plane-Strain Fracture Toughness of Metallic Materials. Philadelphia.

AMERICAN SOCIETY FOR TESTING AND MATERIALS, 2011, "Standard Test Method for K-R Curve Determination", ASTM E561, Philadelphia.

ANDERSON, T. L. (2005).Fracture mechanics fundamentals and applications. $2^{\text {nd }}$ ed. Boca Raton: CRC Press. Cap. 2.

BARSON, J. M., ROLFE, S. T.,1999. Fracture and fatigue control in structures. Applications of fracture mechanics. $3^{a}$ ed. Prentice Hall, Inc., Englewood Cliffs, New Jersey.

Bonazzi, L. H. C., (2013), "Comportamento em fadiga da liga Al-Li AA2050", Dissertação de mestrado, Escola de Engenharia de São Carlos, Universidade de São Paulo.

BRAGA, P.V., (2011). Análise de Ligas de Alumínio Aeronáuticas conformadas por Jateamento com Granalhas - Caracterização e Previsão de Deformação. Dissertação (Mestrado) - Escola Politécnica da Universidade de São Paulo, São Paulo, 2011. 
CALLISTER JR, W. D. JR.(2002); Ciência e engenharia de materiais: uma introdução, $5^{a}$ ed. Rio de Janeiro: Livros Técnicos e Científicos.

CAVALIERE, P. et al. (2009). 2198 Al-Li plates joined by friction stir welding: mechanical and microstructural behavior.Materials Design, Oxford, v.30, n.9, p.3622-3631.

CAMPBEL, F.C., (2008). Elements of metallurgy and engineering alloys, ASM INTERNATIONAL.

DENG, et al.(2014). Influence of Li addition on mechanical property and aging precipitation behavior of $\mathrm{Al}-3,5 \mathrm{Cu}-1,5 \mathrm{Mg}$ alloy. School of Materials Science and Engineering. China, 2014.

DIETER, G. E., 1981, "Metalurgia Mecânica” , 2a ed., Rio de Janeiro, Guanabara Dois.

DOGLIONE, D. F. R., "K-R curves of thin 2195-T8 aluminium alloy plate" Politecnico di Torino, Italy, C.so Duca degli Abruzzi 24, 10129 Torino, Italy. Disponível em: http://www.gruppofrattura.it/ocs/index.php/ICF/ICF10/paper/viewFile/4795/6802. Acesso em: 02abril2015.

DOWLING, N. E. (2007). "Mechanical behavior of materials: engineering methods for deformation, fracture and fatigue". 3thed. Lebanon: Pearson Prentice Hall

DUMONT, D. et al (2003). "A model for predicting fracture mode and toughness in 7000 series aluminium alloys" Domanine Universitaire de Grenoble, INPG, BP 75 , France.

Dursun, T; Soutis C. (2014), Recent Developments in Advanced aircraft aluminium alloys. Aerospace Research Institute, University of Manchester, M13 9PL, UK.

FARAHMAND, B., (1997), "Fatigue and Fracture Mechanics of High Risk Parts: and Application of LEFM \& FMDM Theory", New York, Chapman \& Hall.

FENDONI, A. (2009). The Effect of post weld heat treatment on the corrosion behavior of a AA2050T34-FSW. Thesis (MRes) - University of Bermingham, Bermingham. p. 4-13.

FORTH et al, (2003). "On generating fatigue crack growth thresholds" Langley Research Center, 2003. 
GAMBONI,O.C.(2011). Estudo do efeito do ambiente no comportamento em fadiga de novas ligas de Al de grau aeronáutico. Dissertação (Mestrado) - Escola de Engenharia de São Carlos, Universidade de São Paulo, São Carlos, 2011.

GHALI, E. (2010). Corrosion resistance of aluminum and magnesium alloys: Undestanding, performance and testing.New Jersey: Wiley.

GODEFROID, L. B., (1995), “Fundamentos de Mecânica da Fratura”, $2^{\circ}$ ed.UFOP, Ouro Preto, M.G.

GLAZER, J., et al (1987). "Mechanical behavior of aluminum-lithium alloys at cryogenic temperatures" Lawrence Berkeley Laboratory, Berkeley, CA 94720, 1987.

GREGSON, P. J. and Flower, H. M. (1985), "Microstructural control of toughness in aluminium-lithium alloys" Engineering Materials, Southampton University, London, England.

HAFLEY, R. A.; Domack, M. S.; Hales, S. J.; Shenoy, R. N. (2011). Evaluation of aluminum alloy 2050-T84 microstructure and mechanical properties at ambient and cryogenic temperatures. Langley Research Center, Hampton Virginia.

HENAFF, G. et al. (2007)." Environmentally-assisted fatigue crack growth mechanisms in advanced materials for aerospace applications". Laboratoire de Me'canique et de Physique des Matériaux, 2007.

HERTZBERG, R W, (1989) " Deformation and Fracture Mechanics of Engineering Materials", $3^{\circ}$ ed., New York, John Wiley \& Sons.

HEYER, R.H. 1973 "Crack Growth Resistance Curves (R-Curves) - Literature Review" Fracture Toughness Evaluation by R-Curve Method, ASTM STP 527, American society for Testing and Materials, 1973, pp. 3-16.

HU. H.E., Zhen, L. Zhang, B.Y., Yang, L., Chen, J.Z. (2008). “Microstructure characterization of $\mathbf{7 0 5 0}$ aluminum alloy during dynamic recrystallization and dynamic recovery" School of Materials Science and Engineering, Harbin 15000, PR China, 2008.

JATA, et al. (1985). "Fatigue crack growth and fracture toughness behavior of an Al-Li-Cu alloy". Department of Materials Science. 1985.

JUN-ZHOU, C., et al. (2010). Effects of precipitates on fatigue crack growth rate of AA 7055 aluminum alloy, Beijing Institute of Aeronautical Materials, Beijing 100095, China.

$\mathrm{KAI}$, Shen. et al, (2009). TEM study on microstructure and properties of $\mathbf{7 0 5 0}$ aluminum alloy during thermal exposure. School of Materials Science and Technology, Naning University of Aeronautics and Astronautics, Nanjing 21006, China, 2009 
LAUWSON, L. et al. (1999), “Near-Threshold fatigue: a review” 226 Insterstate Parkway, Bradford, PA 16701, USA, 1999.

LEQUEU et al (2009). "Aluminum-Copper-Lithium Alloy 2050 Developed for Medium to Thick Plate" Alcan Rhenalu, Issoire, France, 2009.

LEE, Y.-L, Pan, J., Hathaway, R., Barkey, M. (2005). Fatigue Testing and analysisTheory and practice. Elsevier Butterworth - Heinemann. USA, 2005

LIAW, P. K.; Logsdon, W. A.,(1985), Fatigue crack growth threshold at cryogenic temperatures, Pittsburgh, PA.

LUO, J. et al, (2011). The correlation between flow behavior and microstructural evolution of $\mathbf{7 0 5 0}$ aluminum alloy. School of Materials Science and Engineering. Xi'an, PR China, 2011.

MACIEL, C. I. S. (2013). Estudo Da Tenacidade À Fratura e Propagação de Trinca por Fadiga em Meio Assistido da Liga AA2050-T84. Dissertação (Mestrado) - Escola de Engenharia de São Carlos, Universidade de São Paulo, São Carlos, 2013.

MADDOX, (1975) The effect of mean stress on fatigue crack propagation- A literature review. The University of Southampton, Southampton S09, England, 1975.

MATSUDA, K. et al. (2000). Precipitation sequence of various of metastable phases in Al-1.0mass\% Mg2Si-0,4mass\% Si alloy. Department of Materials Science and Engineering, Faculty of Engineering, Toyama University, 3190, Toyamashi, Toyama, 930, Japan, 2000.

MAZZER. E.M. (2013). Caracterização microestrutural e mecânica da liga Al7050 reciclada por conformação por spray e extrusão. Dissertação (Mestrado) Engenharia de Materiais - Universidade Federal de São Carlos, 2013.

MAZZER, E.M. (2013). Microstructure study of Al 7050 alloy reprocessed by spray forming and hot extrusion and aged at $121^{\circ} \mathrm{C}$. Department of Materials Engineering, Federal University of São Carlos, 2013.

Mechanical Testing and Evaluation, ASM Handbook (2000), v.8.

MILLER, W.S.; WHITE, J.; LLOYD, D.J.(1986). Aluminum alloys - Physical and mechanical properties. Proceedings... The British Library.

MIRZAEI, M. Fracture Mechanics, Lecture Notes. Dept. of Mechanical Eng., TMU.

NACE STANDARD Laboratory Testing of Metals for Resistance to Sulfide Stress Cracking and Stress Corrosion Cracking in $\mathrm{H}_{2} \mathrm{~S}$ Environments Designation TM0177-2005. In. Annual Book of NACE Standard. Houston, Texas, 2005. 
NAFSIN, N. et al, (2013), Effects of Copper and Magnesium on Microstructure and Hardness of Al-Cu-Mg Alloys. Bangladesh University of Engineering and Technology, 2013.

PADILHA, A. F. Microscopia Eletrônica de Transmissão. PMI-2201 MICROSCOPIA ELETRÔNICA DE TRANSMISSÃO. Disponível em: file://C:/Users/Usuario/Documents/Doutorado/MICROSCOPIA\%20ELETRONICA\%2 0DE\%20TRANSMISS\%C3\%830.pdf. Acesso em: 27 nov. 2014.

PAN, J.; Lin S. H. Fracture Mechanics and Fatigue crack propagation", University of Michigan.

PASANG, T. et al. (2012). Low energy intergranular fracture in Al-Li alloys. Department of Mechanical Engineering. AUT. University, Auckland, New Zeland, 2012.

PEARSON, (1972), The effect of mean stress on fatigue crack propagation in half-inch $(12,7 \mathrm{~mm})$ thick specimens of aluminium alloys of high and low fracture toughness. Materials Department, Royal Aircraft Establishment, Farnborough, Hampshire, England. 1972.

PLASCIK, S. R. et al. (1993). Environmental Fatigue of an Al-Li-Cu alloy: Part II Microscopic Hydrogen Cracking Process. University of Vigirnia, Charlottesville, 1993.

PRASAD, N. E et al (2014) Aluminum-Lithium alloys: Processing, properties and applications. Elsevier Inc.

PRASAD, N. E., Gokhale, A.A., Rao, P.(2003). Mechanical behavior of aluminiumlithium alloys. Defence Metallurgical Research Laboratory, P.O. Kanchanbagh, Hyderabad 500 058, India.

PRASAD, N.E. et al. (1995). R-Curve behavior of Al-Li-Cu-Mg Alloys.

RADMILOVIC, V. et al (1988). Lithium depletion in precipitate free zones (pfz's) in AI-Li base alloys. University of California, Berkeley, California, 94720, USA, 1988.

RICHARD, S.; Baudoux, C. S.; Petit, J.; (2012). Fatigue crack propagation in new generation aluminum alloys. Key Engineering Materials, France, v.488, p. 476-479.

RINGER, S.P., et al. (1998). Microstructural evolution and age hardening in aluminium alloys: Atom probe field-ion microscopy and transmission electron microscopy studies. Department of Materials Engineering, Monash University. Clayton, Victoria, 3168, Australia, 1998.

ROSA, E da (2002). Análise de Resistência Mecânica. Universidade Federal de Santa Catarina, 2002. 
ROSSINO, L.S. et al. (2010). Resistência à fadiga por fretting da liga AA7050T7451. Tecnologia em Metalurgia, Materiais e Mineração, São Paulo, v.6, n.3, p.167-173.

SCHIJVE, J. (2003), Fatigue of Structures and Material" $2^{\circ}$ ed. Amsterdam, Springer.

SCHUBBE, J.J. (2009). Fatigue crack propagation in 7050-T7451 plate alloy Mechanic Engineering Department, US Naval Academy, 2009.

SHA, G, Cerezo A. (2004) "Early-Stage precipitation in Al-Zn-Mg-Cu alloy (7050). University of Oxford, 2004.

SHUMAKER, M.B.; et al (1967). Evaluation of various techniques for stress corrosion testing welded aluminum alloys. Proceedings: Stress Corrosion Testing, ASTM STP 425, Am. Soc. Testing Mats,

SLAVIK, D.C., et al (1993). Intrinsic Fatigue Crack Growth Rates for Al-Li-Cu-Mg Alloys in Vacuum. Department of Materials Science and Engineering, University of Virginia, Charlottesville, VA 22903.

SPNELLI, D. (1996). Corrosão sob tensão de aços inoxidáveis em meio contendo sulfeto de hidrogênio. Tese (Livre docência) - Escola de Engenharia de São Carlos, Universidade de São Paulo, São Carlos, 1996.

STARKE Jr., E. A. et Al. (1996), Application of modern aluminum alloys to aircraft. University of Virginia, Charlottesville, USA, 1996.

STROHAECKER, T. R. Mecânica da Fratura. Escola de Engenharia, Universidade Federal do Rio Grande do Sul.

VENKATESWARA, K. T. et al (1988). Cryogenic toughness of commercial aluminum-lithium alloys: Role of delamination toughening. Lawrence Berkeley Laboratory, Berkeley, CA 94720, 1988.

WEI, L. et al (2014). Influence of grain structure and crystallographic orientation on fatiguecrack propagation behavior of 7050 alloy thick plate, School of Materials Science and Engineering, Central South University, Changsha 410083, China, 2014.

XIAO, D. H. et al, (2002), Effect of Cu content on the mechanical properties of an Al-Cu-Mg-Ag alloy . School of Materials Science and Engineering, Shanghai Jiao Tong University, Shanghai 200030, PR China, 2002.

ZAKHAROV, V. V. (2003) Some problems of the use of aluminum-lithium alloys All-Russia Institute of Light Alloys, Moscow, Russia, 2003.

ZHAO, T. et al. (2008). A study of fatigue crack growth of 7075-T651 aluminum alloy. University of Nevada, 2008. 